\title{
Dynamic regulation of thrombus stability : focus on platelet receptors and downstream signaling
}

Citation for published version (APA):

Cosemans, J. M. E. M. (2009). Dynamic regulation of thrombus stability : focus on platelet receptors and downstream signaling. [Doctoral Thesis, Maastricht University]. Univeritaire Pers Maastricht. https://doi.org/10.26481/dis.20090129jc

Document status and date:

Published: 01/01/2009

DOI:

10.26481/dis.20090129jc

Document Version:

Publisher's PDF, also known as Version of record

\section{Please check the document version of this publication:}

- A submitted manuscript is the version of the article upon submission and before peer-review. There can be important differences between the submitted version and the official published version of record.

People interested in the research are advised to contact the author for the final version of the publication, or visit the DOI to the publisher's website.

- The final author version and the galley proof are versions of the publication after peer review.

- The final published version features the final layout of the paper including the volume, issue and page numbers.

Link to publication

\footnotetext{
General rights rights.

- You may freely distribute the URL identifying the publication in the public portal. please follow below link for the End User Agreement:

www.umlib.nl/taverne-license

Take down policy

If you believe that this document breaches copyright please contact us at:

repository@maastrichtuniversity.nl

providing details and we will investigate your claim.
}

Copyright and moral rights for the publications made accessible in the public portal are retained by the authors and/or other copyright owners and it is a condition of accessing publications that users recognise and abide by the legal requirements associated with these

- Users may download and print one copy of any publication from the public portal for the purpose of private study or research.

- You may not further distribute the material or use it for any profit-making activity or commercial gain

If the publication is distributed under the terms of Article $25 \mathrm{fa}$ of the Dutch Copyright Act, indicated by the "Taverne" license above, 


\section{Dynamic regulation of thrombus stability}

focus on platelet receptors and

downstream signaling 
Dynamic regulation of thrombus stability

focus on platelet receptors and downstream signaling

Thesis Universiteit Maastricht

ISBN 978-90-5278-793-0

(c) J.M.E.M. Cosemans, Maastricht 2008

Printed by Datawyse | Universitaire Pers Maastricht

Cover layout by Marc Coenen 


\section{Dynamic regulation of thrombus stability}

focus on platelet receptors and

downstream signaling

\section{PROEFSCHRIFT}

ter verkrijging van de graad van doctor

aan de Universiteit Maastricht,

op gezag van de Rector Magnificus,

Prof. mr. G.P.M.F. Mols,

volgens het besluit van het College van Decanen,

in het openbaar te verdedigen

op donderdag 29 januari 2009 om 14.00 uur

door

Judith Maria Elisabeth Mathijs Cosemans

Geboren op 27 november 1980 te Born 


\section{Promotor}

Prof. dr. J. Rosing

\section{Copromotor}

Dr. J.W.M. Heemskerk

\section{Beoordelingscommissie}

Prof. dr. F.C.S. Ramaekers (voorzitter)

Prof. dr. J.W.N. Akkerman (Universitair Medisch Centrum Utrecht)

Prof. dr. E.A.L. Biessen

Prof. dr. H. ten Cate

Prof. dr. M. Post

Financial support by the Netherlands Heart Foundation for the publication of this thesis is gratefully acknowledged.

Additional financial support for the publication of this thesis by Centocor, Instrumentation Laboratory, Pfizer, BD Biosciences and Emfret Analytics is gratefully acknowledged. 


\section{Contents}

$\begin{array}{lll}\text { Chapter } 1 & \text { General introduction } & 7\end{array}$

Chapter 2 Contribution of platelet glycoprotein VI to the thrombogenic 23 effect of collagens in fibrous atherosclerotic lesions

Chapter $3 \quad$ Fibrillar type I collagens enhance platelet-dependent thrombin generation via glycoprotein $\mathrm{VI}$ with direct support of $\alpha 2 \beta 1$ but not $\alpha$ llb $\beta 3$ integrin

Chapter $4 \quad$ Effects of plasma- and platelet-derived matrix metalloproteinases on collagen-dependent thrombus formation

Chapter $5 \quad$ Continuous signaling via PI3K isoforms $\beta$ and $\gamma$ is required for platelet ADP receptor function in dynamic thrombus stabilization

Chapter 6 Roles of human and mouse Gas6 and Gas6 receptors in the formation and stabilization of thrombi

Chapter $7 \quad$ Multiple ways to switch platelet integrins on and off

Chapter $8 \quad$ General discussion

Samenvatting

Dankwoord 



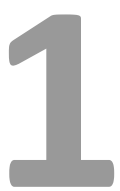

General introduction 


\section{Key role of platelets in atherothrombosis}

The primary trigger of atherothrombosis is rupture of an atherosclerotic plaque, resulting in the exposure of plaque-derived constituents to the blood stream. Platelets adhere at such sites of plaque rupture, become activated and then secrete secondary mediators such as adenosine diphosphate (ADP) and thromboxane $A_{2}\left(T \times A_{2}\right)$. These mediators recruit other platelets to form a multiplatelet aggregate or a thrombus (Fig. 1). Extensive thrombus growth can result in occlusion at the site were the thrombus is formed, or in downstream vessels by embolized parts of the platelet aggregate. These events are the most common cause of myocardial infarction and stroke. Therefore, the primary targets of therapy in arterial thrombosis are platelets and, in particular, the products from platelets that mediate aggregate formation. Aspirin, which indirectly blocks synthesis of the platelet activator $\mathrm{TxA}_{2}$, is the most commonly used antiplatelet drug. ${ }^{1}$ Clopidogrel, also common, produces a metabolite which targets the ADP receptor $\mathrm{P} 2 \mathrm{Y}_{12}$ and, hence, also suppresses platelet aggregation. ${ }^{2}$ Both drugs have been shown to be effective in reducing arterial thrombosis, although their protective effect is no more than partially. Furthermore, either drug has as a main side effect an increased risk of bleeding, which limits their use. 3,4

An alternative clinical approach is use of the drugs, abciximab and eptifibatide, which inhibit the interaction of platelet integrin $\alpha$ llb $\beta 3$ with plasma-derived fibrinogen and, hence, directly interfere in platelet aggregation. Whereas $\alpha$ llb $\beta 3$ inhibitors, intravenously delivered, are effective in treating acute thrombotic events with limited risk of bleeding, attempts to develop integrin blockers for oral use were not successful as these led to increased mortality. ${ }^{5}$ In the past few years, research has focused on finding ways to improve existing antiplatelet therapy, for instance by identifying other platelet receptors and downstream signaling molecules that can act as potential targets for antiplatelet therapy. ${ }^{6}$ However, this search is hampered by our limited knowledge of the precise platelet-activating conditions at the site of plaque rupture. ${ }^{7}$ Another limitation is the lack of full understanding of the complex interplay between the multiple factors that contribute to platelet thrombus formation during the atherothrombotic process.

This chapter provides a background in describing aspects of the complex processes in plaques and platelets that are relevant for this thesis. Emphasis is on the roles of matrix metalloproteinases (MMPs) - which process collagens in plaques and influence platelet activation -, major signaling pathways within platelets - with a key role of phosphoinositide 3-kinase (PI3K) -, and on newly identified autocrine agents produced by platelets - such as Gas6.

\section{Collagens and matrix metalloproteinases}

Atherosclerotic plaques contain a number of thrombogenic constituents that can activate the coagulation system or platelets. Concerning coagulation, advanced, lipid-rich plaques are rich in tissue factor, which is especially expressed on monocytic cells including macrophages. ${ }^{8}$ Once exposed, tissue factor triggers the extrinsic coagulation 


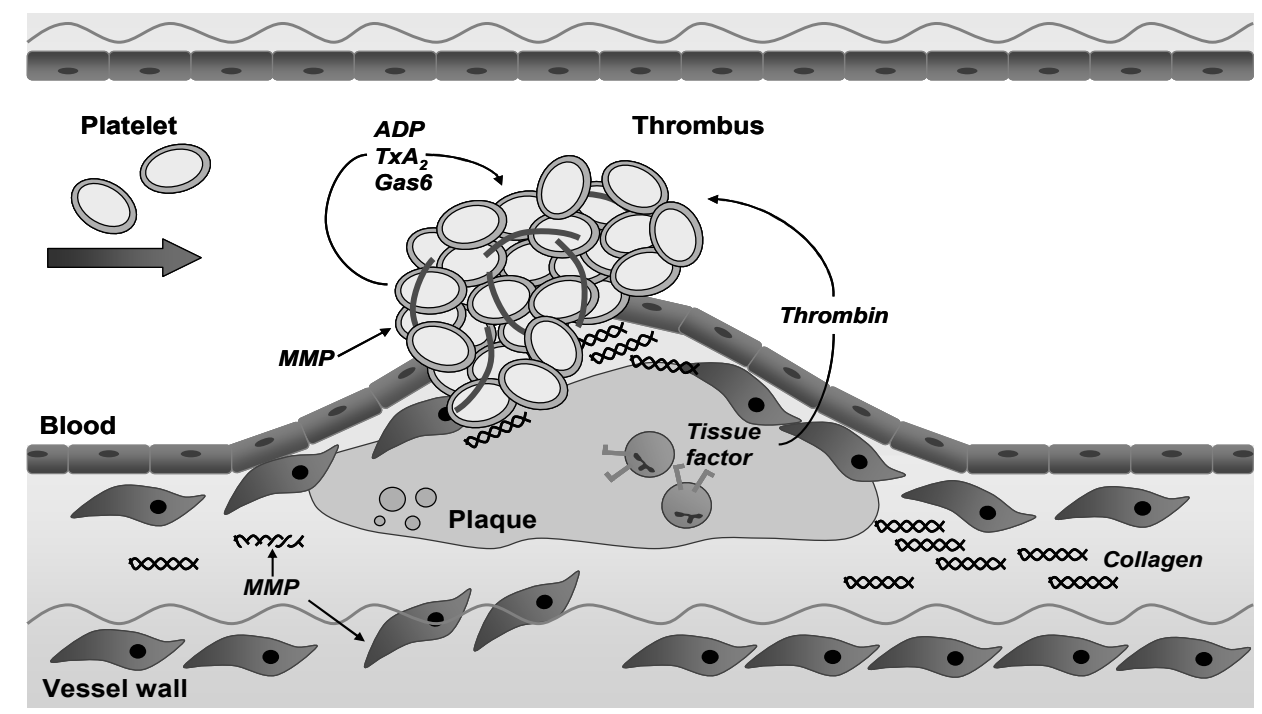

Figure 1. Overview of factors involved in thrombus formation at a site of plaque rupture. A ruptured atherosclerotic plaque rapidly recruits circulating platelets, as these interact with thrombogenic substances such as collagen of the plaque interior. Adhered platelets become activate and secrete the secondary mediators ADP, TxA2 and Gas6 to recruit other platelets and form a platelet aggregate. Matrix metalloproteinases (MMPs) cleave collagen fibers deposited in the plaque area and also affect platelet activation. Tissue factor, present e.g. on differentiating monocytes, is also exposed upon plaque rupture and triggers the coagulation pathway to form thrombin. Thrombin activates platelets and cleaves fibrinogen into fibrin, which acts in thrombus stabilization. Adapted from Refs. ${ }^{94,95}$

cascade by complex formation with factor VIlla, which, via a well-known cascade of cleavages of coagulation factors, generates thrombin and fibrin. ${ }^{9}$

Atherosclerotic plaques contain considerable amounts of collagen, which can act as a potent platelet-activating agent. In several animal models of experimental thrombosis, collagen exposure indeed leads to occlusive thrombus formation. ${ }^{10}$ Plaques that have developed to an advanced fibrotic type, prone to rupture, contain increased amounts of the fibrillar collagen types I, III and V. ${ }^{11,12}$ In contrast, the non-fibrillar collagen type IV, which is a major component of the basement membrane, is not upregulated. In the intact plaque, type I and III collagens fibers function in providing tissue stability and tensile strength. Hence, they protect the fibrous cap against rupture. However, type I and III collagens have also been shown to be strongly adhesive for platelets. ${ }^{13}$ Precisely how collagens activate platelets has long been unknown. The recognition that glycoprotein $\mathrm{VI}$ (GPVI) is the main signaling receptor for collagen on platelets, ${ }^{10}$ and the availability of anti-human GPVI antibodies ${ }^{14}$ have greatly helped to identify the signaling pathways by which various collagen types activate platelets. A specific receptor for collagen type III has been proposed in the literature, ${ }^{15}$ but the importance of this protein is currently being questioned. ${ }^{10}$ Anti-GPVI antibodies provide a powerful tool to study the interaction of plaque collagens with GPVI on platelets, as investigated in the present thesis.

Consistent with a platelet-activating role for especially type I and III collagens in plaques is the observation that, in serial cross-sections of atherosclerotic plaques, the 
pattern of high platelet deposition corresponds well with areas enriched in these collagen types. $^{12}$ However, it is also clear that ruptured plaques contain areas with high enrichment of either collagen type but no platelet adhesion. This may suggest than not only the quantity but also the quality of the collagens in plaques is a determinant of platelet adhesion and activation.

Collagens in general and plaque collagens in particular are continuously processed by matrix metalloproteinases (MMPs). ${ }^{16}$ The family of MMPs consists of more than 20 structurally related proteases with a $\mathrm{Zn}^{2+}$ ion bound to the cysteine in their catalytic domain. In general, MMPs are synthesized and secreted as inactive proenzymes. Proteolytic removal of a propeptide domain and disruption of the cysteine- $\mathrm{Zn}^{2+}$ bond are needed for activation of most MMPs. ${ }^{17}$ The structure and function of MMPs is extensively reviewed elsewhere. ${ }^{17,18}$. To provide background information, Table 1 summarizes key characteristics of several MMP isoforms relevant for this thesis, i.e. their substrate specificity, their function in plaque stability, and reported effects on platelet activation. The collagenase group of MMPs includes the isoforms MMP-1, MMP-8 and MMP-13, of which MMP-1 is only expressed in man and not in mouse. This group of MMP acts by initial cleaving of the triple helical chains of collagen types I-III. The primary cleavage site has been mapped at Gly-lle/Leu residues in the collagen $\alpha$-chain, at three-quarters from the amino terminal end. ${ }^{19,20}$ The three collagenases are upregulated in the shoulder region of atherosclerotic plaques, which is the region that is most prone to rupture..$^{21-23}$ Especially MMP-1 and MMP-8 are associated with plaque instability, while MMP-13 may be of less importance. ${ }^{24}$ MMP-1 is the only collagenase that is expressed in platelets. It is found to stimulate platelet integrin $\alpha$ llb $\beta 3$ activation. ${ }^{25}$

The gelatinases MMP-2 and MMP-9 cleave non-fibrillar collagen types as well as elastin and the products of collagen types I-III after initial cleavage by collagenases (Table 1). Furthermore, MMP-2 is capable of initial cleavage of collagen type $\mathrm{I}^{20}$ Both gelatinases appear to be essential for the migration of smooth muscle cells into the intima layer of a vessel wall, which event contributes to plaque formation and progression. Whereas, MMP-2 is highly expressed in plaque areas that are rich in smooth muscle cells, and its expression associates with increased plaque stability, MMP-9 is more strongly upregulated in the plaque shoulder region, and has unclear effects on plaque stability. ${ }^{21,26-28}$ Platelets contain MMP-2 and MMP-9 which, interestingly, affect the function of platelets in different ways. Whereas MMP-2 enhances platelet adhesion and $\alpha$ llb $\beta 3$ activation, ${ }^{29-32}$ MMP-9 rather inhibits platelet activation mediated via phospholipase C (PLC). ${ }^{25,33}$ The mode of action of these MMP isoforms on platelets is unclear.

Yet another MMP that is expressed in platelets is the stromelysin, MMP-3. This protease cleaves non-helical regions of various collagens as well as other matrix proteins, such as laminin and elastin (Table 1). In plaques, MMP-3 is upregulated in the shoulder region, and this may or may not relate to plaque instability. ${ }^{27,34}$ In contrast to other MMPs in platelets, MMP-3 likely does not affect integrin $\alpha \operatorname{lb} \beta 3$ activation. ${ }^{25}$ Although MMP-1, MMP-2 and MMP-9 haven been shown to affect platelet activation, the exact mechanism underlying these roles is unclear. For instance, it is unknown whether 


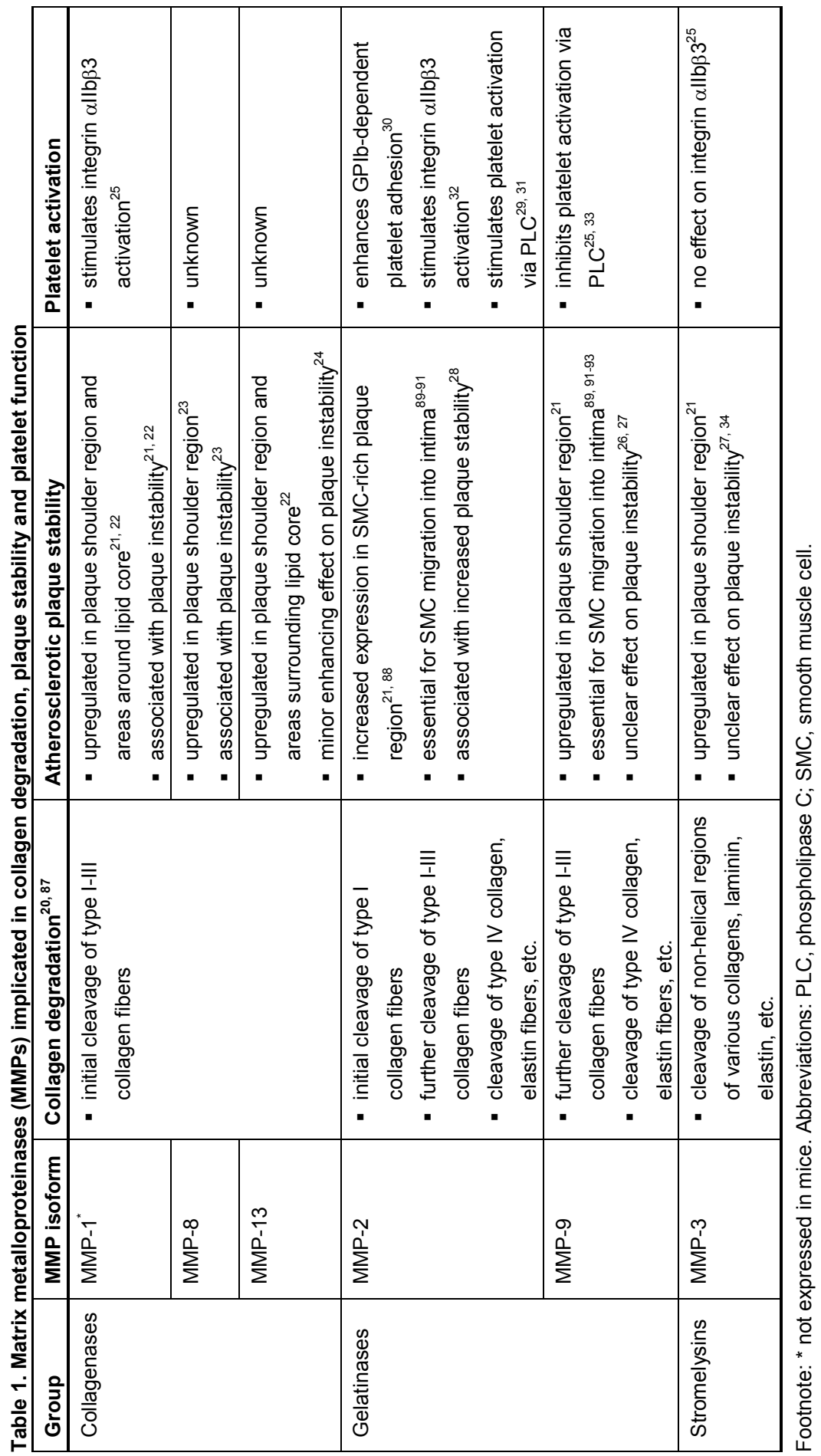


MMPs can cleave specific platelet receptors or adhesive proteins, like certain members of the related metalloproteinase-disintegrin (ADAM) family. ${ }^{35}$ Further note that all the various MMP isoforms listed so far are also present in blood plasma, at a diverse range of concentrations. How these platelet- and plasma-derived MMP isoforms influence exposed collagen has not been investigated. Such study is performed in the present thesis.

\section{Platelet signaling and role of phosphoinositide 3-kinases}

Signaling to platelet activation results in three major responses: integrin $\alpha$ llb $\beta 3$ activation, secretion and development of procoagulant activity (Fig. 2). Activation of $\alpha \mathrm{llb} \beta 3$ is required for fibrinogen binding and platelet aggregate formation. Granular secretion is a principal way of inter-platelet communication, and coagulation-promoting activity is mediated by the surface exposure of the negatively charged phospholipid, phosphatidylserine (PS). Below, a simplified overview is given of key signaling pathways implicated in these responses, with emphasis on the central role of phosphoinositide 3kinases (PI3K).

Platelets are activated in response to collagen via the immunoreceptor family member, GPVI. The second collagen receptor on platelets, integrin $\alpha 2 \beta 1$, rather acts as an adhesive receptor. ${ }^{36-38}$ Collagen binding to GPVI leads to phosphorylation of the GPVI co-receptor, Fc receptor $\gamma$-chain, by activity of Src kinases. The phosphorylated Fc receptor $\gamma$-chain serves as a docking site for a complex of proteins, including various other protein tyrosine kinases. The result is activation of the two effector enzymes, phospholipase $\mathrm{C} \gamma 2$ (PLC $\gamma 2$ ) and $\mathrm{PI}_{3 \mathrm{~K}}{ }^{39}$ Also signaling of thrombin via the receptors PAR1 and PAR4 leads to activation of PLC (here it is the PLC $\beta$ isoform) and PI3K. ${ }^{40,41}$ The PLC $\beta$ and $\gamma$ isoforms are structurally distinct proteins which however fulfill the same function. They are key effectors in the signaling pathway towards PS exposure and secretion (Fig. 2). Both types of PLC isoforms cleave phosphatidylinositol 4,5bisphosphate $\left(\mathrm{PIP}_{2}\right)$ into inositol 1,4,5-trisphosphate $\left(\mathrm{IP}_{3}\right)$ and diacylglycerol (DAG). The second messenger $\mathrm{IP}_{3}$ induces $\mathrm{Ca}^{2+}$ release from intracellular stores by opening $\mathrm{IP}_{3}$ receptor $\mathrm{Ca}^{2+}$ channels in the endoplasmic reticulum, whereas DAG activates protein kinase $C(P K C){ }^{42}$

Elevation in cytosolic $\mathrm{Ca}^{2+}$ is an essential step in platelet activation, since this, together with active PKC, is required for exocytotic secretion of $\alpha$-granules (e.g. containing Gas6) and dense granules (e.g. containing ADP), and for release of $\mathrm{TxA}_{2}$. Furthermore, a prolonged high $\mathrm{Ca}^{2+}$ level leads to scrambling of plasma membrane phospholipids, which results in PS exposure at the platelet surface. ${ }^{43,44}$ This response occurs upon platelet activation with potent agonists, e.g. collagen and thrombin. Some authors describe that PS exposure is induced in only a sub-population of activated platelets. The reason for this is not well understood. ${ }^{45}$ The PS-exposing platelets strongly accelerate thrombin generation by acting as assembly sites for vitamin K-dependent coagulation factors (prothrombin and factors VII, IX and X). ${ }^{46-48}$ 


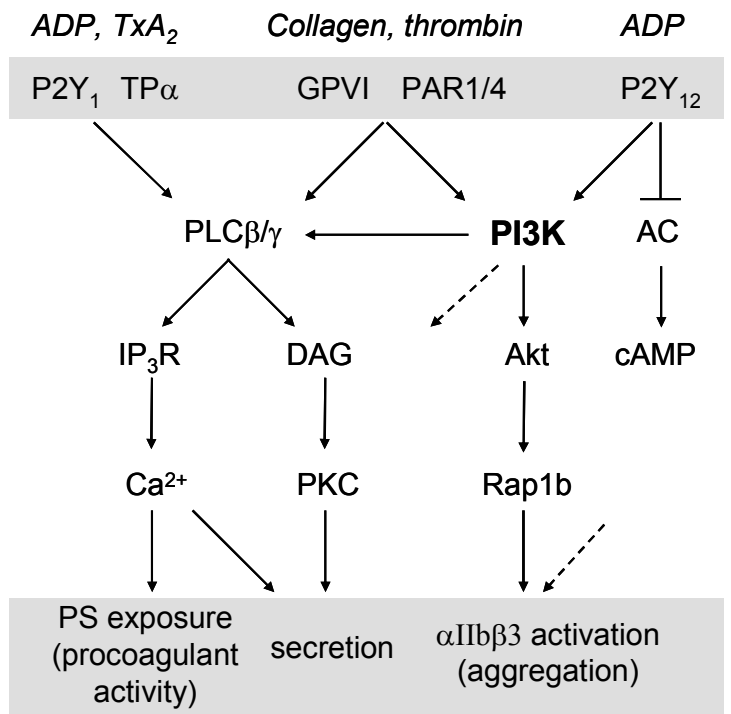

Figure 2. Key signaling pathways in platelets leading to $\alpha$ llb $\beta 3$ activation, $P S$ exposure and secretion. Signaling via the collagen receptor GPVI, the ADP receptors $P 2 Y_{1}$ and $P 2 Y_{12}$, the thrombin receptors PAR1 and PAR4, and the TxA receptor TP $\alpha$, results in the hallmarks of platelet activation, e.g. activated integrin $\alpha$ llb $\beta 3$, PS exposure, and secretion. The agonists collagen and thrombin trigger these responses by activating both the $\mathrm{PI} 3 \mathrm{~K}$ and $\mathrm{PLC} \beta / \gamma$ signaling pathways. Activated PLC $\beta / \gamma$ converts $\mathrm{PIP}_{2}$ into $\mathrm{IP}_{3}$ and $\mathrm{DAG}$. The former second messenger opens $\mathrm{IP}_{3}$ receptor channels $\left(\mathrm{IP}_{3} \mathrm{R}\right)$, which release $\mathrm{Ca}^{2+}$ from intracellular stores. Under certain conditions, increased cytosolic $\mathrm{Ca}^{2+}$ leads to surface exposure of PS and platelet procoagulant activity. The second messenger DAG activates PKC isoforms, which play a key role in granular secretion e.g. of ADP. The PI3K isoforms produce 3-phosphorylated phosphoinositides that regulate several $\mathrm{PH}-$ domain effector molecules, such as PLC $\gamma 2$ and protein kinase B (Akt). Hence, PI3K plays a regulatory role in all platelet responses. It contributes to PS exposure and secretion via PLC, while it also leads to integrin $\alpha$ llb $\beta 3$ activation via Akt and Rap1b. The secondary mediators, ADP and $\mathrm{TXA}_{2}$ provide positive feedback mechanisms. The P2Y ${ }_{1}$ and TP $\alpha$ receptors activate PLC $\beta$, while $\mathrm{P} \mathrm{Y}_{12}$ receptors activate PI3K. Furthermore, $\mathrm{P}_{2} \mathrm{Y}_{12}$ stimulates platelets via inhibition of adenylyl cyclase (AC), which lowers cAMP levels. Note that this figure gives a simplified overview, omitting other relevant signaling pathways and inter-relations between these. Dotted arrows point to signaling pathways that are not further discussed. For abbreviations, see text.

Both GPVI and thrombin receptors furthermore signal to activation of integrin allb $\beta 33^{39,49,50}$ As far as known, PI3K activity plays an important role in the various pathways that lead to $\alpha$ llb $\beta 3$ activation. ${ }^{51,52}$ Particularly active in integrin activation is the agonist ADP, which is released by platelets and stimulates the $P 2 Y_{12}$ receptors in a paracrine way (Fig. 2). $P 2 Y_{12}$ signaling via $G_{i}$ leads to inhibition of adenylyl cyclase (AC), which lowers cyclic AMP (cAMP) and indirectly enhances $\mathrm{Ca}^{2+}$ signal generation. ${ }^{53-55}$ However, this does not appear to be the main route to $\alpha$ llb $\beta 3$ activation, since a reduction in CAMP alone is not sufficient for platelet aggregation. ${ }^{56-58}$ Possibly via $\beta \gamma$ subunits of $G_{i}, P 2 Y_{12}$ also signals via another pathway that still contains missing links, but does involve PI3K and the downstream mediators Akt and Rap1b. ${ }^{59,60}$

The secondary mediator ADP also contributes to platelet activation via $\mathrm{P}_{2} \mathrm{Y}_{1}$ receptors, which are $G_{q}$-coupled and activate $P L C \beta .{ }^{61}$ The short living autocoid $\operatorname{TxA}_{2}$ diffuses across the plasma membrane after its synthesis from arachidonic acid by the 
enzymes cyclo-oxygenase and $\mathrm{TxA}_{2}$ synthase. ${ }^{62}$ At the plasma membrane surface, $\mathrm{Tx} \mathrm{A}_{2}$ binds to $\mathrm{TP} \alpha$ receptors on the same or adjacent platelets, which similarly are $\mathrm{G}_{\mathrm{q}^{-}}$ coupled.

In vitro studies using the pharmacological PI3K inhibitors, LY294002 and wortmannin, have demonstrated that it is likely that in all of these platelet responses integrin $\alpha$ llb $\beta 3$ activation, secretion and development of procoagulant activity - the effector enzyme PI3K plays a central role (Fig. 2). ${ }^{50}$ On the contrary, whether this extends to physiological conditions, such as in flow-dependent thrombus formation, is far from clear. A few studies have noted the involvement of PI3K in platelet adhesion and aggregation by using von Willebrand factor as adhesive substrate. ${ }^{63,64}$ However, there are no reports on $\mathrm{PI} 3 \mathrm{~K}$ in literature where collagen is taken as the thrombogenic substrate. Another outstanding issue relates to the role of PI3K signaling in late platelet activation stages. Since many of the $\mathrm{G}_{\mathrm{q}}$-dependent pathways to $\alpha$ llb $\beta 3$ activation are short-lived, due to receptor down-regulation, sustained integrin activation is considered to require the synergistic contribution of other input signals, such as $\mathrm{G}_{\mathrm{i}}$ - and GPVImediated signaling. Whether these long-term events involve PI3K activity is hardly being studied. The present thesis addresses these issues.

\section{Structure and function of platelet phosphoinositide 3-kinase isoforms}

Platelets express a number of $\mathrm{PI} 3 \mathrm{~K}$ isoforms, including the class $\mathrm{I}_{\mathrm{A}}$ isoforms, $\mathrm{PI} 3 \mathrm{~K} \alpha, \beta$ and $\delta$, and the class $\mathrm{I}_{\mathrm{B}}$ isoform $\mathrm{PI} 3 \mathrm{~K} \gamma .{ }^{50}$ An overview of the domain structure of these isoforms is given in Fig. 3. Both PI3K classes contain a separate catalytic and regulatory subunit. In platelets, class $\mathrm{I}_{\mathrm{A}} \mathrm{PI} 3 \mathrm{~K}$ isoforms comprise three $\mathrm{p} 110$ catalytic subunits $(\alpha, \beta$, and $\delta$ ) and three regulatory subunits (p85 $\alpha, \mathrm{p} 85 \beta$, and $\mathrm{p} 55 \gamma$ ). In addition, the $\mathrm{p} 85 \alpha$ protein possesses two alternatively shorter spliced variants, namely $p 55 \alpha$ and $p 50 \alpha{ }^{65}$ The so-called inter-SH2 domains of $\mathrm{p} 85 \alpha(\mathrm{p} 55 \alpha, \mathrm{p} 50 \alpha), \mathrm{p} 85 \beta$ and $\mathrm{p} 55 \gamma$ interact with the $\mathrm{N}$-terminal domain of $\mathrm{p} 110 \alpha, \beta$ and $\delta$. The class $\mathrm{I}_{\mathrm{A}}$ regulatory subunits are characterized by the presence of $\mathrm{SH} 2$ and $\mathrm{SH} 3$ domains, via which they can interact with growth factor-like receptor complexes, such as the GPVI signaling complex or Gas6 receptors. Binding of the two $\mathrm{SH} 2$ domains to tyrosine-phosphorylated receptors or adaptor proteins activates the kinase function of the $\mathrm{p} 110$ subunits. ${ }^{66}$

The class $\mathrm{I}_{\mathrm{B}} \mathrm{PI} 3 \mathrm{~K} \gamma$ isoform in platelets consists of a $\mathrm{p} 110 \gamma$ catalytic subunit and a unique p101 regulatory subunit (Fig. 3). The p101 protein specifically binds to the $\mathrm{N}$ terminal domain of $\mathrm{p} 110 \gamma$. The $\mathrm{p} 101$ regulatory subunit lacks $\mathrm{SH} 2$ and $\mathrm{SH} 3$ domains, and is considered to interact with the $\beta \gamma$ subunits of heterotrimeric $G$ proteins, like $\mathrm{G}_{\mathrm{i}}{ }^{65,66}$

Delineation of the roles of the individual $\mathrm{PI} 3 \mathrm{~K}$ isoforms in platelet function has for a long time been slow due to the lack of available isoform selective inhibitors and the difficulty to generate viable knockout mouse models. ${ }^{67}$ In the past few years, however, some progress has been made in understanding the function of the $p 110 \beta$ and $p 110 \gamma$ isoforms, in particular by using the PI3K $\beta$-specific inhibitor TGX221 and mice deficient in $\mathrm{p} 110 \gamma$. The $\mathrm{p} 110 \beta$ isoform is considered to be involved in $\alpha$ llb $\beta 3$ activation, ${ }^{68}$ as well as 
Class $\mathrm{I}_{\mathbf{A}}$

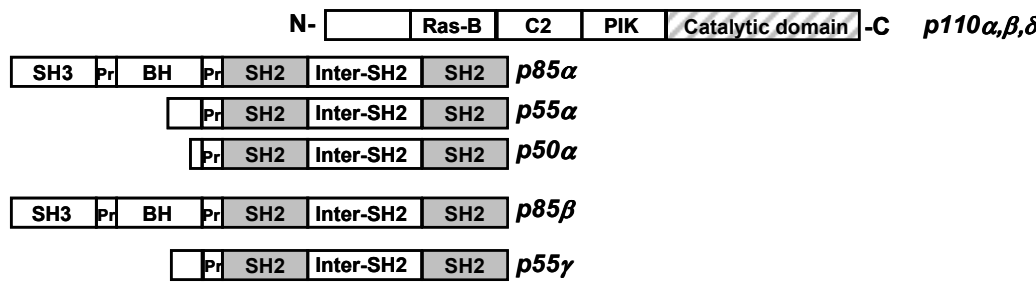

Class $I_{B}$

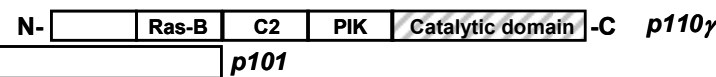

(regulatory)

(catalytic)

Figure 3. Structural characteristics of platelet phosphoinositide 3-kinases (PI3K). Platelets contain class $I_{A}$ and $I_{B} P I 3 K$ isoforms, both of which consist of a catalytic and a regulatory subunit. In class $I_{A}$ isoforms, the inter-SH2 domains of the regulatory subunits $p 85 \alpha, p 55 \alpha, p 50 \alpha, p 85 \beta$ and p55 $\gamma$ interact with corresponding $N$-terminal domains of the catalytic subunits $p 110 \alpha, \beta, \delta$. Two flanking SH2 domains bind to tyrosine-phosphorylated receptors/adaptor proteins, an interaction that is required for activation of the kinase activity of the $p 110$ subunits. The class $I_{B} p 101$ regulatory subunit contains neither $\mathrm{SH} 2$ nor $\mathrm{SH} 3$ domains, and specifically interacts with the $\mathrm{N}$ terminal domain of $\mathrm{p} 110 \gamma$. Abbreviations of domains: $\mathrm{SH} 2 / 3$, Src homology 2/3; $\mathrm{Pr}$, proline-rich region; $\mathrm{BH}$, Bcr homology; Ras-B, Ras binding; PIK, phosphatidylinositol kinase homology. Modified after Koyasu et al. ${ }^{65}$

in $\mathrm{Ca}^{2+}$ signaling and PS exposure downstream of $\mathrm{P} 2 \mathrm{Y}_{12}$ and GPVI. ${ }^{58,69}$ In contrast, the role of $\mathrm{p} 110 \gamma$ seems to be more confined to platelet aggregation via $\mathrm{P} 2 \mathrm{Y}_{12 .}{ }^{70}$ Experiments with $\mathrm{p} 110 \delta$-deficient mice indicate that this isoform plays no more than a minor role in mouse platelet activation. ${ }^{71}$ The function of $p 110 \alpha$ is in essence unclear, but its partner protein $\mathrm{p} 85 \alpha$ has been implicated in platelet function, particularly downstream of GPVI. ${ }^{72}$ In spite of this recent progress, some fundamental aspects of the signaling of $\mathrm{PI} 3 \mathrm{~K}$ isoforms are still to be defined. This concerns the extent of redundancy and overlap of the various isoforms in the various platelet signaling pathways. For example, it remains to be established which of the isoform(s) is (are) predominant downstream of the $\mathrm{G}_{\mathrm{i}}$-coupled $\mathrm{P}_{2} \mathrm{Y}_{12}$ receptor. This issue is addressed in this thesis.

\section{Unresolved role of Gas6 in thrombus formation}

In the past few years, it has been established that platelets in a thrombus are subjected to post-aggregation signal transduction events, which have been implicated in stabilization of the thrombus. The close proximity of platelets in thrombi appears to be the consequence of, and to be mediated by, specific contact-dependent signaling pathways. This subject is reviewed extensively by others. ${ }^{73}$ Here, only one of these pathways, relevant for this thesis is discussed, e.g. the pathway elicited by Gas6.

The product of the growth arrest-specific 6 (Gas6) gene is a multi-modular vitamin Kdependent protein consisting of an $\mathrm{N}$-terminal $\gamma$-carboxylated glutamic acid (Gla) domain, 4 epidermal growth factor-like domains and two C-terminal G-domains (Fig. 4). Gas6 is released by a number of cell types, including endothelial cells, vascular smooth muscle cells and bone marrow cells. ${ }^{74-76}$ It is a ligand for three receptors belonging to the Tyro3 
receptor tyrosine kinase family, namely Axl, Sky and Mer. ${ }^{77,78}$ Gas6 binds via its Gdomains with the two immunoglobulin-like domains of its receptors. ${ }^{79}$ This binding is thought to result in dimerization of two receptor monomers, which provokes autophosphorylation of tyrosine residues in the cytosolic moieties of the receptor (Fig. 4). Screening of expression libraries revealed several potential binding partners for the cytosolic domains, such as Src kinases and the regulatory PI3K subunits, p85 $\alpha$, p85 $\beta$ and $\mathrm{p} 55 \gamma .{ }^{80}$ All these proteins possess $\mathrm{SH} 2$ domains via which they can interact with the phosphorylated tyrosine residues of the receptor chains. Signaling by Gas 6 receptors contributes to various physiological processes, such as reversible cell growth arrest, inflammation, cell survival, proliferation and migration. ${ }^{80}$

The interaction of Gas6 with its receptors on platelets is considered to play an important role in thrombus stabilization in vivo, as mice deficient in Gas6 or any of the three Gas6 receptors are protected against venous and arterial thrombosis. ${ }^{81,82}$ It is postulated that, in mice, platelet activation leads to secretion of Gas 6 and expression of Gas6 receptors onto the platelet surface. ${ }^{81}$ The literature, however, is unclear which receptor isoforms other than Mer are present on human and mouse platelets. ${ }^{81-84}$ Occupation of the platelet Gas6 receptors can activate $\mathrm{PI} 3 \mathrm{~K}$ and $\mathrm{Akt},{ }^{82}$ but the $\mathrm{PI} 3 \mathrm{~K}$ isoform(s) involved are unknown. Furthermore, given the observations that human platelets do not contain Gas6 and that physiological variation in plasma Gas6 levels are not linked to changes in platelet aggregation, ${ }^{85,86}$ it remains to be defined whether Gas 6 in humans has a comparable function as in mice.

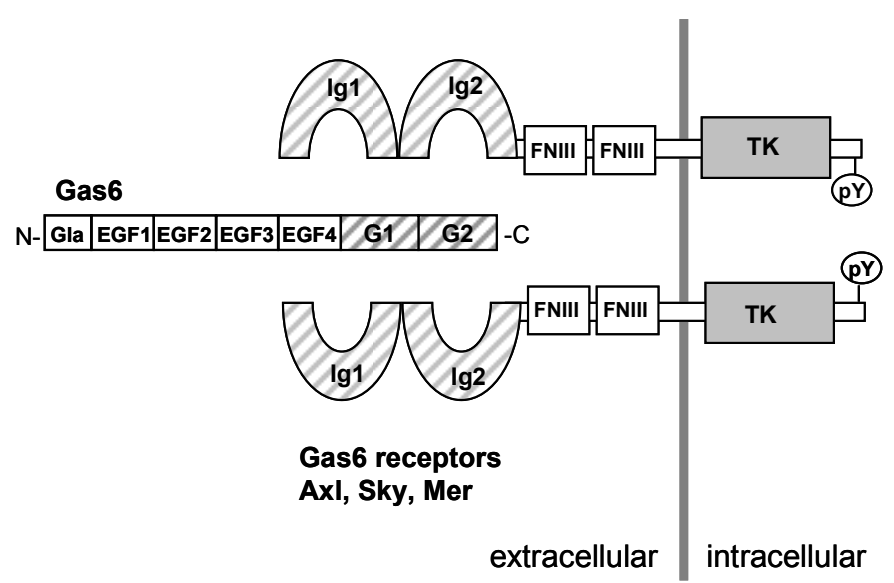

Figure 4. Domain structure of Gas6 and Gas6 receptors. The vitamin K-dependent Gas 6 protein consists of an N-terminal $\gamma$-carboxylated glutamic acid (Gla) domain, four epidermal growth factorlike (EGF) domains and two C-terminal G-domains. The G-domains are considered to interact with Ig-like domains of the three known Gas6 receptors, Axl, Sky and Mer. This interaction promotes homologous dimerization of two Gas6 receptor monomers, which leads to activation of the tyrosine kinase (TK) domains, and causes autophosphorylation of tyrosine residues (pY) in cytosolic domains of the receptors. Two fibronectin type III repeats (FNIII) function as stalking units. Phosphorylated tyrosine residues are recognition sites for proteins with $\mathrm{SH} 2$ domains, such as $\mathrm{Src}$ and the regulatory PI3K subunits, p85 $\alpha, \mathrm{p} 85 \beta$ and $\mathrm{p} 55 \gamma$. Based on Ref. ${ }^{96}$ 


\section{Aims and outline of this thesis}

In the first part of this thesis, studies are presented that establish the thrombogenic role of collagen present in or derived from advanced plaques. In chapter 2 the role of collagen-containing advanced plaques in thrombus formation under flow and thrombin generation under stasis is examined, in comparison to purified type I and III collagens. Particular attention is paid to platelet activation via the GPVI receptor and via autocrine produced ADP. Subsequently, by using various purified type I collagens, the importance of GPVI-dependent procoagulant activity and thrombin generation is studied, as well as the involvement of the integrins $\alpha 2 \beta 1$ and $\alpha$ llb $\beta 3$ herein (chapter 3 ). Based on the findings reported in these chapters, it is hypothesized that the thrombogenic activity of collagens in plaques can be altered due to proteolysis by MMP activity. This is investigated in chapter 4, which assesses how MMP isoforms, present in plasma or in purified form, affect the thrombogenic potential of plaque-derived or purified type I collagen. Furthermore, in this chapter blood from mice deficient in one of the plateletderived MMP isoforms was used to study the roles of these MMPs in platelet activation and thrombus formation.

Control of thrombus growth is an important way to restrict arterial occlusion in atherothrombosis. The mechanisms involved in thrombus growth and stability can well be studied ex vivo by using immobilized collagens as a thrombogenic surface. This setup was used in the second part of this thesis, in which the hypothesis was tested that a thrombus is not static but a highly dynamic structure which requires continuous signaling to keep platelets together and to restrict embolization. Chapter $\mathbf{5}$ focuses on the signaling routes to sustained integrin allb $\beta 3$ activation via ADP receptors and PI3K isoforms. A protein that has specifically been linked to thrombus stabilization is Gas6. Chapter 6 considers how platelet and plasma Gas 6 as well as the Gas6 receptors on the platelet surface can control flow-dependent thrombus formation and stabilization. Furthermore, by using human and mouse blood, the interaction between Gas6 and ADP receptor signaling pathways to integrin $\alpha$ llb $\beta 3$ activation is studied. Based on these data, chapter 7 presents a review which discusses evidence in the literature for reversible $\alpha$ llb $\beta 3$ activation. This chapter also summarizes current knowledge on the existence of different activation stages of platelet integrins. The discussion chapter 8 takes the principal findings of this thesis into a broader perspective.

\section{References}

1. Schrör K. Aspirin and platelets: the antiplatelet action of aspirin and its role in thrombosis treatment and prophylaxis. Semin Thromb Hemost. 1997;23:349-356.

2. Michelson $\mathrm{AD} . \mathrm{P}_{2} \mathrm{Y}_{12}$ antagonism: promises and challenges. Arterioscler Thromb Vasc Biol. 2008;28:s33-38.

3. Berger JS, Roncaglioni MC, Avanzini F, Pangrazzi I, Tognoni G, Brown DL. Aspirin for the primary prevention of cardiovascular events in women and men: a sex-specific meta-analysis of randomized controlled trials. JAMA. 2006;295:306-313.

4. Gurbel PA, Tantry US. Drug insight: clopidogrel nonresponsiveness. Nat Clin Pract Cardiovasc Med. 2006;3:387-395. 
5. Quinn MJ, Plow EF, Topol EJ. Platelet glycoprotein Ilb-Illa inhibitors: recognition of a twoedged sword. Circulation. 2002;106:379-385.

6. Meadows TA, Bhatt DL. Clinical aspects of platelet inhibitors and thrombus formation. Circ Res. 2007;100:1261-1275.

7. Jackson CL, Bennett MR, Biessen EA, Johnson JL, Krams R. Assessment of unstable atherosclerosis in mice. Arterioscler Thromb Vasc Biol. 2007;27:714-720.

8. Wilcox JN, Smith KM, Schwartz SM, Gordon D. Localization of tissue factor in the normal vessel wall and in the atherosclerotic plaque. Proc Natl Acad Sci USA. 1989;86:2839-2843.

9. Dahlbäck B. Blood coagulation. Lancet. 2000;355:1627-1632.

10. Nieswandt B, Watson SP. Platelet-collagen interaction: is GPVI the central receptor? Blood. 2003;102:449-461.

11. Shekhonin BV, Domogatsky SP, Idelson GL, Koteliansky VE, Rukosuev VS. Relative distribution of fibronectin and type I, III, IV, V collagens in normal and atherosclerotic intima of human arteries. Atherosclerosis. 1987;67:9-16.

12. van Zanten GH, de Graaf S, Slootweg PJ, Heijnen HF, Connolly TM, de Groot PG, Sixma JJ. Increased platelet deposition on atherosclerotic coronary arteries. J Clin Invest. 1994;93:615632.

13. Saelman EU, Nieuwenhuis HK, Hese KM, de Groot PG, Heijnen HF, Sage EH, Williams S, McKeown L, Gralnick HR, Sixma JJ. Platelet adhesion to collagen types I through VIII under conditions of stasis and flow is mediated by GPla/lla ( $\alpha 2 \beta 1$-integrin). Blood. 1994;83:12441250.

14. Lecut C, Feeney LA, Kingsbury G, Hopkins J, Lanza F, Gachet C, Villeval JL, Jandrot-Perrus $\mathrm{M}$. Human platelet glycoprotein $\mathrm{VI}$ function is antagonized by monoclonal antibody-derived Fab fragments. J Thromb Haemost. 2003;1:2653-2662.

15. Monnet E, Fauvel-Lafeve F. A new platelet receptor specific to type III collagen. Type III collagen-binding protein. J Biol Chem. 2000;275:10912-10917.

16. Heeneman S, Cleutjens JP, Faber BC, Creemers EE, van Suylen RJ, Lutgens E, Cleutjens $\mathrm{KB}$, Daemen MJ. The dynamic extracellular matrix: intervention strategies during heart failure and atherosclerosis. J Pathol. 2003;200:516-525.

17. Nagase $H$, Visse $R$, Murphy $G$. Structure and function of matrix metalloproteinases and TIMPs. Cardiovasc Res. 2006;69:562-573.

18. Newby AC. Dual role of matrix metalloproteinases (matrixins) in intimal thickening and atherosclerotic plaque rupture. Physiol Rev. 2005;85:1-31.

19. Billinghurst RC, Dahlberg L, lonescu M, Reiner A, Bourne R, Rorabeck C, Mitchell P, Hambor J, Diekmann O, Tschesche H, Chen J, Van Wart H, Poole AR. Enhanced cleavage of type II collagen by collagenases in osteoarthritic articular cartilage. J Clin Invest. 1997;99:15341545.

20. Visse $\mathrm{R}$, Nagase $\mathrm{H}$. Matrix metalloproteinases and tissue inhibitors of metalloproteinases: structure, function, and biochemistry. Circ Res. 2003;92:827-839.

21. Galis ZS, Sukhova GK, Lark MW, Libby P. Increased expression of matrix metalloproteinases and matrix degrading activity in vulnerable regions of human atherosclerotic plaques. $\mathrm{J}$ Clin Invest. 1994;94:2493-2503.

22. Sukhova GK, Schonbeck U, Rabkin E, Schoen FJ, Poole AR, Billinghurst RC, Libby P. Evidence for increased collagenolysis by interstitial collagenases-1 and -3 in vulnerable human atheromatous plaques. Circulation. 1999;99:2503-2509.

23. Herman MP, Sukhova GK, Libby P, Gerdes N, Tang N, Horton DB, Kilbride M, Breitbart RE, Chun M, Schonbeck U. Expression of neutrophil collagenase (matrix metalloproteinase-8) in human atheroma: a novel collagenolytic pathway suggested by transcriptional profiling. Circulation. 2001;104:1899-1904.

24. Newby AC. Do metalloproteinases destabilize vulnerable atherosclerotic plaques? Curr Opin Lipidol. 2006;17:556-561. 
25. Galt SW, Lindemann S, Allen L, Medd DJ, Falk JM, Mclntyre TM, Prescott SM, Kraiss LW Zimmerman GA, Weyrich AS. Outside-in signals delivered by matrix metalloproteinase-1 regulate platelet function. Circ Res. 2002;90:1093-1099.

26. Luttun A, Lutgens E, Manderveld A, Maris K, Collen D, Carmeliet P, Moons L. Loss of matrix metalloproteinase-9 or matrix metalloproteinase-12 protects apolipoprotein E-deficient mice against atherosclerotic media destruction but differentially affects plaque growth. Circulation. 2004;109:1408-1414.

27. Johnson JL, George SJ, Newby AC, Jackson CL. Divergent effects of matrix metalloproteinases $3,7,9$, and 12 on atherosclerotic plaque stability in mouse brachiocephalic arteries. Proc Natl Acad Sci USA. 2005;102:15575-15580.

28. Kuzuya M, Nakamura K, Sasaki T, Cheng XW, Itohara S, Iguchi A. Effect of MMP-2 deficiency on atherosclerotic lesion formation in apoE-deficient mice. Arterioscler Thromb Vasc Biol. 2006;26:1120-1125.

29. Sawicki G, Salas E, Murat J, Miszta-Lane H, Radomski MW. Release of gelatinase A during platelet activation mediates aggregation. Nature. 1997;386:616-619.

30. Radomski A, Stewart MW, Jurasz P, Radomski MW. Pharmacological characteristics of solidphase von Willebrand factor in human platelets. Br J Pharmacol. 2001;134:1013-1020.

31. Falcinelli E, Guglielmini G, Torti M, Gresele P. Intraplatelet signaling mechanisms of the priming effect of matrix metalloproteinase-2 on platelet aggregation. $\mathrm{J}$ Thromb Haemost. 2005;3:2526-2535

32. Choi WS, Jeon $\mathrm{OH}, \mathrm{Kim} \mathrm{HH}$, Kim DS. MMP-2 regulates human platelet activation by interacting with integrin $\alpha$ llb $\beta 3$. J Thromb Haemost. 2008;6:517-523.

33. Sheu JR, Fong TH, Liu CM, Shen MY, Chen TL, Chang Y, Lu MS, Hsiao G. Expression of matrix metalloproteinase-9 in human platelets: regulation of platelet activation in in vitro and in vivo studies. Br J Pharmacol. 2004;143:193-201.

34. Silence J, Lupu F, Collen D, Lijnen HR. Persistence of atherosclerotic plaque but reduced aneurysm formation in mice with stromelysin-1 (MMP-3) gene inactivation. Arterioscler Thromb Vasc Biol. 2001;21:1440-1445.

35. Andrews RK, Karunakaran D, Gardiner EE, Berndt MC. Platelet receptor proteolysis: a mechanism for downregulating platelet reactivity. Arterioscler Thromb Vasc Biol. 2007;27:1511-1520.

36. Nieswandt B, Brakebusch C, Bergmeier W, Schulte V, Bouvard D, Mokhtari-Nejad R, Lindhout T, Heemskerk JWM, Zirngibl H, Fässler R. Glycoprotein VI but not $\alpha 2 \beta 1$ integrin is essential for platelet interaction with collagen. EMBO J. 2001;20:2120-2130.

37. Lecut C, Schoolmeester A, Kuijpers MJ, Broers JL, van Zandvoort MA, Vanhoorelbeke K Deckmyn $H$, Jandrot-Perrus M, Heemskerk JW. Principal role of glycoprotein VI in $\alpha 2 \beta 1$ and $\alpha$ llb $\beta 3$ activation during collagen-induced thrombus formation. Arterioscler Thromb Vasc Biol. 2004;24:1727-1733.

38. Siljander PR, Munnix IC, Smethurst PA, Deckmyn H, Lindhout T, Ouwehand WH, Farndale RW, Heemskerk JW. Platelet receptor interplay regulates collagen-induced thrombus formation in flowing human blood. Blood. 2004;103:1333-1341.

39. Watson SP, Auger JM, McCarty OJ, Pearce AC. GPVI and integrin $\alpha$ llb $\beta 3$ signaling in platelets. J Thromb Haemost. 2005;3:1752-1762.

40. Coughlin SR. Thrombin signalling and protease-activated receptors. Nature. 2000;407:258 264.

41. Kroner C, Eybrechts $\mathrm{K}$, Akkerman JW. Dual regulation of platelet protein kinase B. J Biol Chem. 2000;275:27790-27798.

42. Heemskerk JW. Calcium and platelets. In: The Molecular Basis of Calcium Action in Biology and Medicine (Pochet R, Donato R, Haiech J, Heinzmann C and Gerke V, eds), Kluwer Acad Publ, The Hague (the Netherlands). 2000:45-71.

43. Bevers EM, Comfurius P, van Rijn JL, Hemker HC, Zwaal RF. Generation of prothrombinconverting activity and the exposure of phosphatidylserine at the outer surface of platelets. Eur J Biochem. 1982;122:429-436. 
44. Heemskerk JW, Bevers EM, Lindhout T. Platelet activation and blood coagulation. Thromb Haemost. 2002;88:186-193.

45. Munnix IC, Kuijpers MJ, Auger J, Thomassen CM, Panizzi P, van Zandvoort MA, Rosing J, Bock PE, Watson SP, Heemskerk JW. Segregation of platelet aggregatory and procoagulant microdomains in thrombus formation: regulation by transient integrin activation. Arterioscler Thromb Vasc Biol. 2007;27:2484-2490.

46. Rosing J, Tans G, Govers-Riemslag JW, Zwaal RF, Hemker HC. The role of phospholipids and factor $\mathrm{Va}$ in the prothrombinase complex. J Biol Chem. 1980;255:274-283.

47. van Dieijen G, Tans G, Rosing J, Hemker HC. The role of phospholipid and factor VIIIa in the activation of bovine factor X. J Biol Chem. 1981;256:3433-3442.

48. Monroe DM, Hoffman M, Roberts HR. Platelets and thrombin generation. Arterioscler Thromb Vasc Biol. 2002;22:1381-1389.

49. Chen $\mathrm{H}$, Kahn ML. Reciprocal signaling by integrin and nonintegrin receptors during collagen activation of platelets. Mol Cell Biol. 2003;23:4764-4777.

50. Jackson SF, Schoenwaelder SM. Type I phosphoinositide 3-kinases: potential antithrombotic targets? Cell Mol Life Sci. 2006;63:1085-1090.

51. Shattil SJ, Kashiwagi H, Pampori N. Integrin signaling, the platelet paradigm. Blood. 1998;91:2645-2657.

52. Ma YQ, Qin J, Plow EF. Platelet integrin $\alpha$ llb $\beta 3$ : activation mechanisms. J Thromb Haemost. 2007;5:1345-1352.

53. Paul BZ, Jin J, Kunapuli SP. Molecular mechanism of thromboxane $A_{2}$-induced platelet aggregation. Essential role for P2T $\mathrm{Tc}_{\mathrm{ac}}$ and $\alpha_{2 \mathrm{a}}$ receptors. J Biol Chem. 1999;274:29108-29114.

54. Keularts IM, van Gorp RM, Feijge MA, Vuist WM, Heemskerk JW. $\alpha_{2 A}$-adrenergic receptor stimulation potentiates calcium release in platelets by modulating cAMP levels. J Biol Chem. 2000;275:1763-1772.

55. Conley PB, Delaney SM. Scientific and therapeutic insights into the role of the platelet $P 2 Y_{12}$ receptor in thrombosis. Curr Opin Hematol. 2003;10:333-338.

56. Daniel JL, Dangelmaier C, Jin J, Kim YB, Kunapuli SP. Role of intracellular signaling events in ADP-induced platelet aggregation. Thromb Haemost. 1999;82:1322-1326.

57. Lova P, Paganini S, Sinigaglia F, Balduini C, Torti M. A Gi-dependent pathway is required for activation of the small GTPase Rap1B in human platelets. J Biol Chem. 2002;277:1200912015.

58. van der Meijden PE, Schoenwaelder SM, Feijge MA, Cosemans JM, Munnix IC, Wetzker R, Heller R, Jackson SP, Heemskerk JW. Dual $P 2 Y_{12}$ receptor signaling in thrombin-stimulated platelets - involvement of phosphoinositide 3-kinase $\beta$ but not $\gamma$ isoform in $\mathrm{Ca}^{2+}$ mobilization and procoagulant activity. FEBS J. 2008;275:371-385.

59. Kauffenstein G, Bergmeier W, Eckly A, Ohlmann P, Leon C, Cazenave JP, Nieswandt B, Gachet $\mathrm{C}$. The $\mathrm{P}_{2} \mathrm{Y}_{12}$ receptor induces platelet aggregation through weak activation of the $\alpha$ llb $\beta 3$ integrin-a phosphoinositide 3-kinase-dependent mechanism. FEBS Lett. 2001;505:281-290.

60. Offermanns S. Activation of platelet function through G protein-coupled receptors. Circ Res. 2006;99:1293-1304.

61. Jin J, Kunapuli SP. Coactivation of two different G protein-coupled receptors is essential for ADP-induced platelet aggregation. Proc Natl Acad Sci USA. 1998;95:8070-8074.

62. Narumiya S, Sugimoto Y, Ushikubi F. Prostanoid receptors: structures, properties, and functions. Physiol Rev. 1999;79:1193-1226.

63. Nesbitt WS, Kulkarni S, Giuliano S, Goncalves I, Dopheide SM, Yap CL, Harper IS, Salem $\mathrm{HH}$, Jackson SP. Distinct glycoprotein Ib/V/IX and integrin $\alpha$ llb $\beta 3$-dependent calcium signals cooperatively regulate platelet adhesion under flow. J Biol Chem. 2002;277:2965-2972.

64. Yap CL, Anderson KE, Hughan SC, Dopheide SM, Salem HH, Jackson SP. Essential role for phosphoinositide 3-kinase in shear-dependent signaling between platelet glycoprotein Ib/V/IX and integrin $\alpha \operatorname{llb} \beta 3$. Blood. 2002;99:151-158. 
65. Koyasu S. The role of PI3K in immune cells. Nat Immunol. 2003;4:313-319.

66. Engelman JA, Luo J, Cantley LC. The evolution of phosphatidylinositol 3-kinases as regulators of growth and metabolism. Nat Rev Genet. 2006;7:606-619.

67. Vanhaesebroeck B, Ali K, Bilancio A, Geering B, Foukas LC. Signalling by PI3K isoforms: insights from gene-targeted mice. Trends Biochem Sci. 2005;30:194-204.

68. Jackson SP, Schoenwaelder SM, Goncalves I, Nesbitt WS, Yap CL, Wright CE, Kenche V Anderson KE, Dopheide SM, Yuan Y, Sturgeon SA, Prabaharan H, Thompson PE, Smith GD, Shepherd PR, Daniele N, Kulkarni S, Abbott B, Saylik D, Jones C, Lu L, Giuliano S, Hughan SC, Angus JA, Robertson AD, Salem HH. PI 3-kinase p110 3 : a new target for antithrombotic therapy. Nat Med. 2005;11:507-514.

69. Munnix IC. Platelet signaling to procoagulant activity and heterogeneity in thrombus formation. An in vivo and ex vivo approach. PhD Thesis, Maastricht University, Maastricht, The Netherlands. ISBN 978-90-5278-630-8. 2007.

70. Hirsch E, Bosco O, Tropel P, Laffargue M, Calvez R, Altruda F, Wymann M, Montrucchio G. Resistance to thromboembolism in PI3K $\gamma$-deficient mice. FASEB J. 2001;15:2019-2021.

71. Senis YA, Atkinson BT, Pearce AC, Wonerow P, Auger JM, Okkenhaug K, Pearce W, Vigorito E, Vanhaesebroeck B, Turner M, Watson SP. Role of the p110 $\mathrm{PI}$ 3-kinase in integrin and ITAM receptor signalling in platelets. Platelets. 2005;16:191-202.

72. Watanabe N, Nakajima H, Suzuki H, Oda A, Matsubara Y, Moroi M, Terauchi Y, Kadowaki T, Suzuki H, Koyasu S, Ikeda Y, Handa M. Functional phenotype of phosphoinositide 3-kinase p85 $\alpha$-null platelets characterized by an impaired response to GPVI stimulation. Blood. 2003;102:541-548.

73. Brass LF, Zhu L, Stalker TJ. Minding the gaps to promote thrombus growth and stability. J Clin Invest. 2005;115:3385-3392.

74. Manfioletti G, Brancolini C, Avanzi G, Schneider C. The protein encoded by a growth arrestspecific gene (gas6) is a new member of the vitamin K-dependent proteins related to protein $\mathrm{S}$, a negative coregulator in the blood coagulation cascade. Mol Cell Biol. 1993;13:49764985.

75. Nakano T, Higashino K, Kikuchi N, Kishino J, Nomura K, Fujita H, Ohara O, Arita H. Vascular smooth muscle cell-derived, Gla-containing growth-potentiating factor for $\mathrm{Ca}^{2+}$-mobilizing growth factors. J Biol Chem. 1995;270:5702-5705.

76. Avanzi GC, Gallicchio M, Cavalloni G, Gammaitoni L, Leone F, Rosina A, Boldorini R, Monga G, Pegoraro L, Varnum B, Aglietta M. Gas6, the ligand of Axl and Rse receptors, is expressed in hematopoietic tissue but lacks mitogenic activity. Exp Hematol. 1997;25:12191226.

77. Stitt TN, Conn G, Gore M, Lai C, Bruno J, Radziejewski C, Mattsson K, Fisher J, Gies DR Jones PF, et al. The anticoagulation factor protein $\mathrm{S}$ and its relative, Gas6, are ligands for the Tyro 3/Axl family of receptor tyrosine kinases. Cell. 1995;80:661-670.

78. Nagata K, Ohashi K, Nakano T, Arita H, Zong C, Hanafusa H, Mizuno K. Identification of the product of growth arrest-specific gene 6 as a common ligand for AxI, Sky, and Mer receptor tyrosine kinases. J Biol Chem. 1996;271:30022-30027.

79. Sasaki T, Knyazev PG, Clout NJ, Cheburkin Y, Gohring W, Ullrich A, Timpl R, Hohenester E. Structural basis for Gas6-Axl signalling. EMBO J. 2006;25:80-87.

80. Hafizi S, Dahlbäck B. Signalling and functional diversity within the Axl subfamily of receptor tyrosine kinases. Cytokine Growth Factor Rev. 2006.

81. Angelillo-Scherrer A, de Frutos P, Aparicio C, Melis E, Savi P, Lupu F, Arnout J, Dewerchin M, Hoylaerts M, Herbert J, Collen D, Dahlbäck B, Carmeliet P. Deficiency or inhibition of Gas6 causes platelet dysfunction and protects mice against thrombosis. Nat Med. 2001;7:215-221. 
82. Angelillo-Scherrer A, Burnier L, Flores N, Savi $P$, DeMol M, Schaeffer $P$, Herbert JM, Lemke G, Goff SP, Matsushima GK, Earp HS, Vesin C, Hoylaerts MF, Plaisance S, Collen D, Conway EM, Wehrle-Haller B, Carmeliet P. Role of Gas6 receptors in platelet signaling during thrombus stabilization and implications for antithrombotic therapy. J Clin Invest 2005;115:237-246.

83. Chen C, Li Q, Darrow AL, Wang Y, Derian CK, Yang J, de Garavilla L, Andrade-Gordon P, Damiano BP. Mer receptor tyrosine kinase signaling participates in platelet function. Arterioscler Thromb Vasc Biol. 2004;24:1118-1123.

84. Gould WR, Baxi SM, Schroeder R, Peng YW, Leadley RJ, Peterson JT, Perrin LA. Gas6 receptors Axl, Sky and Mer enhance platelet activation and regulate thrombotic responses. J Thromb Haemost. 2005;3:733-741.

85. Balogh I, Hafizi S, Stenhoff J, Hansson K, Dahlbäck B. Analysis of Gas6 in human platelets and plasma. Arterioscler Thromb Vasc Biol. 2005;24:1280-1206.

86. Clauser S, Bachelot-Lozat C, Fontana P, Gaussem P, Remones V, Aiach M, Borgel D. Physiological plasma Gas6 levels do not influence platelet aggregation. Arterioscler Thromb Vasc Biol. 2006;26:e22.

87. Jones CB, Sane DC, Herrington DM. Matrix metalloproteinases. A review of their structure and role in acute coronary syndrome. Cardiovasc Res. 2003;59:812-823.

88. Sluijter JP, Pulskens WP, Schoneveld AH, Velema E, Strijder CF, Moll F, de Vries JP, Verheijen J, Hanemaaijer R, de Kleijn DP, Pasterkamp G. Matrix metalloproteinase 2 is associated with stable and matrix metalloproteinases 8 and 9 with vulnerable carotid atherosclerotic lesions: a study in human endarterectomy specimen pointing to a role for different extracellular matrix metalloproteinase inducer glycosylation forms. Stroke. 2006;37:235-239.

89. Bendeck MP, Zempo N, Clowes AW, Galardy RE, Reidy MA. Smooth muscle cell migration and matrix metalloproteinase expression after arterial injury in the rat. Circ Res. 1994;75:539545.

90. Kuzuya M, Kanda S, Sasaki T, Tamaya-Mori N, Cheng XW, Itoh T, Itohara S, Iguchi A. Deficiency of gelatinase a suppresses smooth muscle cell invasion and development of experimental intimal hyperplasia. Circulation. 2003;108:1375-1381.

91. Johnson C, Galis ZS. Matrix metalloproteinase-2 and -9 differentially regulate smooth muscle cell migration and cell-mediated collagen organization. Arterioscler Thromb Vasc Biol. 2004;24:54-60.

92. Cho A, Reidy MA. Matrix metalloproteinase-9 is necessary for the regulation of smooth muscle cell replication and migration after arterial injury. Circ Res. 2002;91:845-851.

93. Galis ZS, Johnson C, Godin D, Magid R, Shipley JM, Senior RM, Ivan E. Targeted disruption of the matrix metalloproteinase-9 gene impairs smooth muscle cell migration and geometrical arterial remodeling. Circ Res. 2002;91:852-859.

94. Ruggeri ZM. Platelets in atherothrombosis. Nat Med. 2002;8:1227-1234.

95. Mackman N. Triggers, targets and treatments for thrombosis. Nature. 2008;451:914-918.

96. Saller F, Burnier L, Schapira M, Angelillo-Scherrer A. Role of the growth arrest-specific gene 6 (gas6) product in thrombus stabilization. Blood Cells Mol Dis. 2006;36:373-378. 


\section{Contribution of platelet glycoprotein VI to the thrombogenic effect of collagens in fibrous atherosclerotic lesions}

Judith M.E.M. Cosemans, Marijke J.E. Kuijpers, Christelle Lecut, Sarah T.B.G. Loubele, Sylvia Heeneman, Martine Jandrot-Perrus and Johan W.M. Heemskerk

Atherosclerosis 2005; 181: 19-27

Reprinted with permission from Elsevier 


\begin{abstract}
Collagens (type I and III) are among the strongest thrombus-forming components of the vascular subendothelium. We compared the thrombogenic effects of four collagencontaining advanced atherosclerotic lesions with those of purified type I and III collagen fibers. Cell-free homogenates from the human plaques effectively promoted platelet adhesion and aggregate formation under high-shear flow conditions, as well as exposure of procoagulant phosphatidylserine (PS) on platelets. With all plaques, blocking of the glycoprotein $\mathrm{VI}(\mathrm{GPVI})$ receptor for collagen abolished aggregation and PS exposure. Blocking of platelet ADP receptors resulted in similar, but less complete inhibitory effects. Type I collagen was more potent than type III collagen in inducing aggregation and PS exposure under flow, via stimulation of GPVI and ADP receptors. Type I collagen also more strongly enhanced thrombin generation with platelets and tissue factor, again via GPVI activation and PS exposure. The plaque material enhanced thrombin generation, partly due to the presence of tissue factor and partly via GPVI and ADP receptors. Together, these results indicate that in advanced plaques collagen type $I$ is a major trigger of thrombus formation and PS exposure, acting via GPVI and ADP release, while tissue factor directly enhances coagulation.
\end{abstract}

\title{
Introduction
}

Fibrillar collagens, especially types I and III, are among the strongest platelet-adhesive and platelet-activating substances in the vascular subendothelium. ${ }^{1}$ Two principal receptors are involved in platelet adhesion to collagen and subsequent activation, i.e. integrin $\alpha 2 \beta 1$ and the immunoglobulin superfamily member, glycoprotein $\mathrm{VI}(\mathrm{GPVI}){ }^{2}$ The activating effect of direct platelet-collagen contact is extended by release of autocrine mediators from platelets, particularly ADP, which acts via the $P 2 Y_{1}$ and $P 2 Y_{12}$ receptors and leads to the formation of platelet aggregates. ${ }^{3-5}$ Platelet interaction with collagen via GPVI also stimulates the procoagulant response, which is characterized by the expression of phosphatidylserine (PS) at the platelet outer membrane. ${ }^{6}$ Exposed PS provides a catalytic surface for the assembly and activation of tenase and prothrombinase complexes and, thereby, enhances thrombin formation in plasma by several orders of magnitude. ${ }^{7}$

Rupture or damage of an unstable atherosclerotic plaque leads to contact of the flowing blood with the material from the plaque core. Ensuing formation of platelet thrombi is considered to be a major cause of acute coronary syndrome and ischemic sudden death. ${ }^{8,9}$ In advanced plaque lesions, thrombogenic components are found particularly in the atheromatous core and the surrounding extracellular matrix. ${ }^{10,11}$ The core contains, in addition to cholesterol crystals, lipidic substances that activate platelets such as lysophosphatidic acid. The latter compound is also released by activated platelets themselves, and may act as a primary trigger in thrombus formation. ${ }^{12,13}$ Another thrombogenic substance on ruptured plaques is tissue factor (TF), which is a membrane-bound protein that, when de-encrypted, potently initiates the coagulation cascade. $^{14,15}$ 
Atheromatous plaques are further rich in collagen fibers. Particularly the collagen types I, III and V increase during plaque development up to advanced fibrotic lesions. ${ }^{9,16,17}$ Collagen in plaques has a structural function, as its degradation by metalloproteinases contributes to plaque instability. ${ }^{18}$ However, collagen can also contribute to the thrombogenic reaction upon plaque rupturing. An early report describes that the increased thrombogenicity during plaque progression correlates with changes in quantity and nature of collagen types I and $\mathrm{III}{ }^{17}$ However, until recently no suitable antibodies against platelet collagen receptors were available to evaluate the function of plaque collagens in thrombus formation. Precise information on the platelet-activating effect of plaque collagens is therefore still missing.

Recently, a monoclonal antibody (mAb), 9012, against the collagen-binding domain of human GPVI has been developed. Fab fragments are highly effective in inhibiting collagen-induced secretion, aggregation and procoagulant activity of human platelets and, as a consequence, function as potent inhibitors of human thrombus formation. ${ }^{19,20}$ We anticipated that this antibody can also be used in determining the thrombogenic effect of plaque collagens. Here, we prepared cell-free material from a number of advanced human plaque lesions to investigate thrombus formation and plateletdependent coagulation in the presence of this antibody. The thrombogenic effects of plaque materials were compared with those of purified type I and III collagens.

\section{Materials and Methods}

\section{Materials}

H-Phe-Pro-Arg chloromethyl ketone (PPACK) was obtained from Calbiochem (La Jolla, CA, USA). Bovine factor X, bovine serum albumin (BSA), MRS2179 (MRS), Trizma base and type III collagen were provided by Sigma (St. Louis, MO, USA). Z-Gly-Gly-Arg aminomethyl coumarin (Z-GGR-AMC) came from Bachem (Bubendorf, Switzerland), Oregon green-488 (OG488) labeled annexin A5 from Nexins Research (Hoeven, The Netherlands); recombinant human TF from Dade (Miami, FL, USA). The P2Y 12 receptor antagonist, AR-C69931MX (ARC), was kindly supplied by Astra-Zeneca (Charnwood, UK). Sirius red, hematoxylin, eosin and anti-rabbit poly-AP came from Klinipath (Duiven, The Netherlands). Biotin-labeled swine anti-rabbit antibody, streptavidin-biotin complex with horse-radish peroxidase (streptavidin-ABC-HRP) and diaminobenzidine (DAB) were from Dako (Glostrup, Denmark). Rabbit anti-human polyclonal antibodies against type I and III collagen were provided by Biogenesis (Kingston, NH, USA). Rabbit anti-human polyclonal TF antibody was from American Diagnostica (no. 4502, Greenwich, CT, USA) and alkaline phosphatase substrate kit from Brunschwig Chemie (Amsterdam, The Netherlands). Factor VIla was from Novo Nordisk (Bagsværd, Denmark) and chromogenic substrate S2765 from Chromogenix (Mölndal, Sweden).

Fab fragments of anti-human GPVI mAb, 9012, were produced as described. ${ }^{19}$ Fibrillar 'Horm' type I collagen, used as standard collagen preparation, was obtained from Nycomed (Munich, Germany). Native fibrillar type I collagen was prepared from 
bovine tendon. ${ }^{21}$ Commercial type III collagen was dialyzed overnight against phosphatebuffered saline (PBS; in mmol/l: $\mathrm{KCl} 2.7, \mathrm{KH}_{2} \mathrm{PO}_{4} 1.5, \mathrm{NaCl} 100, \mathrm{Na}_{2} \mathrm{HPO}_{4} 7.3, \mathrm{pH}$ 8.0), and polymerized by a 5 -min incubation at $35^{\circ} \mathrm{C}$ before use. Other reagents were obtained from sources described before. ${ }^{22}$

\section{Preparation of plaque tissues}

Four atherosclerotic plaques were collected at autopsy from carotid artery and used in compliance with institutional guidelines (Department of Pathology, Academic Hospital Maastricht). Permission was obtained from the medical ethics committee. After resection, the atherosclerotic specimens were divided into adjacent parts of $5 \mathrm{~mm}$ for histological analysis or experimental use. Specimens for histology were fixed in formalin $(10 \%$ in PBS), routinely processed and embedded in paraffin. Sections of $4 \mu \mathrm{m}$ were cut, stained with hematoxylin and eosin, and classified for type of lesion according to the morphological criteria of Virmani et al. ${ }^{23}$ Other sections were stained for collagen types I and III or TF. Therefore, they were deparaffinized in xylene and rehydrated in ethanol. For collagen I and III staining, this was followed by 15-min treatment with methanol plus $1 \%$ hydrogen peroxide to block endogenous peroxidase activity. Sections were incubated for $30 \mathrm{~min}$ at room temperature with antibody against collagen I (1:10) or collagen III (1:10), or overnight at $4^{\circ} \mathrm{C}$ with anti-TF antibody. After wash in Tris-buffered saline (TBS; in mmol/l: $\mathrm{NaCl} 136.9$, Trizma base 5.0, 1\% BSA and 0.1\% Tween, $\mathrm{pH} 7.6$ ), sections were treated with secondary biotin-labeled antibody (1:1000 for $30 \mathrm{~min})$ for collagen type I and III, or with secondary poly-AP for TF, and again washed in TBS. Streptavidin-ABC-HRP (1:500) was incubated for $30 \mathrm{~min}$, and DAB was added for chromogenic development of collagen I and III staining. TF was visualized with an alkaline phosphatase substrate kit. Serial sections treated with secondary antibodies alone did not show staining. Total collagen content of plaque material was determined by staining sections with $0.1 \%$ Sirius red in saturated picric acid for $90 \mathrm{~min}$.

Plaque parts destined for experimental use were immediately frozen into liquid nitrogen and stored at $-80^{\circ} \mathrm{C}$. After thawing tissues were homogenized in $\mathrm{PBS} \mathrm{pH} 7.4$ using a potter (Braun, Melsungen, Germany). The homogenates were centrifuged three times at $2240 \mathrm{~g}$ for $10 \mathrm{~min}$. Pellets were resuspended in sterile saline at a concentration of $160 \mathrm{mg}$ tissue wet weight $/ \mathrm{ml}$.

\section{Isolation of platelets and plasma}

Blood was obtained from healthy volunteers after full informed consent according to the Helsinki declaration. Blood was drawn by venapuncture either in 1/10 volume of 129 $\mathrm{mmol} / /$ trisodium citrate, or in $40 \mu \mathrm{mol} / \mathrm{l}$ PPACK. First $2.5 \mathrm{ml}$ of blood were discarded. Citrated blood was centrifuged at $260 \mathrm{~g}$ for $15 \mathrm{~min}$ to obtain platelet-rich plasma (PRP), and twice at $870 \mathrm{~g}$ for $10 \mathrm{~min}$ for platelet-free plasma (PFP). PRP was normalized to 1.5 $\times 10^{8}$ platelets $/ \mathrm{ml}$ with autologous PFP. 


\section{Measurement of thrombus formation and PS exposure under flow}

Flow experiments over collagen were performed at room temperature using PPACKanticoagulated blood. ${ }^{5}$ Collagens $\left(35 \mu \mathrm{g} / \mathrm{cm}^{2}\right)$ or plaque materials $(170 \mu \mathrm{g}$ wet weight $/ \mathrm{cm}^{2}$ ) were spread on cleaned glass coverslips. Coverslips were blocked with HEPES buffer $\mathrm{pH} 7.45$ (in mmol/l: $\mathrm{NaCl} 136$, glucose 10, HEPES 5, $\mathrm{KCl} 2.7, \mathrm{MgCl}_{2} 2$, $\mathrm{CaCl}_{2} 2$, and $1 \% \mathrm{BSA}$ ), and kept wet. Blood was perfused over coated coverslips through a transparent, parallel-plate perfusion chamber at a moderately high wall-shear rate of $1000 \mathrm{~s}^{-1}$ for $4 \mathrm{~min}$. Inhibitors were added to the blood $10 \mathrm{~min}$ prior to perfusion. High-resolution transmission and fluorescent images were recorded in real-time with two different cameras equipped with a Visitech digital imaging system (Sunderland, UK). PS exposing platelets were detected by post-perfusion with HEPES buffer $\mathrm{pH} 7.45$ containing $1 \mathrm{U} / \mathrm{ml}$ heparin and $0.5 \mu \mathrm{g} / \mathrm{ml}$ OG488-annexin $\mathrm{A}^{2} .^{24}$

Phase-contrast and fluorescent images were captured from at least ten different plaque/collagen-containing microscopic fields, which were arbitrarily chosen. Images with background fluorescence that was not attributed to platelets were excluded from analysis. Area coverage from phase-contrast and fluorescent images was analyzed offline. ${ }^{5}$

\section{Thrombin generation measurement}

Thrombin generation was continuously measured in PRP with a well-plate reader (Molecular Devices, Sunnyvale, CA, USA) using the thrombogram method. ${ }^{22}$ Final assay concentrations were: $1 \mathrm{pmol} / \mathrm{I} \mathrm{TF}, 66 \%$ plasma with $1.0 \times 10^{8}$ platelets $/ \mathrm{ml}$ and $2.5 \mathrm{mmol} / \mathrm{l}$ Z-GGR-AMC. First-derivative curves of accumulation of fluorescence were converted into curves of nanomolar thrombin using human thrombin calibrator and thrombinoscope software. ${ }^{22,25,26}$ PRP was pretreated with antibodies or inhibitors at maximally effective concentrations for $10 \mathrm{~min}\left(37^{\circ} \mathrm{C}\right)$. Thrombin generation measurements were started at 10 min after addition of collagen or plaque material. Collagen samples were dialyzed against $10 \mathrm{mmol} / \mathrm{l}$ acetic acid (overnight $4^{\circ} \mathrm{C}$ ) before use. Plaque material, dissolved in saline, was added at $0.28 \mathrm{mg}$ wet weight $/ \mathrm{ml}$. Controls were run with vehicle media.

TF activity was determined in homogenates that were diluted in $25 \mathrm{mM}$ HEPES and $175 \mathrm{mM} \mathrm{NaCl}\left(\mathrm{pH} \mathrm{7.7)}\right.$ ) and incubated at $37^{\circ} \mathrm{C}$ for $20 \mathrm{~min}$. Reactions were started by addition of factor VIla $(0.72 \mathrm{nmol} / \mathrm{l}$, f.c. $)$, factor $X(60 \mathrm{nmol} / \mathrm{l}), \mathrm{CaCl}_{2}(3 \mathrm{mmol} / \mathrm{l})$ and phospholipid vesicles $(7.2 \mu \mathrm{mol} / \mathrm{l}$, PC:PS, 80:20). Factor Xa activity was kinetically measured using the chromogenic substrate $\mathrm{S} 2765$.

\section{Statistics}

Data were tested for significance by using the statistical package for social sciences (SPSS 11.0, Chicago, IL, USA). Significant differences $(P<0.05)$ compared to controls were evaluated with a Mann-Whitney $U$ test, and indicated where applicable. Data are mean values \pm S.E. 


\section{Results}

\section{Characterization of used human plaques}

Four human plaques, obtained at autopsy, were histochemically characterized as fibrous cap atheromas without signs of hemorrhage. Sections of these plaques were immunohistochemically stained for collagen types I and III, i.e. the major collagens in fibrous plaques and vessel wall. ${ }^{17,27}$ As shown for a typical example in Fig. 1, all plaques showed high staining for total collagen and type I collagen. Furthermore, the plaques stained positively for TF, using a blocking polyclonal antibody (Fig. 1D). Significant staining for type III collagen was also detected (data not shown), in accordance to published results. ${ }^{28}$

\section{Effects of plaque material and collagens on thrombus formation in flowing whole blood}

Parts of the four plaques were homogenized and centrifuged to obtain cell- and lipid-free homogenates. The plaque homogenates were evaluated for their thrombogenic effects. Homogenates were spread on a coverslip at an equal density and subjected to perfusion with human PPACK-anticoagulated blood from various donors at a moderately high shear rate of $1000 \mathrm{~s}^{-1}$. With material from each plaque, this resulted in a time-dependent increase in platelet deposition on the coverslip. The coating was optimal, as application of more homogenate on the coverslips did not result in increased platelet adhesion (data not shown). After $4 \mathrm{~min}$ of flow, large platelet aggregates were formed, e.g. as indicated for plaque 1 in Fig. 2A. Surface area coverage with platelets after flow over material from plaques 1-3 was similar, i.e. $8.8 \pm 1.2 \%, 14.6 \pm 1.9 \%$ and $15.4 \pm 3.9 \%$ (mean \pm S.E., $n=$ 4 ) of the total surface (Fig. 2B). Plaque 4 gave highest area coverage, amounting to 28.6 $\pm 3.7 \%$ of the surface. The coverslips were post-perfused with OG488-labeled annexin A5 to monitor PS exposure of adherent platelets and, thereby, procoagulant activity.
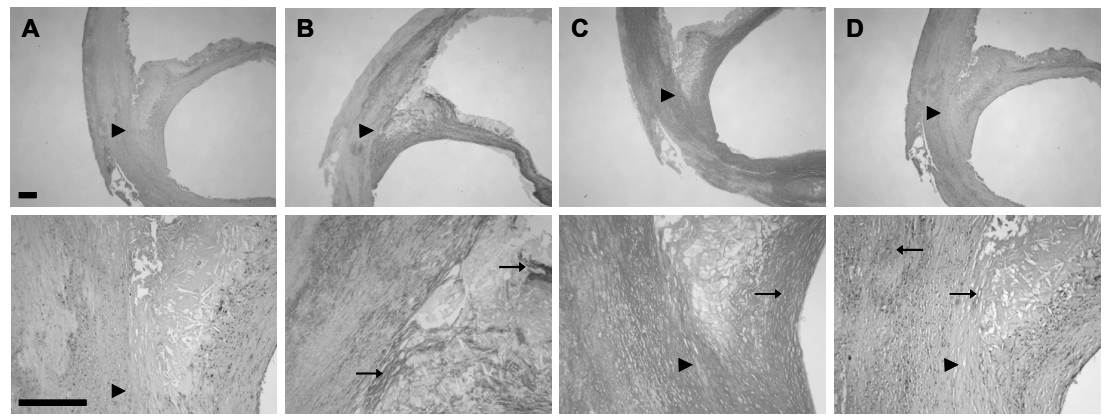

Figure 1. Immunohistochemistry of human plaques tissues. Sections of fixed plaque 1 were stained for (A) hematoxylin and eosin, (B) collagen type I (counterstaining with hematoxylin), (C) Sirius red, or (D) TF. Staining patterns are representative for all used plaques. Bars $=150 \mu \mathrm{m}$; arrowheads indicate plaque shoulder, arrows indicate high specific labeling. 
A
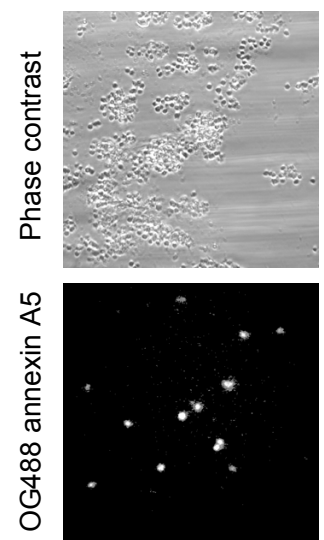

B

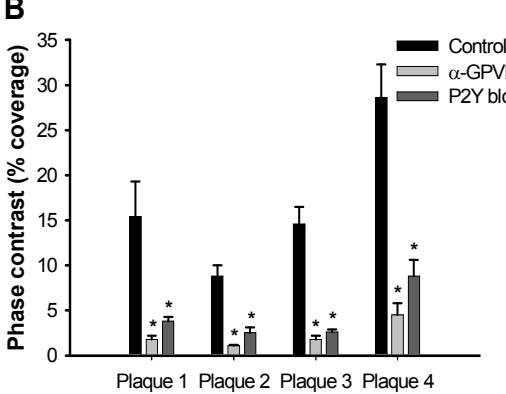

$\alpha-G P V I$
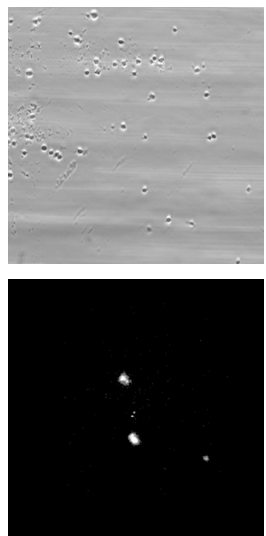

C

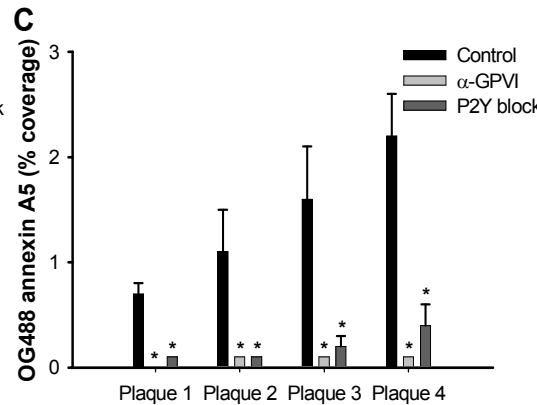

Figure 2. Stimulating effect of human plaque material on thrombus formation under flow. Anticoagulated blood was perfused over coverslips coated with material from one of the plaques numbers $1-4$ at a shear rate of $1000 \mathrm{~s}^{-1}$ for $4 \mathrm{~min}$; PS-exposing platelets were stained by postperfusion with OG488-annexin A5. Blood was pretreated with anti-GPVI mAb (50 $\mu \mathrm{g} / \mathrm{ml} 9012 \mathrm{Fab})$ or ADP receptor blockers $(20 \mu \mathrm{mol} / \mathrm{l}$ MRS and $10 \mu \mathrm{mol} / / \mathrm{ARC})$, as indicated. (A) Representative, phase contrast $(120 \times 120 \mu \mathrm{m})$ and fluorescence $(150 \times 150 \mu \mathrm{m})$ images (different fields) after perfusion over material from plaque 1. (B) Effect of GPVI or ADP receptor blockage on platelet deposition to plaques 1-4. (C) Effect of GPVI or ADP receptor blockage on OG488-annexin A5 fluorescence. Mean \pm S.E. ( $n=4$, blood from 4 donors). ${ }^{*} P<0.05$ compared to control condition.

Significant annexin A5 labeling of platelets was observed with homogenates from all four plaques, while again plaque 4 was most active (Fig. 2C). Note that under these flow conditions platelets did not adhere to control coverslips that were uncoated (data not shown).

Because platelet GPVI-collagen interaction is a potent trigger for PS exposure, ${ }^{5,6}$ we determined the role of this collagen receptor in platelet deposition on plaque-coated coverslips. Staining of the coverslips with Sirius red confirmed that collagen fibers were present in the coated plaque material (data not shown). Fab fragments of the anti-human GPVI mAb 9012 were used, which effectively inhibit GPVI-induced platelet activation and PS exposure under flow conditions. ${ }^{20}$ At a concentration of $50 \mu \mathrm{g} / \mathrm{ml}, 9012$ Fab impaired platelet adhesion, abolished aggregate formation and reduced PS exposure, as illustrated for plaque 1 and quantified for all plaques in Fig. 2. We also determined the involvement of autocrine released ADP, which contributes to adhesion via the $\alpha 2 \beta 1$ 
A) Control
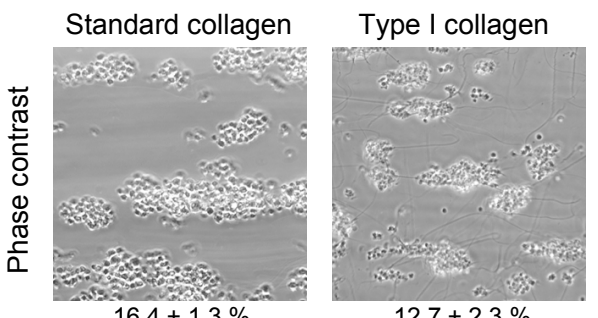

$12.7 \pm 2.3 \%$

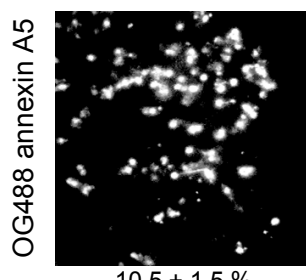

$10.5 \pm 1.5 \%$



$1.9 \pm 0.7 \%$

B) $\alpha-G P V I$

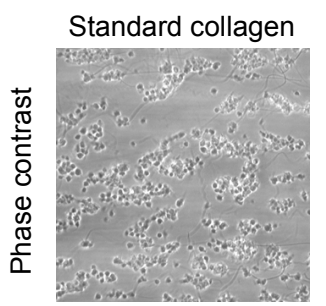

$15.6 \pm 1.2 \%$

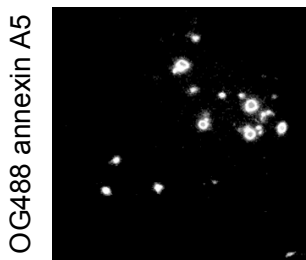

$1.6 \pm 0.4 \%$

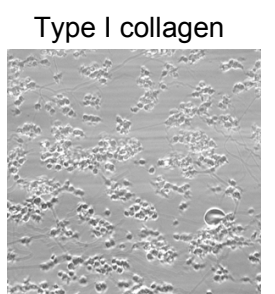

$15.2 \pm 5.3 \%$



$0.21 \pm 0.03 \%$

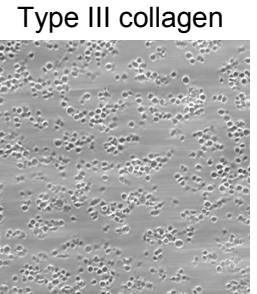

$26.6 \pm 3.2 \%$

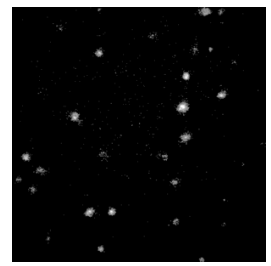

$1.0 \pm 0.5 \%$



$8.9 \pm 0.9 \%$

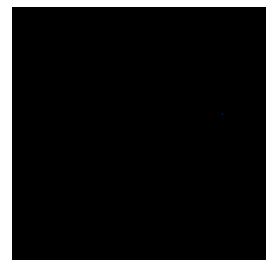

$0.0 \%$

Figure 3. Stimulating effect of purified collagens on thrombus formation under flow. Whole blood was perfused over surfaces coated with saturating concentrations of standard, type I or III collagen at $1000 \mathrm{~s}^{-1}$ for $4 \mathrm{~min}$; procoagulant platelets were stained by post-perfusion with OG488annexin A5. Experiments were carried out in the absence (A) or presence (B) of anti-GPVI mAb (50 $\mu \mathrm{g} / \mathrm{ml} 9012 \mathrm{Fab})$. Shown are representative phase contrast $(120 \times 120 \mu \mathrm{m})$ and fluorescence $(150$ $\times 150 \mu \mathrm{m})$ images after perfusion. Numbers below images represent surface area coverage of platelet deposition or OG488-labeling (mean \pm S.E., from 4 independent experiments with blood from different donors).

integrin receptor for collagen and acts as a second mediator in thrombus formation. ${ }^{5,20,24}$ Blocking of the ADP receptors $\mathrm{P}_{2} \mathrm{Y}_{1}$ and $\mathrm{P}_{2} \mathrm{Y}_{12}$ with the antagonists MRS $(20 \mu \mathrm{mol} / \mathrm{l})$ and ARC $(10 \mu \mathrm{mol} / \mathrm{l})$, respectively, was less effective in inhibiting platelet adhesion, but greatly blocked aggregate formation and PS exposure on coverslips with material from all plaques (Fig. 2). 
Because collagen types I and III form the major collagens in fibrous plaques and vessel walls, ${ }^{17,27}$ we performed a similar set of flow experiments with these collagens in purified form. Coverslips were coated with standard 'Horm' type I collagen (modified in an unknown way), which is the mostly used collagen preparation in platelet activation studies. Other coverslips were coated with native type I or type III collagen fibers, all at a density giving optimal platelet adhesion. After $4 \mathrm{~min}$ of flow, large platelet aggregates were formed on standard and native type I collagens; averaged surface area coverage was similar in either case, i.e. $16.4 \pm 1.3 \%$ and $12.7 \pm 2.3 \%(n=4)$, respectively, whereas PS exposure was much higher for platelets adhered on the standard collagen, i.e. $10.5 \pm 1.5 \%$ versus $1.9 \pm 0.7 \%$ (Fig. $3 \mathrm{~A}$ ). This is in agreement with the known high activity of standard collagen in causing PS exposure under static conditions. ${ }^{5}$ In comparison, flow over native type III collagen surface resulted in adhesion of mostly single platelets and small aggregates. Surface area coverage was high in this case (26.6 $\pm 3.2 \%$ ), albeit only few platelets exposed PS $(1.0 \pm 0.5 \%)$. Treatment of the blood with anti-GPVI 9012 Fab resulted in similar effects with all three collagen surfaces: considerable reduction in platelet aggregate size and PS exposure. However, platelet adhesion was not reduced except in case of type III collagen (Fig. 3B). Treatment with ADP receptor blockers resulted in complete inhibition of aggregate formation on all collagen surfaces. All platelet adhesion was abolished with 9012 Fab in combination with anti- $\alpha 2 \beta 1 \mathrm{mAb}$ (compare Ref. ${ }^{20}$ ). These results confirm and extend earlier findings with standard collagen, that GPVI is a principal receptor mediating collagen-induced human platelet aggregation and PS exposure under flow, but is dispensable in plateletcollagen adhesion. ${ }^{5,20}$

\section{Effects of plaque material and collagens on platelet-dependent thrombin generation}

The observed exposure of PS by platelets adhered to plaque homogenates suggested that the contact of platelets with plaque collagen led to coagulation-stimulating activity. To investigate this more directly, we compared the homogenates and the purified collagens in the thrombin-forming process with platelets and plasma present. Thrombin generation was triggered with a low, submaximal dose of TF, added to normalized PRP $\left(1.5 \times 10^{8}\right.$ platelets $\left./ \mathrm{ml}\right)$. The potency of plaques to enhance platelet-dependent thrombin generation was evaluated from their effect on the time-to-peak and the peak height of the thrombin generation curves. These thrombogram parameters are indicators of the maximal rate of thrombin formation and sensitive to platelet activation. ${ }^{22}$ Further, the endogenous thrombin potential (area-under-the-curve) was determined, which reflects the integrated enzymatic activity of thrombin during coagulation.

All plaques dose-dependently stimulated thrombin generation in $\mathrm{TF} / \mathrm{CaCl}_{2}$-triggered PRP. When applied at a dose of $0.28 \mathrm{mg} / \mathrm{ml}$, the material from plaque 4 caused greatest reduction in time-to-peak and highest increase in thrombin peak height (Fig. 4), namely a $2.4 \pm 0.5$ fold higher peak in comparison to the control (Table 1). With other plaques, peak height increased about 1.5 fold. All plaques caused a similar, small increase (1.2 fold) of the endogenous thrombin potential. Pretreatment of the PRP with anti-GPVI 

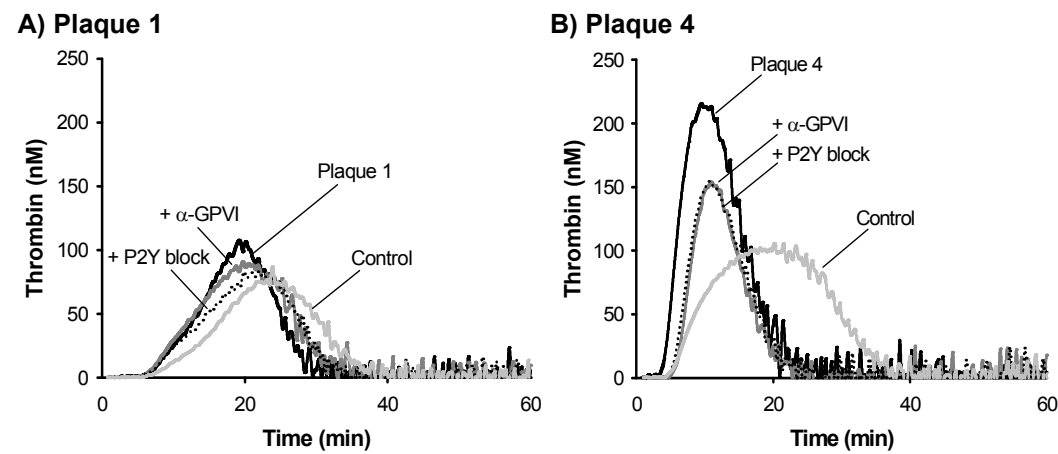

Figure 4. Enhancing effects of human plaque material on thrombin generation in PRP. Citrated PRP was incubated with vehicle (control), $0.28 \mathrm{mg} / \mathrm{ml}$ homogenate from plaque 1 (A) or plaque 4 (B). Coagulation in PRP was initiated with $1 \mathrm{pmol} / \mathrm{l} \mathrm{TF}$ (f.c.) and $16.6 \mathrm{mmol} / / \mathrm{CaCl}_{2}$. Pretreatment for $10 \mathrm{~min}$ with anti-GPVI $9012 \mathrm{Fab}(50 \mu \mathrm{g} / \mathrm{ml})$ or ADP receptor blockers $(20 \mu \mathrm{mol} / /$ MRS and $10 \mu \mathrm{mol} / / \mathrm{ARC}$ ), as indicated. Curves are representative of at least 3 independent experiments.

Table 1 Enhancing effect of plaque material on thrombin generation in PRP

\begin{tabular}{lccc}
\hline Condition ( $\mathbf{n})$ & Time-to-peak (min) & $\begin{array}{c}\text { Peak height } \\
\text { (\% of control) }\end{array}$ & ETP (\% of control) \\
\hline Control (33) & $22.9 \pm 0.8$ & 100 & 100 \\
Plaque 1 (6) & $17.5 \pm 1.2$ & $144 \pm 9$ & $118 \pm 13$ \\
$\quad+\alpha$-GPVI (3) & $16.0 \pm 1.9$ & $136 \pm 26$ & $134 \pm 30$ \\
$\quad+$ P2Y block (3) & $18.1 \pm 2.4$ & $148 \pm 38$ & $133 \pm 27$ \\
Plaque 2 (6) & $15.7 \pm 1.0$ & $152 \pm 17$ & $122 \pm 13$ \\
$\quad+\alpha$-GPVI (3) & $13.4 \pm 1.4$ & $151 \pm 25$ & $129 \pm 31$ \\
$\quad+$ P2Y block (4) & $16.1 \pm 2.0$ & $150 \pm 27$ & $134 \pm 19$ \\
Plaque 3 (6) & $16.6 \pm 1.0$ & $150 \pm 17$ & $120 \pm 14$ \\
$\quad+\alpha-G P V I ~(3)$ & $14.3 \pm 1.8$ & $140 \pm 27$ & $128 \pm 30$ \\
$\quad+$ P2Y block (3) & $15.8 \pm 1.8$ & $156 \pm 34$ & $134 \pm 26$ \\
Plaque 4 (6) & $10.0 \pm 1.5$ & $244 \pm 47$ & $120 \pm 13$ \\
$\quad+\alpha-G P V I ~(3)$ & $12.4 \pm 1.1$ & $181 \pm 40$ & $132 \pm 31$ \\
$\quad+$ P2Y block (3) & $11.7 \pm 1.0$ & $194 \pm 47$ & $131 \pm 29$ \\
Plaque 1-4 (3) & & & 0 \\
$\quad+$ annexin A5 (3) & $>60$ & 0 & \\
\hline
\end{tabular}

Thrombin generation was measured in citrated PRP triggered with TF and $\mathrm{CaCl}_{2}$, as described for Fig. 4. PRP was pre-incubated for $10 \mathrm{~min}$ with anti-GPVI $9012 \mathrm{Fab}(50 \mu \mathrm{g} / \mathrm{ml})$, ADP receptor blockers $(20 \mu \mathrm{mol} / \mathrm{l}$ MRS and $10 \mu \mathrm{mol} / \mathrm{l}$ ARC) or annexin A5 $(50 \mu \mathrm{g} / \mathrm{ml})$, and then with $0.28 \mathrm{mg} / \mathrm{ml}$ plaque material, as indicated. Data are compared to control condition without plaque material or antagonist, mean \pm S.E. ( $n=3-6$ experiments).

9012 Fab or with ADP receptor antagonists (MRS and ARC) resulted only with plaque 4 in partial (not significant) prolongation of the time-to-peak and partial reduction in thrombin peak height (Fig. 4). With other plaques, hardly any inhibiting effect on thrombin generation was seen (Table 1). 
A) Standard collagen

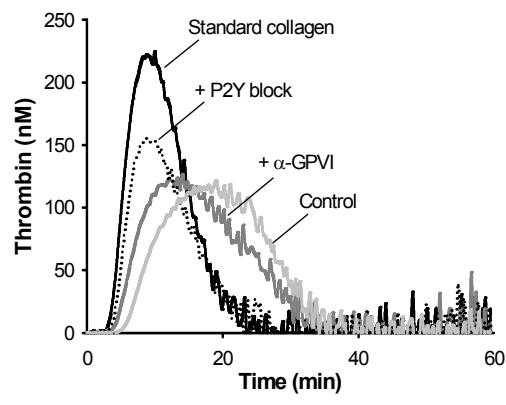

B) Type I collagen

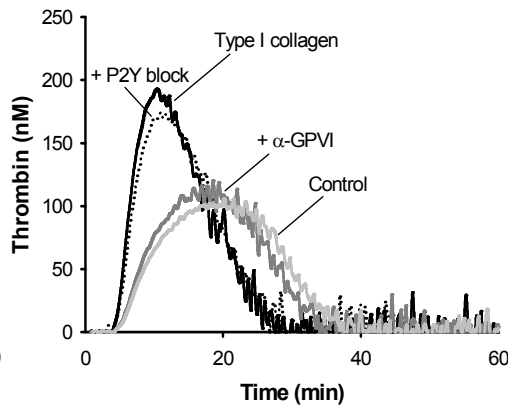

C) Type III collagen

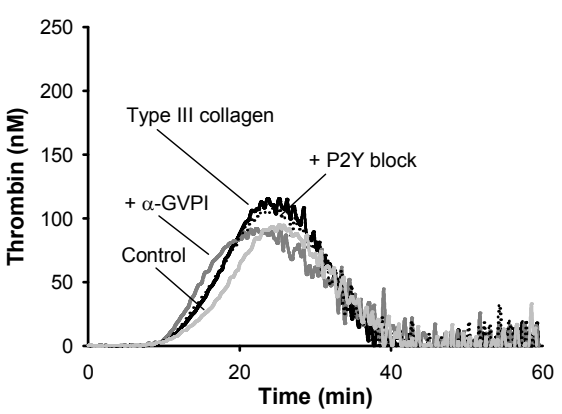

Figure 5. Effects of standard, type I and III collagen on thrombin generation in PRP; involvement of collagen and ADP. PRP was incubated for 10 min with vehicle (control) or $5 \mu \mathrm{g} / \mathrm{ml}$ standard collagen (A), $20 \mu \mathrm{g} / \mathrm{ml}$ type I collagen (B) or $20 \mu \mathrm{g} / \mathrm{ml}$ type III collagen (C). Pretreatment for $10 \mathrm{~min}$ was with anti-GPVI $9012 \mathrm{Fab}(50 \mu \mathrm{g} / \mathrm{ml})$ or ADP receptor blockers $(20 \mu \mathrm{mol} / \mathrm{l} \mathrm{MRS}$ and $10 \mu \mathrm{mol} / \mathrm{l}$ ARC), as indicated. Coagulation was initiated with $\mathrm{TF} / \mathrm{CaCl}_{2}$, as described for Fig. 4. Curves are representative of at least 4 independent experiments.

Preincubation of PRP with the PS-scavenging protein, annexin A5 (50 $\mu \mathrm{g} / \mathrm{ml})$, completely suppressed thrombin generation in the presence of all plaque homogenates. Apparently, the stimulating effect of plaques on thrombin generation relied on the presence of procoagulant phospholipids (PS). Furthermore, all four homogenates showed TF activity in the picomolar range, with plaque 4 having a $3 \pm 1$ times higher TF concentration than the other plaques 1-3. Together, this indicated that the enhanced thrombin generation was determined by TF activity of the plaques themselves.

The effects of purified collagens on thrombin generation were also examined. In the collagen preparations TF antigen could not be detected. In agreement with earlier findings, ${ }^{22}$ standard collagen at a concentration of $5 \mu \mathrm{g} / \mathrm{ml}$ potently enhanced the thrombin peak height by $2.3 \pm 0.4$ fold (Fig. $5 \mathrm{~A}$ ). A similar enhancing effect was obtained with a higher concentration of $20 \mu \mathrm{g} / \mathrm{ml}$ native type I collagen (Fig. 5B), whereas type III collagen gave a smaller but still significant increase (Fig. 5C). With all collagens, antiGPVI treatment caused complete inhibition of the collagen-induced curve shifts $(n=4$ $10, P<0.05$ ) (Fig. 5). Blocking of the ADP receptors with MRS and ARC resulted in a partially suppressing effect on the collagen-induced curves shift. Addition of annexin A5 $(50 \mu \mathrm{g} / \mathrm{ml})$ completely suppressed all thrombin generation in the presence of collagens. 
Together, this indicates that GPVI stimulation enhanced thrombin formation with collagen partly via autocrine effects of ADP and completely via PS exposure.

\section{Discussion}

The present results indicate that the examined homogenates from fibrous plaques are highly platelet-activating and procoagulant in nature. Collagen (type I) in plaques appears to be a potent trigger of thrombus formation, while TF in plaques enhances thrombin generation and coagulation. As collagen fibers and TF are found in the atheromatous plaque core, both thrombogenic substances may act in concert following plaque rupturing.

Flow experiments, carried out with anticoagulated whole blood, showed that all four plaques rapidly triggered platelet adhesion, aggregate formation and PS exposure. In this respect, the plaque homogenates were similarly active as native type I collagen fibers. The (modified) standard type I collagen fibers were more potent in causing PS exposure while, on the other hand, type III collagen fibers were only weak triggers of aggregate formation and PS exposure. Blocking of the principal signaling collagen receptor GPVI with 9012 Fab severely inhibited platelet adhesion, aggregate formation and PS exposure with each of the four plaques; blocking of the ADP receptors resulted in less complete inhibition. GPVI blockage similarly inhibited aggregate formation and PS exposure of platelets on the collagen surfaces, but platelet adhesion in this case was no more than weakly affected. The failure of GPVI antagonists to abrogate platelet adhesion to fibrillar collagens has been attributed to the abundant presence of integrin $\alpha 2 \beta 1$ binding sites on these collagens. ${ }^{5,20}$ Surprisingly, GPVI blockage did suppress the adhesion of platelets to the plaque materials. Explanations for this inhibition can be the relatively low amount of collagen fibers in the plaque material or the masking of $\alpha 2 \beta 1$ binding sites on plaque collagens. A low availability of collagen fibers in the plaques may also explain why platelet ADP receptor blockage causes similar though less complete inhibitory effects than GPVI blockage, because ADP has been recognized as a potent agonist in reinforcing platelet (GPVI) collagen contact via $\alpha 2 \beta 1 .^{20}$ Together, these data indicate that especially collagen type $I$ is a major platelet-activating component in fibrous plaques, and that the signaling by plaque-collagen primarily goes via the GPVI receptor. This corresponds well with the observation from others that type I collagen is the main collagen form in human fibrous plaques. ${ }^{28}$

In line with the results from the flow studies, standard and native type I collagen greatly enhances TF-triggered thrombin generation in PRP, while native type III collagen was hardly effective. The enhancing effect completely relies on GPVI stimulation, as is apparent from the complete inhibition with anti-GPVI mAb. The plaque materials similarly enhance thrombin generation in PRP. This effect is probably mainly due to the presence of TF and procoagulant phospholipids in the plaque material, which confirms reports by others. ${ }^{29,30}$ However, as we show in this study, GPVI-collagen interaction also plays a role, since GPVI blockage has an antagonistic effect with some of the plaques. In the arterial circulation, the generation of thrombin is likely to be much lower than in the 
(optimized) thrombin generation assay. Accordingly, in vivo, under (patho) physiological conditions, platelet GPVI interaction with plaque collagens can still be an important trigger for thrombus formation upon plaque rupture.

\section{Acknowledgements}

We acknowledge A. Janssen and dr. H. Spronk for histological analysis and stimulating discussions. We thank AgroBio (France) for supply of 9012 antibody.

\section{References}

1. Ruggeri ZM. Platelets in atherothrombosis. Nat Med. 2002;8:1227-1234.

2. Nieswandt B, Watson SP. Platelet-collagen interaction: is GPVI the central receptor? Blood. 2003;102:449-461.

3. Remijn JA, Wu YP, Jeninga EH, IJsseldijk MJ, van Willigen G, de Groot PG, Sixma JJ, Nurden AT, Nurden P. Role of ADP receptor $\mathrm{P}_{2} \mathrm{Y}_{12}$ in platelet adhesion and thrombus formation in flowing blood. Arterioscler Thromb Vasc Biol. 2002;22:686-691.

4. Kunapuli SP, Dorsam RT, Kim S, Quinton TM. Platelet purinergic receptors. Curr Opin Pharmacol. 2003;3:175-180.

5. Siljander PR, Munnix IC, Smethurst PA, Deckmyn H, Lindhout T, Ouwehand WH, Farndale RW, Heemskerk JW. Platelet receptor interplay regulates collagen-induced thrombus formation in flowing human blood. Blood. 2004;103:1333-1341.

6. Heemskerk JW, Siljander P, Vuist WM, Breikers G, Reutelingsperger CP, Barnes MJ, Knight CG, Lassila R, Farndale RW. Function of glycoprotein VI and integrin $\alpha 2 \beta 1$ in the procoagulant response of single, collagen-adherent platelets. Thromb Haemost. 1999;81:782-792.

7. Zwaal RF, Schroit AJ. Pathophysiologic implications of membrane phospholipid asymmetry in blood cells. Blood. 1997;89:1121-1132.

8. Barnes MJ, Farndale RW. Collagens and atherosclerosis. Exp Gerontol. 1999;34:513-525.

9. Badimon L. Atherosclerosis and thrombosis: lessons from animal models. Thromb Haemost. 2001;86:356-365

10. Jeynes BJ, Warren BA. Thrombogenicity of components of atheromatous material. An animal and in vitro model of cerebral atheroembolism. Arch Pathol Lab Med. 1981;105:353-357.

11. Fernandez-Ortiz A, Badimon JJ, Falk E, Fuster V, Meyer B, Mailhac A, Weng D, Shah PK Badimon L. Characterization of the relative thrombogenicity of atherosclerotic plaque components: implications for consequences of plaque rupture. J Am Coll Cardiol. 1994;23:1562-1569.

12. Siess W, Zangl KJ, Essler M, Bauer M, Brandl R, Corrinth C, Bittman R, Tigyi G Aepfelbacher M. Lysophosphatidic acid mediates the rapid activation of platelets and endothelial cells by mildly oxidized low density lipoprotein and accumulates in human atherosclerotic lesions. Proc Natl Acad Sci USA. 1999;96:6931-6936.

13. Siess W. Athero- and thrombogenic actions of lysophosphatidic acid and sphingosine-1phosphate. Biochim Biophys Acta. 2002;1582:204-215.

14. Wilcox JN, Smith KM, Schwartz SM, Gordon D. Localization of tissue factor in the normal vessel wall and in the atherosclerotic plaque. Proc Natl Acad Sci USA. 1989;86:2839-2843.

15. Taubman MB, Giesen PL, Schecter AD, Nemerson $Y$. Regulation of the procoagulant response to arterial injury. Thromb Haemost. 1999;82:801-805.

16. Shekhonin BV, Domogatsky SP, Idelson GL, Koteliansky VE, Rukosuev VS. Relative distribution of fibronectin and type I, III, IV, V collagens in normal and atherosclerotic intima of human arteries. Atherosclerosis. 1987;67:9-16. 
17. Van Zanten GH, de Graaf S, Slootweg PJ, Heijnen HF, Connolly TM, de Groot PG, Sixma JJ. Increased platelet deposition on atherosclerotic coronary arteries. J Clin Invest. 1994;93:615632.

18. Lutgens E, van Suylen RJ, Faber BC, Gijbels MJ, Eurlings PM, Bijnens AP, Cleutjens KB Heeneman S, Daemen MJ. Atherosclerotic plaque rupture: local or systemic process? Arterioscler Thromb Vasc Biol. 2003;23:2123-2130.

19. Lecut C, Feeney LA, Kingsbury G, Hopkins J, Lanza F, Gachet C, Villeval JL, Jandrot-Perrus M. Human platelet glycoprotein VI function is antagonized by monoclonal antibody-derived Fab fragments. J Thromb Haemost. 2003;1:2653-2662.

20. Lecut C, Schoolmeester A, Kuijpers MJ, Broers JL, van Zandvoort MA, Vanhoorelbeke K, Deckmyn H, Jandrot-Perrus M, Heemskerk JW. Principal role of glycoprotein VI in $\alpha 2 \beta 1$ and $\alpha$ llb $\beta 3$ activation during collagen-induced thrombus formation. Arterioscler Thromb Vasc Biol. 2004;24:1727-1733.

21. Siljander P, Lassila R. Studies of adhesion-dependent platelet activation: distinct roles for different participating receptors can be dissociated by proteolysis of collagen. Arterioscler Thromb Vasc Biol. 1999;19:3033-3043.

22. Vanschoonbeek K, Feijge MA, van Kampen RJ, Kenis H, Hemker HC, Giesen PL, Heemskerk JW. Initiating and potentiating role of platelets in tissue factor-induced thrombin generation in the presence of plasma: subject-dependent variation in thrombogram characteristics. J Thromb Haemost. 2004;2:476-484.

23. Virmani R, Kolodgie FD, Burke AP, Farb A, Schwartz SM. Lessons from sudden coronary death: a comprehensive morphological classification scheme for atherosclerotic lesions. Arterioscler Thromb Vasc Biol. 2000;20:1262-1275.

24. Kuijpers MJ, Schulte V, Bergmeier W, Lindhout $T$, Brakebusch C, Offermanns S, Fässler R, Heemskerk JW, Nieswandt B. Complementary roles of glycoprotein VI and $\alpha 2 \beta 1$ integrin in collagen-induced thrombus formation in flowing whole blood ex vivo. FASEB J. 2003;17:685687.

25. Hemker HC, Giesen PL, Ramjee M, Wagenvoord R, Beguin S. The thrombogram: monitoring thrombin generation in platelet-rich plasma. Thromb Haemost. 2000;83:589-591.

26. Hemker HC, Giesen P, Al Dieri R, Regnault V, de Smedt E, Wagenvoord R, Lecompte T, Beguin S. Calibrated automated thrombin generation measurement in clotting plasma. Pathophysiol Haemost Thromb. 2003;33:4-15.

27. Ross R. Atherosclerosis, an inflammatory disease. N Engl J Med. 1999;340:115-126.

28. Morton LF, Barnes MJ. Collagen polymorphism in the normal and diseased blood vessel wall. Investigation of collagens types I, III and V. Atherosclerosis. 1982;42:41-51.

29. Badimon JJ, Lettino M, Toschi V, Fuster V, Berrozpe M, Chesebro JH, Badimon L. Loca inhibition of tissue factor reduces the thrombogenicity of disrupted human atherosclerotic plaques: effects of tissue factor pathway inhibitor on plaque thrombogenicity under flow conditions. Circulation. 1999;99:1780-1787.

30. Niemetz J, Fallon JT, Harrington E, Hathcock J. Rapid generation of thrombin by atheroma and platelets. J Thromb Haemost. 2004;2:321-326. 


\section{Fibrillar type I collagens enhance platelet-dependent thrombin generation via glycoprotein VI with direct support of $\alpha 2 \beta 1$ but not $\alpha$ llb $\beta 3$ integrin}

Christelle Lecut, Marion A.H. Feijge ${ }^{*}$, Judith M.E.M. Cosemans*, Martine Jandrot-Perrus and Johan W.M. Heemskerk

Thromb Haemost 2005; 94: 107-114

Reprinted with permission

*Authors contributed equally to this work 


\begin{abstract}
The role of collagens and collagen receptors was investigated in stimulating plateletdependent thrombin generation. Fibrillar type-I collagens, including collagen from human heart, were most potent in enhancing thrombin generation, in a way dependent on exposure of phosphatidylserine (PS) at the platelet surface. Soluble, non-fibrillar type-I collagen required pre-activation of integrin $\alpha 2 \beta 1$ with $\mathrm{Mn}^{2+}$ for enhancement of thrombin generation. With all preparations, blocking of glycoprotein VI (GPVI) with 9012 antibody abrogated the collagen-enhanced thrombin generation, regardless of the $\alpha 2 \beta 1$ activation state. Blockade of $\alpha 2 \beta 1$ alone or antagonism of autocrine thromboxane $A_{2}$ and ADP were less effective. Blockade of $\alpha$ llb $\beta 3$ with abciximab suppressed thrombin generation in platelet-rich plasma, but this did not abolish the enhancing effect of collagens. The high activity of type-I fibrillar collagens in stimulating GPVI-dependent procoagulant activity was confirmed in whole-blood flow studies, showing that these collagens induced relatively high expression of PS. Together, these results indicate that: i) fibrillar type-I collagen greatly enhances thrombin generation, ii) GPVI-induced platelet activation is principally responsible for the procoagulant activity of fibrillar and non-fibrillar collagens, iii) $\alpha 2 \beta 1$ and signaling via autocrine mediators facilitate and amplify this GPVI activity, and iv) $\alpha$ llb $\beta 3$ is not directly involved in the collagen effect.
\end{abstract}

\title{
Introduction
}

Platelet binding to collagen exposed at a damaged vessel wall is considered an initial and key step in thrombus formation. ${ }^{1}$ Two receptors mediate the stable interaction of platelets with collagen fibers: the adhesive receptor, integrin $\alpha 2 \beta 1$, and the signaling receptor, glycoprotein $\mathrm{VI}$ (GPVI), which is a member of the immunoglobulin receptor family; the contribution of additional receptors for collagen is still disputed. ${ }^{2}$ Both receptors appear to cooperate in collagen-induced thrombus formation: the low affinity GPVI receptor plays an activating role, e.g. inducing higher-affinity binding sites of integrin $\alpha 2 \beta 1$ for collagen. The activated integrin, in turn, stabilizes the binding of GPVI and signaling through this receptor. ${ }^{3-6}$ Particularly at high, arterial shear rates, also platelet binding via glycoprotein Ib-IX-V to Willebrand factor (VWF, which avidly binds to collagen) participates in the interplay of collagen receptors, both directly and by stabilization via integrin $\alpha \mathrm{llb} \beta 3{ }^{6,7}$ Additional factors contributing to the stabilization of platelet-collagen contact are the autocrine mediators, thromboxane $A_{2}\left(T_{x} A_{2}\right)$ and ADP, which are both released from activated platelets, ${ }^{8,9}$ e.g. by enhancing the $\alpha 2 \beta 1$ and $\alpha$ llb $\beta 3$ activation. ${ }^{10}$ In addition, these secondary mediators trigger nearby, flowing platelets to assemble on the primary layer of collagen-adherent platelets with as a result formation of a platelet thrombus.

Whereas the function and interplay of these direct and indirect collagen receptors in platelet adhesion and aggregate formation is relatively well understood, much less is known of the importance of these receptors for collagen-induced thrombin generation and coagulation. Earlier data indicate that type-I collagen fibers stimulate $\mathrm{Ca}^{2+}$. dependent shedding of microvesicles and scrambling of plasma membrane 
phospholipids, with as a result expression of procoagulant phosphatidylserine (PS) at the surface of vesicles and remnant platelets. ${ }^{11}$ The exposed PS is necessary but perhaps not sufficient for platelets to mediate prothrombinase activation, thrombin generation and clot formation. ${ }^{12}$ By comparing the PS-exposing effect of collagen with that of more specific GPVI-activating agonists, such as convulxin and collagen-related peptide, it was concluded that GPVI plays a prominent role in the procoagulant reaction of collagen. ${ }^{13,14}$ This agrees with the observation that variation in platelet GPVI content led to a corresponding change in GPVI-mediated prothrombinase activity. ${ }^{15}$

Typically, in washed platelets, fibrillar collagen by itself is only a weak stimulus of the procoagulant platelet response. Co-activation of platelets with thrombin is required to obtain significant procoagulant activity with collagen. ${ }^{16,17}$ This may imply that, in analogy to collagen-induced aggregate formation, next to GPVI additional receptors (and ligands) support PS expression and thrombin formation; candidates receptors are glycoprotein lb$\mathrm{V}-\mathrm{IX}(\mathrm{VWF}$ ), integrins $\alpha 2 \beta 1$ and $\alpha \mathrm{llb} \beta 3$ (fibrinogen), and the autocrine mediators ADP and $\mathrm{TxA}_{2}$. An indication that the adhesive receptors indeed contribute to collageninduced procoagulant activity comes from the observation that adhesion per se enhances GPVI-induced PS expression. ${ }^{18}$ Yet, non-fibrillar, soluble collagens with limited GPVI binding sites and to which platelets adhere mainly via $\alpha 2 \beta 1,{ }^{19}$ are only weak stimulators of PS expression and thrombin formation, ${ }^{20}$ which questions a role of $\alpha 2 \beta 1$ in this response. Further, in collagen-adherent platelets, the autocrine ADP and $\operatorname{TxA}_{2}$ mediate integrin affinity changes and may thus influence collagen-induced PS expression. ${ }^{6,10}$ Whether and how these adhesive receptors interact with collagen to stimulate procoagulant activity, and what the precise requirement herein is of the collagen (fibrillar) structure, are still unresolved issues.

Here, we set to study the contribution of collagen receptors and autocrine agents in thrombin generation with different collagens under physiologically relevant conditions, in platelet-rich plasma (PRP) that was triggered with a low dose of tissue factor. To investigate this, we compared type-I collagen preparations with different affinities for collagen receptors, i.e. Horm type-I collagen (used as reference) and fibrillar and nonfibrillar (soluble) collagens and, in addition, a collagen enriched in type-I fibers derived from human heart.

\section{Material and Methods}

\section{Materials}

Abciximab (Reopro) was from Centocor (Leiden, The Netherlands); AR-C69931MX was kindly provided by Astra-Zeneca (Charnwood, UK). Z-Gly-Gly-Arg aminomethyl coumarin (Z-GGR-AMC) came from Bachem (Bubendorf, Switzerland), acetylsalicylic acid (aspirin) from Lorex Synthelabo (Maarssen, The Netherlands); unlabeled and Oregon Green-488 (OG488) labeled annexin A5 (annexin V) from Nexins Research (Hoeven, The Netherlands); recombinant human tissue factor from Dade (Miami, FL, USA). Human thrombin calibrator and thrombogram software were supplied by Synapse (Maastricht, 
The Netherlands). Other reagents came from Sigma (St. Louis, MO, USA). Fab fragments of monoclonal anti-human GPVI antibody 9012 were produced and characterized as described. ${ }^{21}$ Anti-integrin $\alpha 2 \beta 1 \mathrm{mAb} 6 \mathrm{~F} 1$ was a kind gift from Dr. B. Coller (Mount Sinai Hospital, Boston, MA, USA).

\section{Source and preparation of collagens}

Fibrillar 'Horm' type I collagen, used as reference collagen preparation, was bought from Nycomed (Munich, Germany). Native fibrillar type-I collagen was prepared from bovine tendon, and pepsin-digested to obtain soluble (non-fibrillar) collagen, following a procedure described elsewhere. ${ }^{20}$ Tissue from healthy human heart, obtained by autopsy, was kindly provided by Dr. J. Cleutjens (Dept. of Pathology, Maastricht University). Permission was given by the local Medical Ethical Committee. Native total collagen fibrils were extracted from heart tissue, basically as described. ${ }^{22}$ Briefly, tissue was washed with phosphate-buffered saline containing protease inhibitors $\left(10 \mathrm{mg} \mathrm{mL}^{-1}\right.$ EDTA, $1 \mu \mathrm{g} \mathrm{mL} \mathrm{m}^{-1}$ pepstatin, $2 \mu \mathrm{g} \mathrm{mL}^{-1}$ aprotinin and $0.5 . \mu \mathrm{g} \mathrm{mL} \mathrm{m}^{-1}$ leupeptin), homogenized, and extracted with $0.5 \mathrm{~mol} \mathrm{~L}^{-1}$ acetic acid. The mixture was vigorously shaken at $5^{\circ} \mathrm{C}$ for $24 \mathrm{~h}$, then filtered and centrifuged at $48,400 \mathrm{~g}$ for $2 \mathrm{~h}$. Collagen fibrils in the supernatant were precipitated by addition of $1.7 \mathrm{~mol} \mathrm{~L}^{-1} \mathrm{NaCl}$ and a 24-h incubation at $5^{\circ} \mathrm{C}$. After $1 \mathrm{~h}$ of centrifugation at $35,000 \mathrm{~g}$, the collagen-containing pellet was solubilized in $0.5 \mathrm{~mol} \mathrm{~L}^{-1}$ acetic acid and dialyzed against $0.1 \mathrm{~mol} \mathrm{~L}^{-1}$ acetic acid. Fibrillar collagen content was determined by Sirius red staining.

\section{Isolation of platelets and plasma}

Blood was obtained from healthy volunteers after full informed consent according to the Helsinki declaration. Blood was drawn by venapuncture into $1 / 10$ volume of $129 \mathrm{mmol} \mathrm{L}^{-1}$ trisodium citrate. First $2.5 \mathrm{~mL}$ of blood were discarded. The blood was centrifuged at 260 $\mathrm{g}$ for $15 \mathrm{~min}$ to obtain PRP, and twice at $870 \mathrm{~g}$ for $10 \mathrm{~min}$ for platelet-free plasma (PFP). Platelet concentration was determined with a Beckman MicroDiff18 counter (Coulter Electronics, Luton, UK). PRP was normalized to $1.5 \times 10^{8}$ platelets $\mathrm{mL}^{-1}$ with autologous PFP.

\section{Thrombin generation measurement}

Thrombin generation was continuously measured in PRP using the thrombogram method essentially as described. ${ }^{23}$ Briefly, triplicate samples of $80 \mu \mathrm{L}$ PRP $\left(1.5 \times 10^{8}\right.$ platelets $\mathrm{mL}^{-1}$ ) were pipetted into wells of a 96-wells plate (Immulon 2HB, Dynex, Chantilly, VA, USA), containing $20 \mu \mathrm{L}$ tissue factor $\left(3 \mathrm{pmol} \mathrm{L}{ }^{-1}\right)$ in buffer $\mathrm{A}\left(20 \mathrm{mmol} \mathrm{L}^{-1}\right.$ Hepes, $\left.140 \mathrm{mmol} \mathrm{L}^{-1} \mathrm{NaCl}, 5 \mathrm{mg} \mathrm{mL}^{-1} \mathrm{BSA}, \mathrm{pH} 7.35\right)$. Plates were pre-warmed at $37^{\circ} \mathrm{C}$ in a well-plate reader (Molecular Devices), and pre-heated to $37^{\circ} \mathrm{C}$ for $5 \mathrm{~min}$. Coagulation was started by automated addition of $20 \mu \mathrm{L}$ of buffer $\mathrm{B}\left(20 \mathrm{mmol} \mathrm{L}^{-1}\right.$ Hepes, $\left.0.1 \mathrm{~mol} \mathrm{~L}^{-1} \mathrm{CaCl}_{2}, 60 \mathrm{mg} \mathrm{mL}^{-1} \mathrm{BSA}, \mathrm{pH} 7.35\right)$ containing Z-GGR-AMC $\left(2.5 \mathrm{mmol} \mathrm{L}^{-1}\right)$. Final concentrations were $0.5 \mathrm{pmol} \mathrm{L}^{-1}$ tissue factor and $0.42 \mathrm{~mol} \mathrm{~L}^{-1} \mathrm{Z}-\mathrm{GGR}-A M C$. Fluorescence accumulation from cleaved AMC was continuously measured at excitation 
and emission wavelengths of 390 and $460 \mathrm{~nm}$, respectively $\left(37^{\circ} \mathrm{C}\right)$. First-derivative curves of accumulation of fluorescence were converted into curves of nanomolar thrombin using a human thrombin calibrator and by correction for the fluorescence due to $\alpha_{2}$-macroglobulin-bound thrombin. ${ }^{24}$ PRP was pretreated with antibodies or inhibitors at maximally effective concentrations for $10 \mathrm{~min}\left(37^{\circ} \mathrm{C}\right)$. Thrombin generation measurements were started at $10 \mathrm{~min}$ after collagen addition. All collagen samples were dialyzed against $10 \mathrm{mmol} \mathrm{L}^{-1}$ acetic acid (overnight $4^{\circ} \mathrm{C}$ ) before using for thrombin generation. Controls were always run with vehicle media.

The potency of collagens preparations to enhance platelet-dependent thrombin generation was evaluated from effects on the thrombin peak height. This thrombogram parameter is an indicator of the maximal rate of thrombin formation, ${ }^{23}$ and is sensitive to platelet activation. ${ }^{24}$

\section{Measurement of thrombus formation and PS exposure under flow}

Flow experiments over collagen were performed at room temperature using blood anticoagulated with $40 \mu \mathrm{mol} \mathrm{L}{ }^{-1}$ PPACK. $^{6,25}$ Collagen preparations were spread on cleaned glass coverslips at an optimal density of $35 \mu \mathrm{g} \mathrm{cm}^{-2}$. After coating for $1 \mathrm{~h}$ in a moist chamber, the coverslips were rinsed with saline, blocked during 30 min with Hepes buffer pH 7.45 (in mmol L-1: $\mathrm{NaCl} 136$, glucose 10, Hepes 5, $\mathrm{KCl} 2.7, \mathrm{MgCl}_{2} 2, \mathrm{CaCl}_{2}$ ), supplemented with $1 \% \mathrm{BSA}$, and washed again with saline. After staining with Sirius red, this resulted in about $40 \%$ area coverage with red colour. Whole blood was perfused for 4 min over the collagen surface at a moderately high wall-shear rate of $1000 \mathrm{~s}^{-1}$. Highresolution transmission and fluorescent images were recorded in real-time with a Visitech digital imaging system (Sunderland, UK). PS exposure was detected by postperfusion with rinsing Hepes buffer $\mathrm{pH} 7.45$ containing $1 \mathrm{U} \mathrm{mL}^{-1}$ heparin and $1 \mu \mathrm{g} \mathrm{mL}^{-1}$ OG488-annexin A5.

Phase-contrast and fluorescent images were obtained from at least ten different collagen-containing microscopic fields, which were arbitrarily chosen. Area coverage from phase-contrast and fluorescent images was analyzed off-line, as described. ${ }^{6}$

\section{Statistics}

Experiments were performed with PRP or blood from at least three different donors. Statistical indications were made using the Kruskal-Wallis test, followed by a Dunn test for comparison between treatments. Data are means \pm S.E.

\section{Results}

Fibrillar but not soluble type I collagen enhances thrombin generation in plateletrich plasma

Thrombin generation in PRP with normalized platelet count, triggered with a low concentration of tissue factor $\left(0.5 \mathrm{pmol} \mathrm{L}^{-1}\right)$, relies on platelet activation and $\mathrm{PS}$ 
exposure. ${ }^{24}$ We determined the effects of several type-I collagen preparations on platelet-dependent generation of thrombin. Fibrillar Horm type-I collagen, which is mostly used as a reference collagen preparation to aggregate platelets (with fibers stabilized in an unpublished way), greatly enhanced the thrombin-generating process (Fig. 1A). Addition of $5 \mu \mathrm{g} \mathrm{mL}^{-1}$ Horm collagen to PRP resulted in a $1.70 \pm 0.06$ fold $(n=25)$ increase in thrombin peak height, which was accompanied by a shortening of the timeto-peak from $22.1 \pm 1.0$ to $9.4 \pm 0.4 \mathrm{~min}$ in comparison to the control condition. Addition of $10 \mu \mathrm{g} \mathrm{mL}^{-1}$ annexin A5, a protein that specifically chelates $\mathrm{PS},{ }^{26}$ completely abolished thrombin generation in the presence of collagen (Fig. 1A). Platelet inhibition with cAMPelevating $\mathrm{PGE}_{1}$ also abolished the collagen effect, confirming it relied on activation of the platelets.

In comparison to Horm collagen, native type-I collagen fibrils $\left(10 \mu \mathrm{g} \mathrm{mL}^{-1}\right)$ were somewhat less effective in enhancing thrombin generation. Also with this purified fibrillar collagen, the time-to-peak was reduced and the peak height increased when compared to the control condition (Fig. 1B). On the other hand, a soluble type-I


Figure 1. Effect of different collagen preparations on thrombin generation in PRP. Coagulation in PRP was initiated with $0.5 \mathrm{pmol} \mathrm{L}^{-1}$ tissue factor (f.c.) and $16.6 \mathrm{mmol} \mathrm{L}^{-1} \mathrm{CaCl}_{2}$. (A) PRP was pre-incubated with vehicle (control) or activated with $5 \mu \mathrm{g} \mathrm{mL}^{-1} \mathrm{Horm}$ type-I collagen (reference collagen, $\mathrm{HC}$ ) for $10 \mathrm{~min}$. Pretreatment before activation was with $\mathrm{PGE}_{1}\left(10 \mu \mathrm{mol} \mathrm{L}^{-1}\right)$ or annexin A5 (Anx A5, $10 \mu \mathrm{g} \mathrm{mL}^{-1}$ ). (B) PRP was treated with vehicle (control) or was activated for 10 min with $10 \mu \mathrm{g} \mathrm{mL}^{-1}$ of either Horm type-I, fibrillar type-I collagen or soluble type-I collagen. (C) Dose-response of effect of collagens on thrombin peak height in thrombin generation (mean \pm S.E., $n=3-6$ ). (D) Effect of collagen from heart tissue on thrombin generation. PRP was incubated with vehicle (control) or collagen from heart tissue $\left(20 \mu \mathrm{g} \mathrm{mL}^{-1}\right)$; pretreatment was with anti-GPVI 9012 $\left(50 \mu \mathrm{g} \mathrm{mL}^{-1}\right)$ or MRS2179/AR-C69931MX (40 and $\left.20 \mu \mathrm{mol} \mathrm{L}^{-1}\right)$. Traces of thrombin generation are representative of three or more independent experiments. 
collagen - obtained by controlled proteolytic digestion of native type-I collagen fibers, lacking the telopeptides and the 'banded' quaternary structure of fibrillar collagen- ${ }^{20}$ was of little effect in stimulating thrombin generation. Dose-response curves showed that only soluble collagen concentrations $>20 \mu \mathrm{g} \mathrm{mL}^{-1}$ were weakly stimulatory, whereas the Horm and native type-I collagen fibers were active at about ten-fold lower concentrations (Fig. 1C). Collagen that was purified from human heart tissue, enriched in type-I fibers, was also active in enhancing thrombin generation (Fig. 1D).

\section{Principally GPVI determines the enhancement of thrombin generation by fibrillar collagen}

To evaluate the importance of GPVI in the effect of collagen fibers, blocking Fab fragments were used of the mAb 9012, directed against the collagen-binding site of human GPVI. ${ }^{21}$ Pre-incubation of PRP with $50 \mu \mathrm{g} \mathrm{mL}^{-1} 9012$ resulted in complete antagonism of the curve shift in thrombin generation induced by Horm type-I collagen (Fig. 2A). With both $9012 \mathrm{Fab}$ and collagen present, thrombin generation was delayed and reduced to the level of untreated, control PRP (Table 1). The blocking anti- $\alpha 2 \mathrm{mAb}$ $6 \mathrm{~F} 1$, active in plasma, was used to abolish the contribution of this integrin to collageninduced activation. ${ }^{6}$ Differently from 9012, pretreatment of PRP with saturating 6F1 resulted in an incomplete, $25 \%$ antagonism of the stimulation of thrombin generation by collagen (Fig. 2A and Table 1). Control experiments indicated that neither 9012 nor 6F1 by itself altered thrombin generation in the absence of collagen.

The secondary mediators, $\mathrm{TxA}_{2}$ and ADP contribute to the thrombin generation in tissue factor-triggered PRP. ${ }^{24,27}$ To determine their involvement in the collagen effect, $\mathrm{PRP}$ was pretreated with aspirin and/or maximally effective doses of the $\mathrm{P}_{2} \mathrm{Y}_{1}$ and $\mathrm{P} 2 \mathrm{Y}_{12}$ receptors antagonists, MRS2179 and AR-C69931MX, respectively. Aspirin pre-treatment resulted in partial reversal of the collagen effect on the thrombin peak (Fig. 2B); this is
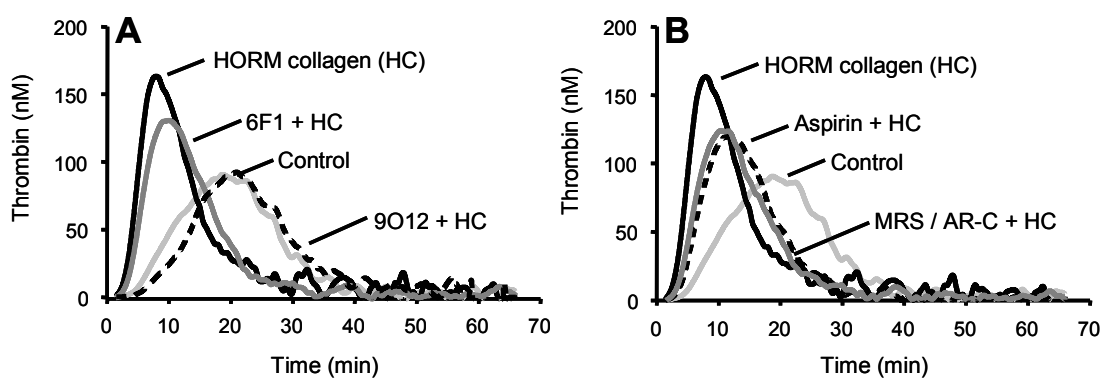

Figure 2. Contribution of GPVI, $\alpha 2 \beta 1$ and autocrine mediators to collagen-enhanced thrombin generation. PRP was incubated with vehicle (control) or activated with $5 \mu \mathrm{g} \mathrm{mL}^{-1} \mathrm{Horm}$ type-I collagen (HC). Coagulation was initiated with tissue factor $/ \mathrm{CaCl}_{2}$ (see Fig. 1). (A) Pretreatment with anti-GPVI Fab $9012\left(50 \mu \mathrm{g} \mathrm{mL}^{-1}\right)$ or anti- $\alpha 2 \beta 1 \mathrm{mAb} 6 \mathrm{~F} 1\left(10 \mu \mathrm{g} \mathrm{mL}^{-1}\right)$ before collagen activation. (B) Pretreatment with aspirin $\left(100 \mu \mathrm{mol} \mathrm{L}^{-1}\right)$ or ADP receptor blockers $(40 \mu \mathrm{mol}$ $\mathrm{L}^{-1} \mathrm{MRS} 2179$ and $20 \mu \mathrm{mol} \mathrm{L}^{-1} \mathrm{AR}-\mathrm{C69931MX)}$ before activation. Curves are representative of at least three independent experiments. 
Table 1 Effect of blocking agents on collagen-enhanced thrombin generation

\begin{tabular}{lcc}
\hline & Time-to-peak (min) & $\begin{array}{c}\text { Peak height } \\
\text { (\% of control) }\end{array}$ \\
\hline Control & $22.1 \pm 1.0$ & $100(25)$ \\
Horm type I collagen & & \\
$\quad$ + vehicle & $9.2 \pm 0.4$ & $169.4 \pm 5.6(20)$ \\
+ 9O12 & $16.7 \pm 1.2$ & $95.2 \pm 6.6(5)$ \\
+ 6F1 & $9.5 \pm 0.6$ & $150.8 \pm 11.1(4)$ \\
+ aspirin & $10.5 \pm 1.0$ & $144.8 \pm 12.8(6)$ \\
+ AR-C69931MX & $10.7 \pm 1.1$ & $136.7 \pm 18.8(4)$ \\
+ MRS2179 & $9.1 \pm 0.8$ & $168.4 \pm 8.3(6)$ \\
+ MRS + AR-C & $10.9 \pm 0.7$ & $133.8 \pm 12.3(5)$ \\
\hline
\end{tabular}

PRP was untreated (control) or activated with $5 \mu \mathrm{g} \mathrm{mL^{-1 }}$ Horm type-l collagen. Pretreatment was with anti-GPVI $9012 \mathrm{Fab}\left(50 \mu \mathrm{g} \mathrm{mL}^{-1}\right)$, anti- $\alpha 2 \beta 16 \mathrm{~F} 1$ antibody $\left(10 \mu \mathrm{gL} \mathrm{m}^{-1}\right)$, aspirin $\left(100 \mu \mathrm{mol} \mathrm{L}^{-1}\right)$, MRS2179 $\left(40 \mu \mathrm{mol} \mathrm{L}^{-1}\right)$ and/or AR-C69931MX (AR-C, $\left.20 \mu \mathrm{mol} \mathrm{L}^{-1}\right)$, before activation with collagen. Thrombin generation was measured upon triggering with tissue factor/CaCl 2 (see Fig. 1). Data are compared to the control condition without collagen or antagonist (mean \pm S.E., $n$ experiments in triplicate).

similar to its small inhibitory effect, reported earlier in the absence of collagen. ${ }^{24}$ Also, pretreatment with AR-C69931MX (but not with MRS2179), caused a small, reducing effect on the thrombin peak (Table 1). This observation corresponds well with studies reporting that - in the absence of collagen - only $P 2 Y_{12}$ contributes to platelet procoagulant activity in man and mouse. ${ }^{27,28}$ Together, these results indicate that the collagen-enhanced thrombin generation completely relies on GPVI activity, but can be reinforced by $\alpha 2 \beta 1$ binding and by release of autocrine $\mathrm{TxA}_{2}$ and $A D P$.

\section{Activated integrin $\alpha 2 \beta 1$ potentiates GPVI-mediated thrombin generation}

In comparison to type-I collagen fibers, digested non-fibrillar collagen forms are more strongly dependent on $\alpha 2 \beta 1$ for platelet binding. ${ }^{14,20}$ The divalent cation $\mathrm{Mn}^{2+}$ switches $\alpha 2 \beta 1$ and other integrins to a higher affinity state by exposing a cation- and ligand induced binding site (CLIBS). ${ }^{29,30}$ Others have shown that the affinity of platelet $\alpha 2 \beta 1$ for soluble collagen is significantly increased by $\mathrm{Mn}^{2+}$ treatment. ${ }^{31}$ We found that incubation of PRP with $2 \mathrm{mmol} \mathrm{L}^{-1} \mathrm{MnCl}_{2}$ enhanced the effect of the soluble collagen $\left(5 \mu \mathrm{g} \mathrm{mL}^{-1}\right)$ on thrombin generation; the $\mathrm{Mn}^{2+}$ ions caused a marked decrease in time-to-peak and a $1.12 \pm 0.07$ fold increase in thrombin peak height (Fig. 3A). The stimulation by soluble collagen plus $\mathrm{Mn}^{2+}$ was partly reversed by the anti- $\alpha 26 \mathrm{~F} 1 \mathrm{mAb}$ and more than completely antagonized by anti-GPVI 9012 fragments (Fig. 3B-C). In the latter case, the extra inhibition was not due to the simultaneous presence of $\mathrm{Mn}^{2+}$ and 9012 , as this combination alone did not influence thrombin generation. Possibly, the soluble collagen plus $\mathrm{Mn}^{2+}$ triggers a platelet-inhibiting pathway. Together, these results point to complete dependency of the stimulating collagen/ $/ \mathrm{Mn}^{2+}$ effect on GPVI activity.

When Horm type-I collagen fibers were used instead of soluble collagen, pretreatment of PRP with $\mathrm{Mn}^{2+}$ resulted in a similar curve shift. Again, $\mathrm{Mn}^{2+}$ ions caused 

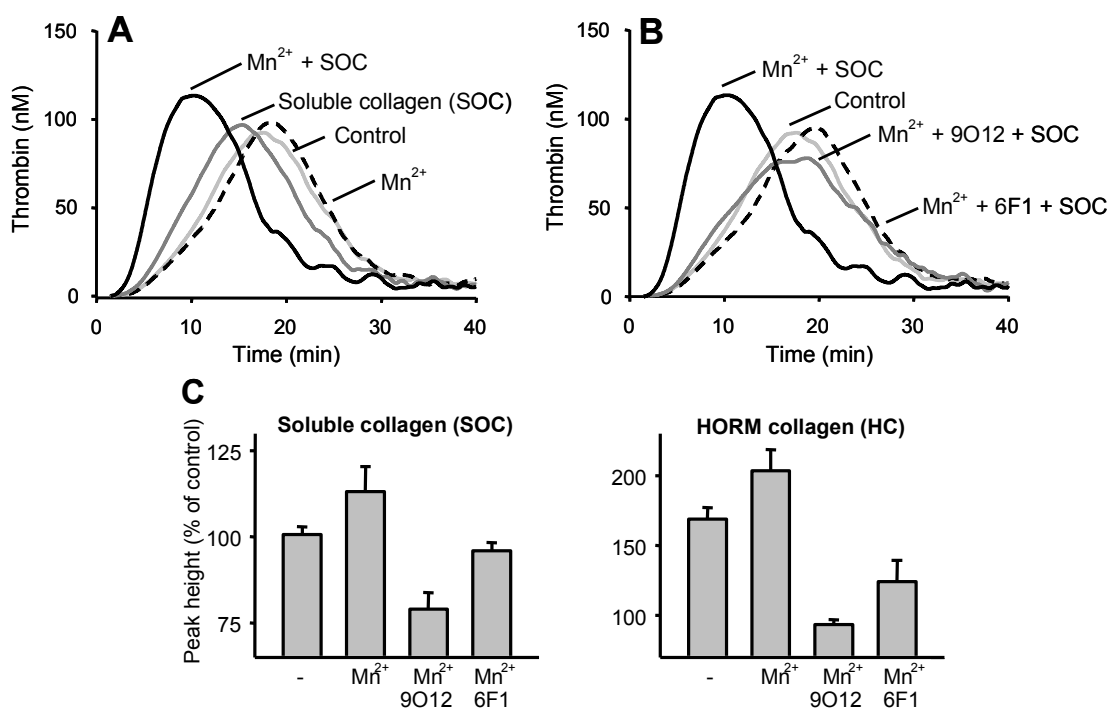

Figure 3. Potentiation of GPVI-mediated thrombin generation by activated integrin $\alpha 2 \beta 1$. (A) PRP was incubated with vehicle (control) or activated with $5 \mu \mathrm{g} \mathrm{mL}^{-1}$ soluble type-I collagen (SOC); where indicated, the PRP was pretreated with $2 \mathrm{mmol} \mathrm{L}^{-1} \mathrm{MnCl}_{2}\left(\mathrm{Mn}^{2+}\right)$ before activation. Thrombin generation was then measured upon triggering with tissue factor/ $\mathrm{CaCl}_{2}$, as in Fig. 1. (B) Conditions as for panel A, but PRP was pretreated with $\mathrm{Mn}^{2+}$ plus $10 \mu \mathrm{g} \mathrm{mL}^{-1} 6 \mathrm{~F} 1$ or $50 \mu \mathrm{g} \mathrm{mL}{ }^{-1} \mathrm{Fab} 9012$ before activation with SOC. (C) Quantitative effect of treatments on thrombin generation with SOC or Horm type-I collagen (each $5 \mu \mathrm{g} \mathrm{mL} \mathrm{L}^{-1}$ ). Data are percentages relative to the thrombin peakheight under control conditions taken as $100 \%$ (mean \pm S.E., $n=4-6$ ). ${ }^{*} P<0.05$.

a $1.21 \pm 0.09$ fold increase in thrombin peak height (Fig. 3C). The collagen/ $/ \mathrm{Mn}^{2+}$ effect was largely inhibited by anti- $\alpha 2$ antibody and completely inhibited by anti-GPVI 9012 Fab. To determine whether $\alpha 2 \beta 1$ contributes to the thrombin generation with GPVIspecific agonists, PRP was stimulated with convulxin $\left(100 \mathrm{ng} \mathrm{mL}^{-1}\right)$, which is a snake peptide causing direct GPVI activation. ${ }^{32}$ In agreement with earlier data, ${ }^{24}$ convulxin treatment resulted in a $2.99 \pm 0.05$ fold $(n=4)$ increase in the thrombin peak. In the presence of anti- $\alpha 2 \beta 1 \mathrm{mAb} 6 \mathrm{~F} 1$, the convulxin effect was hardly changed to a $2.89 \pm$ 0.04 fold increase, pointing to absence of integrin activity. Together, these experiments thus indicate that $\alpha 2 \beta 1$ contributes to the effects on thrombin generation of fibrillar and non-fibrillar collagens but not of convulxin, likely by enhancing the activating effect of platelet GPVI.

\section{Integrin $\alpha$ llb $\beta 3$ is not directly involved in collagen-enhanced thrombin generation}

Platelets adhere to collagen-associated proteins like VWF factor via integrin allb $\beta 3$. Antagonists of $\alpha$ llb $\beta 3$ such as abciximab along with VWF antagonists have been reported to suppress platelet-dependent thrombin generation. ${ }^{33-36}$ Without collagen, we found that abciximab greatly delayed and diminished the formation of thrombin at a maximally effective dose of $40 \mu \mathrm{g} \mathrm{mL}^{-1}$ (Fig. 4A). In combination with Horm collagen (Fig. 4B), abciximab slightly prolonged the time-to-peak from $9.2 \pm 0.4$ to $11.8 \pm 0.9 \mathrm{~min}(n=$ 6 ); and it partially lowered the thrombin peak (from $169.4 \pm 5.6 \%$ to $121.3 \pm 6.9 \%$ of 



Fig. 4. GPVI-enhanced thrombin generation is not mediated by integrin $\alpha$ llb $\beta 3$. (A) PRP was incubated with vehicle (control), $5 \mu \mathrm{g} \mathrm{mL}^{-1}$ Horm type-I collagen $\left(\mathrm{HC}\right.$ ), or $40 \mu \mathrm{gL} \mathrm{m}^{-1}$ abciximab. (B) PRP was pretreated with abciximab alone or in combination with $50 \mu \mathrm{g} \mathrm{mL}^{-1}$ anti-GPVI Fab 9012 , before activation with Horm collagen. Thrombin generation was measured after triggering with tissue factor $/ \mathrm{CaCl}_{2}$. Curves are representative of three or more independent experiments.

control level, $P<0.01)$. Notably, in combination with abciximab, anti-GPVI 9012 further diminished the thrombin generation to give a trace similar to that of abciximab alone $(62.7 \pm 12.2 \%$ of control level). Thus, treatment with 9012 , but not abciximab, was needed to completely antagonize the collagen-enhancing effect on thrombin generation. These results indicate that the enhancing effect of GPVI is mostly not mediated by $\alpha$ llb $\beta 3$ and, thus, that the effect of the integrin relies on a distinct mechanism.

\section{Collagen enriched in type-I from human heart tissue enhances thrombin generation via GPVI}

In human myocardium, collagen is abundantly present as a network of mostly type-I fibrils with fewer type-III fibrils. ${ }^{37}$ For comparison of the above results with bovine type-I collagen, we purified a collagen preparation from human heart tissue. Microscopic observation of this preparation, spread on glass, showed intense Sirius red staining of the surface with thin collagen fibers. At maximally effective concentration, this fibrillar collagen significantly enhanced thrombin generation in PRP: time-to-peak shortened with $15.3 \pm 2.1 \mathrm{~min}$ and peak height increased by $1.8 \pm 0.4$ fold (Fig. 1D). The procoagulant effect also of the heart collagen was almost completely inhibited with anti-GPVI mAb 9012. Thus, GPVI appears to be a key receptor in the procoagulant activity of this collagen derived from the human cardiovascular system.

\section{Type-I collagens differently stimulate PS exposure on adherent platelets under flow}

Using the fibrillar Horm collagen, it has been described that GPVI is the major collagen receptor regulating thrombus formation of human and mouse platelets under flow conditions. ${ }^{6,25}$ Using moderately high shear conditions (4 min at $1000 \mathrm{~s}^{-1}$ ), checked to be sensitive to GPIb blockade, we performed a series of flow experiments where human blood was perfused over surfaces coated with the different collagen preparations. With 


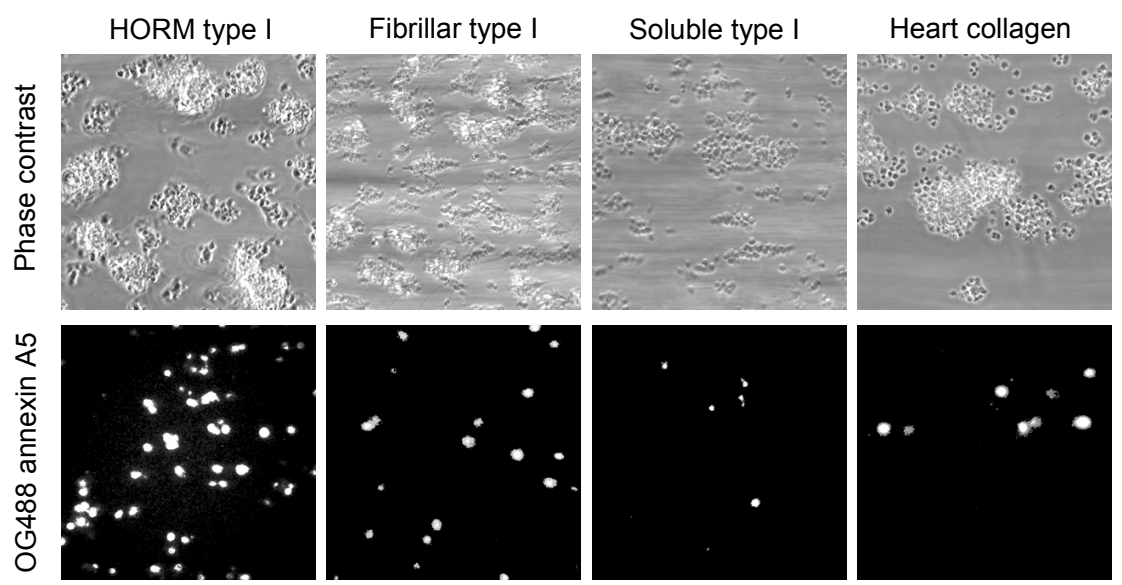

Fig. 5. Effect of various collagens on platelet deposition and PS exposure under flow. Whole blood, anticoagulated with $40 \mu \mathrm{mol} \mathrm{L} \mathrm{L}^{-1}$ PPACK, was perfused for $4 \mathrm{~min}$ at a shear rate of $1000 \mathrm{~s}^{-1}$ over Horm type-I collagen, fibrillar type-I fibers, soluble type-I collagen, or collagen from human heart tissue (each spread at $35 \mu \mathrm{g} \mathrm{cm}{ }^{-2}$ ). Adhered platelets were stained post-perfusion with OG488-annexin A5 $\left(1 \mu \mathrm{g} \mathrm{mL}^{-1}\right)$. Shown are representative phase contrast $(120 \times 120 \mu \mathrm{m})$ and fluorescent $(150 \times 150 \mu \mathrm{m})$ images after perfusion.

all collagen forms, it appeared that platelet deposition increased with the spreading density up to a spreading concentration of $30-40 \mu \mathrm{g} \mathrm{cm}^{-2}$, at which platelet deposition was maximal under this experimental condition (data not shown). At this density (35 $\mu \mathrm{g}$ $\mathrm{cm}^{-2}$ ), staining of the collagen surfaces with Sirius red showed a dense, uniform distribution of red fibers (for fibrillar collagens) or of small red spots (soluble collagen). After 4-min perfusion of blood over the fibrillar Horm collagen and (bovine) type-I collagen surfaces, multi-layered platelet aggregates were detected (Fig. 5). Perfusion of the blood over soluble type-I collagen resulted in formation of smaller aggregates, while perfusion over human heart collagen gave aggregates of variable sizes. Total surface area covered by adherent platelets - earlier demonstrated to increase about linearly in time ${ }^{10}$ - was similar for all (fibrillar and soluble) collagens at this time point (Table 2). Staining with OG488-annexin A5, to measure PS expression, was typically higher for Horm collagen (10.5\% of surface area covered with fluorescence) than for the bovine fibrillar type-I collagen (3.8\% coverage with fluorescence); annexin A5 staining was still lower for the heart $(0.7 \%)$ and soluble type-I $(0.25 \%)$ collagen (Fig. 5 and Table 2 ).

GPVI blockade by 9012 Fab severely impaired aggregate formation (not shown) and PS exposure (Table 2) on all collagens. However, 9012 did not reduce platelet adhesion, except for heart collagen (Table 2). Platelet adhesion to all collagens was abolished by combined blockade of GPVI with 9012 and $\alpha 2 \beta 1$ with $6 \mathrm{~F} 1 \mathrm{mAb}$ (not shown), such as was demonstrated earlier for Horm collagen. ${ }^{10}$ This suggested that the heart collagen was limited in adhesion sites for (unstimulated) $\alpha 2 \beta 1$, in a similar way as recently found for (type I) collagen in human plaque tissue. ${ }^{38} \mathrm{GPVI}$-dependent adhesion of platelets to the plaque collagen can be suppressed by blocking of the ADP receptors, e.g. causing $\alpha 2 \beta 1$ activation. ${ }^{38}$ To determine whether this was also the case for the 
Table 2 Effect of anti-GPVI treatment on collagen-induced platelet adhesion and PS exposure under flow

\begin{tabular}{ccc}
\hline & $\begin{array}{c}\text { Phase contrast } \\
\text { (\% surface area covered) }\end{array}$ \\
\hline Horm type I collagen & $16.4 \pm 1.3$ & $\begin{array}{c}\text { OG488-Annexin A5 } \\
\text { + 9012 }\end{array}$ \\
Fibrillar type I collagen & $15.6 \pm 1.2$ & $1.6 \pm 1.5$ \\
+ 9012 & $22.8 \pm 4.3$ & $3.8 \pm 1.0$ \\
Soluble type I collagen & $19.0 \pm 3.2$ & $0.3 \pm 0.1$ \\
+ 9012 & $11.9 \pm 3.8$ & $0.2 \pm 0.1$ \\
Heart collagen & $15.9 \pm 0.9$ & $0.1 \pm 0.0$ \\
+ 9012 & $25.5 \pm 2.4$ & $0.7 \pm 0.0$ \\
\hline
\end{tabular}

Whole blood, anticoagulated with $40 \mu \mathrm{mol} \mathrm{L}^{-1}$ PPACK, was perfused for $4 \mathrm{~min}$ at shear rate of 1000 $\mathrm{s}^{-1}$ over various collagens (see Fig. 5). The blood was pretreated for $10 \mathrm{~min}$ with anti-GPVI 9012 $\left(50 \mu \mathrm{g} \mathrm{mL}^{-1}\right)$. Adhered platelets were stained post-perfusion with OG488-annexin A5 $\left(0.5 \mu \mathrm{g} \mathrm{mL}^{-1}\right)$. Data show surface area coverage of all platelets (phase contrast) and of fluorescent-labeled platelets (mean \pm S.E., $n=3-4$ experiments with blood from different donors).

GPVI-dependent adhesion to heart collagen, flow experiments were performed in the presence of MRS2179 $\left(40 \mu \mathrm{mol} \mathrm{L}^{-1}\right)$ and AR-C69931MX $\left(20 \mu \mathrm{mol} \mathrm{L}^{-1}\right)$. Indeed, ADP receptor blockade resulted in a greatly reduced platelet coverage with heart collagen (12 $\pm 2 \%$ of control, mean \pm S.E., $n=3$ ). In contrast, the blockers were much less inhibiting on platelet adhesion to Horm and fibrillar type-l collagens (131 $\pm 16 \%$ and $89 \pm 9 \%$ of controls, respectively).

\section{Discussion}

The present data show that especially fibrillar Horm and bovine type-I collagens are potent stimulators of platelet-dependent thrombin generation in PRP. Thus, under conditions of coagulation triggered with tissue factor, platelet interaction with fibrillar collagens greatly enhances the rate of thrombin generation (correlated with the thrombin peak-height). This potentiating effect of the fibrillar collagens is completely abolished by treatment of PRP with the blocking anti-GPVI mAb 9012. Accordingly, platelet activation by the signaling collagen receptor GPVI plays a key role in this procoagulant collagen effect, which is in agreement with earlier observations that GPVI causes PS expression on platelets and stimulates prothrombinase activity. ${ }^{5,14,21,25}$ We further show that the effect of fibrillar collagen on thrombin generation is antagonized by platelet inhibition with $\mathrm{PGE}_{1}$ and by scavenging $\mathrm{PS}$ with annexin $\mathrm{A} 5$, indicating that it relies on platelet activation and subsequent PS expression.

We also find that a fibrillar collagen preparation from human heart, enriched in type I and fewer type III collagens, significantly stimulates thrombin generation in the presence of platelets. Also in this case the stimulating effect is blocked by anti-GPVI mAb and thus relies on GPVI. On the other hand, a soluble form of bovine type I collagen, lacking the telopeptides and the typical striated morphology of fibrillar collagen, requires prior 
activation of $\alpha 2 \beta 1$ (with $\mathrm{Mn}^{2+}$ ) for stimulation of thrombin generation. The stimulation also in this case ultimately relies on GPVI, as is concluded from the complete suppression by anti-GPVI mAb.

Soluble type I collagen expresses multiple $\alpha 2 \beta 1$ binding sites. ${ }^{9,20}$ It has been described that $\mathrm{Mn}^{2+}$ ions and weak agonists such as ADP increase the binding of this collagen to platelets by changing $\alpha 2 \beta 1$ to an intermediate, higher affinity conformation. ${ }^{8}$ Our results indicate that, not only with soluble collagen but also with fibrillar type I collagen, pre-activation of the integrin with $\mathrm{Mn}^{2+}$ ions enhances thrombin generation. Because GPVI blockade completely reverses the effect of collagen/ $\mathrm{Mn}^{2+}$, GPVI must act as a principal platelet receptor in all collagen-enhanced procoagulant activity. In a different context, it has already been observed that integrin activation in interplay with human and mouse GPVI regulates platelet aggregation and thrombus formation under conditions where coagulation was absent. ${ }^{3-6}$ These present results significantly extend this work by showing that activated $\alpha 2 \beta 1$, also under coagulant conditions, enhances the signaling function of GPVI likely by reinforcing platelet contact with collagen. In contrast, they do not provide evidence for a direct signaling effect via $\alpha 2 \beta 1$ in the collagenstimulated thrombin generation.

In the absence of collagen, the secondary mediators, $\mathrm{TxA}_{2}$ and ADP, have a modest stimulatory effect on platelet procoagulant activity, notably via stimulation of $P 2 Y_{12}$ receptors. ${ }^{27,28}$ This appears also to be true in thrombin generation measurements with collagen present (Table 1), possibly by enforcing platelet-collagen interaction. This modest effect differs from the regulation of platelet aggregation, where autocrine $\mathrm{TxA}_{2}$ and ADP are considered to be relatively important. ${ }^{39}$

Various studies have reported that integrin $\alpha \mathrm{llb} \beta 3$ has a supporting role in plateletdependent thrombin generation. ${ }^{11,33}$ It is also proposed that the $\alpha$ llb $\beta 3$ antagonist abciximab affects the procoagulant activity of platelets adhered to collagen. ${ }^{36}$ We note a clear lowering effect of abciximab on thrombin generation levels both in the absence and presence of collagen. In addition, we find that the enhancing effect of collagen on thrombin generation persists in the presence of $\alpha \mathrm{llb} \beta 3$ antagonism with abciximab, which makes it unlikely that the integrin plays is directly involved in the platelet-collagen interactions implicated in procoagulant activity. Abciximab then may act by interfering in the interaction of platelets with fibrin(ogen) or coagulation factors.

In general, we find a correlation between collagen-stimulated, PS-dependent thrombin generation in PRP and collagen-induced PS exposure under flow (in the absence of coagulation). In either assay, fibrillar type I collagens are more active than the soluble collagen. Only the heart-derived collagen is less active in causing PS exposure (but not aggregate formation) under flow than is predicted from the enhancing effect on thrombin generation. On the other hand, with all collagens including the heart collagen, thrombin generation as well as platelet activation (PS exposure) and aggregate formation under flow are completely dependent on GPVI activity.

The differences in effects of the collagen preparations are likely to reside in the contribution of $\alpha 2 \beta 1$. We find that only for heart collagen adhesion under flow relies on GPVI. Similarly to the situation with plaque-derived collagens, ${ }^{38}$ this may point to a low 
number of interactions sites for the (unactivated) $\alpha 2 \beta 1$ integrin. Adhesion to the others collagens is not exclusively dependent on GPVI, such in agreement with previous findings with Horm collagen. ${ }^{6,10}$ However, as described elsewhere, for human as well as murine platelets, GPVI activity is likely to play a role in the stable adhesion to collagens. ${ }^{40}$ Others have shown that soluble type-I collagen relies more strongly on $\alpha 2 \beta 1$ for platelet adhesion and thrombus formation than 'banded', fibrillar collagen. ${ }^{9}$ The present results are compatible with the presence of a significant number of interaction sites for (unactivated) $\alpha 2 \beta 1$ in both soluble and fibrillar collagen, which seem to variably allow GPVI-collagen interaction. Together, the results depict a physiological mechanism, in which GPVI interaction with collagen fibers, supported by $\alpha 2 \beta 1$, plays a central, bridging role in not only primary thrombus formation, but also platelet-dependent coagulation.

\section{Acknowledgments}

We acknowledge Dr. J. Cleutjens for providing human heart tissue and Dr. B. Coller for the kind gift of 6F1 antibody. Support was obtained from the European Community (Marie-Curie QLK5-CT-2000-60007) and the Netherlands Organization for Scientific Research (902-16-276).

\section{References}

1. Ruggeri ZM. Platelets in atherothrombosis. Nat Med. 2002;8:1227-1234.

2. Nieswandt B, Watson SP. Platelet-collagen interaction: is GPVI the central receptor? Blood. 2003;102:449-461.

3. Atkinson BT, Jarvis GE, Watson SP. Activation of GPVI by collagen is regulated by $\alpha 2 \beta 1$ and secondary mediators. J Thromb Haemost. 2003;1:1278-1287.

4. Chen $\mathrm{H}, \mathrm{Kahn} \mathrm{ML}$. Reciprocal signaling by integrin and nonintegrin receptors during collagen activation of platelets. Mol Cell Biol. 2003;23:4764-4777.

5. Nieswandt B, Brakebusch C, Bergmeier W, Schulte V, Bouvard D, Mokhtari-Nejad R, Lindhout T, Heemskerk JW, Zirngibl H, Fässler R. Glycoprotein VI but not $\alpha 2 \beta 1$ integrin is essential for platelet interaction with collagen. EMBO J. 2001;20:2120-2130.

6. Siljander PR, Munnix IC, Smethurst PA, Deckmyn H, Lindhout T, Ouwehand WH, Farndale RW, Heemskerk JW. Platelet receptor interplay regulates collagen-induced thrombus formation in flowing human blood. Blood. 2004;103:1333-1341.

7. Savage B, Almus-Jacobs F, Ruggeri ZM. Specific synergy of multiple substrate-receptor interactions in platelet thrombus formation under flow. Cell. 1998;94:657-666.

8. Jung SM, Moroi M. Platelet collagen receptor integrin $\alpha 2 \beta 1$ activation involves differential participation of ADP-receptor subtypes $\mathrm{P}_{2} \mathrm{Y}_{1}$ and $\mathrm{P} 2 \mathrm{Y}_{12}$ but not intracellular calcium change. Eur J Biochem. 2001;268:3513-3522.

9. Savage B, Ginsberg MH, Ruggeri ZM. Influence of fibrillar collagen structure on the mechanisms of platelet thrombus formation under flow. Blood. 1999;94:2704-2715.

10. Lecut C, Schoolmeester A, Kuijpers MJ, Broers JL, van Zandvoort MA, Vanhoorelbeke K Deckmyn H, Jandrot-Perrus M, Heemskerk JW. Principal role of glycoprotein VI in $\alpha 2 \beta 1$ and $\alpha$ llb $\beta 3$ activation during collagen-induced thrombus formation. Arterioscler Thromb Vasc Biol. 2004;24:1727-1733.

11. Heemskerk JW, Bevers EM, Lindhout T. Platelet activation and blood coagulation. Thromb Haemost. 2002;88:186-193. 
12. Monroe DM, Hoffman M, Roberts HR. Platelets and thrombin generation. Arterioscler Thromb Vasc Biol. 2002;22:1381-1389.

13. Alberio L, Safa O, Clemetson KJ, Esmon CT, Dale GL. Surface expression and functional characterization of $\alpha$-granule factor $V$ in human platelets. Blood. 2000;95:1694-1702.

14. Heemskerk JW, Siljander P, Vuist WM, Breikers G, Reutelingsperger CP, Barnes MJ, Knight CG, Lassila R, Farndale RW. Function of glycoprotein VI and integrin $\alpha 2 \beta 1$ in the procoagulant response of single, collagen-adherent platelets. Thromb Haemost. 1999;81:782-792.

15. Furihata K, Clemetson KJ, Deguchi H, Kunicki TJ. Variation in human platelet glycoprotein VI content modulates glycoprotein VI-specific prothrombinase activity. Arterioscler Thromb Vasc Biol. 2001;21:1857-1863

16. Andersen H, Greenberg DL, Fujikawa K, Xu WF, Chung DW, Davie EW. Protease-activated receptor 1 is the primary mediator of thrombin-stimulated platelet procoagulant activity. Proc Natl Acad Sci USA. 1999;96:11189-11193.

17. Bevers EM, Comfurius P, van Rijn JL, Hemker HC, Zwaal RF. Generation of prothrombinconverting activity and the exposure of phosphatidylserine at the outer surface of platelets. Eur J Biochem. 1982;122:429-436.

18. Siljander P, Farndale RW, Feijge MA, Comfurius P, Kos S, Bevers EM, Heemskerk JW Platelet adhesion enhances the glycoprotein VI-dependent procoagulant response. Arterioscler Thromb Vasc Biol. 2001;21:618-627.

19. Farndale RW, Sixma JJ, Barnes MJ, de Groot PG. The role of collagen in thrombosis and hemostasis. J Thromb Haemost. 2004;2:561-573.

20. Siljander P, Lassila R. Studies of adhesion-dependent platelet activation. Arterioscler Thromb Vasc Biol. 1999;19:3033-3043.

21. Lecut C, Feeney LA, Kingsbury G, Hopkins J, Lanza F, Gachet C, Villeval JL, Jandrot-Perrus M. Human platelet glycoprotein VI function is antagonized by monoclonal antibody-derived Fab fragments. J Thromb Haemost. 2003;1:2653-2662.

22. Miller EJ, Rhodes RK. Preparation and characterization of the different types of collagen. Meth Enzymol. 1982;82:33-64.

23. Hemker HC, Giesen PL, Ramjee M, Wagenvoord R, Béguin S. The thrombogram: monitoring thrombin generation in platelet-rich plasma. Thromb Haemost. 2000;83:589-591.

24. Vanschoonbeek K, Feijge MA, van Kampen RJ, Kenis H, Hemker HC, Giesen PL, Heemskerk JW. Initiating and potentiating role of platelets in tissue factor-induced thrombin generation in the presence of plasma. J Thromb Haemost. 2004;2:476-484.

25. Kuijpers MJ, Schulte V, Bergmeier W, Lindhout T, Brakebusch C, Offermanns S, Fässler R, Heemskerk JW, Nieswandt B. Complementary roles of glycoprotein VI and $\alpha 2 \beta 1$ integrin in collagen-induced thrombus formation in flowing whole blood ex vivo. FASEB J. 2003;17:685687.

26. Andree HA, Reutelingsperger CP, Hauptmann R, Hemker HC, Hermens WT, Willems GM. Binding of vascular anticoagulant $\alpha(\mathrm{VAC} \alpha)$ to planar phospholipid bilayers. J Biol Chem. 1990;265:4923-4928.

27. Léon C, Ravanat C, Freund M, Cazenave JP, Gachet C. Differential involvement of the P2Y and $\mathrm{P}_{2} \mathrm{Y}_{12}$ receptor in platelet procoagulant activity. Arterioscler Thromb Vasc Biol. 2003;23:1941-1947.

28. Dorsam RT, Tuluc M, Kunapuli SP. Role of protease-activated and ADP receptor subtypes in thrombin generation on human platelets. J Thromb Haemost. 2004;2:804-812.

29. Bazzoni G, Shih DT, Buck CA, Hemler ME. Monoclonal antibody 9EG7 defines a novel $\beta 1$ integrin epitope induced by soluble ligand and manganese, but inhibited by calcium. J Biol Chem. 1995;270:25570-25577.

30. Humphries MJ. Integrin structure. Biochem Soc Trans. 2000;28:311-339.

31. Jung SM, Moroi M. Platelets interact with soluble and insoluble collagens through characteristically different reactions. J Biol Chem. 1998;273:14827-14837. 
32. Jandrot-Perrus M, Lagrue AH, Okuma M, Bon C. Adhesion and activation of human platelets induced by convulxin involve glycoprotein $\mathrm{VI}$ and integrin $\alpha 2 \beta 1$. J Biol Chem. 1997;272:27035-27041.

33. Reverter JC, Béguin S, Kessels H, Kumar R, Hemker HC, Coller BS. Inhibition of plateletmediated, tissue-factor-induced thrombin generation by the mouse/human chimeric 7E3 antibody. J Clin Invest. 1996;98:863-874.

34. Béguin S, Kumar R, Keularts I, Seligsohn U, Coller BS, Hemker HC. Fibrin-dependent platelet procoagulant activity requires GPIb receptors and von Willebrand factor. Blood. 1999;93:564-570.

35. Butenas S, Cawthern KM, van 't Veer C, Dilorenzo ME, Lock JB, Mann KG. Antiplatelet agents in tissue factor-induced blood coagulation. Blood. 2001;97:2314-2322.

36. Ilveskero $\mathrm{S}$, Lassila R. Abciximab inhibits procoagulant activity but not the release reaction upon collagen- or clot-adherent platelets. J Thromb Haemost. 2003;1:805-813.

37. Weber KT, Sun Y, Tyagi SC, Cleutjens JP. Collagen network of the myocardium. J Mol Cell Cardiol. 1994;26:279-292.

38. Cosemans JM, Kuijpers MJ, Lecut C, Loubele ST, Heeneman S, Jandrot-Perrus M, Heemskerk JW. Contribution of platelet glycoprotein VI to the thrombogenic effect of collagens in fibrous atherosclerotic lesions. Atherosclerosis. 2005;181:19-27.

39. Kunapuli SP, Dorsam RT, Kim S, Quinton TM. Platelet purinergic receptors. Curr Opin Pharmacol. 2003;3:175-180.

40. Auger JM, Kuijpers MJ, Senis YA, Watson SP, Heemskerk JW. Adhesion of human and mouse platelets to collagen under shear: a unifying model. FASEB J. 2005;19:825-827. 


\title{
4
}

Effects of plasma- and platelet-derived matrix metalloproteinases on collagendependent thrombus formation

\author{
Judith M.E.M. Cosemans, Paola E.J. van der Meijden, Marion A.H. Feijge, \\ Imke C.A. Munnix, Jack P.M. Cleutjens, Alastair W. Poole, Jason L. Johnson and \\ Johan W.M. Heemskerk
}

Submitted for publication 


\begin{abstract}
Plasma and platelets contain various matrix metalloproteinases (MMPs), including MMP-1, MMP-2, MMP-3 and MMP-9. While in vitro studies have shown opposing effects of MMP isoforms on platelet activation, their role in collagen-dependent platelet adhesion and thrombus formation under flow conditions has not been assessed. The present results show that fibrillar type I collagen is degraded by both plasma- and plateletderived MMPs, and that this degradation annuls the role of collagen in supporting flowdependent platelet adhesion and thrombus formation. Collagen treatment with purified MMP preparations caused substantial collagen-degradation and anti-thrombogenic effects, in which case treatment with MMP-1 was more effective than treatment with MMP-2 or MMP-9. Measurements of collagen-dependent thrombus formation at moderately high shear rate on intact collagen indicated that MMP-2 deficiency resulted in reduced platelet deposition and activation, while MMP-9 deficiency had the opposite effect. Deficiency in MMP-3 had no effect on thrombus formation. Together, these data demonstrate that plasma- and platelet-derived MMP isoforms have a dual function in collagen-dependent thrombus formation. They have a balancing effect on platelet adhesion to collagen and thrombus formation under flow, and on a longer term downregulate the thrombogenic role of collagen fibers by proteolytic cleavage.
\end{abstract}

\title{
Introduction
}

Matrix metalloproteinases (MMPs) represent a group of $\mathrm{Zn}^{2+}$ and $\mathrm{Ca}^{2+}$-dependent proteinases, which jointly regulate the turnover of the extracellular matrix under physiological and pathological conditions. ${ }^{1}$ The activity of MMPs is precisely controlled at the level of transcription, by posttranslational activation of the precursor zymogens, and by specific inactivation through tissue inhibitors of metalloproteinases (TIMPs). Loss of activity control of one or more of the MMPs is suggested to contribute to diseases such as inflammation, cancer and atherosclerosis. ${ }^{1,2}$

Advanced atherosclerotic plaques contain increased amounts of fibrillar collagen types I and III., ${ }^{3,4}$ These collagens provide stability to the plaque tissue, but are also susceptible to degradation by MMPs that are abundantly present in the plaque shoulder regions. ${ }^{5}$ The same collagens, once exposed to the blood, are strongly platelet-activating and hence thrombogenic. Degradation of collagen types I and III makes a plaque more prone to rupture, but may also reduce the thrombogenic effect of the collagens. Fibrillar collagens are degraded by MMPs of the collagenase group (MMP-1, MMP-8, MMP-13 and MMP-18), which act by initial cleaving of the triple helical chains of the collagen. ${ }^{6-8}$ The MMPs of the gelatinase group (MMP-2 and MMP-9) digest the products of collagenase-degraded collagens and cleave non-fibrillar collagen types. However, MMP2 was also found to be capable of initial cleavage of collagen type 1. ${ }^{9}$ The MMP group of stromelysins (MMP-3, MMP-7, MMP-10, MMP-11) has a much broader substrate specificity. They degrade a wide range of extracellular matrix components, including nonhelical regions of various collagens, laminin and elastin. ${ }^{1,2}$ 
Plasma contains considerable amounts of MMP isoforms, which originate from vascular cells, such as endothelial- and smooth muscle cells. ${ }^{10}$ Also activated platelets release MMPs into the blood in an inactive form, i.e. pro-MMP-1, pro-MMP-2, pro-MMP-3 and pro-MMP-9. ${ }^{11-14}$ Like other MMP isoforms, these require removal of the propeptide domain and disruption of a cysteine- $\mathrm{Zn}^{2+}$ bond in order to become active. ${ }^{2}$ The activating mechanism is reasonably well understood and differs between isoforms. Pro-MMP-1, pro-MMP-2 and pro-MMP-3 isoforms can be activated at or near the platelet surface. ${ }^{15-17}$ This raises the possibility that following vessel wall damage and collagen exposure, these locally activated MMPs may act to degrade the exposed collagen. This possibility was investigated in the present paper.

In addition to degrading collagens, MMPs are known to affect platelet activation. Platelet-derived MMP-1 and MMP-2 can prime platelets for increased adhesion and aggregation, likely by interacting with integrin $\alpha$ llb $\beta 3$ at the platelet surface. ${ }^{14,18}$ Furthermore, MMP-2 is found to enhance key signaling pathways in platelets involving phospholipase $\mathrm{C}$ and phosphatidylinositol 3-kinase. ${ }^{19}$ In contrast, the other gelatinase, MMP-9, appears to have a different function by counteracting the stimulatory effects of MMP-2. ${ }^{14}$ How the signaling functions of MMP isoforms relate to their matrix proteindegrading effect is unclear.

Here, we investigated how platelet- and plasma-derived MMPs affect the thrombogenic role of collagen in plaque material or in purified form. Furthermore, we examined how MMP isoforms contributed to platelet activation and thrombogenic activity under flow conditions, by using blood from mice deficient in MMP-2, MMP-3 or MMP-9 isoforms.

\section{Methods}

\section{Materials}

The general MMP inhibitor GM6001 was obtained from Biomol (Plymouth Meeting, PA, USA). 1,10-Phenanthrolin monohydrate, N,N,N',N'-tetrakis (2-pyridylmethyl) ethylenediamine (TPEN), and collagenase derived from Clostridium histolyticum were from Sigma-Aldrich (St. Louis, MO, USA). MMP-1 proenzyme (from human rheumatoid synovial fibroblast), active MMP-2 (human recombinant), MMP-9 (human recombinant), p-aminophenyl mercuric acetate (APMA), and H-Phe-Pro-Arg chloromethyl ketone (PPACK) were from Calbiochem (La Jolla, CA, USA). Horm collagen was from Nycomed (Munich, Germany). Penicillin/streptomycin solution and 5,6 carboxyfluorescein diacetate succinimidyl ester (CFSE) were from Invitrogen (Carlsbad, CA, USA). Sirius red came from Klinipath (Duiven, The Netherlands). Annexin A5 labeled with Alexa Fluor (AF)-647 was from Molecular Probes (Leiden, The Netherlands). The glycoprotein VI agonist, convulxin, was purified to homogeneity from the venom of Crotalus durissus terrificus (Latoxan), as described. ${ }^{20}$ FITC-conjugated rat anti-mouse P-selectin (CD62P) mAb was obtained from Emfret Analytics (Würzburg, Germany). 


\section{Preparation of plaque material}

Five advanced fibrous atherosclerotic plaques were collected at autopsy from carotid arteries, and were used in compliance with institutional guidelines (Department of Pathology, $\mathrm{MUMC}^{+}$, Maastricht). Permission was obtained from the Medical Ethics Committee. The plaque material, free from non-plaque vascular tissue, was pooled and homogenized in phosphate-buffered saline pH 7.45 using a potter (Braun, Melsungen, Germany) to a final concentration of $165 \mathrm{mg}$ tissue wet weight $/ \mathrm{mL}$, as described before. $^{21}$

\section{Human blood and platelet isolation}

Blood was drawn from healthy volunteers after full informed consent. The blood was collected into either $10 \% 129 \mathrm{mM}$ trisodium citrate, $17 \%$ acid-citrate-dextrose or into 40 $\mu \mathrm{M}$ PPACK, as required. ${ }^{22}$ Platelet-free plasma and washed platelets were obtained, as described. ${ }^{23}$ Washed platelets $\left(50 \times 10^{8}\right.$ platelets $\left./ \mathrm{mL}\right)$ were activated with convulxin (50 $\mathrm{ng} / \mathrm{mL}$ ) for $5 \mathrm{~min}$, after which the supernatant was collected by $10 \mathrm{~min}$ centrifugation at $20.000 \mathrm{~g}$.

\section{Mouse blood and platelet isolation}

Animal experiments were approved by the local Animal Experimental Committees. Mice deficient in MMP-2, background strain C57BL/6 were provided by dr. L. Matrisian (Vanderbilt University, Nashville, TN, USA); mice deficient in MMP-3, background strain B10.RIII, were provided by dr. J. Mudgett (Merck Research Laboratories, Rahway, NJ, USA); mice deficient in MMP-9, background strain CD1, were from dr. S. Shapiro (Harvard Medical School, Boston, PA, USA). Wildtype mice (same genetic background) came from the same institutions. Mice of all genotypes had platelet counts in the normal range. Mouse blood was collected into $10 \% 129 \mathrm{mM}$ trisodium citrate and $5 \mathrm{U} / \mathrm{mL}$ heparin. Prior to flow experiments, the blood was recalcified with $7.5 \mathrm{mM} \mathrm{CaCl}_{2}$ and 3.75 $\mathrm{mM} \mathrm{MgCl} 2$. Platelet-free mouse plasma was obtained, as described. ${ }^{23}$

\section{Enzymatic treatment of immobilized collagen and plaque material}

Degreased coverslips (24 x $60 \mathrm{~mm}$ ) were coated with two spots (10 mm apart) of homogenized plaque material ( $1 \mu \mathrm{L}$ of $165 \mathrm{mg} / \mathrm{mL}$ ) for $15 \mathrm{~min}$; or with two spots of fibrillar type I Horm collagen ( $5 \mu \mathrm{L}$ of $200 \mu \mathrm{g}$ collagen $/ \mathrm{mL}$ ) for $60 \mathrm{~min}$. After coating, the coverslips were rinsed with saline. One spot on each coverslip, serving as a control, was treated with vehicle solution. The other spot on the coverslip was treated with $10 \mu \mathrm{L}$ of one of the following MMP sources: broad-spectrum collagenase $(1 \mathrm{mg} / \mathrm{mL})$; purified MMP-1 (20 $\mu \mathrm{g} / \mathrm{mL})$; purified MMP-2 or MMP-9 $(50 \mu \mathrm{g} / \mathrm{mL})$; plasma (10 $\mu \mathrm{L} / \mathrm{spot})$; or supernatant from convulxin-activated platelets $(10 \mu \mathrm{L} / \mathrm{spot})$. Prior to use, citrateanticoagulated plasma was incubated with hirudin $(20 \mu \mathrm{g} / \mathrm{mL})$ to prevent coagulation and with $\mathrm{ZnCl}_{2}(1 \mathrm{mM})$ to enable MMP action. The plasma was then recalcified with $7.5 \mathrm{mM}$ $\mathrm{CaCl}_{2}$ and $3.75 \mathrm{mM} \mathrm{MgCl}$. The purified MMP preparations were pre-activated with 
APMA, as described. ${ }^{24}$ The coverslips were incubated at $37^{\circ} \mathrm{C}$ in a humid chamber. Penicillin and streptomycin (1:100) were added to prevent bacterial growth during the incubation. After overnight incubation, the coverslips were rinsed three times with saline, blocked with HEPES buffer pH 7.45 (136 mM NaCl, $10 \mathrm{mM}$ glucose, $5 \mathrm{mM}$ HEPES, 2.7 $\mathrm{mM} \mathrm{KCl}, 2 \mathrm{mM} \mathrm{MgCl}$, and $2 \mathrm{mM} \mathrm{CaCl}_{2}$ ) containing $1 \%$ bovine serum albumin, and then used for surface analysis and flow experiments.

\section{Thrombus formation on immobilized plaque material or collagen under flow}

Flow experiments were performed using anticoagulated human or mouse blood. Collagen- or plaque-coated coverslips were inserted into a transparent parallel-plate perfusion chamber, which was mounted on an inverted microscope (Nikon Diaphot 22; Nikon, Tokyo, Japan). The blood was perfused through the flow chamber at a shear rate of $1000 \mathrm{~s}^{-1}$ for $4 \mathrm{~min}$. For visualization of platelet adhesion to plaque material, the platelets were pre-labeled with CFSE $(2.7 \mu \mathrm{M})$, and added back to autologous blood. ${ }^{25}$ Coverslips were post-stained with FITC-annexin A5 $(0.5 \mu \mathrm{g} / \mathrm{mL})$ in HEPES buffer $\mathrm{pH}$ 7.45 at the same flow rate. Microscopic images were collected with a Visitech digital imaging system (Sunderland, UK), equipped with two sensitive, intensified, chargecoupled device cameras. ${ }^{26}$ This setup allowed capturing of high-resolution phasecontrast and fluorescent images in parallel in real-time. Images were taken from $>10$ random microscopic fields. The images were analyzed on surface area coverage, as described. $^{22}$

\section{Two photon laser scanning microscopy}

Coverslips with thrombi were also examined with a Bio-Rad 2100 multiphoton microscopic system (Zeiss, Jena, Germany). Excitation was by a Spectra-Physics Tsunami Ti:Sapphire laser (Mountain View, CA, USA), tuned and mode-locked at 800 $\mathrm{nm}$, producing pulses of $100 \mathrm{fs}$ wide (repetition rate $82 \mathrm{MHz}$ ), which was connected to an upright Nikon E600FN fluorescence microscope. ${ }^{27}$ Excitation at $647 \mathrm{~nm}$ was induced by a parallel-placed red diode laser. Fluorescence was detected at 508 to $523 \mathrm{~nm}$ and above $660 \mathrm{~nm}$. Mouse thrombi, double stained with FITC-labeled anti-P-selectin mAb and AF647-annexin A5, were scanned at the end of perfusions. Analysis of confocal images was with ImagePro/LaserPix software (Media Cybernetics, Silver Spring, MD, USA).

\section{Histology}

Coverslips with thrombi were fixed with $4 \%$ paraformaldehyde and stained with $0.1 \%$ sirius red in saturated picric acid for $90 \mathrm{~min}$. Sirius red stains collagens by integrating into the triple-helical structure of collagen fibers. ${ }^{28}$ Collagen degradation was determined by detecting sirius red absorbance (bright-field) and the sirius red double-crossed polarization signal (polarized light), using a Leica DM5000B microscope, equipped with a Leica DC 300FX camera. Analysis was with Qwin image software V 3.2.1 (Leica, Cambridge, UK). 


\section{Statistics}

Significance of differences was determined with the Mann-Whitney U-test or the independent samples t-test, as appropriate, using the statistical package for social sciences (SPSS 11.0, Chicago, IL, USA).

\section{Results}

\section{Collagen degradation by a collagenase abrogates the thrombogenic effect of human atherosclerotic plaques}

Plaque collagens are known to be subjected to continuous turnover by MMPs. ${ }^{29}$ To assess the effect of such collagen processing, human plaque material was coated on coverslips and treated overnight with a broad-spectrum collagenase at $37^{\circ} \mathrm{C}$. Microscopic inspection indicated that the collagenase treatment did not lead to detachment of plaque material from the coverslip (Fig. 1A). Sirius red staining of the

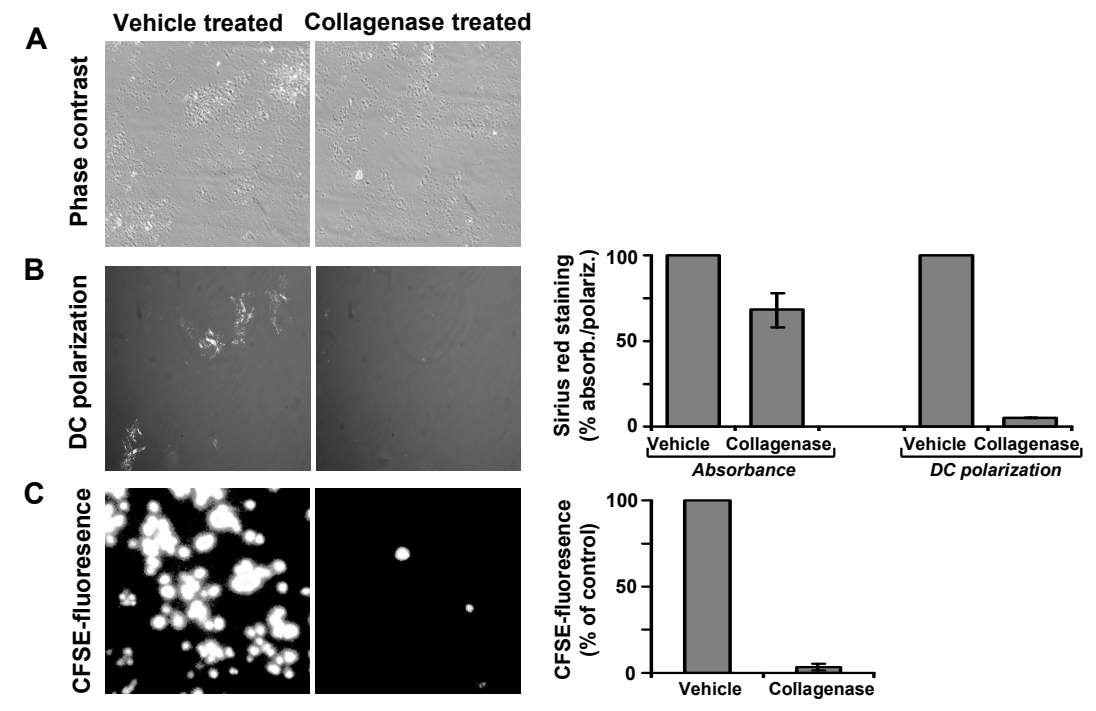

Figure 1. Treatment of plaque material with collagenase abolishes flow-dependent platelet adhesion. Coverslips coated with two spots of human plaque material were treated overnight with vehicle (1 spot) or with $1 \mathrm{mg} / \mathrm{mL}$ broad-spectrum collagenase $(1 \mathrm{spot})$ at $37^{\circ} \mathrm{C}$. (A) Phase contrast images $(120 \times 120 \mu \mathrm{m})$ of plaque material after treatment with vehicle buffer or collagenase. (B) Staining of coated plaque material with sirius red. Shown are double-crossed (DC) polarization images $(175 \times 175 \mu \mathrm{m})$ indicating triple-helical collagen fibers. Surface area coverage of DC polarization signal was $19.4 \pm 4.3 \%$ (vehicle-treated) and $1.5 \pm 0.4 \%$ (collagenase-treated). Bar graph represents relative effect of collagenase treatment on surface area coverage of sirius red staining (absorbance and DC polarization). Data are mean \pm SEM $(n=4)$. (C) Effect of collagenase treatment on platelet adhesion. Spots with plaque material treated with collagenase or vehicle were perfused with PPACK-anticoagulated human blood for $4 \mathrm{~min}$ at $1000 \mathrm{~s}^{-1}$. Shown are representative fluorescence images of CFSE-labeled platelets $(75 \times 75 \mu \mathrm{m})$, and quantitative analysis of surface area coverage for CFSE staining (mean \pm SEM, $n=4$ ). 
coverslips for collagen showed a moderate decrease in absorbance after collagenase treatment. However, analysis of the double-crossed polarization signal of sirius red indicative for the presence of collagen triple helices - showed a marked reduction (Fig. 1B). This pointed to a substantial reduction in triple-helical collagen structures of the immobilized plaque material.

The functional effect of collagenase treatment then was investigated by measuring the potency of the plaque material to support platelet adhesion and activation. Human, PPACK-anticoagulated blood was flowed over the (treated) plaque surface at a shear rate of $1000 \mathrm{~s}^{-1}$. Platelets in the blood were prelabeled with CFSE to monitor their adhesion and aggregation by fluorescence microscopy. In the absence of treatment, the plaque material caused high platelet deposition (Fig. 1C), which is consistent with previous results. ${ }^{21,30}$ However, following collagenase treatment hardly any platelets stably adhered, which by implication suggested that the triple-helical structure of collagen plays a key role in the platelet-adhesive function of plaque material. Earlier experiments have indicated that, in human plaques, type I collagen is the major plateletactivating collagen type. ${ }^{21,30}$ Hence, further experiments were conducted with purified type I collagen.

\section{Collagen degradation by plasma- and platelet-derived MMPs abolishes platelet adhesion and thrombus formation}

Fibrillar type I collagens are more potent than degraded soluble type I collagens in supporting platelet adhesion and activation under flow. ${ }^{31,32}$ However, it is unknown whether collagen degradation by plasma- and platelet-derived MMPs affects its capability for platelet adhesion.

To investigate the effect of the collagenase activity of plasma, coverslips coated with type I collagen fibers were treated with human plasma. For these experiments, citrateanticoagulated plasma was recalcified in the presence of hirudin, to prevent coagulation, and of $\mathrm{ZnCl}_{2}$, to activate MMPs. After overnight treatment, coverslips no longer stained for sirius red, indicating disappearance of the collagen fibers (Fig. 2A, B). When the plasma-treated coverslips were perfused with blood, platelets no longer adhered and thrombi were no longer formed (Fig. 2C). Control experiments, in which the MMP inhibitor phenanthrolin (1 $\mathrm{mM}$ ) was added to the plasma, resulted in unchanged sirius red staining (not shown) and high platelet adhesion and thrombus formation (Fig. 2C). Together, this suggested that plasma-derived MMP activity was responsible for the degradation of the collagen fibers and, as a consequence, for the abolished platelet adhesion and thrombus formation.

To investigate the effect of the collagenase activity of platelet-derived constituents, thrombi were formed on collagen under flow, and then incubated overnight with buffer at $37^{\circ} \mathrm{C}$. Also this incubation resulted in complete degradation of the collagen fibers (Fig $3 A)$. When the incubation was performed with the MMP inhibitors, phenanthrolin (1 $\mathrm{mM})$, TPEN $(1 \mathrm{mM})$ or GM6001 $(25 \mu \mathrm{M})$, the collagen fibers were still intact. To confirm that the collagen degradation effect was due to MMPs produced by the platelets, another set of experiments was performed. Collagen fibers on coverslips were incubated with the 

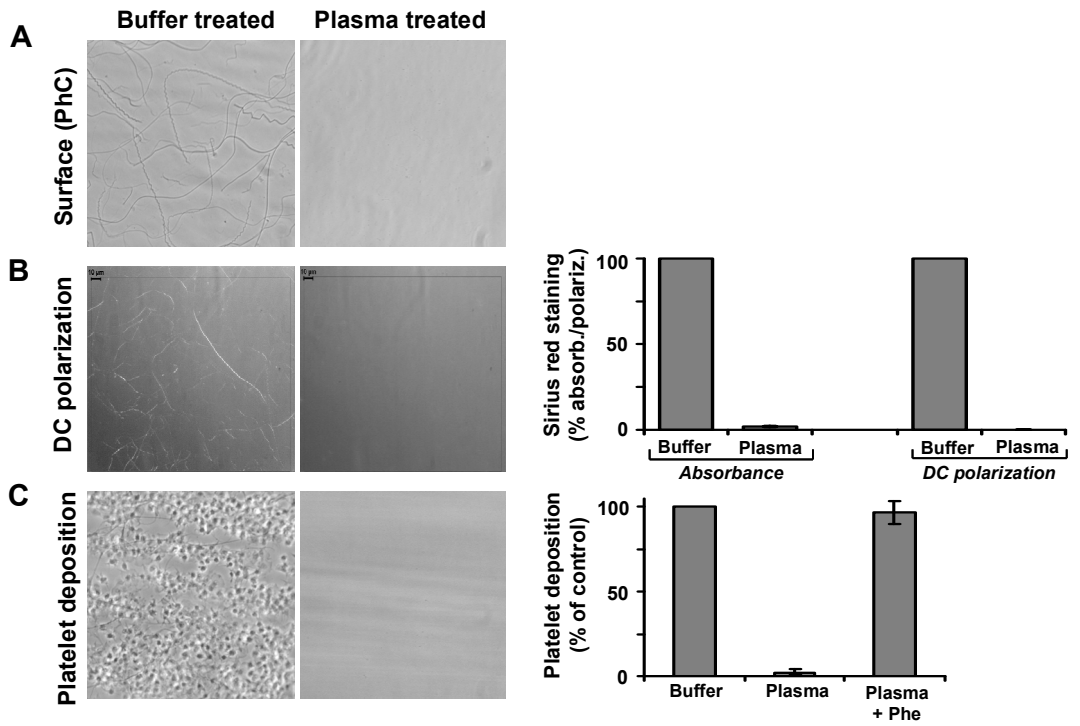

Figure 2. Treatment of immobilized collagen with plasma-derived MMP abolishes flowdependent platelet adhesion and thrombus formation. Coverslips coated with two spots of type I collagen were treated overnight at $37^{\circ} \mathrm{C}$ with buffer $(10 \mu \mathrm{L}, 1 \mathrm{spot})$ or human plasma (10 $\mu \mathrm{L}, 1$ spot). Citrated plasma was recalcified in the presence of hirudin and activated with $\mathrm{ZnCl}_{2}$. The MMP inhibitor phenanthrolin $(1 \mathrm{mM})$ was added, as indicated. (A) Phase contrast images $(120 \times 120$ $\mu \mathrm{m})$ showing collagen coating on spots after treatment with buffer or plasma. (B) Staining of spots with sirius red. Shown are double-crossed (DC) polarization images $(175 \times 175 \mu \mathrm{m})$ indicating triplehelical collagen fibers. Bar graph indicates effect of plasma treatment on surface area coverage of collagen coated spots, as detected from sirius red absorbance and DC polarization. Data are relative to buffer. (C) PPACK-anticoagulated human blood was perfused over the spots for $4 \mathrm{~min}$ at $1000 \mathrm{~s}^{-1}$, and platelet deposition was monitored. Shown are representative phase contrast images $(120 \times 120 \mu \mathrm{m})$. Bar graph represents effect of plasma treatment on platelet deposition (mean \pm SEM, $n=4)$.

supernatant from convulxin-activated platelets, containing most of the released granular contents including MMPs. This incubation resulted in almost complete collagen degradation (Fig. 3B). Collagen degradation was prevented if a MMP inhibitor (phenanthrolin, TPEN or GM6001) was present. Furthermore, collagen fibers also remained intact when incubated with supernatant from unstimulated platelets (Fig. 3B).

Incubation with the supernatant from activated platelets resulted in adhesion of only few platelets following whole-blood perfusion. However, with MMP inhibitor present during the incubation, platelets adhered normally and large thrombi were formed (Fig. $3 \mathrm{C})$. Together, these results indicate that both plasma- and platelet-derived MMPs can degrade immobilized fibrillar collagen and downregulate its thrombogenic effect.

\section{Both collagenases and gelatinases impair the thrombogenic activity of immobilized collagen}

Human platelets have been shown to contain the isoforms MMP-1, MMP-2, MMP-3 and MMP-9. ${ }^{12-14}$ To separately assess the effect of these MMP isoforms, collagen-containing surfaces were treated overnight with purified MMP-1, MMP-2 and MMP-9, alone or in 
A

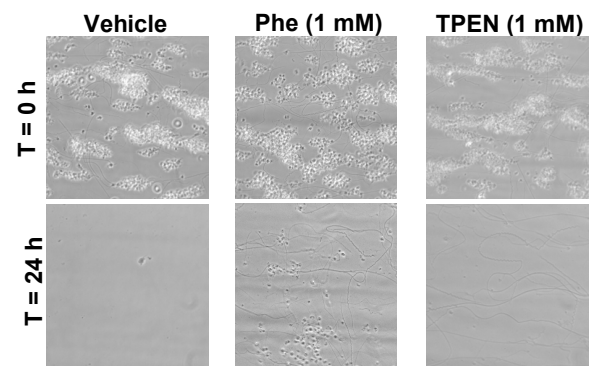

B

口Absorbance
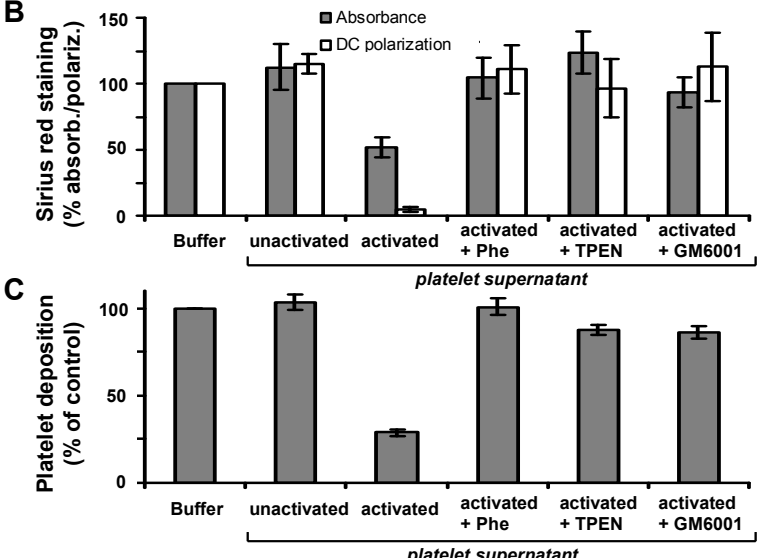

Figure 3. Treatment of immobilized collagen with platelet release product inhibits flowdependent platelet adhesion and thrombus formation. (A) PPACK-anticoagulated human blood was perfused over immobilized collagen at a shear rate of $1000 \mathrm{~s}^{-1}$ for 4 min. Thrombi formed on the collagen-coated coverslip were incubated overnight with HEPES buffer pH $7.45\left(37^{\circ} \mathrm{C}\right)$, to which phenanthrolin (Phe, $1 \mathrm{mM}$ ) or TPEN $(1 \mathrm{mM})$ was added, as indicated. Representative phase contrast images $(120 \times 120 \mu \mathrm{m})$ are shown of collagen surface at start $(0 \mathrm{~h})$ and after $24 \mathrm{~h}$ of incubation. Note the disappearance of collagen fibers, except after incubation with Phe or TPEN. $(B+C)$ Coverslips containing collagen spots were treated overnight with either HEPES buffer or platelet supernatant $(10 \mu \mathrm{L} / \mathrm{spot})$ at $37^{\circ} \mathrm{C}$. Supernatants were collected from non-activated or convulxin-activated platelets. The MMP inhibitors, phenanthrolin (Phe, $1 \mathrm{mM})$, TPEN (1 mM) or GM6001 $(25 \mu \mathrm{M})$ were added, as indicated. (B) Surface area coverage of collagen after overnight treatment, as detected from sirius red absorbance and double-crossed polarization measurement. Data are relative to buffer. (C) Platelet deposition after perfusion of PPACK-anticoagulated human blood (4 min at $\left.1000 \mathrm{~s}^{-1}\right)$ over treated coverslips. Data are from 4 independent experiments (mean \pm SEM).

combinations. Prior to use, the MMPs were activated with APMA, such as described elsewhere. ${ }^{24}$ Treatment of fibrillar collagen with the collagenase MMP-1 $(20 \mu \mathrm{g} / \mathrm{mL})$ resulted in substantial degradation $(>80 \%)$, as deduced from sirius red absorbance and double-crossed polarization measurements (Fig. 4A). Treatment with even a higher concentration of one of the gelatinases MMP-2 or MMP-9 $(50 \mu \mathrm{g} / \mathrm{mL})$ resulted in partial degradation, but combined treatment was as effective as MMP-1 alone. These results with MMP-1 and MMP-2 are in line with the literature, indicating a role for both isoforms in the initial cleavage of type I and III collagen fibers. ${ }^{2,17}$ However, the partial degradation of fibrillar type I collagen by purified MMP-9 was unexpected, as this gelatinase is 
considered to process collagen only after initial cleavage of the collagen by a collagenase. $^{2}$

In order to determine the thrombogenicity of the MMP-treated surfaces, these were also used for whole-blood perfusion studies. Consistent with the reduced sirius red staining, platelet adhesion was greatly diminished after treatment of the collagen with MMP-1 (Fig. 4B). Surfaces treated with MMP-2 or MMP-9 also showed decreased platelet adhesion, but at a slightly lesser extent than after treatment with MMP-1. Combined treatment with MMP-1, -2 and -9 completely abolished platelet adhesion and thrombus formation (Fig. 4C). Together these results indicate that collagenase- and gelatinase-mediated cleavage of immobilized collagen fibers strongly diminishes the thrombogenicity of the collagen surface.

Further experiments were carried out with mouse plasma, as this allowed us to examine the relative importance of individual MMP isoforms in plasma. Coverslips with collagen fibers were incubated with plasma from mice deficient in MMP-2, MMP-3 or MMP-9, and the surfaces were then tested for platelet adhesion. Note that the effect of MMP-1 could not be evaluated, as this isoform is not expressed in mice. Before use, the

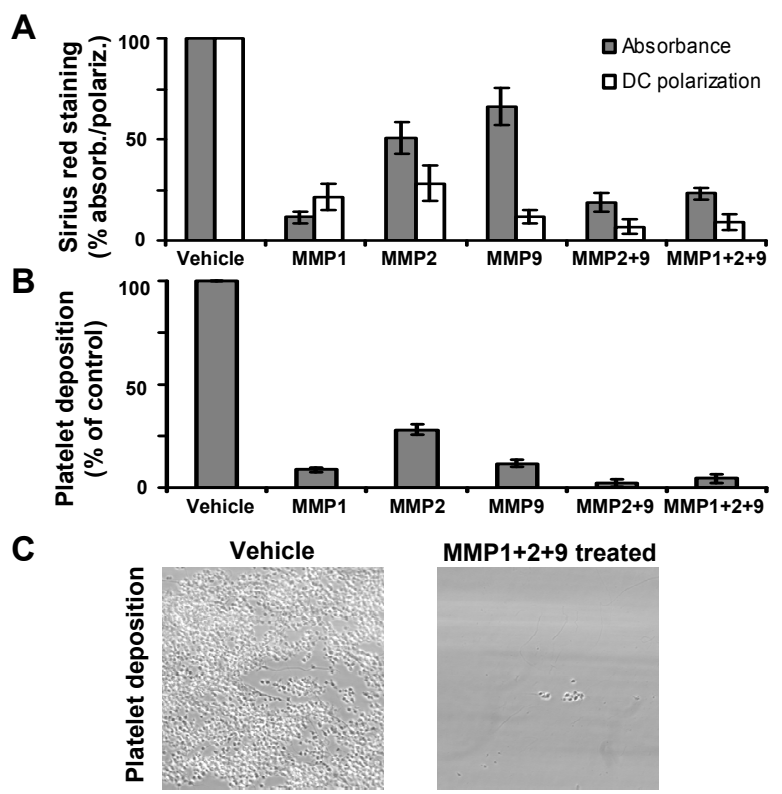

Figure 4. Treatment of immobilized collagen with purified MMP isoforms reduces flowdependent platelet adhesion and thrombus formation. Coverslips with collagen spots were treated overnight with vehicle buffer (1 spot) or with one or more purified MMPs (1 spot) at $37^{\circ} \mathrm{C}$. The MMP preparations were pre-activated with APMA, and applied at a concentration of $20 \mu \mathrm{g} / \mathrm{mL}$ (MMP-1) or $50 \mu \mathrm{g} / \mathrm{mL}$ (MMP-2, MMP-9). (A) Surface area coverage of collagen on coverslip, as detected by sirius red absorbance and double-crossed polarization measurement. Data are relative to the vehicle control. $(B+C)$ Effect of collagen treatment with purified MMPs on platelet deposition after perfusion of PPACK-anticoagulated human blood for $4 \mathrm{~min}$ at $1000 \mathrm{~s}^{-1}$. (B) Platelet surface area coverage after the perfusion. (C) Representative phase contrast images $(150 \times 150 \mu \mathrm{m})$ after the perfusion. Data are from 4 independent experiments (mean \pm SEM). 


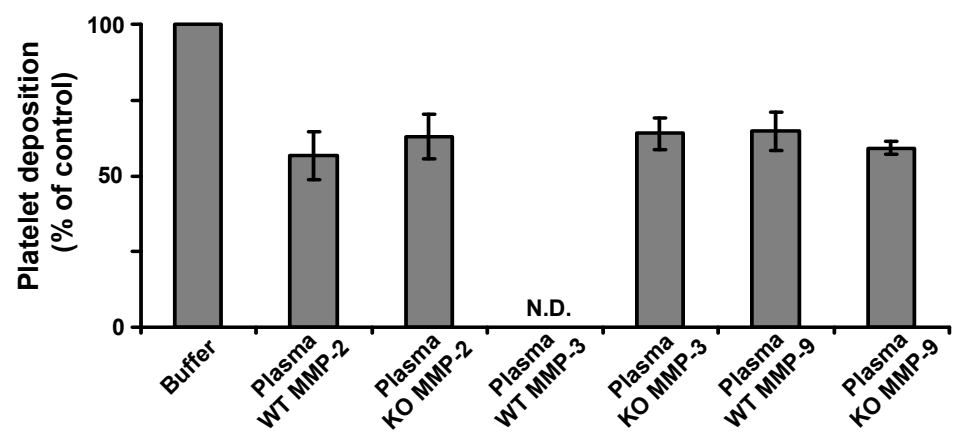

Figure 5. Treatment of immobilized collagen with plasma from MMP-deficient mice reduces flow-dependent platelet adhesion and thrombus formation. Coverslips with collagen spots were treated overnight at $37^{\circ} \mathrm{C}$ with plasma from mice deficient in MMP-2, MMP-3 or MMP-9 or with control plasma from corresponding wildtype mice $(10 \mu \mathrm{L} / \mathrm{spot})$. The plasmas were recalcified with hirudin and activated with $\mathrm{ZnCl}_{2}$. PPACK-anticoagulated whole blood was then perfused over the coverslips for $4 \mathrm{~min}$ at $1000 \mathrm{~s}^{-1}$. Bar graph shows platelet deposition per spot after perfusion. Data are from 4 independent experiments (mean \pm SEM). N.D. = not determined.

plasmas were recalcified in the presence of hirudin and $\mathrm{ZnCl}_{2}$. Sirius red staining of the collagen surfaces indicated partial degradation by all plasmas, which was antagonized by the presence of $1 \mathrm{mM}$ phenanthrolin (not shown). Flow-dependent platelet adhesion and thrombus formation were also only partial decreased on collagen surface treated with mouse plasmas. Interestingly, there was no difference between the wildtype and various MMP-deficient plasmas samples (Fig. 5). This suggested that another protease than MMP-2, -3 or -9 is responsible for the majority of collagen degradation by murine plasma.

\section{Opposite effects of MMP-2 and MMP-9 on collagen-dependent thrombus formation}

In addition to degrading collagen, platelet-produced MMP isoforms can also affect the platelet activation process itself. ${ }^{33}$ Initial experiments showed that incubation of wildtype mouse blood with GM6001 $(25 \mu \mathrm{M})$ markedly inhibited platelet adhesion and thrombus formation under flow (not shown). This result however may be misleading, since GM6001 also inhibits the related metalloproteinase disintegrins (ADAMs). By using blood from deficient mice, it was then investigated how the absence of MMP-2, -3 or -9 altered the thrombus formation on native collagen fibers. When using blood from MMP-2 deficient mice, thrombi on collagen tended to be smaller in size than wildtype thrombi (Fig. 6A). Platelet activation was monitored by post-staining the thrombi on collagen with AF647-annexin A5, probing phosphatidylserine exposure, and with FITC-anti-P-selectin $\mathrm{mAb}$, detecting $\mathrm{P}$-selectin expression. ${ }^{34}$ Both activation markers were significantly reduced in thrombi formed by MMP-2 deficient blood in comparison to wildtype blood (Fig. 6B, C).

When similar flow experiments were performed with blood from MMP-3 deficient mice, no significant effects of the knockout were found on aggregate formation and exposure of phosphatidylserine and P-selectin (Fig. 7). In contrast, thrombi formed by 

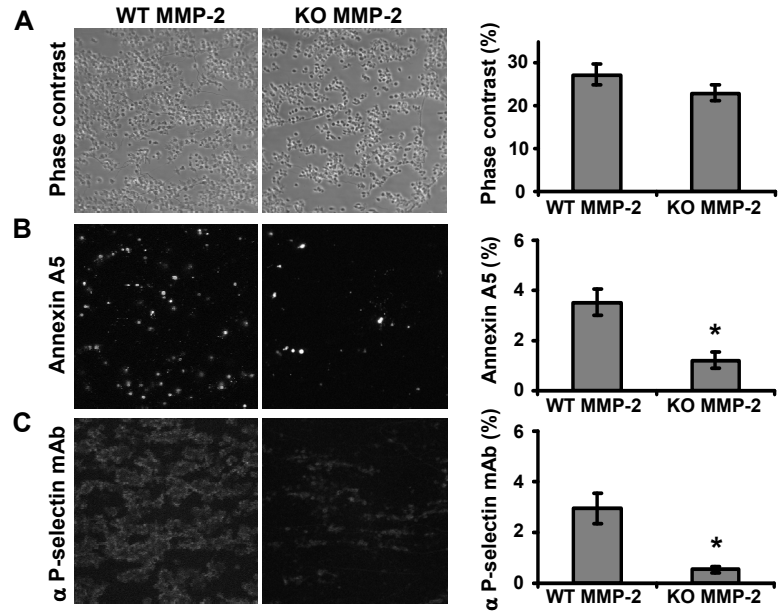

Figure 6. Murine MMP-2 stimulates collagen-dependent platelet activation and thrombus formation under flow. Blood from MMP-2 deficient mice (KO MMP-2) or matched wildtype mice (WT MMP-2) was flowed over collagen-coated coverslips at a shear rate of $1000 \mathrm{~s}^{-1}$ for $4 \mathrm{~min}$. Citrate-anticoagulated blood was recalcified in the presence of $40 \mu \mathrm{M}$ PPACK. Thrombi on coverslip were stained for exposure of phosphatidylserine and P-selectin by post-perfusion with AF647-annexin A5 and FITC-labeled anti-P-selectin mAb, respectively. (A-C) Shown are representative phase contrast $(120 \times 120 \mu \mathrm{m})$ and fluorescence images $(180 \times 180 \mu \mathrm{m})$. Bar graphs represent analysis of surface area coverage with (stained) platelets. Data are mean $\pm \operatorname{SEM}(n=4)$; ${ }^{*} \mathrm{P}<0.05$.

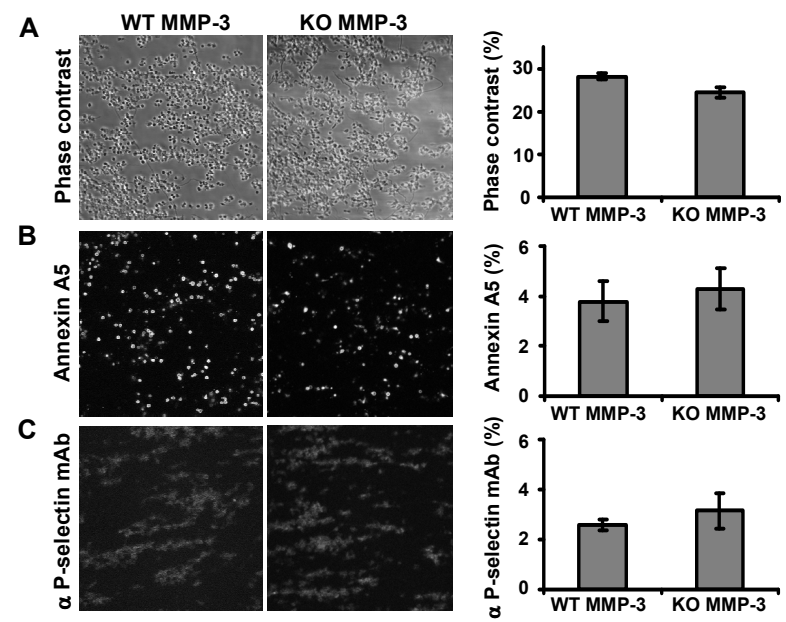

Figure 7. Murine MMP-3 does not affect collagen-dependent platelet activation and thrombus formation under flow. Blood from MMP-3 deficient mice (KO MMP-3) or matched wildtype mice (WT MMP-3) was flowed over collagen-coated coverslips at a shear rate of $1000 \mathrm{~s}^{-1}$ for $4 \mathrm{~min}$. Citrate-anticoagulated blood was recalcified in the presence of $40 \mu \mathrm{M}$ PPACK. Thrombi on coverslip were stained for exposure of phosphatidylserine and P-selectin by post-perfusion with AF647-annexin A5 and FITC-labeled anti-P-selectin mAb, respectively. (A-C) Shown are representative phase contrast $(120 \times 120 \mu \mathrm{m})$ and fluorescence images $(180 \times 180 \mu \mathrm{m})$ after staining. Bar graphs represent analysis of surface area coverage with (stained) platelets. Data are mean \pm $\operatorname{SEM}(n=4) ;{ }^{*} P<0.05$. 

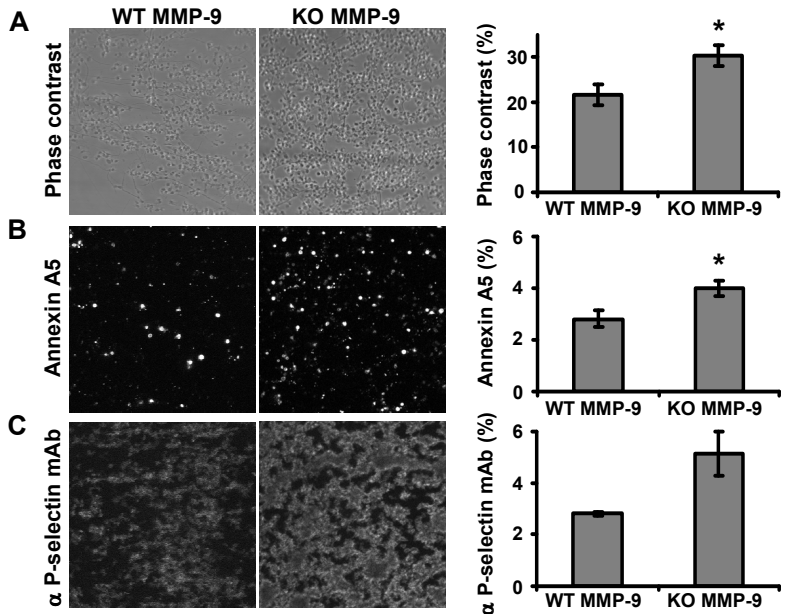

Figure 8. Murine MMP-9 suppresses collagen-dependent platelet activation and thrombus formation under flow. Blood from MMP-9 deficient mice (KO MMP-9) or matched wildtype mice (WT MMP-9) was flowed over collagen-coated coverslips at a shear rate of $1000 \mathrm{~s}^{-1}$ for $4 \mathrm{~min}$. Citrate-anticoagulated blood was recalcified in the presence of $40 \mu \mathrm{M}$ PPACK. Thrombi on coverslip were stained for exposure of phosphatidylserine and P-selectin by post-perfusion with AF647-annexin A5 and FITC-labeled anti-P-selectin mAb, respectively. (A-C) Shown are representative phase contrast $(120 \times 120 \mu \mathrm{m})$ and fluorescence images $(180 \times 180 \mu \mathrm{m})$ after staining. Bar graphs represent analysis of surface area coverage with (stained) platelets. Data are mean \pm $\operatorname{SEM}(n=4) ;{ }^{*} P<0.05$

MMP-9 deficient blood were significantly larger, and had higher levels of phosphatidylserine and P-selectin exposure than corresponding wildtype thrombi (Fig. 8). Thus, in mice, the gelatinases MMP-2 and MMP-9 appeared to have opposite effects on collagen-dependent platelet activation and thrombus formation.

\section{Discussion}

The present results indicate that plasma- and platelet-derived MMP isoforms play a dual role in collagen-dependent thrombus formation. They mediate acute effects on platelet activation and aggregation and, on a longer term, they also modulate the thrombogenic role of collagen.

Consistent with a proposed role of the collagenase MMP-1 and the gelatinase MMP2 in initial cleaving of the triple helical chains of collagen types I and $\mathrm{II}^{2}{ }^{2}$ we found that treatment of collagen fibers with purified MMP-1 or MMP-2 strongly reduced their thrombogenic effect. The gelatinase MMP-9 is considered to process collagen types I and III only after initial cleavage by collagenases. ${ }^{2}$ However, the present results also point to a role of this isoform in initial collagen degradation. This is in agreement with a recent report, indicating that MMP-9 can cleave fibrillar collagens in their native form. ${ }^{35}$

Current pharmacological MMP inhibitors show a low level of selectivity towards individual members of the MMP family, which limits their use. Therefore, mice deficient in MMP-2, MMP-3 or MMP-9 were studied to provide information on the roles of the individual isoforms. A first observation was that the collagen-degrading effect of wildtype 
murine plasma was considerably lower than that of human plasma. This species difference is possibly due to low MMP levels in mouse plasma or, alternatively, to the presence of relatively large amounts of MMP inhibitors, such as TIMP isoforms and $\alpha 2-$ macroglobulin. The literature so far does not provide information on the levels of (activated) MMP isoforms and inhibitors in mouse plasma. When comparing the collagen-degrading effect of plasmas from mice deficient in MMP-2, MMP-3 or MMP-9, no significant differences were detected. This may imply redundancy in function of these three isoforms, although it is also possible that another collagenase-type of MMP is responsible for the majority of collagen degradation. Since the MMP-1 isoform is not expressed in mice, and MMP-13 is thought to provide the necessary collagenolytic activity, ${ }^{36}$ it may be this isoform that largely fulfils this role in mouse plasma.

Experiments in which immobilized type I collagen fibers were treated with human plasma or with supernatant from activated human platelets showed that the MMPs derived from plasma as well as from platelets were capable of cleaving the triple helical structure of this collagen. After treatment with the supernatant of activated platelets, the thrombogenic function of the collagen was severely impaired, as it mediated adhesion of only few platelets under shear conditions, and thrombi were no longer formed. The adhesion and aggregation of platelets at a shear condition of $1000 \mathrm{~s}^{-1}$ is known to rely on the interaction of collagen-bound von Willebrand factor with glycoprotein Ib-V-IX complex and integrin $\alpha \mathrm{llb} \beta 3$. Furthermore ligandation of the collagen receptors glycoprotein $\mathrm{VI}$ and integrin $\alpha 2 \beta 1$ is important for platelet-collagen interaction. ${ }^{22,34,37}$ Which of the ligand interaction sites on collagen is affected by MMPs was not investigated, but this is an important question for further study.

Experiments designed to determine the contribution of MMP isoforms to flowdependent thrombus formation on intact collagen fibers indicated a reduced platelet deposition and activation with blood from mice lacking MMP-2, and opposite results with blood from mice lacking MMP-9. The studies did not reveal whether the plasma- or platelet-derived MMPs pools were responsible for these changes, but they do indicate that - in mouse - the various MMP isoforms have a balancing effect on the thrombusforming process. Our findings are further in agreement with several reports where pharmacological MMP inhibitors and recombinant MMP proteins were used. In these in vitro studies, a stimulating role of MMP-2 and an inhibiting role of MMP-9 on platelet activation was described. ${ }^{11,13,19,38}$ In other papers it was reported that MMP-2 facilitates the modification of glycoprotein Ib-V-IX and $\alpha \mathrm{llb} \beta 3$, thereby enhancing platelet adhesion and aggregation. ${ }^{18,39}$ Since we observed that glycoprotein VI-induced phosphatidylserine exposure is differentially affected by MMP-2 and MMP-9, it is also possible that these MMPs target this collagen receptor. In line with this hypothesis is a study, where a role for MMPs in causing platelet receptor ectodomain shedding has been suggested. ${ }^{40}$ However, more recent evidence shows that this shedding is mediated by the protease ADAM-10. ${ }^{41}$ While MMPs not seem to be responsible for glycoprotein VI ectodomain shedding, it is still possible that they modify this glycoprotein. Alternatively, the MMPs might bind to collagen (or collagen-adherent von Willebrand factor) and, interfere with the collagen-receptor interactions. These possibilities require further investigation. 


\section{Acknowledgment}

We acknowledge Dr. S. Heeneman for providing human atherosclerotic plaques. This work was supported by grants from the Netherlands Organization for Scientific Research (11-400-076 and 902-16-276).

\section{References}

1. Sternlicht MD, Werb Z. How matrix metalloproteinases regulate cell behavior. Annu Rev Cell Dev Biol. 2001;17:463-516.

2. Visse $R$, Nagase $H$. Matrix metalloproteinases and tissue inhibitors of metalloproteinases: structure, function, and biochemistry. Circ Res. 2003;92:827-839.

3. Shekhonin BV, Domogatsky SP, Idelson GL, Koteliansky VE, Rukosuev VS. Relative distribution of fibronectin and type I, III, IV, V collagens in normal and atherosclerotic intima of human arteries. Atherosclerosis. 1987;67:9-16.

4. Saelman EU, Nieuwenhuis HK, Hese KM, de Groot PG, Heijnen HF, Sage EH, Williams S, McKeown L, Gralnick HR, Sixma JJ. Platelet adhesion to collagen types I through VIII under conditions of stasis and flow is mediated by GPla/lla ( $\alpha 2 \beta 1$-integrin). Blood. 1994;83:12441250.

5. Galis ZS, Sukhova GK, Lark MW, Libby P. Increased expression of matrix metalloproteinases and matrix degrading activity in vulnerable regions of human atherosclerotic plaques. J Clin Invest. 1994;94:2493-2503.

6. Freije JM, Diez-Itza I, Balbin M, Sanchez LM, Blasco R, Tolivia J, Lopez-Otin C. Molecular cloning and expression of collagenase-3, a novel human matrix metalloproteinase produced by breast carcinomas. J Biol Chem. 1994;269:16766-16773.

7. Hasty KA, Jeffrey JJ, Hibbs MS, Welgus HG. The collagen substrate specificity of human neutrophil collagenase. J Biol Chem. 1987;262:10048-10052.

8. Welgus HG, Jeffrey JJ, Eisen AZ. The collagen substrate specificity of human skin fibroblast collagenase. J Biol Chem. 1981;256:9511-9515.

9. Aimes RT, Quigley JP. Matrix metalloproteinase-2 is an interstitial collagenase. Inhibitor-free enzyme catalyzes the cleavage of collagen fibrils and soluble native type I collagen generating the specific 3/4- and 1/4-length fragments. J Biol Chem. 1995;270:5872-5876.

10. Newby AC. Dual role of matrix metalloproteinases (matrixins) in intimal thickening and atherosclerotic plaque rupture. Physiol Rev. 2005;85:1-31

11. Sawicki G, Salas E, Murat J, Miszta-Lane H, Radomski MW. Release of gelatinase A during platelet activation mediates aggregation. Nature. 1997;386:616-619.

12. Sawicki G, Sanders EJ, Salas E, Wozniak M, Rodrigo J, Radomski MW. Localization and translocation of MMP-2 during aggregation of human platelets. Thromb Haemost. 1998;80:836-839.

13. Fernandez-Patron C, Martinez-Cuesta MA, Salas E, Sawicki G, Wozniak M, Radomski MW Davidge ST. Differential regulation of platelet aggregation by matrix metalloproteinases- 9 and -2. Thromb Haemost. 1999;82:1730-1735

14. Galt SW, Lindemann S, Allen L, Medd DJ, Falk JM, Mclntyre TM, Prescott SM, Kraiss LW Zimmerman GA, Weyrich AS. Outside-in signals delivered by matrix metalloproteinase-1 regulate platelet function. Circ Res. 2002;90:1093-1099.

15. Kazes I, Elalamy I, Sraer JD, Hatmi M, Nguyen G. Platelet release of trimolecular complex components MT1-MMP/TIMP2/MMP2: involvement in MMP2 activation and platelet aggregation. Blood. 2000;96:3064-3069.

16. Lijnen HR. Plasmin and matrix metalloproteinases in vascular remodeling. Thromb Haemost. 2001;86:324-333

17. Jones CB, Sane DC, Herrington DM. Matrix metalloproteinases. A review of their structure and role in acute coronary syndrome. Cardiovasc Res. 2003;59:812-823. 
18. Choi WS, Jeon $\mathrm{OH}$, Kim HH, Kim DS. MMP-2 regulates human platelet activation by interacting with integrin $\alpha$ llb $\beta 3$. J Thromb Haemost. 2008;6:517-523.

19. Falcinelli E, Guglielmini G, Torti M, Gresele P. Intraplatelet signaling mechanisms of the priming effect of matrix metalloproteinase-2 on platelet aggregation. $\mathrm{J}$ Thromb Haemost. 2005;3:2526-2535.

20. Siljander PR, Farndale RW, Feijge MA, Comfurius P, Kos S, Bevers EM, Heemskerk JW. Platelet adhesion enhances the glycoprotein VI-dependent procoagulant response: Involvement of p38 MAP kinase and calpain. Arterioscler Thromb Vasc Biol. 2001;21:618627.

21. Cosemans JM, Kuijpers MJ, Lecut C, Loubele ST, Heeneman S, Jandrot-Perrus M Heemskerk JW. Contribution of platelet glycoprotein VI to the thrombogenic effect of collagens in fibrous atherosclerotic lesions. Atherosclerosis. 2005;181:19-27.

22. Siljander PR, Munnix IC, Smethurst PA, Deckmyn H, Lindhout T, Ouwehand WH, Farndale RW, Heemskerk JW. Platelet receptor interplay regulates collagen-induced thrombus formation in flowing human blood. Blood. 2004;103:1333-1341.

23. Van der Meijden PE, Feijge MA, Giesen PL, Huijberts M, van Raak LP, Heemskerk JW. Platelet $P 2 Y_{12}$ receptors enhance signalling towards procoagulant activity and thrombin generation. A study with healthy subjects and patients at thrombotic risk. Thromb Haemost. 2005;93:1128-1136.

24. Stricklin GP, Jeffrey JJ, Roswit WT, Eisen AZ. Human skin fibroblast procollagenase: mechanisms of activation by organomercurials and trypsin. Biochemistry. 1983;22:61-68.

25. Gruner S, Prostredna M, Schulte V, Krieg T, Eckes B, Brakebusch C, Nieswandt B. Multiple integrin-ligand interactions synergize in shear-resistant platelet adhesion at sites of arterial injury in vivo. Blood. 2003;102:4021-4027.

26. Heemskerk JW, Willems GM, Rook MB, Sage SO. Ragged spiking of free calcium in ADPstimulated human platelets: regulation of puff-like calcium signals in vitro and ex vivo. $\mathrm{J}$ Physiol. 2001;535:625-635.

27. Van Zandvoort M, Engels W, Douma K, Beckers L, Oude Egbrink M, Daemen M, Slaaf DW Two-photon microscopy for imaging of the (atherosclerotic) vascular wall: a proof of concept study. J Vasc Res. 2004;41:54-63.

28. Junqueira LC, Bignolas G, Brentani RR. Picrosirius staining plus polarization microscopy, a specific method for collagen detection in tissue sections. Histochem J. 1979;11:447-455.

29. Heeneman S, Cleutjens JP, Faber BC, Creemers EE, van Suylen RJ, Lutgens E, Cleutjens $\mathrm{KB}$, Daemen MJ. The dynamic extracellular matrix: intervention strategies during heart failure and atherosclerosis. J Pathol. 2003;200:516-525.

30. Penz S, Reininger AJ, Brandl R, Goyal P, Rabie T, Bernlochner I, Rother E, Goetz C, Engelmann B, Smethurst PA, Ouwehand WH, Farndale R, Nieswandt B, Siess W. Human atheromatous plaques stimulate thrombus formation by activating platelet glycoprotein $\mathrm{VI}$. FASEB J. 2005;19:898-909.

31. Siljander P, Lassila R. Studies of adhesion-dependent platelet activation: distinct roles for different participating receptors can be dissociated by proteolysis of collagen. Arterioscler Thromb Vasc Biol. 1999;19:3033-3043.

32. Heemskerk JW, Kuijpers MJ, Munnix IC, Siljander PR. Platelet collagen receptors and coagulation. A characteristic platelet response as possible target for antithrombotic treatment. Trends Cardiovasc Med. 2005;15:86-92.

33. Santos-Martinez MJ, Medina C, Jurasz P, Radomski MW. Role of metalloproteinases in platelet function. Thromb Res. 2008;121:535-542.

34. Lecut C, Schoolmeester A, Kuijpers MJ, Broers JL, van Zandvoort MA, Vanhoorelbeke K, Deckmyn H, Jandrot-Perrus M, Heemskerk JW. Principal role of glycoprotein VI in $\alpha 2 \beta 1$ and $\alpha$ llb $\beta 3$ activation during collagen-induced thrombus formation. Arterioscler Thromb Vasc Biol. 2004;24:1727-1733.

35. Bigg HF, Rowan AD, Barker MD, Cawston TE. Activity of matrix metalloproteinase-9 against native collagen types I and III. FEBS J. 2007;274:1246-1255. 
36. Vincenti MP, Coon Cl, Mengshol JA, Yocum S, Mitchell P, Brinckerhoff CE. Cloning of the gene for interstitial collagenase-3 (matrix metalloproteinase-13) from rabbit synovial fibroblasts: differential expression with collagenase-1 (matrix metalloproteinase-1). Biochem J. 1998;331:341-346.

37. Kuijpers MJ, Schulte V, Bergmeier W, Lindhout $T$, Brakebusch C, Offermanns S, Fassler R, Heemskerk JW, Nieswandt B. Complementary roles of glycoprotein VI and $\alpha 2 \beta 1$ integrin in collagen-induced thrombus formation in flowing whole blood ex vivo. FASEB J. 2003;17:685687.

38. Sheu JR, Fong TH, Liu CM, Shen MY, Chen TL, Chang Y, Lu MS, Hsiao G. Expression of matrix metalloproteinase-9 in human platelets: regulation of platelet activation in in vitro and in vivo studies. Br J Pharmacol. 2004;143:193-201.

39. Radomski A, Stewart MW, Jurasz P, Radomski MW. Pharmacological characteristics of solidphase von Willebrand factor in human platelets. Br J Pharmacol. 2001;134:1013-1020.

40. Stephens G, Yan Y, Jandrot-Perrus M, Villeval JL, Clemetson KJ, Phillips DR. Platelet activation induces metalloproteinase-dependent GPVI cleavage to down-regulate platelet reactivity to collagen. Blood. 2005;105:186-191.

41. Gardiner EE, Karunakaran D, Shen Y, Arthur JF, Andrews RK, Berndt MC. Controlled shedding of platelet glycoprotein (GP)VI and GPIb-IX-V by ADAM family metalloproteinases. J Thromb Haemost. 2007;5:1530-1537. 



\section{Continuous signaling via $\mathrm{PI} 3 \mathrm{~K}$ isoforms $\beta$ and $\gamma$ is required for platelet ADP receptor function in dynamic thrombus stabilization}

Judith M.E.M. Cosemans, Imke C.A. Munnix, Reinhard Wetzker, Regine Heller,

Shaun P. Jackson and Johan W.M. Heemskerk

This research was originally published in Blood

Blood 2006; 108: 3045-3052

(C) the American Society of Hematology 


\section{Abstract}

Signaling from collagen and G-protein-coupled receptors leads to platelet adhesion and subsequent thrombus formation. Paracrine agonists such as ADP, thromboxane and Gas6 are required for platelet aggregate formation. We hypothesized that thrombi are intrinsically unstable structures and that their stabilization requires persistent paracrine activity and continuous signaling, maintaining integrin $\alpha$ llb $\beta 3$ activation. Here, we studied the disassembly of human and murine thrombi formed on collagen under high shear conditions. Platelet aggregates rapidly disintegrated: (1) in the absence of fibrinogencontaining plasma; (2) by blocking or inhibiting allb $\beta 3$; (3) by blocking $\mathrm{P}_{2} \mathrm{Y}_{12}$ receptors; (4) by suppression of phosphoinositide 3-kinase (PI3K) $\beta$. In murine blood, absence of $\mathrm{PI} 3 \mathrm{~K} \gamma$ led to formation of unstable thrombi, leading to dissociation of multiplatelet aggregates. In addition, blocking PI3K $\beta$ delayed initial thrombus formation, and reduced individual platelet-platelet contact. Similarly without flow, agonist-induced aggregation was reversed by late suppression of $\mathrm{P}_{2} \mathrm{Y}_{12}$ or $\mathrm{PI} 3 \mathrm{~K}$ isoforms, resulting in single platelets that had inactivated $\alpha$ llb $\beta 3$ and no longer bound fibrinogen. Together, the data indicate that continuous outside-in signaling via $\mathrm{P}_{2} \mathrm{Y}_{12}$ and both $\mathrm{PI} 3 \mathrm{~K} \beta$ and $\mathrm{PI} 3 \mathrm{~K} \gamma$ isoforms is required for perpetuated $\alpha$ llb $\beta 3$ activation and maintenance of a platelet aggregate. This novel concept of intrinsic, dynamic thrombus instability gives possibilities for the use of antiplatelet therapy.

\section{Introduction}

Platelet plug formation at sites of vascular injury is considered to consist of 3 phases: initiation, propagation and perpetuation. ${ }^{1,2}$ The initiation phase involves platelet adhesion to von Willebrand factor (VWF) and to collagen exposed in the vessel wall. In the propagation phase, activated platelets secrete mediators such as ADP, thromboxane $A_{2}$ $\left(\mathrm{TXA}_{2}\right)$ and Gas6, which activate other platelets to form aggregates. In the perpetuation phase, fibrin formation and less well understood postaggregation events are assumed to accomplish stabilization of the thrombus.

At arterial shear rates, the thrombotic process is initiated by the tethering of platelets via glycoprotein (GP) Ib-IX-V to VWF, bound to collagen. ${ }^{3}$ In human and murine platelets, two interacting collagen receptors, GPVI and integrin $\alpha 2 \beta 1$, mediate stable adhesion to collagen.$^{4-7}$ The signaling receptor GPVI triggers series of activation events, including integrin $\alpha$ llb $\beta 3$ activation (providing binding sites, for example, for fibrinogen) and $\mathrm{Ca}^{2+}$ mobilization and secretion, which all function to recruit other platelets. ${ }^{8,9}$

During the propagation phase of thrombus formation, released ADP and $T_{X A_{2}}$ in a paracrine way pursue the activation process, mediated by $P 2 Y_{1}, P 2 Y_{12}$ and TP $\alpha$ receptors. ${ }^{8,10,11}$ The Gq-coupled $\mathrm{P} 2 \mathrm{Y}_{1}$ and TP $\alpha$ receptors evoke $\mathrm{Ca}^{2+}$ mobilization and protein kinase $\mathrm{C}$ activity. The $\mathrm{P}_{2} \mathrm{Y}_{12}$ signaling pathway involves Gi-mediated inhibition of adenylyl cyclase, which lowers cyclic AMP and indirectly enhances $\mathrm{Ca}^{2+}$ signal generation. ${ }^{12-14} \mathrm{P}_{2} \mathrm{Y}_{12}$ signaling via $\mathrm{Gi}$ also leads to activation of the phosphoinositide 3kinase (PI3K) and protein kinase $B$ signaling pathways. However, it is still unclear how all these various components combine to mediate inside-out $\alpha$ llb $\beta 3$ signaling. ${ }^{15-17}$ Platelets 
express various PI3K isoforms, including the class la isoforms, $\mathrm{p} 110 \alpha$ and $\mathrm{p} 110 \beta$ $(\mathrm{PI} 3 \mathrm{~K} \beta)$, and the class $\mathrm{lb}$ isoform, $\mathrm{p} 110 \gamma\left(\mathrm{PI} 3 \mathrm{~K} \gamma\right.$; Jackson et $\left.\mathrm{al}{ }^{18}\right)$. The literature is also unclear whether $\mathrm{PI} 3 \mathrm{~K} \beta^{18}$ or $\mathrm{PI} 3 \mathrm{~K} \gamma^{19}$ regulates $\alpha \mathrm{llb} \beta 3$ activation and, thus platelet aggregation.

Recent studies using knock-out mouse models have pointed to the existence of 'late' mechanisms in the so-called 'stabilization phase' of thrombus formation. Several molecular components appear to trigger the formation of close platelet-platelet contacts and hence consolidate thrombi to stable, nonembolizing structures. These include the $\mathrm{P}_{2} \mathrm{Y}_{1}$ and $\mathrm{P} 2 \mathrm{Y}_{12}$ receptors, ${ }^{10,20}$ Gas6 and Gas6-receptors, ${ }^{21}$ ephrins and Eph kinases, ${ }^{22}$ CD40 ligand (CD4OL), ${ }^{23}$ and signaling lymphocytic activation molecule (SLAM) ${ }^{24}$ Mice deficient in 1 of these components exhibit an intriguing similarity in phenotype (i.e. all showing diminished thrombus formation and increased embolisation). In essence, these findings raise the possibility that thrombi are intrinsically unstable, and may require multiple postaggregation events to become stabilized. This implies that a common platelet signaling mechanism may convoy the transition from unstable to stable aggregates.

In this paper, we hypothesized that thrombi are highly dynamic structures, which require continuous paracrine activity and signaling, needed for persistent integrin activation to keep platelets together and prevent their embolization. In contrast to the current static (3-phase) model of thrombus formation, the present results point to a dynamic model of thrombus buildup and stabilization, operative in human and murine blood and involving 2 different PI3K isoforms.

\section{Methods}

\section{Materials}

MRS2179, indomethacin and wortmannin were from Sigma (St. Louis, MO). The P2Y 12 receptor antagonist AR-C69931MX was kindly provided by Astra-Zeneca (Charnwoord, UK). LY294002 was from Calbiochem (La Jolla, CA), aggrastat from Merck-SharpDohme (Haarlem, NL), iloprost (llomedine) from Schering (Berlin, D) and Oregon green 488 (OG)-fibrinogen from Molecular Probes (Eugene, OR). Isoform-selective PI3K inhibitors were a kind gift of Baker Heart Research Institute (Melbourne, Victoria, AUS): TGX221, selective for the $p 110 \beta$ isoform, AS252424, selective for $p 110 \gamma$, and IC87114, selective for PI3K $\delta$, synthesized as described. ${ }^{18,25}$ FITC-labeled mAb PAC1 was from Becton-Dickinson (San Jose, CA) and non-blocking Alexa fluor 568 (AF)-labeled mAb Xia.B2 directed against mouse and human GPIb was a kind gift from Emfret (Würzburg, D). Other reagents were from sources as described before. ${ }^{26}$

\section{Human blood and platelets}

Human blood was drawn from healthy volunteers after full informed consent. Blood was collected into citrate, acid citrate dextrose (ACD) or $40 \mu \mathrm{M}$ Phe-Pro-Arg chloromethyl 
ketone (PPACK), as required. ${ }^{7}$ Platelet-rich plasma (PRP), platelet-free plasma (PFP) and washed platelets were obtained as described. ${ }^{27}$

\section{Animal blood and platelets}

Animal experiments were approved by the local animal experimental committees. Mice deficient in $\mathrm{p} 110 \gamma(\mathrm{PI} 3 \mathrm{~K} \gamma$ ) and control, wildtype mice on 129sv genetic background were generated, as described. ${ }^{28}$ Mouse blood was collected in $40 \mu \mathrm{M}$ PPACK and $5 \mathrm{U} / \mathrm{mL}$ heparin. $^{26}$

\section{Thrombus formation under flow}

Flow experiments over collagen were performed using human blood collected in $40 \mu \mathrm{M}$ PPACK, or mouse blood collected in $40 \mu \mathrm{M}$ PPACK and $5 \mathrm{U} / \mathrm{mL}$ heparin. Coverslips were coated with fibrillar type I Horm collagen and blocked. Coverslips inserted into a transparent, parallel-plate perfusion chamber were subjected to fluorescence microscopy, as described. ${ }^{7}$ A Visitech digital imaging system (Visitech, Sunderland, United Kingdom) equipped with 2 intensified, charge-coupled device (CCD) cameras was used. The system was connected to an inverted microscope (Nikon Diaphot 200; Nikon, Tokyo, Japan). Blood was perfused through the flow chamber at shear rates of 150 to $1000 \mathrm{~s}^{-1}$ for usually 4 minutes. Secondary perfusion was performed with plasma or HEPES buffer $\mathrm{pH} 7.45$ for 10 minutes at the same shear rate. High-resolution phasecontrast and fluorescent images were recorded in parallel in real-time $(>10$ random microscopic fields with a 40x/1.3 NA oil objective). Where indicated, FITC-PAC1 (1:20) was added during secondary perfusion. Images were analyzed on surface area coverage and on distribution of areas of individual segmented features using Image Pro software, version 4.1 (Image Pro, Silver Spring, MD). ${ }^{7}$ Shear experiments under coagulant conditions were performed by infusion of $1 / 10$ volume $75 \mathrm{mM} \mathrm{CaCl} 2$ and $37.5 \mathrm{mM} \mathrm{MgCl}_{2}$ into the citrated blood during flow, basically as described elsewhere. ${ }^{29}$

\section{High-speed confocal laser scanning microscopy}

Using the same flow chamber, high-speed laser scanning microscopy was performed with blood containing anti-GPIb-labeled platelets to measure thrombus stability. A singlephoton, LSM Live5 line-scanning confocal system from Carl Zeiss (Jena, Germany) was used to collect in real-time three-dimensional overviews of thrombi at an excitation wavelength of $532 \mathrm{~nm}$ and emission wavelength of 550 to $615 \mathrm{~nm}$. Z-stacks of 8 slices $(160 \times 160 \times 19.7 \mu \mathrm{m})$ were collected at 150 full frames/sec. Images were analyzed with minimal processing using LSM 3D deconvolution software (Carl Zeiss, Jena, Germany).

\section{Flow cytometry}

Platelets were stimulated with indicated agonist, after which inhibitors were added. After 10 minutes, label was added and samples were fixed in PBS with $1 \%$ paraformaldehyde. 
Integrin $\alpha$ llb $\beta 3$ activation was detected from the binding of FITC-PAC1 antibody to the activated $\beta 3$ chain of $\alpha$ llb $\beta 3$, or using OG-labeled fibrinogen. ${ }^{21}$

\section{Platelet aggregation}

Platelet shape change and aggregation were measured by aggregometry (Chronolog, Havertown, PA) under constant stirring $\left(37^{\circ} \mathrm{C}\right)$. PPACK-anticoagulated PRP was adjusted to $250 \times 10^{9}$ platelets $/ L$.

\section{Statistics}

Data are means \pm SEM. Significance of differences was determined with the MannWhitney U-test or the independent samples T-test, as appropriate, using the statistical package for social sciences (SPSS 11.0, Chicago, IL). Size distribution of platelet aggregates was evaluated by $\chi^{2}$ analysis. ${ }^{7}$

\section{Results}

\section{Presence of fibrinogen and continuous platelet signaling is required to prevent disassembly of thrombi under flow}

High-shear perfusion of PPACK-anticoagulated blood (containing physiological millimolar concentrations of free $\mathrm{Ca}^{2+}$ and $\mathrm{Mg}^{2+}$ ) over VWF/collagen leads to rapid thrombus formation in a process that is similarly regulated for human and mouse platelets. ${ }^{4,8,18,26}$ With human thrombi that were formed via GPVI on a VWF/collagen surface at high shear rate $\left(1000 \mathrm{~s}^{-1}\right)$, we studied the factors contributing to thrombus disassembly by microscopic imaging. During secondary perfusion with plasma, platelet aggregates typically remained stable; only few platelets left the microscopic field (Figure 1Ai-ii and Video S1, which is available on the Blood website; see the Supplemental Videos link at the top of the online article.). However, secondary perfusion with fibrinogen-depleted plasma provoked marked instability. Aggregates completely disintegrated, leaving only a single platelet layer at the WWF/collagen surface (Figure 1Aiii). Measurement of the size distribution of the remaining features showed that large and small aggregates were almost completely dissolved (Figure 1B). Essentially, the same results were obtained in perfusion experiments at low-shear rate of $150 \mathrm{~s}^{-1}$ (not shown).

The role of ADP release and signaling was investigated by secondary perfusion with plasma containing the $\mathrm{P}_{2} \mathrm{Y}_{12}$ receptor antagonist AR-C69931MX. ${ }^{10,13}$ Application of this compound resulted in immediate disintegration of the thrombi, with a $50 \%$ reduction in aggregate size after 4 to 6 minutes (Figure 1Aiv). Quantitative analysis again indicated complete disappearance of large aggregates after 10 minutes (Figure 1B). Secondary perfusion with the $\alpha \mathrm{llb} \beta 3$ antagonist aggrastat also gave rapid, complete disaggregation (data not shown). Further, secondary perfusion with the PI3K inhibitors wortmannin (Figure 1Av) or LY294002 (not shown) had a strong but less complete effect, leaving only small aggregates adhered to the collagen. 
A

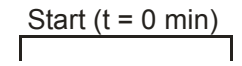

Secondary-perfusion ( $\mathrm{t}=10 \mathrm{~min})$


Figure 1. Fibrinogen binding and ADP receptor function are needed for thrombus stability under flow. (A) Human blood was flowed over VWF/collagen at $1000 \mathrm{~s}^{-1}$ for 4 minutes. Thrombi were formed on coverslips (i). These were then perfused again for 10 minutes with PPACKanticoagulated plasma containing indicated antagonists: vehicle (ii), fibrinogen-depleted plasma (iii); AR-C69931MX (30 $\mu \mathrm{M})$ (iv), wortmannin $(1 \mu \mathrm{M})(\mathrm{v})$, MRS2179 $(100 \mu \mathrm{M})(\mathrm{vi})$, AR-C69931MX plus MRS2179 (vii). Representative phase-contrast images $(180 \times 180 \mu \mathrm{m})$ are given after secondary perfusion $(n=3-5)$. (B) Histograms of features obtained by image analysis; estimated numbers of platelets per feature were 1 to 2,2 to 8,8 to 40,40 to 130 and more than 130 , as indicated. Secondary perfusion was with control plasma, fibrinogen-depleted plasma, or plasma plus AR-C69931MX ( $\chi^{2}$ analysis). Data are shown as mean \pm SEM $(n=3-5)$.

Secondary perfusion of the thrombi with plasma containing the $\mathrm{P}_{2} \mathrm{Y}_{1}$ receptor blocker, MRS2179, led to a delayed and partial disappearance of platelets, which was about 3-fold slower than observed with AR-C69931MX (Figure 1Avi). Simultaneous blocking of $P 2 Y_{12}$ and $P 2 Y_{1}$ did not further increase the AR-C69931MX effect (Figure 1Avii). Apparently, $\mathrm{P}_{2} \mathrm{Y}_{12}$ plays a more important role in stabilization of the thrombi than $\mathrm{P} 2 \mathrm{Y}_{1}$.

In a next set of experiments, aggregates on $\mathrm{VWF} /$ collagen were perfused again with HEPES buffer instead of plasma. This resulted in rapid dissolution, in which platelets detached from the aggregates and sometimes readhered to uncovered collagen surface (Figure 2Ai-ii; Video S2). Real-time confocal microscopic recording, using platelets stained with AF-labeled mAb against GPIb indicated that both height and volume of the thrombi rapidly decreased upon secondary perfusion with HEPES buffer but not plasma (not shown). In marked contrast, addition of ADP to the HEPES buffer prevented the disaggregation and resulted in compact and stable thrombi that remained resistant to 
A No coagulation


B Coagulation

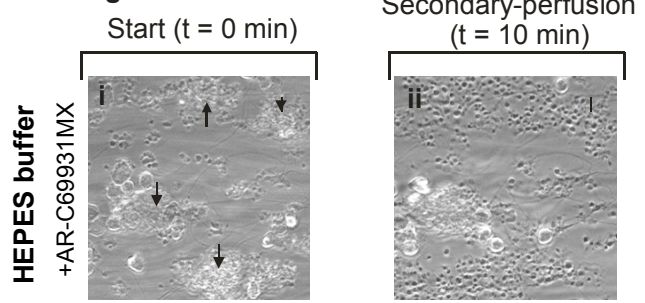

Figure 2. Key role of ADP receptor in thrombus stability in the absence and presence of coagulation. (A) Human PPACK-anticoagulated blood was flowed over VWF/collagen at $1000 \mathrm{~s}^{-1}$ for 4 minutes. Thrombi were formed on coverslips (i). These were perfused again for 10 minutes with HEPES buffer $\mathrm{pH} 7.45$ containing $2 \mathrm{mM} \mathrm{CaCl}_{2}$ and $2 \mathrm{mM} \mathrm{MgCl}_{2}$. Vehicle (ii) or ADP $(20 \mu \mathrm{M})$ (iii) was added during secondary perfusion. Representative phase-contrast images $(180 \times 180 \mu \mathrm{m})$ are given after 10 minutes. Strings of platelets connected by tethers (dotted line) detaching during 27 seconds of perfusion (iv-v). (B) Citrated blood was recalcified with $\mathrm{CaCl}_{2} / \mathrm{MgCl}_{2}$ before flow over $\mathrm{VWF} /$ collagen at $1000 \mathrm{~s}^{-1}$. Fibrin-containing thrombi on coverslips were perfused again for 10 minutes with the same HEPES buffer supplemented with AR-C69931MX (30 $\mu \mathrm{M})$ (Video S3). Representative phase contrast images are given of 1 field before and after secondary perfusion (iii). Note dissolution of all but one of the fibrin-containing thrombi. Arrow heads indicates fibrincontaining thrombi. Shown are representative images ( $n=3-5$ experiments).

disassembly as long as ADP was present (Figure 2Aiii). Without ADP, platelets typically detached as strings connected by membrane tethers (Figure 2Aiv,v). Together, these results indicate that the presence of plasma fibrinogen and continuous platelet signaling via $A D P, P 2 Y_{12}$ and $P I 3 K$ is required to prevent disintegration of the thrombi.

Since these experiments were performed in the absence of coagulation, we examined whether continuous ADP signaling also controls thrombus stability under conditions of thrombin and fibrin formation. In perfusion experiments where citrated blood was recalcified before reaching the flow chamber, mixed thrombi of platelets and fibrin were formed on the VWF/collagen surface (Figure 2Bi). Seconday perfusion with AR-C69931MX in buffer resulted in disaggregation of the fibrin-containing thrombi, except for those which contained large amounts of visible fibrin and had a central core with rigid appearance (Figure 2Bi-ii; Video S3). Again, this disaggregation was completely prevented by secondary perfusion with ADP (Video S4). These results demonstrate the importance of persistent ADP receptor function in thrombus stability under conditions of coagulation. 


\section{Continuous signaling via $P 2 Y_{12}$ and $P I 3 K$ isoforms is required for irreversible platelet aggregation and persistent $\alpha$ llb $\beta 3$ activation}

Aggregation of platelets in suspension in response to weak agonist like ADP or thrombinreceptor-activating peptide can be reversible. ${ }^{19}$ In particular, this is true at physiologic millimolar concentrations of free $\mathrm{Ca}^{2+}$ and $\mathrm{Mg}^{2+}$. However, the mechanism underlying this reversibility is still obscure. We examined the disaggregation of platelets at conditions mimicking those of the flow experiments (ie, in PPACK-anticoagulated plasma). Platelets were first activated with ADP, after which interventions were applied at the time of maximal aggregation (Figure 3A). Secondary platelet inhibition with cyclic AMP-elevating iloprost or $\alpha$ llb $\beta 3$ blockade with aggrastat caused rapid and complete disassembly of the aggregates, but cyclooxygenase blocking with indomethacin was only partly effective (Figure 3B). A similar rapid reversion of aggregation was seen, when ADP-degrading apyrase or the $\mathrm{P}_{2} \mathrm{Y}_{12}$ receptor antagonist AR-C69931MX was added. In contrast, the $\mathrm{P}_{2} \mathrm{Y}_{1}$ receptor blocker MRS2179 was only partly effective. Secondary addition of ARC69931MX regained as much as $98 \%$ of the original platelet concentration, illustrating
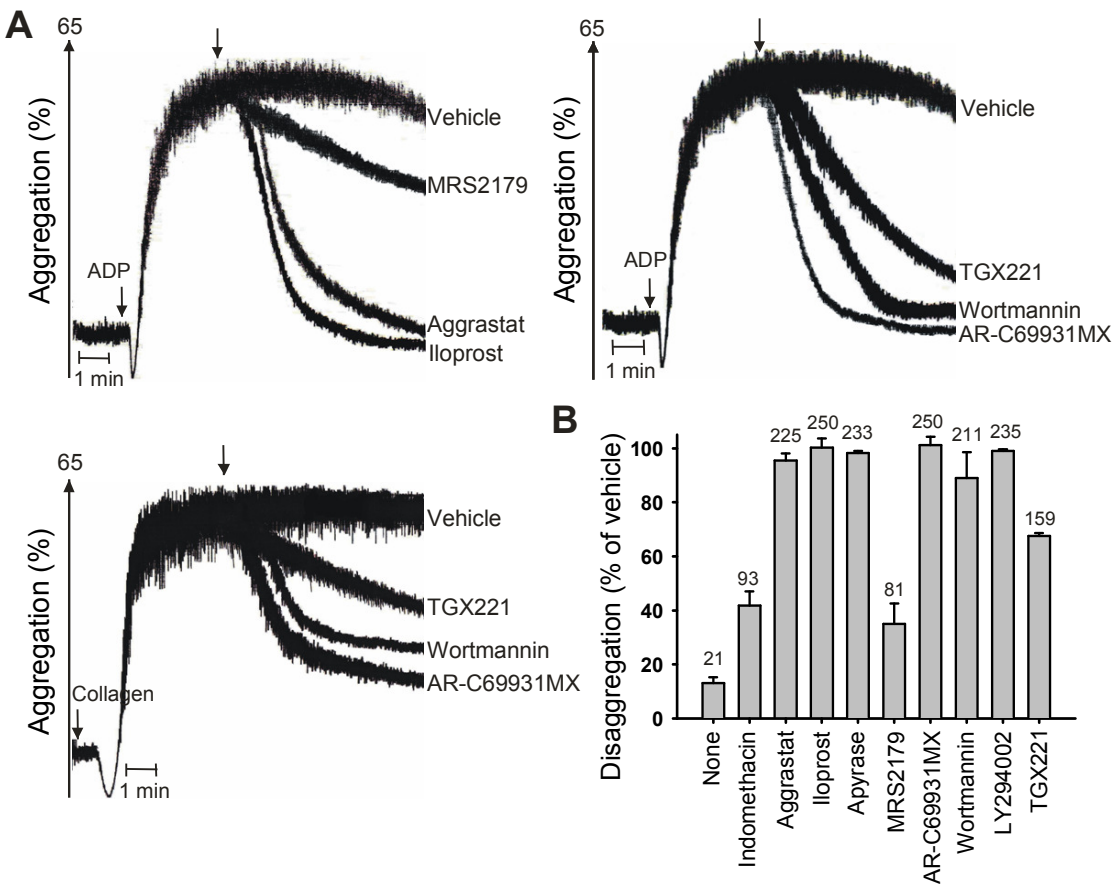

Figure 3. Continuous ADP-induced signaling via $P 2 Y_{12}$ and $P I 3 K \beta$ is needed for irreversible platelet aggregation. (A) Aggregation of PPACK-anticoagulated PRP was triggered while stirring with $20 \mu \mathrm{M}$ ADP or $1 \mu \mathrm{g} / \mathrm{mL}$ collagen $(\mathrm{n}=3-5)$. Inhibitors were added after 2 minutes, when aggregation was maximal: indomethacin $(55 \mu \mathrm{M})$, aggrastat $(2 \mu \mathrm{g} / \mathrm{mL})$, iloprost $(20 \mathrm{nM})$, apyrase $(0.2 \mathrm{U} / \mathrm{mL})$, MRS2179 $(100 \mu \mathrm{M})$, AR-C69931MX $(30 \mu \mathrm{M})$, wortmannin $(1 \mu \mathrm{M}), \mathrm{LY} 294002(50 \mu \mathrm{M})$ or TGX221 $(1 \mu \mathrm{M})$. Shown are representative aggregation traces. Arrows indicate addition of inhibitors. (B) Percentages of disaggregation with ADP after 12 minutes; numbers above bars indicate platelet counts $\left(\times 10^{9} / \mathrm{L}\right)$. Data are mean \pm SEM 
complete reversibility of the aggregation process. After 2 to 3 minutes, the disaggregation was partially complete, which is in a similar time interval as seen in the flow experiments. AC-C69931MX also reverted most of the platelet aggregation induced with collagen (72\%; Figure $3 A$ ) or thrombin-receptor peptide SFFLRN (63\%).

To identify the involvement of signaling pathways downstream of the $\mathrm{P}_{2} \mathrm{Y}_{12}$ receptor, the PI3K inhibitors wortmannin and LY294002 were added 2 minutes after ADP or collagen stimulation (Figure 3A, B). Either compound completely (ADP) or nearly completely (collagen or SFFLRN) reversed the aggregate formation. In case of ADP stimulation, secondary $\mathrm{PI} 3 \mathrm{~K}$ inhibition almost fully regained the original platelet count. Together, these results suggest that persistent ADP- or collagen-induced signaling via $\mathrm{PI} 3 \mathrm{~K}$ is required to keep platelet aggregates together. This was confirmed by triggering aggregation with the Gz-stimulating agonist epinephrine. A substantial part of the aggregation with epinephrine became reversible by secondary inhibition of $\mathrm{P}_{2} \mathrm{Y}_{12}$ or $\mathrm{PI} \mathrm{K}$ (data not shown). Typically, the specific PI3K $\beta$ inhibitor TGX221 (Figure 3A) had a marked but less complete disaggregating effect, when given after ADP, collagen, or SFFLRN.

There is earlier and new evidence that $\alpha \mathrm{llb} \beta 3$, once activated, can be switched off by late platelet inhibition. ${ }^{30,31}$ We used flow cytometry to determine how secondary $\mathrm{P}^{2} \mathrm{Y}_{12}$ and $\mathrm{PI} 3 \mathrm{~K}$ blockade affected the active conformation of $\alpha$ llb $\beta 3$ in human platelets that were stimulated with ADP or other agonists. Secondary addition of AR-C69931MX to ADP-stimulated platelets rapidly and nearly completely reversed binding of fluorescent PAC1 mAb, directed against the activated $\beta 3$ chain (Figure 4A). AR-C69931MX also abolished the binding of fluorescent fibrinogen to $\alpha$ llb $\beta 3$ on pre-activated platelets; apyrase and prostaglandin $E_{1}$ were similarly effective. PI3K contributed to this perpetuation of integrin activation, since secondary addition of wortmannin (Figure 4B) or

A



B

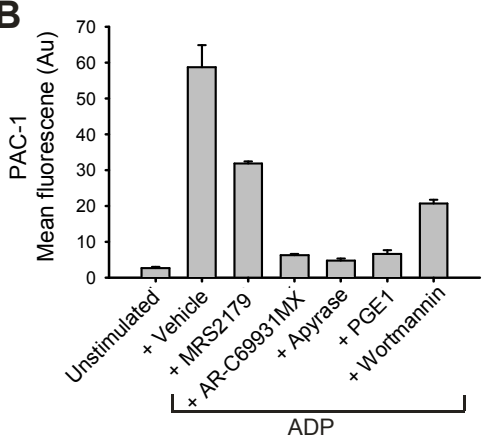

Figure 4. Continuous $P 2 Y_{12}$ signaling is required for persistent $\alpha$ llb $\beta 3$ activation. (A) Platelets in PPACK-anticoagulated PRP were activated with ADP (no stirring), and 2 minutes later inhibitors or antagonists were added (Figure 3 ). At indicated time points, activated $\alpha$ llb $\beta 3$ was detected with FITC-PAC1, and integrin function was analyzed with OG-labeled fibrinogen. Histograms are given of FITC-PAC1 and OG-fibrinogen fluorescence distribution before and after AR-C69931MX addition. (B) Mean FITC-PAC1 fluorescence intensities \pm SEM after incubation with inhibitor/antagonist $(n=3-4)$. 

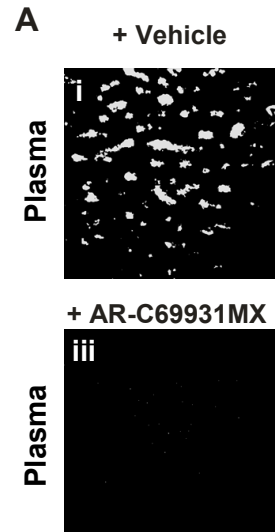

Control

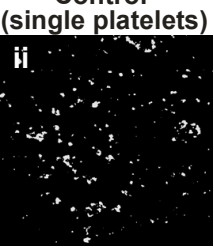

+ Wortmannin

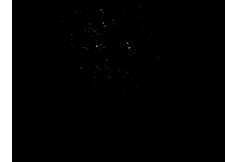

B

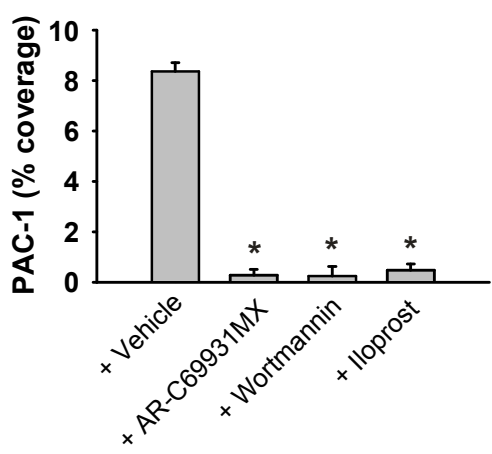

Figure 5. $\mathrm{P} 2 \mathrm{Y}_{12}$ and $\mathrm{PI} 3 \mathrm{~K}$ signaling is needed for persistent $\alpha \mathrm{llb} \beta 3$ activation under flow. (A) Human blood was flowed over VWF/collagen at $1000 \mathrm{~s}^{-1}$ for 4 minutes. Thrombi on coverslips were perfused again for 10 minutes with PPACK-anticoagulated plasma, and stained with FITC-PAC1 (1:20). Indicated antagonists were present during secondary perfusion: vehicle (i), AR-C69931MX $(30 \mu \mathrm{M})$ (ii-iii), wortmannin $(1 \mu \mathrm{M})$ (iv). As positive control, single platelets on coverslip were allowed to spread on collagen for 20 minutes before staining (ii). Shown are representative fluorescent images $(180 \times 180 \mu \mathrm{m})$ after secondary perfusion. (B) Mean surface area coverage of FITC-PAC1 fluorescence after secondary perfusion $(n=3)$; iloprost $(20 \mathrm{nM})$ was present as indicated. Mean \pm SEM; ${ }^{*} P<0.05$ vs vehicle.

TGX221 reversed the binding of PAC1 and fibrinogen. Together, this indicates that ADPstimulated allb $\beta 3$ activation requires continuous inside-out stimulation via $\mathrm{P}_{2} \mathrm{Y}_{12}$ and $\mathrm{PI} 3 \mathrm{~K}$ to remain in an active state.

Integrin allb $\beta 3$ activation was also investigated under flow conditions. Thrombi formed by perfusion of PPACK-anticoagulated blood were perfused again with plasma containing vehicle or antagonist. In the presence of vehicle, large PAC1-staining aggregates were seen (Figure 5Ai, 5B). In agreement with the flow cytometry results, secondary perfusion with AR-C69931MX (Figure 5Aiii), wortmannin (Figure 5Aiv) or iloprost (Figure 5B) led to almost complete reversion of the PAC1 staining of platelets on the coverslip. To demonstrate that the absence of staining was not due to limited detection sensitivity, single platelets on collagen were allowed to spread for 20 minutes, and thereafter were stained with fluorescent PAC1 mAb (Figure 5Aii). These results indicate that also under shear $\mathrm{P}_{2} \mathrm{Y}_{12}$ and $\mathrm{PI} 3 \mathrm{~K}$ are important for the persistent activation status of $\alpha$ llb $\beta 3$. These novel findings indicate that platelet aggregation and $\alpha$ llb $\beta 3$ activation are in fact intrinsically dynamic processes which require continuous (paracrine) signaling via especially $\mathrm{P}_{2} \mathrm{Y}_{12}$ and $\mathrm{PI} 3 \mathrm{~K}$ to become irreversible.

\section{Dual contribution of murine $p 110 \beta$ and $p 110 \gamma$ PI3K isoforms to thrombus stability on collagen under flow}

In mouse platelets, PI3K $\gamma(\mathrm{p} 110 \gamma)$ has been implicated in ADP-dependent thrombus formation in vivo. ${ }^{19}$ We studied the contribution of this PI3K isoform to thrombus stabilization using blood from PI $3 \mathrm{~K} \gamma-/$ - and wildtype control mice. Upon flow of blood over VWF/collagen, PI3K $\gamma$-deficient platelets were normally activated via GPVI (not shown). 


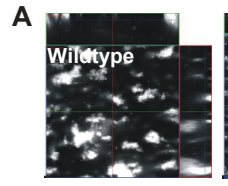

B
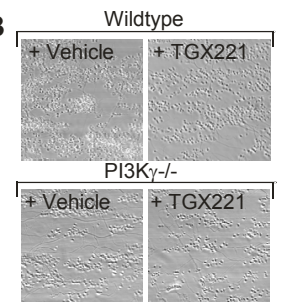



C
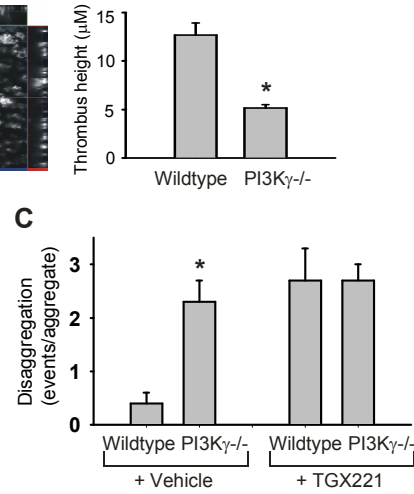

D

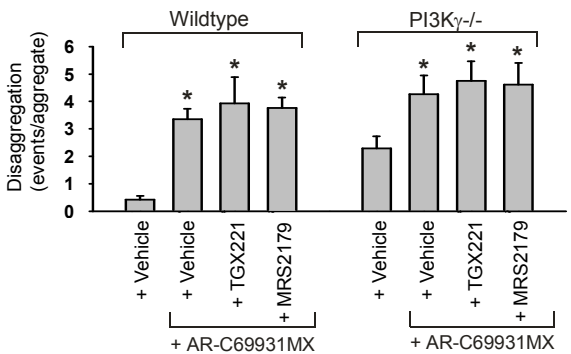

Figure 6. Complementary roles of PI3K $\beta$ and PI3Ky in stabilization of murine thrombi. (A) Formation of thrombi during flow over VWF/collagen at $1000 \mathrm{~s}-1$ for 4 minutes, recorded by highspeed fluorescence imaging. Blood from wildtype and $\mathrm{PI} 3 \mathrm{~K} \gamma-/-$ mice was labeled with non-blocking AF5-568-anti-GPIb mAb Xia B2. Left panel shows representative $x-y$ images, partitions represent $x-$ $z$ and $y-z$ cross-sections. Right panel shows height of thrombi after 4 minutes. (B-C) Murine blood containing vehicle or TGX221 $(1 \mu \mathrm{M})$ was flowed over VWF/collagen. (B) Representative phase contrast images $(120 \times 120 \mu \mathrm{M})$ after secondary perfusion. (C) Disaggregation events from murine thrombi during 4 minutes of flow. (D) Disaggregation events from murine thrombi in the presence of AR-C69931MX (30 $\mu \mathrm{M})$ with/without TGX221 $(1 \mu \mathrm{M})$ or MRS2179 $(100 \mu \mathrm{M})$. Indicated are numbers of embolizing events (single or clustered) platelets per aggregate. Data are means \pm SEM $(n=3-5$ experiments; ${ }^{*} \mathrm{P}<0.05$ vs vehicle).

However, they formed loose and very mobile thrombi, which often disintegrated shortly after the formation (Figure 6A; Video S5). This sharply contrasted to the quite stable thrombi that were formed with PI3K $\gamma+/+$ blood (Figure 6A; Video S6). As a consequence, the average thrombus height reached after 4 minutes of perfusion was $60 \%$ lower in the case of PI3K $\gamma-$ - blood (Figure $6 \mathrm{~A}$ ). Total thrombus volume per microscopic field was reduced similarly. While in wildtype blood platelets only incidentally left from the aggregates, the knock-out platelets detached at a much higher frequency (Figure 6B-C). These platelets typically disaggregated as strings connected by membrane tethers, similarly as seen upon buffer perfusion of human blood.

Using newly designed isoform-selective PI3K inhibitors, it has appeared that PI3K $\beta$ is involved in shear-induced platelet adhesion to VWF. ${ }^{18}$ Here, we used these inhibitors, applied at selective doses ${ }^{18}$, to study the contribution to thrombus stability of the isoforms, $\mathrm{PI} 3 \mathrm{~K} \beta$ or $\mathrm{p} 110 \beta$ (TGX221), PI3K $\gamma$ or p110 $(\mathrm{AS} 252424)$, and PI3K (IC87114). In murine thrombus formation, inhibition of PI3K $\beta$ with TGX221 caused detachment of platelets in case of wildtype blood, but did not further enhance the high detachment in 
PI3K $\gamma-/$ - blood (Figure 6C). Secondary perfusion with TGX221 resulted in nearly complete disintegration of aggregates of both $\mathrm{PI} 3 \mathrm{~K} \gamma+/+$ and $\mathrm{PI} 3 \mathrm{~K} \gamma-/-$ blood, whereas wildtype aggregates remained largely intact after secondary perfusion with vehicle. Together, this indicates that $\mathrm{PI} 3 \mathrm{~K} \beta$ and $\mathrm{PI} 3 \mathrm{~K} \gamma$ are both necessary for the formation of stable murine aggregates.

Yet, despite the similar number of disaggregation events of TGX221-treated wildtype blood and $\mathrm{PI} 3 \mathrm{~K} \gamma-/-$ blood, there were marked differences in the type of detachment. Whereas TGX221 provoked detachment of (strings of) single platelets from a thrombus, in PI3K $\gamma$-/- blood many multi-platelet complexes were separating. Addition of TGX221 to the $\mathrm{PI} 3 \mathrm{~K} \gamma$-/- blood greatly increased the time to initial thrombus formation, from 30 to 51 s. This suggests that $\mathrm{PI} 3 \mathrm{~K} \beta$ and $\mathrm{PI} 3 \mathrm{~K} \gamma$ have complementary but different roles in thrombus buildup and stability, in which PI3K $\beta$ functions to keep individual platelets together on the collagen surface, while $\mathrm{PI} 3 \mathrm{~K} \gamma$ is essential for maintaining thrombus integrity.

To determine the importance of $\mathrm{P}_{2} \mathrm{Y}_{12}$ activity, the stability of murine thrombi under flow was measured in the presence of AR-C69931MX. The blockage of $P 2 Y_{12}$ in $\mathrm{PI} 3 \mathrm{~K} \gamma+/+$ and also in $\mathrm{PI} 3 \mathrm{~K} \gamma-/-$ blood led to a significant increase in number of disaggregation events (Figure 6D). Combined blockage of P2Y 12 and PI3K $\beta$ (TGX221) did not further increase these disaggregation events in either wildtype or PI3K $\gamma$-deficient blood. Also, combined blockage of $\mathrm{P}_{2} \mathrm{Y}_{12}$ and $\mathrm{P} 2 \mathrm{Y}_{1}$ with MRS2179 did not further increase the number of disaggregating platelets (Figure 6D). Together, this suggests that the $\mathrm{P}_{2} \mathrm{Y}_{12}$ signaling pathway controls murine thrombus stability in part via $\mathrm{PI} 3 \mathrm{~K} \gamma$ and, in a compensatory way, via $\mathrm{PI} 3 \mathrm{~K} \beta$.

\section{Roles of human $p 110 \beta$ and $p 110 \gamma$ PI3K isoforms in thrombus stability on collagen under flow}

To study the function of the PI3K isoforms, human thrombi were formed on WWF/collagen under flow. When added to plasma after perfusion, either TGX221 or AS252424 greatly promoted the detachment of platelets (Figure 7A). In either case, strings of platelets continuously detached from the preformed aggregates, resulting in thrombus disintegration. Simultaneous application of both compounds to block both $\mathrm{PI} 3 \mathrm{~K} \beta$ and $\mathrm{PI} 3 \mathrm{~K} \gamma$ did not have an extra effect. Inhibition of PI3K $\delta$ with IC87114 was completely ineffective.

To determine whether the contribution of $\mathrm{PI} 3 \mathrm{~K} \beta$ and $\mathrm{PI} 3 \mathrm{~K} \gamma$ indeed involves $\mathrm{P}_{2} \mathrm{Y}_{12}$ receptor function, human thrombi were perfused again with human plasma supplemented with AR-C69931MX, alone or in combination with PI3K inhibitors. As shown in Figure 7B, additional inhibition of PI3K $\beta$ (TGX221) and/or PI3K $\gamma$ (AS252424) did not further increase the aggregate destabilizing effect of AR-C69931MX ( $P>0.87)$. Since $\mathrm{P}_{2} \mathrm{Y}_{1}$ receptor blockage with MRS2179 could partly reverse the ADP-induced aggregation in platelet suspensions (Figure 3A, 3B), we re-examined the effect of this blocker under flow. In second perfusion with plasma, MRS2179 led to a $156 \% \pm 32 \%$ increase in disaggregation events (ie, about one-third of the effect seen with ARC69931MX). Importantly, MRS2179 was unable to further enlarge the effect of P2Y 12 
A

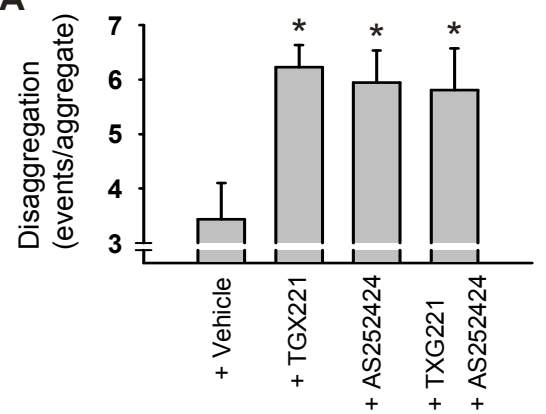

B

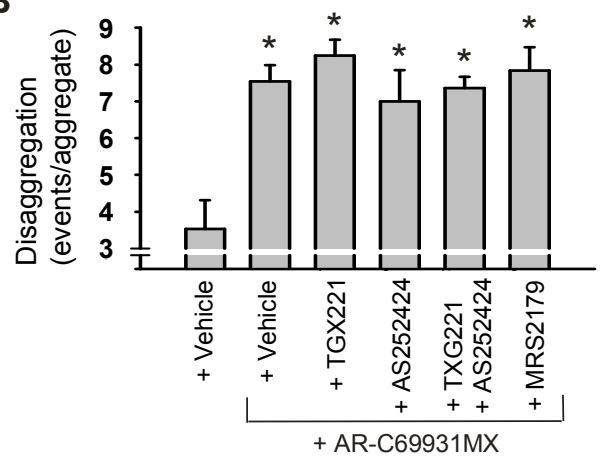

Figure 7. Roles of $\mathrm{P}_{2} \mathrm{Y}_{12}, \mathrm{PI} 3 \mathrm{~K} \beta$ and $\mathrm{PI} 3 \mathrm{~K} \gamma$ in stabilization of human thrombi. Human blood was flowed over VWF/collagen at $1000 \mathrm{~s}-1$ for 4 minutes. Disaggregation events were measured from thrombi during 10 minutes of secondary perfusion with plasma containing indicated inhibitors. (A) Effect of PI3K inhibitors TGX221 $(1 \mu \mathrm{M})$ and AS252424 (1 $\mu \mathrm{M})$. (B) Effect of P2Y12 inhibitor AR-C69931MX $(30 \mu \mathrm{M})$ alone or in combination with TGX221 $(1 \mu \mathrm{M})$, AS252424 $(1 \mu \mathrm{M})$, or MRS2179 $(100 \mu M)$. Data are means \pm SEM $\left(n=4\right.$ experiments, ${ }^{*} P<0.05$ vs vehicle $)$.

blockage with AR-C69931MX (Figure 7B). On the other hand, MRS2179 increased the combined effect of $\mathrm{PI} 3 \mathrm{~K} \beta$ and $\mathrm{PI} 3 \mathrm{~K} \gamma$ inhibition on disaggregation events up to $158 \% \pm$ $26 \%(n=4, P=0.05)$. Similar results were obtained with blood from wildtype and PI3K $\gamma$ I- mice (data not shown). These results strongly suggest that the PI3K isoforms operate via a different pathway than $\mathrm{P}_{2} \mathrm{Y}_{1}$ receptors, but via the same pathway as used by $\mathrm{P}_{2} \mathrm{Y}_{12}$ receptors. Together with the earlier results, this indicates that the PI3K isoforms play a major role in thrombus stabilization mostly or exclusively downstream of $\mathrm{P} 2 \mathrm{Y}_{12}$.

\section{Discussion}

The present results indicate that, at physiological, millimolar concentrations of $\mathrm{Ca}^{2+}$ and $\mathrm{Mg}^{2+}$, continuous paracrine release of ADP and persistent signaling via PI3K is required to prevent dissociation of thrombi formed on VWF/collagen. This leads to the novel insight that thrombi are intrinsically dynamic structures, which is in contrast to the hitherto 'static' model of thrombus initiation, propagation, and consolidation. Accordingly, platelet aggregation appears to be a reversible process, which can be reverted by suppressing paracrine processes, absence of fibrinogen, blocking of $\mathrm{P}_{2} \mathrm{Y}_{12}$ or $\alpha \mathrm{llb} \beta 3$, or late platelet inhibition with cyclic AMP-elevating or PI3K-inhibiting agents. Together, this strongly suggests that, during the thrombotic process, integrins need to be continuously activated to prevent disassembly of platelet aggregates. Video microscopic imaging indicated that this disaggregation was an ongoing process, with platelets detaching as strings connected by membrane tethers. This suggests a gradual closing down of integrins, perhaps leaving patches of activated $\alpha \mathrm{llb} \beta 3$ at contact sites in the tethered ends.

The current data explain why in animal thrombosis models ${ }^{10,32}$ and in human flow studies, ${ }^{8,18}$ absence or blocking of ADP receptors (P2Y $\left.{ }_{12}\right)$ is accompanied by increased embolization and reduced thrombus stability. Moreover, our data indicate that, paracrine 
ADP and $\mathrm{P}_{2} \mathrm{Y}_{12}$ receptors play a crucial role in the dynamic stabilization of aggregates, both under static and flow conditions. Other signaling pathways (eg, by thromboxane receptors) also seemed to play moderate roles. Importantly, we also found that the thrombus-stabilizing effect of $\mathrm{P}_{2} \mathrm{Y}_{12}$ persists at conditions of thrombin generation and (limited) fibrin formation, which is relevant for the in vivo situation, where coagulation usually accompanies platelet aggregation.

Our findings are in contrast to the recent observation that $\mathrm{P}_{2} \mathrm{Y}_{1}$ and $\mathrm{Ca}^{2+}$ signaling are major factors contributing to late integrin activation. ${ }^{31}$ On the other hand, others have noted that $\mathrm{P}_{2} \mathrm{Y}_{1-}$, thromboxane-, and PAR1-dependent activation events, in turn, rely on feed-forward loops mediated by $\mathrm{P} 2 \mathrm{Y}_{12 .}{ }^{12,33}$ In all current sets of experiments (ie, disaggregation of platelets in suspension and in disaggregation of human and murine thrombi under flow), blocking of $\mathrm{P}_{2} \mathrm{Y}_{1}$ receptors with MRS2179 had a small, but significant effect in causing aggregate instability. However, in these experiments, blocking of $\mathrm{P}_{2} \mathrm{Y}_{12}$ had a much larger effect and, importantly, MRS2179 did not increase the effect of $P 2 Y_{12}$ blockage. Furthermore, the disaggregation effect of $P 2 Y_{1}$ blockage, but not of $\mathrm{P}_{2} \mathrm{Y}_{12}$ blockage, was surpassed by additional inhibition of PI3K $\beta$ (TGX221) and $\mathrm{PI} 3 \mathrm{~K} \gamma$ (AS252424). We thus can conclude that $\mathrm{P}_{2} \mathrm{Y}_{12}$ or $\mathrm{PI} 3 \mathrm{~K}$ neutralization has a much larger effect on thrombus stability than $\mathrm{P}_{2} \mathrm{Y}_{1}$ inhibition, but also that it overlaps with the effect of $\mathrm{P}_{2} \mathrm{Y}_{1}$ inhibition. Together, this indicates that the contribution of $\mathrm{P} 2 \mathrm{Y}_{1}$ to thrombus stabilization is either downstream of, or bypassed by, $\mathrm{P} 2 \mathrm{Y}_{12}$ signaling.

Our findings lead to the intriguing concept that integrin $\alpha$ llb $\beta 3$ needs continuous inside-out stimulatory signals (eg, by $\mathrm{P}_{2} \mathrm{Y}_{12}$ signaling) to prevent its inactivation. Phosphorylation of the $\beta 3$-chain is supposed to be required for irreversible $\alpha$ llb $\beta 3$ activation. ${ }^{34}$ However, because this phosphorylation can be reversible as well, the relation between the integrin phosphorylation state and the presently studied delayed platelet disaggregation still needs to be established. This also holds for the cAMP/protein kinase A-mediated mechanism of integrin closure, which is likely to be distinct from the cAMP effect on $\mathrm{Ca}^{2+}$ signal generation ${ }^{35}$, but is still unidentified.

Others have proposed that $\mathrm{P}_{2} \mathrm{Y}_{12}$ plays a common role in the regulation of thrombus stabilization. ${ }^{10}$ The current findings significantly extend this by showing that the role of $\mathrm{P}_{2} \mathrm{Y}_{12}(1)$ is a continuous and long-term one; and (2) involves 2 effector pathways that are nonexclusively downstream of $\mathrm{P}_{2} \mathrm{Y}_{12}$ (ie, those of PI3K $\beta$ and $\mathrm{PI} 3 \mathrm{~K} \gamma$ ). Although both $\mathrm{PI} 3 \mathrm{~K}$ isoforms are activated by ADP and have been implicated in integrin activation, likely via $\mathrm{Gi}$, the downstream signaling effects are still debated (discussed in Jackson et $\mathrm{al}^{18}$ ). PI3K has been linked to Akt and Rap1b activation. ${ }^{17}$ Also, protein kinase $\mathrm{C}$ and the GDP-exchange proteins, Vav and CaIDAG-GEFI, have been implicated in Rap1b and subsequent integrin activation. ${ }^{36,37}$ The literature thus points to various signaling pathways that can lead to conformational changes of $\alpha$ llb $\beta 3$. It remains to be determined how PI3K isoforms are involved in these signaling pathways.

In vivo, knock-out mouse models lacking Gas6 (receptors), CD40L or SLAM have in common with $\mathrm{P}_{2} \mathrm{Y}_{12} /-$ mice a delayed and impaired thrombus growth and an increased embolization. $^{21,23,24}$ Platelets from these knock-out mice share an impaired ability to aggregate with ADP, suggesting that a common mechanism is responsible for the 
decreased thrombus stability. One possibility is that $\mathrm{P}_{2} \mathrm{Y}_{12}$ activity is a prerequisite for late contact-dependent signaling via these proteins or, alternatively, that diminished platelet-platelet contact may lead to reduced ADP secretion and paracrine activation via $P 2 Y_{12}$. Recent data indicate that occupied Gas6 receptors of platelets signal via class la $\mathrm{PI} 3 \mathrm{~K}$ forms, although the precise isoform is unknown. ${ }^{21}$ Considering our current findings, it is not unlikely that ADP secretion and the $P 2 Y_{12}$ pathway is de facto upstream of Gas6 signaling via $\mathrm{PI} 3 \mathrm{~K}$, but this remains to be determined.

The finding that PI3K $\gamma$ has a distinct function in the stabilization of aggregates is not unexpected. This corresponds with published evidence that $\mathrm{PI} 3 \mathrm{~K} \gamma$-deficient mice show impaired platelet aggregation together with a reduced thrombotic tendency. ${ }^{19,38}$ Interestingly, this isoform accomplishes kinase-dependent and independent effects in a variety of cells. ${ }^{39}$ Whether (lipid) kinase activity is involved in the thrombus-stabilizing effect is currently unknown. Using the isoform-specific inhibitor TGX221, we also find that $\mathrm{PI} 3 \mathrm{~K} \beta$ contributes to the dynamic consolidation of thrombi, in both human and murine (PI3K $\gamma$ knock-out) blood. This compound has a highly specific inhibitory activity towards $\mathrm{PI} 3 \mathrm{KK} \beta$ (inhibitory concentration at $50 \%$ [IC $\mathrm{C}_{50}$ ], $5 \mathrm{nM}$ with 1000 -fold selectivity over a broad range of protein kinases), and has previously been shown to affect $\alpha$ llb $\beta 3$ mediated stable adhesion under high shear. ${ }^{18} \mathrm{PI} 3 \mathrm{~K} \beta$ is likely to be an important effector, since TGX221 is similarly active in provoking disaggregation as the general PI3K inhibitor wortmannin. In the prevention of platelet disaggregation, each isoform PI3K $\beta$ and $\mathrm{PI} 3 \mathrm{~K} \gamma$ seems to have a distinct function. Active PI3K $\beta$ appears to mediate individual platelet-platelet contact, whereas $\mathrm{PI} 3 \mathrm{~K} \gamma$ is essential for keeping the thrombus together (ie, to maintain the integrity of the entire thrombus). In sum, in contrast to the static (3phase) model of thrombus formation, we propose a dynamic model of thrombus buildup and stabilization. Herein, continuous signaling, involving paracrine $P 2 Y_{12}$ and both isoforms $\mathrm{PI} 3 \mathrm{~K} \beta$ and $\mathrm{PI} 3 \mathrm{~K} \gamma$, are needed to stabilize growing thrombi and prevent their dissolution. This signaling then leads to perpetuated $\alpha$ llb $\beta 3$ activity and fibrinogen binding, both in human and mouse platelets. This novel concept of intrinsic, dynamic thrombus instability gives new possibilities for the use of antiplatelet therapy (eg, with $\mathrm{PI} 3 \mathrm{~K} \beta$ and $\mathrm{PI} 3 \mathrm{~K} \gamma$ as new targets). Also, we infer that $\mathrm{P} 2 \mathrm{Y}_{12}$-inhibitory medication such as clopidogrel, although this drug is only partly effective in blocking $\mathrm{P}_{2} \mathrm{Y}_{12}$ signaling, ${ }^{27}$ may not only prevent thrombus formation, but also act to dissolve preformed thrombotic aggregates.

\section{Acknowledgment}

We thank Carl Zeiss Jena for access to confocal equipment and D. van Meensel for assistance.

\section{References}

1. Ruggeri ZM. Platelets in atherothrombosis. Nat Med. 2002;8:1227-1234.

2. Furie B, Furie BC. Thrombus formation in vivo. J Clin Invest. 2005;115:3355-3362. 
3. Maxwell MJ, Dopheide SM, Turner SJ, Jackson SP. Shear induces a unique series of morphological changes in translocating platelets: effects of morphology on translocation dynamics. Arterioscler Thromb Vasc Biol. 2006;26:663-669.

4. Auger JM, Kuijpers MJ, Senis YA, Watson SP, Heemskerk JW. Adhesion of human and mouse platelets to collagen under shear: a unifying model. FASEB J. 2005;19:825-827.

5. Chen H, Kahn ML. Reciprocal signaling by integrin and nonintegrin receptors during collagen activation of platelets. Mol Cell Biol. 2003;23:4764-4777.

6. Nieswandt B, Brakebusch C, Bergmeier W, Schulte V, Bouvard D, Mokhtari-Nejad R, Lindhout T, Heemskerk JW, Zirngibl H, Fassler R. Glycoprotein VI but not $\alpha 2 \beta 1$ integrin is essential for platelet interaction with collagen. EMBO J. 2001;20:2120-2130.

7. Siljander PR, Munnix IC, Smethurst PA, Deckmyn H, Lindhout T, Ouwehand WH, Farndale RW, Heemskerk JW. Platelet receptor interplay regulates collagen-induced thrombus formation in flowing human blood. Blood. 2004;103:1333-1341.

8. Lecut C, Schoolmeester A, Kuijpers MJ, Broers JL, van Zandvoort MA, Vanhoorelbeke K, Deckmyn H, Jandrot-Perrus M, Heemskerk JW. Principal role of glycoprotein VI in $\alpha 2 \beta 1$ and $\alpha$ llb $\beta 3$ activation during collagen-induced thrombus formation. Arterioscler Thromb Vasc Biol. 2004;24:1727-1733.

9. Nieswandt B, Watson SP. Platelet-collagen interaction: is GPVI the central receptor? Blood 2003;102:449-461.

10. Andre P, Delaney SM, LaRocca T, Vincent D, DeGuzman F, Jurek M, Koller B, Phillips DR, Conley $\mathrm{PB} . \mathrm{P}_{2} \mathrm{Y}_{12}$ regulates platelet adhesion/activation, thrombus growth, and thrombus stability in injured arteries. J Clin Invest. 2003;112:398-406.

11. Remijn JA, Wu YP, Jeninga EH, MJ IJ, van Willigen G, de Groot PG, Sixma JJ, Nurden AT, Nurden $\mathrm{P}$. Role of ADP receptor $\mathrm{P}_{2} \mathrm{Y}_{12}$ in platelet adhesion and thrombus formation in flowing blood. Arterioscler Thromb Vasc Biol. 2002;22:686-691.

12. Paul BZ, Jin J, Kunapuli SP. Molecular mechanism of thromboxane $A_{2}$-induced platelet aggregation. Essential role for P2T $\mathrm{T}_{\text {ac }}$ and $\alpha_{2 \mathrm{~A}}$ receptors. J Biol Chem. 1999;274:29108-29114.

13. Conley PB, Delaney SM. Scientific and therapeutic insights into the role of the platelet $P 2 Y_{12}$ receptor in thrombosis. Curr Opin Hematol. 2003;10:333-338.

14. Coughlin SR. Protease-activated receptors in hemostasis, thrombosis and vascular biology. $\mathrm{J}$ Thromb Haemost. 2005;3:1800-1814.

15. Kauffenstein G, Bergmeier W, Eckly A, OhImann P, Leon C, Cazenave JP, Nieswandt B, Gachet C. The P2Y 12 receptor induces platelet aggregation through weak activation of the allb $\beta 3$ integrin - a phosphoinositide 3-kinase-dependent mechanism. FEBS Lett. 2001;505:281-290.

16. Jackson SP, Yap CL, Anderson KE. Phosphoinositide 3-kinases and the regulation of platelet function. Biochem Soc Trans. 2004;32:387-392.

17. Kim S, Jin J, Kunapuli SP. Akt activation in platelets depends on Gi signaling pathways. J Biol Chem. 2004;279:4186-4195

18. Jackson SP, Schoenwaelder SM, Goncalves I, Nesbitt WS, Yap CL, Wright CE, Kenche V, Anderson KE, Dopheide SM, Yuan Y, Sturgeon SA, Prabaharan H, Thompson PE, Smith GD, Shepherd PR, Daniele N, Kulkarni S, Abbott B, Saylik D, Jones C, Lu L, Giuliano S, Hughan SC, Angus JA, Robertson AD, Salem HH. PI 3-kinase p110ß: a new target for antithrombotic therapy. Nat Med. 2005;11:507-514

19. Hirsch E, Bosco O, Tropel P, Laffargue M, Calvez R, Altruda F, Wymann M, Montrucchio G. Resistance to thromboembolism in PI3K $\gamma$-deficient mice. FASEB J. 2001;15:2019-2021.

20. Fabre JE, Nguyen M, Latour A, Keifer JA, Audoly LP, Coffman TM, Koller BH. Decreased platelet aggregation, increased bleeding time and resistance to thromboembolism in $\mathrm{P}_{2} \mathrm{Y}_{1-}$ deficient mice. Nat Med. 1999;5:1199-1202. 
21. Angelillo-Scherrer A, Burnier L, Flores N, Savi P, DeMol M, Schaeffer P, Herbert JM, Lemke G, Goff SP, Matsushima GK, Earp HS, Vesin C, Hoylaerts MF, Plaisance S, Collen D, Conway EM, Wehrle-Haller B, Carmeliet P. Role of Gas6 receptors in platelet signaling during thrombus stabilization and implications for antithrombotic therapy. $\mathrm{J}$ Clin Invest. 2005;115:237-246.

22. Prevost N, Woulfe DS, Jiang H, Stalker TJ, Marchese P, Ruggeri ZM, Brass LF. Eph kinases and ephrins support thrombus growth and stability by regulating integrin outside-in signaling in platelets. Proc Natl Acad Sci USA. 2005;102:9820-9825.

23. Andre P, Prasad KS, Denis CV, He M, Papalia JM, Hynes RO, Phillips DR, Wagner DD. CD40L stabilizes arterial thrombi by a $\beta 3$ integrin-dependent mechanism. Nat Med. 2002;8:247-252.

24. Nanda N, Andre P, Bao M, Clauser K, Deguzman F, Howie D, Conley PB, Terhorst C, Phillips DR. Platelet aggregation induces platelet aggregate stability via SLAM family receptor signaling. Blood. 2005;106:3028-3034.

25. Condliffe AM, Davidson $\mathrm{K}$, Anderson KE, Ellson CD, Crabbe T, Okkenhaug $\mathrm{K}$ Vanhaesebroeck B, Turner M, Webb L, Wymann MP, Hirsch E, Ruckle T, Camps M, Romme C, Jackson SP, Chilvers ER, Stephens LR, Hawkins PT. Sequential activation of class IB and class IA PI3K is important for the primed respiratory burst of human but not murine neutrophils. Blood. 2005;106:1432-1440.

26. Kuijpers MJ, Schulte V, Bergmeier W, Lindhout T, Brakebusch C, Offermanns S, Fassler R Heemskerk JW, Nieswandt B. Complementary roles of glycoprotein VI and $\alpha 2 \beta 1$ integrin in collagen-induced thrombus formation in flowing whole blood ex vivo. FASEB J. 2003;17:685687.

27. van der Meijden PE, Feijge MA, Giesen PL, Huijberts M, van Raak LP, Heemskerk JW Platelet $\mathrm{P}_{2} \mathrm{Y}_{12}$ receptors enhance signalling towards procoagulant activity and thrombin generation. A study with healthy subjects and patients at thrombotic risk. Thromb Haemost. 2005;93:1128-1136.

28. Hirsch E, Katanaev VL, Garlanda C, Azzolino O, Pirola L, Silengo L, Sozzani S, Mantovani A, Altruda F, Wymann MP. Central role for G protein-coupled phosphoinositide 3-kinase $\gamma$ in inflammation. Science. 2000;287:1049-1053.

29. Munnix IC, Strehl A, Kuijpers MJ, Auger JM, van der Meijden PE, van Zandvoort MA, oude Egbrink MG, Nieswandt B, Heemskerk JW. The glycoprotein VI-phospholipase C $\gamma 2$ signaling pathway controls thrombus formation induced by collagen and tissue factor in vitro and in vivo. Arterioscler Thromb Vasc Biol. 2005;25:2673-2678.

30. van Willigen G, Hers I, Gorter G, Akkerman JW. Exposure of ligand-binding sites on platelet integrin $\alpha$ llB/ $\beta 3$ by phosphorylation of the $\beta 3$ subunit. Biochem J. 1996;314 ( Pt 3):769-779.

31. Goto S, Tamura N, Ishida H, Ruggeri ZM. Dependence of platelet thrombus stability on sustained glycoprotein IIb/IIla activation through adenosine 5'-diphosphate receptor stimulation and cyclic calcium signaling. J Am Coll Cardiol. 2006;47:155-162.

32. van Gestel MA, Heemskerk JW, Slaaf DW, Heijnen VV, Reneman RS, oude Egbrink MG. In vivo blockade of platelet ADP receptor $\mathrm{P}_{2} \mathrm{Y}_{12}$ reduces embolus and thrombus formation but not thrombus stability. Arterioscler Thromb Vasc Biol. 2003;23:518-523.

33. Trumel C, Payrastre B, Plantavid M, Hechler B, Viala C, Presek P, Martinson EA, Cazenave JP, Chap H, Gachet C. A key role of adenosine diphosphate in the irreversible platelet aggregation induced by the PAR1-activating peptide through the late activation of phosphoinositide 3-kinase. Blood. 1999;94:4156-4165.

34. Lerea KM, Cordero KP, Sakariassen KS, Kirk RI, Fried VA. Phosphorylation sites in the integrin $\beta 3$ cytoplasmic domain in intact platelets. J Biol Chem. 1999;274:1914-1919.

35. Kuijpers MJ, Nieuwenhuys CM, Feijge MA, Kloots W, Giesen PL, Jerling JC, oude Egbrink MG, Heemskerk JW. Regulation of tissue factor-induced coagulation and platelet aggregation in flowing whole blood. Thromb Haemost. 2005;93:97-105.

36. Bernardi B, Guidetti GF, Campus F, Crittenden JR, Graybiel AM, Balduini C, Torti M. The small GTPase Rap1b regulates the cross talk between platelet integrin $\alpha 2 \beta 1$ and integrin $\alpha$ ll $\beta 3$. Blood. 2006;107:2728-2735. 
37. Crittenden JR, Bergmeier W, Zhang Y, Piffath CL, Liang Y, Wagner DD, Housman DE, Graybiel AM. CalDAG-GEFI integrates signaling for platelet aggregation and thrombus formation. Nat Med. 2004;10:982-986.

38. Lian L, Wang Y, Draznin J, Eslin D, Bennett JS, Poncz M, Wu D, Abrams CS. The relative role of PLC $\beta$ and PI3K $\gamma$ in platelet activation. Blood. 2005;106:110-117.

39. Wetzker R, Bohmer FD. Transactivation joins multiple tracks to the ERK/MAPK cascade. Nat Rev Mol Cell Biol. 2003;4:651-657. 


\section{Role of human and mouse Gas6 and Gas6 receptors in the formation and stabilization of thrombi}




\begin{abstract}
In vivo mouse thrombosis models have shown that binding of Gas6 to Gas6 receptors (Axl, Sky and Mer) on activated platelets contributes to thrombus formation and stabilization. In mouse platelets, this interaction is considered to evoke activation of phosphoinositide 3-kinase (PI3K), which stabilizes integrin allb $\beta 3$-dependent platelet aggregation. However, a role of Gas 6 in human platelet activation has been questioned. Here, we compared the contribution of human and mouse Gas6 in flow-dependent thrombus formation, and examined how Gas6 signaling via PI3K interfered with the ADP/P2Y 12 pathway. In the human system, Gas6 is abundantly present in plasma but only limitedly in platelets. Yet, both in human and mouse blood, Gas6 stabilized the thrombi formed on collagen under flow, and it prevented dissolution of platelets. In mouse, deficiency in one of the Gas6 receptors (Axl, Sky, Mer) led to thrombus destabilization on collagen, an effect that was antagonized upon co-perfusion with ADP. The absence of Gas6 or Gas6 receptors did not abrogate PI3K-dependent $\alpha$ llb $\beta 3$ activation and platelet aggregation. Furthermore, platelet activation by glycoprotein $\mathrm{VI}$ was unaffected. Collectively, these data show that Gas6-Gas6 receptor interaction cosignals with ADP/P2Y 12 in the formation and stabilization of human and murine thrombi, likely via PI3K. The data further refute the hypothesis that Gas6 receptor signaling acts upstream of ADP-dependent integrin activation.
\end{abstract}

\title{
Introduction
}

Gas6, encoded by growth arrest-specific gene 6, is a vitamin-K dependent protein that is expressed in and released by many cell types, including endothelial cells, vascular smooth muscle cells, bone marrow cells, and platelets. ${ }^{1-3}$ Consistent with its wide distribution, Gas 6 has been implicated in a variety of cellular functions, such as reversible cell growth arrest, ${ }^{1}$ survival, ${ }^{4}$ proliferation, ${ }^{2,4}$ migration, ${ }^{5,6}$ and inflammation. ${ }^{7}$ As far as is known, Gas6 exerts these functions by acting as an extracellular ligand for three receptors belonging to the Tyro3 receptor tyrosine kinase family: Axl (Tyro7), Sky (Tyro3) and Mer (Tyro12). ${ }^{8-10}$ The relative affinities of these receptors for Gas6 vary over hundred-fold, with Axl presenting the highest affinity, followed by Sky and then Mer. ${ }^{10}$

In mice, the interaction of Gas6 with platelet Gas6 receptors is demonstrated to have an important role in thrombus formation in vivo, as mice deficient in Gas6 or in any one of the receptor proteins Axl, Sky or Mer are protected against venous and arterial thrombosis, without having a bleeding phenotype. ${ }^{11,12}$ These characteristics make Gas6 an attractive target for antithrombotic therapy.

The current postulation is that, in mice, the binding of secreted Gas6 to its receptors on activated platelets evokes signaling via phosphoinositide (PI3K). ${ }^{12}$ Also studies with other cell types report Gas6-Gas6 receptor signaling via PI3K. ${ }^{13,14}$ Complementary to this is the evidence that ADP-P2Y 12 induced activation of the $\mathrm{PI} 3 \mathrm{~K} \beta$ and $\mathrm{PI} 3 \mathrm{~K} \gamma$ isoforms plays a key role in the stabilization of a thrombus under flow in vivo and ex vivo. ${ }^{15-17}$ From a mechanistic point of view, however, the latter is surprising, because the Gicoupled $\mathrm{P}_{2} \mathrm{Y}_{12}$ receptor does not have recognition sites to bind to $\mathrm{SH} 2 / 3$ domains in the 
p85 regulatory subunit of $\mathrm{PI} 3 \mathrm{~K} \beta .^{18}$ On the other hand, Gas6 receptors do contain such recognition sites, ${ }^{19}$ thus raising the hypothesis that the feed-forward loop of $\mathrm{P}_{2} \mathrm{Y}_{12}$ and PI3K $\beta$ activation can be the result of a second, nested feed-forward loop of Gas 6 release and Gas6 receptor signaling.

In contrast to the well-defined role of Gas6 in murine thrombus formation, it is controversial whether human Gas6 has a similar function. Initial studies show that Gas 6 mRNA is present in human platelets. ${ }^{11,20}$ However, a more recent report states that human platelets neither store nor secrete Gas6 protein. ${ }^{21}$ On the other hand, Gas 6 has been identified in plasma from healthy subjects at an appreciable, though variable concentration of $15-65 \mu \mathrm{g} / \mathrm{L} .^{21,22}$ Since this variation in plasma Gas6 is not linked to changes in platelet aggregation, ${ }^{23}$ it has been questioned whether Gas6-Gas6 interaction is relevant for human thrombus formation. In the present study, we compared the functions of human and mouse Gas 6 in flow-dependent thrombus formation ex vivo, and examined how ADP receptor signaling interfered with the Gas6 pathway.

\section{Materials and methods}

\section{Materials}

Fibrillar Horm type I collagen, was obtained from Nycomed (Munich, Germany). ADP and bovine serum albumin (BSA) came from Sigma (St. Louis, MO, USA). H-Phe-Pro-Arg chloromethyl ketone (PPACK) was obtained from Calbiochem (La Jolla, CA, USA); fragmin from Pfizer (Capelle a/d IJssel, The Netherlands). Oregon green (OG) 488labeled fibrinogen was from Molecular Probes (Eugene, OR, USA); fluorescein isothiocyanate (FITC)-labeled annexin A5 from PharmaTarget (Maastricht, The Netherlands). Selective inhibitor for the $p 110 \beta$ isoform of PI3K, TGX221 was a kind gift of the Baker Heart Research Institute (Melbourne, Victoria, Australia). Phycoerythrin (PE)-labeled monoclonal antibody (Ab) JON/A was from Emfret (Würzburg, Germany). Recombinant human Gas6 (rhGas6) was from Abnova (Taipei, Taiwan); polyclonal antihuman Gas6 Ab (sc1936) from Santa Cruz Biotechnology (Santa Cruz, CA, USA).

\section{Human blood and platelets}

Human blood was drawn from healthy volunteers after full informed consent. Blood was collected in 17 vol\% of acid-citrate-dextrose (ACD), or in $40 \mu \mathrm{M} \mathrm{PPACK}$, as required. ${ }^{24}$ Platelet-rich plasma (PRP), platelet-free plasma (PFP), and washed platelets were obtained, as described. ${ }^{25}$

\section{Mouse blood and platelets}

Mice deficient in Gas6, Axl, Sky or Mer and wildtype mice of the same genetic background (129/Sv or mixed) were generated, as described. ${ }^{11,26}$ All mice had platelet counts in the normal range. Experiments were approved by the local animal experimental committees. For flow chamber experiments, mouse blood was collected in 
$40 \mu \mathrm{M}$ PPACK and $5 \mathrm{U} / \mathrm{mL}$ heparin. For flow cytometry, blood was collected into $5 \mathrm{U} / \mathrm{mL}$ fragmin and $5 \mathrm{U} / \mathrm{mL}$ heparin.

\section{Detection of Gas6 in human plasma and platelets}

Human platelets $\left(100 \times 10^{8} / \mathrm{mL}\right)$ were washed three times in HEPES buffer pH $6.6(136$ $\mathrm{mM} \mathrm{NaCl}, 10 \mathrm{mM}$ glucose, $5 \mathrm{mM}$ HEPES, $2.7 \mathrm{mM} \mathrm{KCl}, 2 \mathrm{mM} \mathrm{MgCl} 2,2 \mathrm{mM} \mathrm{CaCl}_{2}, 0.1 \%$ BSA), and then lysed in RIPA buffer containing a cocktail of protease inhibitors. ${ }^{12}$ The lysates were centrifuged at $15,000 \mathrm{~g}$ for $5 \mathrm{~min}$ to remove membrane fragments. Supernatants were incubated overnight at $4{ }^{\circ} \mathrm{C}$ with polyclonal anti-Gas $6 \mathrm{Ab}$, coupled to protein-A sepharose beads. Assuming a normal platelet count of $3 \times 10^{8} / \mathrm{mL}$, a corresponding volume of citrate-anticoagulated human pooled plasma was also incubated overnight with anti-Gas 6 Ab beads. Beads were collected by centrifugation, washed twice in phosphate-buffered saline, and eluted in sodium dodecyl sulfate (SDS) sample buffer. Protein samples were separated in SDS-PAGE (7.5\% polyacrylamide), transferred onto polyvinylidine fluoride membrane, and stained with goat anti-human Gas6 Ab. Detection on blot was with rabbit anti-goat IgG conjugated with horseradish peroxidase, followed by enhanced chemiluminescence (Pierce, Rockford, IL, USA).

\section{Preparation of human Gas6-depleted plasma}

Anti-human Gas6 Ab was coupled to aldehyde-activated bead agarose resin using the Seize primary immunoprecipitation kit from Pierce. Pooled human citrate-anticoagulated plasma was incubated overnight with the Gas6 Ab-resin complex at $4{ }^{\circ} \mathrm{C}$. Barium citrate precipitation was performed to verify Gas6 depletion, such as described by others. ${ }^{27}$ Precipitates were dissolved into SDS sample buffer, and subjected to SDS-PAGE and Western blotting. Gas6-depleted plasmas as well as eluted Gas6 samples were frozen at $-80{ }^{\circ} \mathrm{C}$ until use.

\section{Platelet aggregation}

Platelet shape change and aggregation were measured by light-transmission aggregometry (Chronolog, Havertown, PA, USA) under constant stirring at $1000 \mathrm{rpm}$ $\left(37^{\circ} \mathrm{C}\right) .{ }^{17}$ Control and Gas6-depleted plasmas (anticoagulated with citrate) were reconstituted with washed human platelets at a final concentration of $2.5 \times 10^{8} / \mathrm{L}$. Prior to addition of agonist, plasmas were recalcified with $7.5 \mathrm{mM} \mathrm{CaCl} 2$ and $3.75 \mathrm{mM} \mathrm{MgCl}_{2}$ in the presence of $40 \mu \mathrm{M}$ PPACK.

\section{Flow cytometry}

Anticoagulated mouse blood was diluted twenty fold in Tyrode's buffer pH 7.0 (134 mM $\mathrm{NaCl}, 0.34 \mathrm{mM} \mathrm{Na}_{2} \mathrm{HPO}_{4}, 2.9 \mathrm{mM} \mathrm{KCl}, 12 \mathrm{mM} \mathrm{NaHCO}_{3}, 20 \mathrm{mM}$ HEPES, $5 \mathrm{mM}$ glucose, $0.35 \%$ BSA). After agonist stimulation, mouse integrin $\alpha$ llb $\beta 3$ activation was detected with PE-conjugated JON/A mAb. Human $\alpha$ llb $\beta 3$ activation in stimulated platelets, resuspended in HEPES buffer $\mathrm{pH} 7.45\left(1 \times 10^{8} / \mathrm{mL}\right)$, was detected with OG488-labeled 
fibrinogen. Platelets were stimulated with ADP under non-stirred conditions. Flow cytometry was performed as described. ${ }^{11}$ Platelets were identified from their scatter profiles; at least 5000 events were counted per sample.

\section{Measurement of thrombus formation and phosphatidylserine exposure under flow}

Flow experiments over collagen were performed using mouse blood (anticoagulated with $40 \mu \mathrm{M}$ PPACK and $5 \mathrm{U} / \mathrm{mL}$ heparin) or human blood (in $40 \mu \mathrm{M}$ PPACK). Degreased rectangular coverslips $(24 \times 60 \mathrm{~mm})$ were coated with fibrillar type I Horm collagen $(25$ $\mu \mathrm{L}$ of $200 \mu \mathrm{g}$ collagen $/ \mathrm{mL}$ ). Where indicated, coating was at reduced concentrations of 10 or $50 \mu \mathrm{g}$ collagen $/ \mathrm{mL}$. After coating for $60 \mathrm{~min}$, coverslips were rinsed with saline, and blocked with HEPES buffer pH 7.45 containing 1\% BSA. Relative amounts of collagen on the coverslip with verified by staining with Sirius red.

Coated coverslips were inserted into a transparent parallel-plate perfusion chamber, which was mounted on an inverted microscope (Nikon Diaphot 22; Nikon, Tokyo, Japan). Blood was perfused through the flow chamber at a shear rate of $1000 \mathrm{~s}^{-1}$ for 4 min. Postperfusion was at the same shear rate with HEPES buffer $\mathrm{pH} 7.45$, or with recalcified citrate-anticoagulated plasma containing FITC-annexin A5 $(0.5 \mu \mathrm{g} / \mathrm{ml})$, as indicated. Collection of fluorescence images was with a Visitech digital imaging system (Sunderland, United Kingdom), equipped with two sensitive, intensified, charge-coupled device cameras. ${ }^{28}$ This setup allowed to capture high-resolution phase-contrast and fluorescent images in parallel in real-time ( $>10$ random microscopic fields). Video recordings were taken if appropriate. Images were analyzed on surface area coverage and on distribution of areas of individual segmented features, as described. ${ }^{24}$ For analysis of disaggregation, events were counted of individually leaving single, and aggregated platelets from video movies. ${ }^{17}$

\section{Statistics}

Data are means \pm SEM. Significance of differences was determined with the MannWhitney U-test or the independent samples t-test, as appropriate, using the statistical package for social sciences (SPSS 11.0, Chicago, IL, USA). Size distribution of platelet aggregates was evaluated by $\chi^{2}$ analysis.

\section{Results}

\section{Gas6 levels in human platelets and plasma}

The literature is unclear whether ${ }^{11,20}$ or not $^{21}$ human platelets express effective amounts of Gas6. We determined the content of Gas6 in washed human platelets $\left(5 \times 10^{7}\right)$ and in a corresponding volume of human plasma $(150 \mu \mathrm{L})$, assuming a normal platelet count of $3 \times 10^{8} / \mathrm{mL}$. Gas6 was immunoprecipitated from the lysed platelets and plasma, and the precipitates were subjected to gel electrophoresis and Western blotting. As shown in Figure $1 \mathrm{~A}$, the preparation from platelet lysate gave one band at $75 \mathrm{kDa}$, i.e. at the size 
A

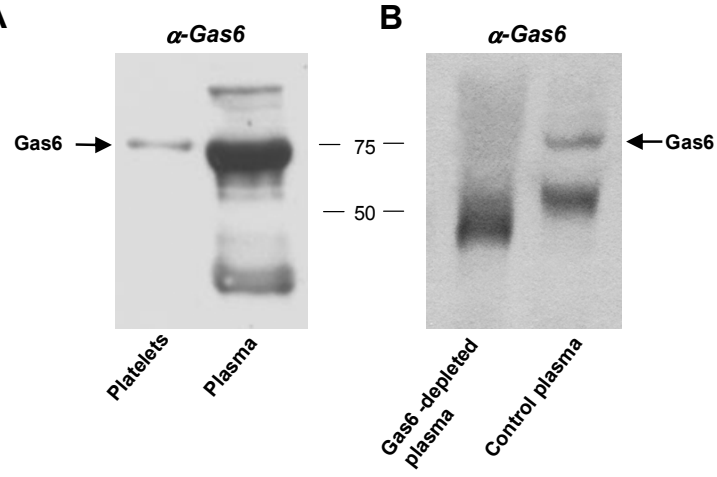

Figure 1. Presence of Gas6 in human platelets and plasma. (A) Relative amounts of Gas6 present in human platelets and plasma. Gas6 was immunoprecipitated from $5 \times 10^{7}$ washed platelets and a corresponding volume of plasma $(150 \mu \mathrm{L})$. Western blot of separated platelet- and plasma proteins after staining with anti-Gas 6 antibody. Note the small band in the platelet immunoprecipitate at $75 \mathrm{kDa}$ versus the dense band in the plasma immunoprecipitate. (B) Confirmation of absence of Gas6 in human Gas6-depleted plasma. Western blot of separated barium citrate precipitate from Gas6-depleted and control plasmas.

of Gas6. The corresponding plasma-derived preparation gave a much denser band, pointing to higher Gas6 levels in plasma. Comparison with reference samples gave an estimated Gas6 content in human platelets of $\sim 0.5 \mathrm{ng} / 10^{8}$ platelets $(\sim 1 \mu \mathrm{g} / \mathrm{L})$, and a plasma concentration of $\sim 20 \mu \mathrm{g} / \mathrm{L}$. The Gas6 present in platelets and plasma was $\gamma$ glutamyl carboxylated, as was verified by staining of the blots with anti-Gla mAb (not shown). Given the limited amount of Gas 6 in human platelets, a role of Gas6 in platelet activation should come from the larger plasma pool.

For a larger scale preparation of human Gas6-depleted plasma, pooled citrateanticoagulated plasma was partly treated with anti-Gas $6 \mathrm{Ab}$ complexed to agarose resin, while the other part of plasma was left untreated for use as a control. Samples of both plasmas were subjected to barium citrate precipitation, and then examined for extent of Gas6 depletion. Western blot analysis showed complete absence of the $75 \mathrm{kDa}$ band, representing Gas6, in the precipitate of anti-Gas6 Ab-treated plasma (Fig. 1B). This plasma was used for further studies.

\section{Plasma-derived Gas6 stabilizes aggregation of human platelets}

In contrast to mouse, where Gas6 is found to enhance thrombus formation ${ }^{11,12,20}$, the role of Gas6 in the human system is unclear. The Gas6-depleted plasma was used to investigate the contribution of Gas6 to human platelet aggregation. Depleted and control plasmas were reconstituted with washed platelets from one donor, and recalcified in the presence of anticoagulant to obtain physiological levels of divalent cations, $\mathrm{Mg}^{2+}$ and $\mathrm{Ca}^{2+}$. When triggered with a suboptimal dose of ADP $(10 \mu \mathrm{M})$, platelets reconstituted in Gas6-depleted plasma aggregated in a transient way, while the aggregation was irreversible in reconstituted control plasma (Fig 2A). The same results were obtained at a higher, optimal concentration of $20 \mu \mathrm{M}$ ADP (not shown). To confirm that the difference 

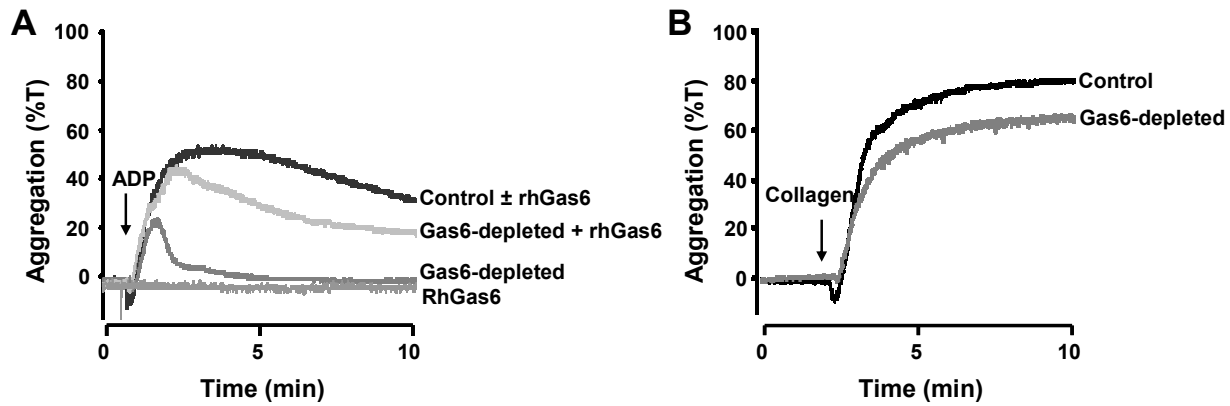

Figure 2. Reversible ADP-induced aggregation of platelets in human Gas6-depleted plasma. Human Gas6-depleted and control plasmas (citrate-anticoagulated) were reconstituted with washed platelets from one donor (final concentration $2.5 \times 10^{8}$ platelets $/ \mathrm{mL}$ plasma). Prior to addition of agonist, plasmas were recalcified with $7.5 \mathrm{mM} \mathrm{CaCl} 2$ and $3.75 \mathrm{mM} \mathrm{MgCl}_{2}$, in the presence of $40 \mu \mathrm{M}$ PPACK. Preincubation was with recombinant human Gas6 (rhGas6, 500 $\mathrm{ng} / \mathrm{mL}$ ), as indicated. Platelet aggregation was evoked by $10 \mu \mathrm{M}$ ADP (A) or $5 \mu \mathrm{g} / \mathrm{mL}$ collagen (B). Aggregation traces shown are representative of four independent experiments.

was due to Gas6 depletion, experiments were carried out with recombinant human Gas6 (rhGas6). By itself, rhGas6 was unable to induce shape change or platelet aggregation up to $2 \mu \mathrm{g} / \mathrm{mL}$ (Fig. 2A). However, a concentration of $500 \mathrm{ng} / \mathrm{mL}$ rhGas6 restored the impaired aggregation of platelets in Gas6-depleted plasma, while it did not influence the aggregation in control plasma (Fig. 2A). Collagen-induced platelet aggregation was only slightly impaired in Gas6-depleted plasma in comparison to control plasma. This was the case at a suboptimal concentration of $5 \mu \mathrm{g} / \mathrm{mL}$ collagen (Fig. 2B), and also at higher collagen concentrations (not shown). Together, these data suggest that Gas6 in human plasma contributes to the stabilization of platelet aggregate formation particularly in response to ADP.

\section{Plasma Gas 6 contributes to stabilization of human thrombi}

The function of plasma Gas6 was also investigated in human thrombus formation and stabilization under flow. An earlier established procedure was used, where platelet aggregates were preformed on immobilized collagen, and then their tendency to disaggregate was measured upon post-perfusion with plasma. ${ }^{17}$ During secondary perfusion with control plasma, few platelets were leaving from the top of the thrombi, while most of the thrombus core remained unaltered (Fig. 3A). On the contrary, secondary perfusion with Gas6-depleted plasma provoked marked instability of the thrombi and led to complete disintegration (Fig. 3A). Strikingly, most of the platelets left the thrombi after 3 minutes of secondary perfusion, such in contrast to secondary perfusion with control plasma (Fig. 3B). Measurement of the size distribution of the remaining features after post-perfusion showed that in case of control plasma remaining platelets were still in large aggregates, whereas with Gas6-depleted plasma the large aggregates had almost completely disappeared (Fig. $3 \mathrm{C}$ ). Taken together, this points to an important role of plasma-derived Gas6 in aggregate stabilization. 
A

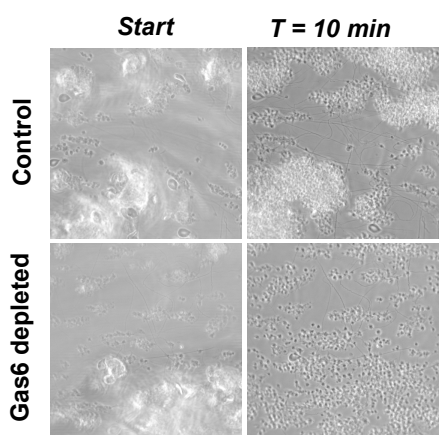

C

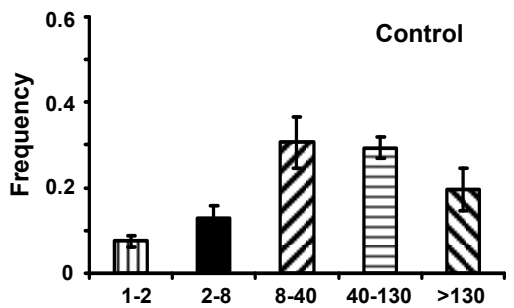

B
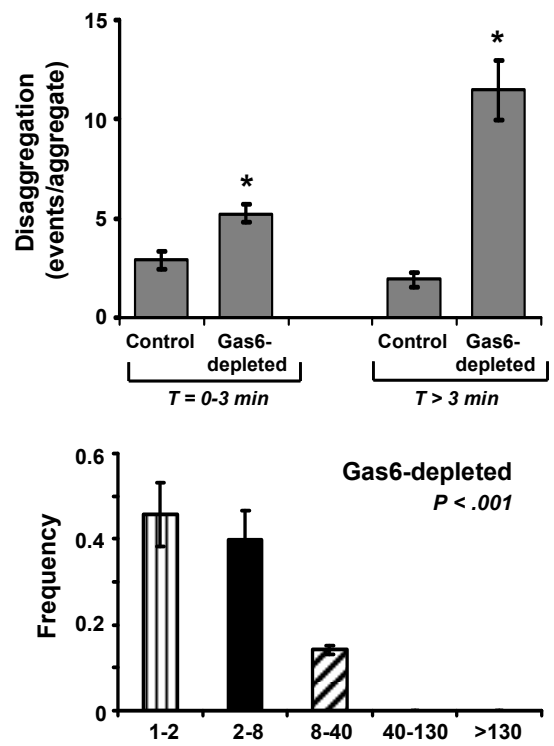

Figure 3. Role of plasma Gas 6 in human thrombus formation on collagen under flow. Human PPACK-anticoagulated whole blood was flowed over a collagen-coated coverslip at a shear rate of $1000 \mathrm{~s}-1$ for $4 \mathrm{~min}$. Thrombi, formed on the coverslip, were secondarily perfused with control plasma or with Gas6-depleted plasma at the same flow rate for $10 \mathrm{~min}$. (A) Representative phase contrast images of thrombi at start and after $10 \mathrm{~min}$ of secondary perfusion $(120 \times 120 \mu \mathrm{m})$. (B) Number of disaggregation events per aggregate during initial $(T=0-3 \mathrm{~min})$ and later $(T>3 \mathrm{~min})$ phases of secondary perfusion with control or Gas6-depleted plasma. (C) Histograms of features left on the coverslip after 10 min of secondary perfusion. Estimated numbers of platelets per feature are 1 to 2,2 to 8,8 to 40,40 to 130 , and $>130$, as indicated. Data are representative of 4 independent experiments (means \pm SEM).

\section{Gas6 and Gas6 receptors are required to form stable murine thrombi}

Mice lacking Gas6 or any of the three Gas6 receptors, Axl, Sky or Mer, have been shown to be protected against arterial thrombus formation in various in vivo thrombosis models. ${ }^{11,12,20}$ To examine the underlying mechanism in more detail, blood from these mice was used in flow chamber studies, with immobilized collagen as thrombogenic surface. Experiments were carried out at a moderately high shear rate of $1000 \mathrm{~s}^{-1}$. With blood from Gas6 -/- mice, smaller aggregates formed on collagen in comparison to wildtype blood (Fig. 4A). Signaling by the collagen receptor, glycoprotein VI (GPVI), was monitored by measuring the capability of collagen-adhered platelets to expose phosphatidylserine (PS), using FITC-labeled annexin A5. ${ }^{29}$ Only single platelets attached to the collagen stained with annexin $\mathrm{A} 5$, as also described before. ${ }^{30}$ However, in spite of the marked difference in thrombus size, no difference in annexin A5 staining was observed between Gas6 -/- and wildtype platelets (Fig 4A). To investigate this further, subsequent flow experiments were carried out using lower densities of collagen coatings. Except for the lowest collagen density, platelet deposition was lower for Gas6-deficient than for wildtype blood (Fig. 4B). Again, annexin A5 staining of collagen-bound platelets 


\section{A



Gas6 +/+

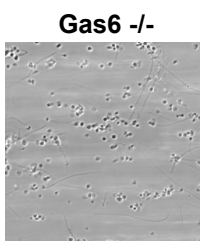

B

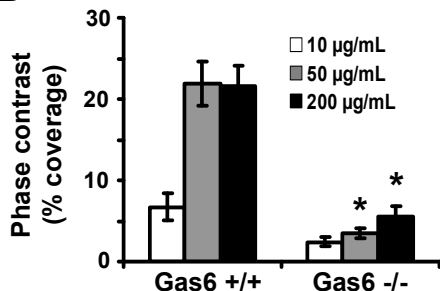

Gas6 +/+

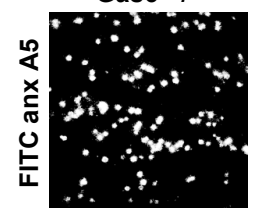

C

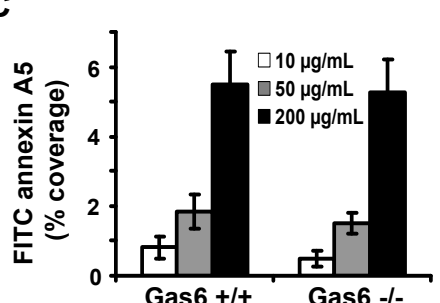

Figure 4. Contribution of Gas 6 to murine thrombus formation on collagen under flow. Coverslips were coated with different concentrations of collagen $(25 \mu \mathrm{L}$ of $10-200 \mu \mathrm{g}$ collagen $/ \mathrm{mL}$ ). Blood from Gas6 +/+ or Gas6 -/- mice was flowed over collagen at a shear rate of $1000 \mathrm{~s}^{-1}$ for 4 min. Procoagulant platelets were stained by post-perfusion with FITC-annexin A5. (A) Representative phase contrast $(120 \times 120 \mu \mathrm{m})$ and annexin A5 fluorescence $(150 \times 150 \mu \mathrm{m})$ images after perfusion. (B, C) Percentage surface area coverage of all deposited platelets and of PS-exposing platelets on the coverslips, coated with different amounts of collagen. Data are means $\pm \operatorname{SEM}(n=4) ;{ }^{*} p<0.05$

was not influenced by the genotype (Fig. 4C). These results suggest that the effect of Gas6 deficiency is not due to reduced platelet interaction with collagen nor to diminished GPVI-mediated activation by collagen. Hence, Gas6 likely regulates thrombus formation by influencing platelet-platelet interactions.

Further flow experiments on collagen (highest coating density) were performed with blood from mice lacking one of the Gas6 receptors, Axl, Sky or Mer. For all receptor deficient mice, surface area coverage with platelets was reduced in comparison to wildtype controls, but to a somewhat smaller extent than in case of Gas6 deficiency (Fig. $5 A)$. The aggregates formed were also smaller, whereas staining with FITC-annexin A5 was unchanged (Fig. 5B). Video movies showed that, in the absence of one of the Gas6 receptors, the adhered platelets disaggregated more frequently from thrombi than in the wildtype situation (Fig. 5C). This resembles the observations with Gas6 -/- blood.

To study the interaction between Gas 6 and ADP signaling, ADP was co-infused with blood from mice deficient in Gas6 or one of the three Gas6 receptors. In all cases, this resulted in full restoration of the thrombus formation on collagen (Fig. 6A). Furthermore, as established for Gas6-deficient blood, the thrombi formed with ADP were quite stable with essentially no platelets leaving the aggregates (Fig. 6B). Thus, ADP receptor activation can restore the defect caused by impaired Gas6-Gas6 receptor interaction. Other control experiments indicated that plasma coagulant activity was not affected by knockout of Gas6, since with PRP from Gas6 -/- mice, tissue factor-induced thrombin generation was similar to that in wildtype PRP (data not shown). Also, the stimulating effect of collagen on thrombin generation was similar between genotypes, which confirms that collagen-induced activation of platelets is not affected in these mice. 
A

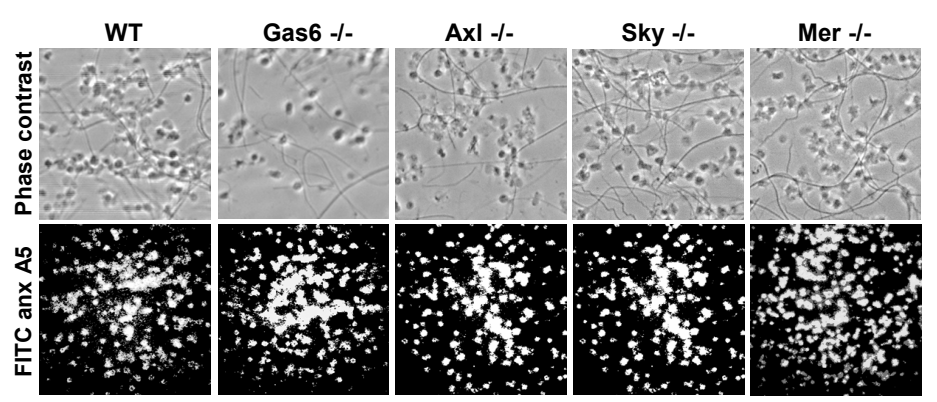

B

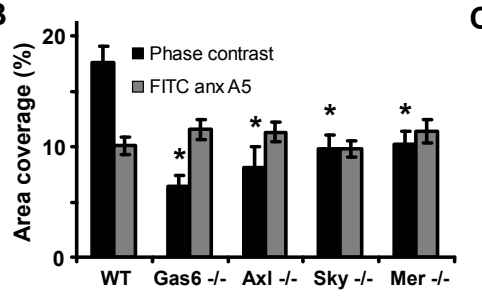

C

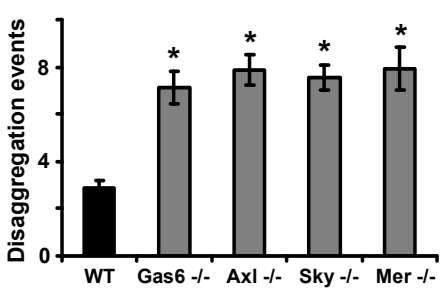

Figure 5. Murine Gas6 and Gas6 receptors, AxI, Sky and Mer, contribute to stabilization of murine thrombi formed under flow. Blood from wildtype mice or mice deficient in Gas6, Axl, Sky or Mer was flowed over collagen-coated coverslips at a shear rate of $1000 \mathrm{~s}^{-1}$ for 4 min. PSexposing platelets were stained by post-perfusion with FITC-annexin A5. (A) Representative phase contrast $(50 \times 50 \mu \mathrm{m})$ and fluorescence $(100 \times 100 \mu \mathrm{m})$ images after perfusion. (B) Surface area coverage of deposition of total platelets and of PS-exposing platelets. (C) Disaggregation events monitored during thrombus formation by real-time video recording. Numbers indicate events per aggregate. Means \pm SEM $(n=4) ;{ }^{*} p<0.05$.

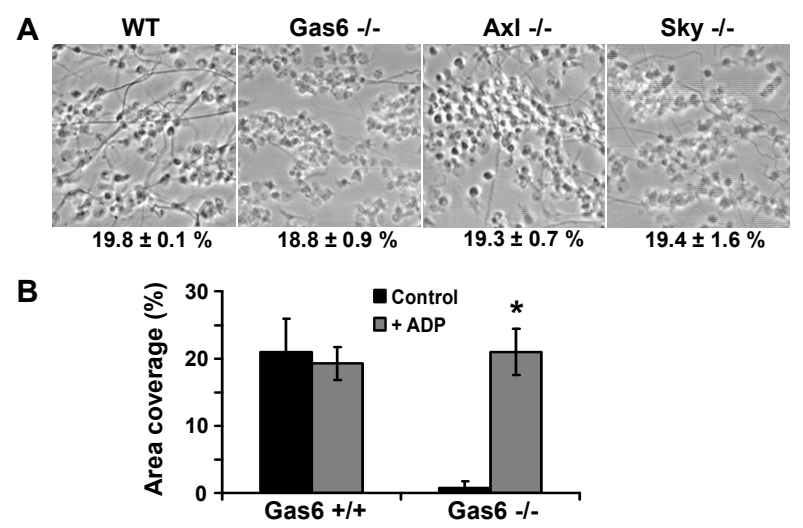

Figure 6. Co-perfusion with ADP normalizes murine thrombus formation in the absence of Gas6 or Gas6 receptors. Blood from wildtype mice or mice deficient in Gas6, Axl or Sky was coperfused with ADP $\left(40 \mu \mathrm{M}\right.$, final concentration) during flow over collagen at $1000 \mathrm{~s}^{-1}$ for $4 \mathrm{~min}$. (A) Representative phase contrast $(50 \times 50 \mu \mathrm{m})$ images after perfusion. Numbers below images indicate surface area coverage of deposited platelets. (B) Effect of co-infusion with ADP on platelet deposition during flow with Gas $6+/+$ and Gas 6 -/- blood. Data are means \pm SEM $(n=4) ;{ }^{*} p<0.05$. 


\section{Additive effect of human and murine Gas6 on ADP-induced $\alpha$ llb $\beta 3$ activation}

The PI3K $\beta$ isoform plays a crucial role in ADP/P2Y 12 -mediated sustained activation of integrin $\alpha \operatorname{llb} \beta 3 .{ }^{16,17}$ To investigate whether the PI3K $\beta$ pathway of integrin activation was dependent on Gas6-Gas6-receptor interaction, the activation state of murine allb $\beta 3$ was determined by flow cytometry using JON/A mAb. In both wildtype and Gas6 -/- platelets, ADP caused a low but significant increase in integrin activation (Fig. 7A). The role of $\mathrm{PI} 3 \mathrm{~K} \beta$ was determined by pretreatment of platelets with the specific inhibitor, TGX221. ${ }^{16}$ In both wildtype and Gas6 -/- platelets, TGX221 pretreatment abolished ADP-induced $\alpha$ llb $\beta 3$ activation. This was confirmed by aggregation measurements showing that TGX221 suppressed ADP-induced aggregation of wildtype and Gas6 -/- platelets at the same extent (Fig. 7B).

To investigate this for the human system, washed human platelets were stimulated with ADP in the presence or absence of rhGas6. Integrin $\alpha$ llb $\beta 3$ activation was monitored by measuring the binding of OG488-fibrinogen to platelets (Fig. 7C). Preincubation with TGX221 abolished fibrinogen binding, regardless of whether rhGas 6 was present or not. Taken together, these results indicate that in both mouse and human
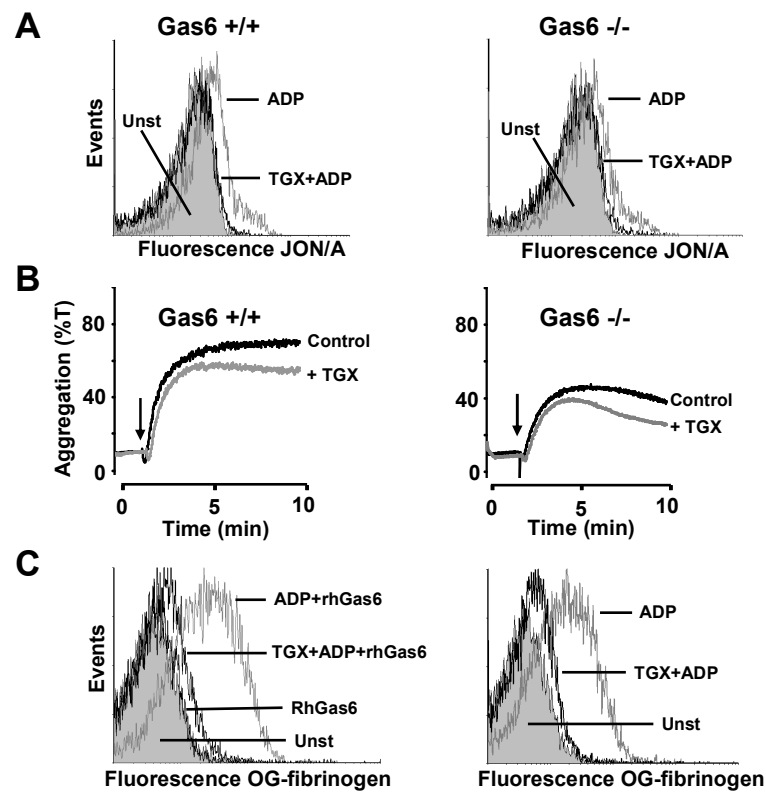

Figure 7. Role of murine and human Gas 6 in integrin allbß3 activation. (A) Suspended platelets from wildtype and Gas6 deficient mice were preincubated with TGX221 (TGX, $1 \mu \mathrm{M})$ and activated with ADP $(25 \mu \mathrm{M})$, as indicated. Activated integrin $\alpha$ llb $\beta 3$ was detected by flow cytometry with PE-JON/A. (B) Mouse PRP was preincubated with TGX221 $(1 \mu \mathrm{M})$ and activated with ADP $(25$ $\mu \mathrm{M})$. Platelet aggregation was monitored in time. (C) Suspended human platelets were preincubated with TGX221 $(1 \mu \mathrm{M})$ and/or recombinant human Gas6 (rhGas6, $500 \mathrm{ng} / \mathrm{mL}$ ) and activated with ADP $(20 \mu \mathrm{M})$. Activated $\alpha$ llb $\beta 3$ was detected by flow cytometry using OG488fibrinogen. Shown are histograms representative of 3-4 independent experiments; shaded areas represent unstimulated (Unst) platelets. 
platelets, $\mathrm{P} 2 \mathrm{Y}_{12} / \mathrm{PI} 3 \mathrm{~K} \beta$-dependent activation of integrin $\alpha \mathrm{llb} \beta 3$ does not rely on Gas6Gas6 receptor interaction and signaling.

\section{Discussion}

The present findings show for the first time that Gas 6 contributes to human platelet aggregation and thrombus stabilization, and that its function closely resembles that of murine Gas6. The stimulating roles of human and murine Gas6 appear to be particular prominent under flow conditions.

In contrast to the relatively high expression of Gas 6 in mouse platelets, ${ }^{11,20}$ we could detect only minute amounts in human platelets. The latter contrasts to a report that this protein is not detected in human platelets. ${ }^{21}$ The difference likely is a consequence of the more sensitive detection method used to stain Western blots with enhanced chemiluminescence, instead of horseradish peroxidase. ${ }^{21}$ In comparison to human platelets, Gas6 was found to be present in human plasma at a 20-fold higher concentration, which is in agreement with levels measured by others of $15-60 \mu \mathrm{g} / \mathrm{L} .^{21,22}$ Accordingly, in the human system, plasma-derived Gas6 is responsible for the majority of effects of this protein. Since the Gas6 level in mouse plasma is substantially lower, around $6 \mu \mathrm{g} / \mathrm{L},{ }^{31}$ it is likely that in mice both plasma- and platelet-derived Gas 6 contribute to the stimulation of platelet aggregation.

The data demonstrate that in mice Gas6 interaction with platelet Gas6 receptors plays an important role in thrombus formation under flow on collagen, in particular by preventing disassembly of formed thrombi. In contrast, the absence of Gas6 or its receptors does not appear to impair platelet activation by collagen. In mice, all three Gas6 receptors (Axl, Sky, Mer) seem to be equally important, as knockout of each receptor produced a similar phenotype of reduced thrombus formation. The latter finding agrees with earlier data showing reduced experimental thrombosis in vivo in the absence of any of the Gas 6 receptors. ${ }^{12}$

Our results seemingly contrast to those of a paper claiming that only the Mer receptor may be expressed on platelets and mediate Gas 6 effects. ${ }^{20}$ On the opposite, two studies have provided solid evidence for the presence of three Gas6 receptors in human and mouse platelets, evidenced by mRNA expression analysis and identification of the receptor proteins at the platelet surface. ${ }^{12,32}$ Some authors have used blocking anti-Gas6 receptor antibodies to demonstrate effective interaction of Gas6 with its receptors during platelet activation. ${ }^{32}$ Unfortunately, in our hands this anti-human Gas6 Ab (sc1935) only inhibited platelet aggregation when it contained the preserving reagent azide (data not shown). Hence, further investigation is needed to show via which receptors human Gas6 contributes to platelet activation.

It has been reported that Gas6 levels markedly vary between plasmas from healthy subjects, and that this variation does not correlate with platelet aggregation. ${ }^{23}$ However, we find that ADP-induced platelets aggregation is significantly impaired in plasma completely lacking Gas6, and that recombinant Gas6 reverses this impairment. 
Together, this suggests that the physiological range of Gas6 levels is more than sufficient to be effective. Furthermore, Gas6 derived from human plasma supports moderate high-shear thrombus formation on collagen. In particular, Gas6 appears to synergize with ADP to keep the aggregates together. Interestingly, during post-perfusion with Gas6-depleted plasma, most platelets left the aggregates after a 3-min delay. This suggests that at earlier time points other signaling events - likely ADP-mediated - mask the involvement of Gas6. It is conceivable that the ADP/P2 $Y_{12}$-dependent contribution to persistent $\alpha$ llb $\beta 3$ activation ${ }^{17}$ is limited after several minutes, and that from this time point on the contribution of Gas6 signaling becomes critical. In suspended platelets (PRP), a similar situation may occur, since ADP is rapidly degraded by the exonucleotidases present in plasma. ${ }^{33}$

Both in human and mouse, Gas6 synergizes with ADP in platelet aggregation. In mice, Gas6 interaction with its receptors on activated murine platelets was shown to involve PI3K and Akt. ${ }^{12}$ We found that also in resting human platelets, rhGas6 induced Akt phosphorylation. Furthermore, rhGas6 enhanced Akt phosphorylation in ADPstimulated human platelets (data not shown). Earlier, we have described a key role for $\mathrm{PI} 3 \mathrm{~K} \beta$ and Akt, downstream of $\mathrm{P}_{2} \mathrm{Y}_{12}$ signaling in causing sustained integrin $\alpha$ llb $\beta 3$ activation and thrombus stability in both man and mouse. ${ }^{17}$ Since the $\mathrm{P}_{2} \mathrm{Y}_{12}$ receptor does not have recognition sites for $\mathrm{SH} 2 / 3$ domains to bind the $\mathrm{p} 85$ regulatory subunit of $\mathrm{PI} 3 \mathrm{~K} \beta$, while all Gas6 receptors do contain such sites, ${ }^{19}$ it was postulated that $\mathrm{PI} 3 \mathrm{~K}$ mediated $\mathrm{P} 2 \mathrm{Y}_{12}$-dependent $\alpha$ llb $\beta 3$ activation may rely on Gas6-Gas6 receptor signaling. Instead, we found that the PI3K $\beta$ inhibitor TGX221 suppressed $\alpha$ llb $\beta 3$ activation to a similar degree in the presence and absence of Gas6 in both human and mouse platelets. It is thus concluded that $\mathrm{P}_{2} \mathrm{Y}_{12}$ can directly signal via $\mathrm{PI} 3 \mathrm{~K}$, which agrees with a recent study where PI3K $\beta$ was reported to interact with the $\beta \gamma$ subunit of G-protein coupled receptors in macrophages and fibroblasts. ${ }^{34}$

Besides receptor binding via its C-terminal G-domains, Gas6 is also thought to bind to PS with its N-terminal Gla-domains. ${ }^{6,35}$ In other cell types, it has been shown that $\gamma$ carboxylation of these Gla-residues is essential for Gas6-Gas6 receptor binding. ${ }^{36,37}$ For platelets, this has not been investigated. Furthermore, it is unknown whether the interaction of Gas6 with PS does affect coagulant activity. The present results suggest, however, that the latter is unlikely, since tissue factor-induced thrombin generation was unaltered in PRP from Gas6-deficient mice.

Together, the present results lead to the following scheme on the roles of Gas 6 and Gas6 receptors in thrombus formation (Fig. 8). Platelet activation on collagen results in the secretion of considerable amounts of ADP (human and mouse) and Gas6 (mouse) and likely in the exposure of Gas6 receptors. Both ADP (acting via P2Y ${ }_{12}$ ) and Gas6 (via $\mathrm{Axl}$, Sky and Mer) elicit signaling to keep integrin $\alpha$ llb $\beta 3$ in its activated state. These events cooperate in the formation as well as the stabilization of platelet aggregates. Jointly, $\mathrm{P} 2 \mathrm{Y}_{12}$ and Gas6 receptors stimulate $\mathrm{PI} 3 \mathrm{~K} \beta$, which is one of the major proteins to irreversible integrin activation via Akt/PKB and Rap1b. ${ }^{38}$ Other signaling pathways, e.g. mediated by $\mathrm{Gq}$-coupled receptors for $\mathrm{ADP}, \mathrm{TxA}_{2}$ and thrombin will assist in achieving maximal thrombus stability. 


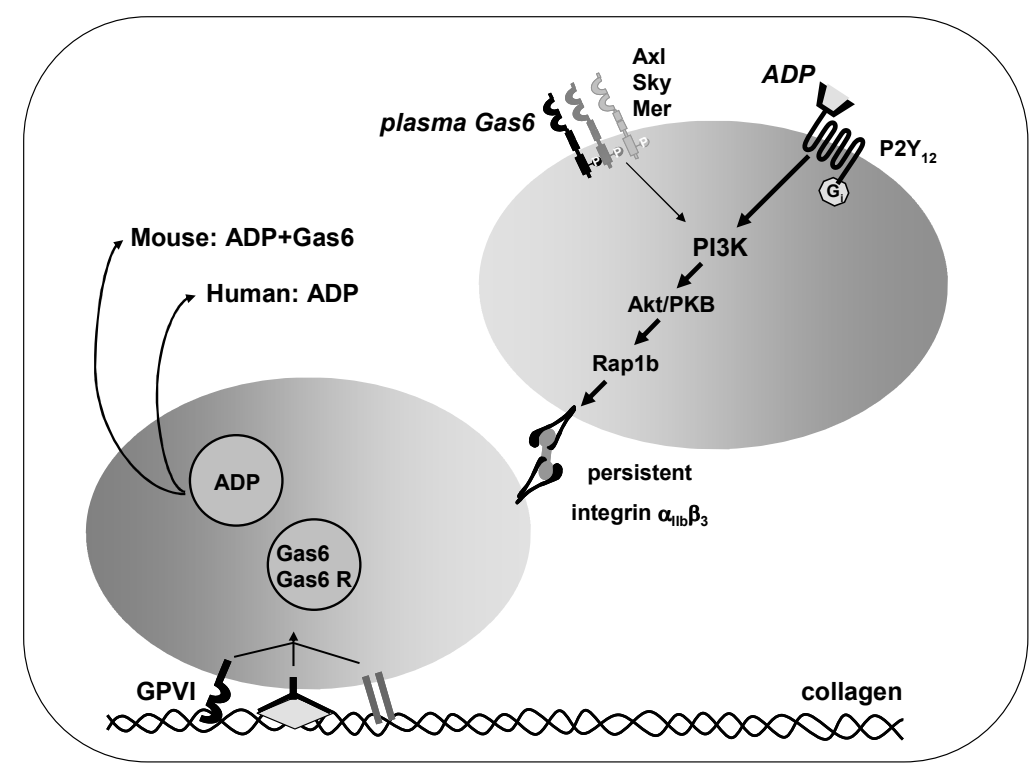

Figure 8. Proposed roles of Gas6 and PI3K in thrombus stabilization. Receptors for Gas6 (AxI, Sky, Mer) and ADP (P2Y 12 ) cooperate in the activation of PI3K isoforms to achieve persistent $\alpha$ llb $\beta 3$ activation. Platelet activation on collagen results in the secretion of considerable amounts of ADP (human and mouse) and Gas6 (mouse) and likely in the exposure of Gas6 receptors. Downstream of PI3K is the activation of Akt/PKB (protein kinase B), which activates $\alpha$ llbb33 via Rap1b. ${ }^{16,38}$ Gas6 derived from platelets or plasma augments this signaling pathway. Not indicated is the involvement of other signaling pathways in persistent $\alpha$ llb $\beta 3$ activation, e.g. through Gqcoupled receptors for ADP, TxA $A_{2}$ and thrombin.

\section{Acknowledgment}

This work was supported by grants of the Netherlands Organization for Scientific Research (11-400-076 and 902-16-276).

\section{References}

1. Manfioletti G, Brancolini C, Avanzi G, Schneider C. The protein encoded by a growth arrestspecific gene (gas6) is a new member of the vitamin K-dependent proteins related to protein S, a negative coregulator in the blood coagulation cascade. Mol Cell Biol. 1993;13:49764985.

2. Nakano T, Higashino K, Kikuchi N, Kishino J, Nomura K, Fujita H, Ohara O, Arita H. Vascular smooth muscle cell-derived, Gla-containing growth-potentiating factor for $\mathrm{Ca}^{2+}$-mobilizing growth factors. J Biol Chem. 1995;270:5702-5705.

3. Avanzi GC, Gallicchio M, Cavalloni G, Gammaitoni L, Leone F, Rosina A, Boldorini R, Monga G, Pegoraro L, Varnum B, Aglietta M. Gas6, the ligand of Axl and Rse receptors, is expressed in hematopoietic tissue but lacks mitogenic activity. Exp Hematol. 1997;25:12191226.

4. Goruppi S, Ruaro E, Schneider C. Gas6, the ligand of Axl tyrosine kinase receptor, has mitogenic and survival activities for serum starved NIH3T3 fibroblasts. Oncogene. 1996;12:471-480.

5. McCloskey P, Fridell YW, Attar E, Villa J, Jin Y, Varnum B, Liu ET. Gas6 mediates adhesion of cells expressing the receptor tyrosine kinase Axl. J Biol Chem. 1997;272:23285-23291. 
6. Nakano T, Ishimoto Y, Kishino J, Umeda M, Inoue K, Nagata K, Ohashi K, Mizuno K, Arita H. Cell adhesion to phosphatidylserine mediated by a product of growth arrest-specific gene 6 . J Biol Chem. 1997;272:29411-29414.

7. Tjwa M, Bellido-Martin L, Lin Y, Lutgens E, Plaisance S, Bono F, Delesque-Touchard N, Herve C, Moura R, Billiau AD, Aparicio C, Levi M, Daemen M, Dewerchin M, Lupu F, Arnout J, Herbert JM, Waer M, Garcia de Frutos P, Dahlbäck B, Carmeliet P, Hoylaerts MF, Moons L. Gas6 promotes inflammation by enhancing interactions between endothelial cells, platelets, and leukocytes. Blood. 2008;111:4096-4105.

8. Stitt TN, Conn G, Gore M, Lai C, Bruno J, Radziejewski C, Mattsson K, Fisher J, Gies DR, Jones $\mathrm{PF}$, et al. The anticoagulation factor protein $\mathrm{S}$ and its relative, Gas6, are ligands for the Tyro 3/AxI family of receptor tyrosine kinases. Cell. 1995;80:661-670.

9. Varnum BC, Young C, Elliott G, Garcia A, Bartley TD, Fridell YW, Hunt RW, Trail G, Clogston $\mathrm{C}$, Toso $\mathrm{RJ}$, et al. Axl receptor tyrosine kinase stimulated by the vitamin K-dependent protein encoded by growth-arrest-specific gene 6. Nature. 1995;373:623-626.

10. Nagata K, Ohashi K, Nakano T, Arita H, Zong C, Hanafusa H, Mizuno K. Identification of the product of growth arrest-specific gene 6 as a common ligand for Axl, Sky, and Mer receptor tyrosine kinases. J Biol Chem. 1996;271:30022-30027.

11. Angelillo-Scherrer A, de Frutos P, Aparicio C, Melis E, Savi P, Lupu F, Arnout J, Dewerchin M, Hoylaerts M, Herbert J, Collen D, Dahlbäck B, Carmeliet P. Deficiency or inhibition of Gas6 causes platelet dysfunction and protects mice against thrombosis. Nat Med. 2001;7:215-221.

12. Angelillo-Scherrer A, Burnier L, Flores N, Savi P, DeMol M, Schaeffer P, Herbert JM, Lemke G, Goff SP, Matsushima GK, Earp HS, Vesin C, Hoylaerts MF, Plaisance S, Collen D Conway EM, Wehrle-Haller B, Carmeliet P. Role of Gas6 receptors in platelet signaling during thrombus stabilization and implications for antithrombotic therapy. $J$ Clin Invest. 2005;115:237-246.

13. Goruppi S, Ruaro E, Varnum B, Schneider C. Requirement of phosphatidylinositol 3-kinasedependent pathway and Src for Gas6-Axl mitogenic and survival activities in NIH 3T3 fibroblasts. Mol Cell Biol. 1997;17:4442-4453.

14. Melaragno MG, Cavet ME, Yan C, Tai LK, Jin ZG, Haendeler J, Berk BC. Gas6 inhibits apoptosis in vascular smooth muscle: role of Axl kinase and Akt. J Mol Cell Cardiol. 2004;37:881-887.

15. Hirsch E, Bosco O, Tropel P, Laffargue M, Calvez R, Altruda F, Wymann M, Montrucchio G. Resistance to thromboembolism in PI3K $\gamma$-deficient mice. FASEB J. 2001;15:2019-2021.

16. Jackson SP, Schoenwaelder SM, Goncalves I, Nesbitt WS, Yap CL, Wright CE, Kenche V Anderson KE, Dopheide SM, Yuan Y, Sturgeon SA, Prabaharan H, Thompson PE, Smith GD, Shepherd PR, Daniele N, Kulkarni S, Abbott B, Saylik D, Jones C, Lu L, Giuliano S, Hughan SC, Angus JA, Robertson AD, Salem HH. PI 3-kinase p110 3 : a new target for antithrombotic therapy. Nat Med. 2005;11:507-514.

17. Cosemans JM, Munnix IC, Wetzker R, Heller R, Jackson SP, Heemskerk JW. Continuous signaling via PI3K isoforms $\beta$ and $\gamma$ is required for platelet ADP receptor function in dynamic thrombus stabilization. Blood. 2006;108:3045-3052.

18. Engelman JA, Luo J, Cantley LC. The evolution of phosphatidylinositol 3-kinases as regulators of growth and metabolism. Nat Rev Genet. 2006;7:606-619.

19. Hafizi S, Dahlbäck B. Signalling and functional diversity within the Axl subfamily of receptor tyrosine kinases. Cytokine Growth Factor Rev. 2006;17:295-304.

20. Chen C, Li Q, Darrow AL, Wang Y, Derian CK, Yang J, de Garavilla L, Andrade-Gordon P, Damiano BP. Mer receptor tyrosine kinase signaling participates in platelet function. Arterioscler Thromb Vasc Biol. 2004;24:1118-1123.

21. Balogh I, Hafizi S, Stenhoff J, Hansson K, Dahlbäck B. Analysis of Gas6 in human platelets and plasma. Arterioscler Thromb Vasc Biol. 2005;24:1280-1206.

22. Clauser S, Peyrard S, Gaussem P, Crespin M, Emmerich J, Aiach M, Borgel D. Development of a novel immunoassay for the assessment of plasma Gas6 concentrations and their variation with hormonal status. Clin Chem. 2007;53:1808-1813. 
23. Clauser S, Bachelot-Lozat C, Fontana P, Gaussem P, Remones V, Aiach M, Borgel D. Physiological plasma Gas6 levels do not influence platelet aggregation. Arterioscler Thromb Vasc Biol. 2006;26:e22.

24. Siljander PR, Munnix IC, Smethurst PA, Deckmyn H, Lindhout T, Ouwehand WH, Farndale RW, Heemskerk JW. Platelet receptor interplay regulates collagen-induced thrombus formation in flowing human blood. Blood. 2004;103:1333-1341.

25. Van der Meijden PE, Feijge MA, Giesen PL, Huijberts M, van Raak LP, Heemskerk JW Platelet $P 2 Y_{12}$ receptors enhance signalling towards procoagulant activity and thrombin generation. A study with healthy subjects and patients at thrombotic risk. Thromb Haemost. 2005;93:1128-1136.

26. Lu Q, Gore M, Zhang Q, Camenisch T, Boast S, Casagranda F, Lai C, Skinner MK, Klein R, Matsushima GK, Earp HS, Goff SP, Lemke G. Tyro-3 family receptors are essential regulators of mammalian spermatogenesis. Nature. 1999;398:723-728.

27. Dahlbäck B. Purification of human vitamin K-dependent protein $S$ and its limited proteolysis by thrombin. Biochem J. 1983;209:837-846.

28. Heemskerk JW, Willems GM, Rook MB, Sage SO. Ragged spiking of free calcium in ADPstimulated human platelets: regulation of puff-like calcium signals in vitro and ex vivo. $J$ Physiol. 2001;535:625-635.

29. Kuijpers MJ, Schulte $V$, Bergmeier $W$, Lindhout $T$, Brakebusch $C$, Offermanns S, Fassler R, Heemskerk JW, Nieswandt B. Complementary roles of glycoprotein VI and $\alpha 2 \beta 1$ integrin in collagen-induced thrombus formation in flowing whole blood ex vivo. FASEB J. 2003;17:685687.

30. Munnix IC, Kuijpers MJ, Auger J, Thomassen CM, Panizzi P, van Zandvoort MA, Rosing J, Bock PE, Watson SP, Heemskerk JW. Segregation of platelet aggregatory and procoagulant microdomains in thrombus formation: regulation by transient integrin activation. Arterioscler Thromb Vasc Biol. 2007;27:2484-2490.

31. Angelillo-Scherrer A, Burnier L, Lambrechts D, Fish RJ, Tjwa M, Plaisance S, Sugamele R, DeMol M, Martinez-Soria E, Maxwell PH, Lemke G, Goff SP, Matsushima GK, Earp HS, Chanson M, Collen D, Izui S, Schapira M, Conway EM, Carmeliet P. Role of Gas6 in erythropoiesis and anemia in mice. J Clin Invest. 2008;118:583-596.

32. Gould WR, Baxi SM, Schroeder R, Peng YW, Leadley RJ, Peterson JT, Perrin LA. Gas6 receptors Axl, Sky and Mer enhance platelet activation and regulate thrombotic responses. $J$ Thromb Haemost. 2005;3:733-741.

33. Cauwenberghs S, Feijge MA, Hageman G, Hoylaerts M, Akkerman JW, Curvers J, Heemskerk JW. Plasma ectonucleotidases prevent desensitization of purinergic receptors in stored platelets: importance for platelet activity during thrombus formation. Transfusion. 2006;46:1018-1028.

34. Guillermet-Guibert J, Bjorklof K, Salpekar A, Gonella C, Ramadani F, Bilancio A, Meek S, Smith AJH, Okkenhaug K, Vanhaesebroeck B. The p110 3 isoform of phosphoinositide 3kinase signals downstream of $\mathrm{G}$ protein-coupled receptors and is functionally redundant with p110 $\gamma$. Proc Natl Acad Sci USA. 2008;105:8292-8297.

35. Sasaki T, Knyazev PG, Clout NJ, Cheburkin Y, Gohring W, Ullrich A, Timpl R, Hohenester E. Structural basis for Gas6-Axl signalling. EMBO J. 2006;25:80-87.

36. Nakano T, Kawamoto K, Kishino J, Nomura K, Higashino K, Arita H. Requirement of gammacarboxyglutamic acid residues for the biological activity of Gas6: contribution of endogenous Gas6 to the proliferation of vascular smooth muscle cells. Biochem J. 1997;323:387-392.

37. Tanabe K, Nagata K, Ohashi K, Nakano T, Arita H, Mizuno K. Roles of $\gamma$-carboxylation and a sex hormone-binding globulin-like domain in receptor-binding and in biological activities of Gas6. FEBS Lett. 1997;408:306-310.

38. Cosemans JM, Iserbyt BF, Deckmyn H, Heemskerk JW. Multiple ways to switch platelet integrins on and off. J Thromb Haemost. 2008;6:1253-1261. 


\section{Multiple ways to switch platelet integrins on and off}

Judith M.E.M. Cosemans, Brecht F. Iserbyt, Hans Deckmyn and Johan W.M. Heemskerk

J Thromb Haemost 2008; 6: 1253-1261

Reprinted with permission 


\begin{abstract}
In the classical concept of platelet integrin activation, it is considered that unidirectional conformation changes of $\alpha \mathrm{llb} \beta 3$ and $\alpha 2 \beta 1$ regulate the adhesiveness of platelets for fibrin(ogen) and collagen, respectively. Here, we summarise recent evidence that these conformational changes (i) can also occur in the reverse direction and, (ii) are not independent events. Platelet stimulation through the $\mathrm{P} 2 \mathrm{Y}_{12}$ receptors provokes only transient $\alpha$ llb $\beta 3$ activation via signaling routes involving phosphoinositide 3-kinases and Rap1b. Furthermore, $\alpha$ llb $\beta 3$ can be secondarily inactivated in platelets with prolonged high $\mathrm{Ca}^{2+}$ rises, which expose phosphatidylserine and bind coagulation factors. Thus, platelet stimulation with strong agonists (collagen and thrombin) also results in transient integrin activation. Integrin $\alpha 2 \beta 1$ is found to be activated by a mechanism that is directly linked to $\alpha \operatorname{llb} \beta 3$ activation. Integrin $\alpha 2 \beta 1$ can adopt different activation states, depending on the trigger. Conclusively, reversibility and synchrony of platelet integrin activation are newly identified mechanisms to restrict thrombus growth and to allow optimal coagulation factor binding. Back-shifting of activated integrins towards their resting state may be a novel goal of antithrombotic medication.
\end{abstract}

\title{
Structural aspects of $\alpha 2 \beta 1$ and $\alpha$ llb $\beta 3$ activation
}

Integrins are of key importance for the adhesive and signaling functions of platelets. Like other integrins, the platelet 'collagen receptor' $\alpha 2 \beta 1$ and the 'fibrinogen receptor' $\alpha$ llb $\beta 3$ are heterodimers with a transmembrane $\alpha$ and $\beta$ chain. The large extracellular moieties of both chains consist of a stalk-like region and a globular head moiety, the latter of which bears cation-binding domains and the ligand recognition sites (Table 1). The globular heads of both the $\alpha 2$ and $\alpha$ llb chains contain a $\mathrm{Ca}^{2+}$-binding $\beta$-propeller domain, whereas the $\alpha 2$ head uniquely has a so-called inserted domain (I-domain). ${ }^{1}$ This $\alpha 2$ I-domain characteristically has a metal ion-dependent adhesion site (MIDAS), which coordinates the binding of a $\mathrm{Mg}^{2+}$ ion and thereby controls ligand binding. ${ }^{2}$ Within the head moieties of the $\beta 1$ and $\beta 3$ chains, binding of ligands is confined to $\beta A$-domains, which contain several metal-binding (MIDAS-like) sites and recognize $\mathrm{Ca}^{2+}, \mathrm{Mg}^{2+}$ and $\mathrm{Mn}^{2+}$ ions. $^{3}$ The adhesive properties of $\alpha 2 \beta 1$ and $\alpha$ llb $\beta 3$ are therefore quite sensitive to the extracellular levels of divalent cations.

Platelet integrin $\alpha 2 \beta 1$ serves as adhesion receptor for a variety of ligands, the most important ones are soluble and fibrillar collagens. It is the second most abundant platelet integrin, being expressed at 2,000-4,000 copies per platelet (Table 1). Integrin $\alpha 2 \beta 1$ binds with high-affinity to triple-helical peptides that contain the collagen-derived hexapeptide sequence, GFOGER (where $O$ stands for hydroxyproline). ${ }^{4}$ Cocrystallisation studies of the $\alpha 2$ I-domain with a GFOGER peptide showed that the binding was mediated by $\mathrm{Mg}^{2+}$ ion in the $\alpha 2$ MIDAS and the GER sequence in the peptide ligand. ${ }^{4,5}$ There is good evidence that native $\alpha 2 \beta 1$ binds to similar stretches of amino acids in collagen fibers, again in a $\mathrm{Mg}^{2+}$-dependent manner, where the affinity decreases when the $F$ in the second position is changed into $L>M>A ., 7$ 





Integrin $\alpha \mathrm{llb} \beta 3$ is expressed on the platelet surface at much higher copy numbers, in the order of $60,000-80,000$, with an additional pool that becomes available after granule release following platelet stimulation. ${ }^{8}$ In spite of the abundant presence, in resting platelets $\alpha$ llb $\beta 3$ has a remarkably low affinity for its ligands. However, platelet stimulation greatly increases the affinity of $\alpha$ llb $\beta 3$ for fibrinogen, fibrin, fibronectin, von Willebrand factor and other ligands, most of which contain RGD or KGD sequences (Table 1). This increase in affinity is achieved by a major conformational change, probably consisting of an extension or 'opening' of the two globular head domains. ${ }^{1}$ Indeed, $\alpha$ llb $\beta 3$ activation is often considered as a synonym for platelet activation, which illustrates the importance of this structural change. The activated state of this integrin can be probed with several anti- $\alpha$ llb $\beta 3$ antibodies, for example directed against ligand-induced binding sites (LIBS antibodies) or to the fibrinogen binding site (PAC-1 antibody). ${ }^{8,9}$

It is considered that the extracellular stalk-like regions of $\alpha$ llb $\beta 3$ and likely also of $\alpha 2 \beta 1$ are severely bent under resting conditions. In stimulated platelets, integrin insideout signaling causes straightening of the $\alpha$ and $\beta$ chains via a switchblade like motion. ${ }^{10}$ In the active $\alpha$ llb $\beta 3$ conformation, ligands nestle into the interface between the $\alpha$ llb $\beta$ propeller domain and the $\beta A$-domain. ${ }^{3}$ An additional increase in ligand affinity is caused by clustering of $\alpha$ llb $\beta 3$ into dimers via so-called outside-in signaling (integrin avidity regulation). ${ }^{8}$ The current view is that the switchblade like conformation change is controlled by cytoplasmic regions of the $\alpha$ llb and $\beta 3$ chains close to the membrane. In the resting state of the integrin, these regions may form a stabilising clasp. ${ }^{1}$ Upon platelet activation, binding of integrin-associated proteins to the $\beta 3$ chain triggers unclasping. The precise molecular events are unclear, also because of the large variety in signaling, cytoskeletal and other proteins that can bind to $\beta 3$. The unclasping of $\beta 3$ and $\alpha \mathrm{llb}$ is considered to be an equilibrium-controlled process, which implies reversibility. It provides the driving force for the extracellular conformational change of the integrin. There are several pieces of evidence that interaction of cytoskeletal talin with $\beta 3$ plays a key role in the unclasping and conformational change. ${ }^{1}$ This is confirmed by recent studies with knockout mice, indicating that talin as well as (cytoskeletal-associated) kindlin-3 are required for $\alpha$ llb $\beta 3$ activation. ${ }^{11-13}$

The classical model of inside-out integrin activation stipulates that unidirectional conformation changes of $\alpha \mathrm{llb} \beta 3$ and $\alpha 2 \beta 1$ convert platelets from non-adherent to adherent cells. However, evidence is emerging that in a variety of cells, integrinmediated processes can be reversible, implying that the affinity regulation of the integrin receptors is a dynamic rather than a static mechanism. ${ }^{14}$ Here we discuss recent findings, that also in platelets, the activating changes of integrins are dynamically controlled and often occur in the reverse direction.

\section{Reversibility of $\alpha$ llb $\beta 3$ activation in relation to platelet aggregation}

Binding of von Willebrand factor and fibrinogen to activated $\alpha \operatorname{llb} \beta 3$ are initial steps in multiplatelet aggregate formation. ${ }^{15}$ There are several pieces of evidence in the literature that this aggregation process can be highly reversible, especially under conditions where 


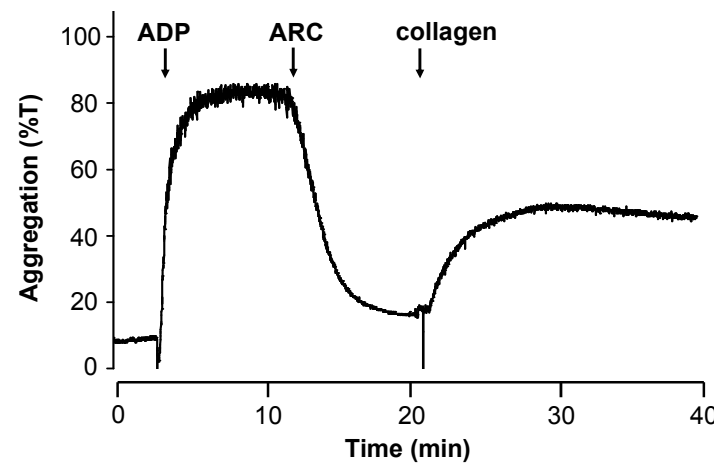

Figure 1. Repetitive aggregation of platelets. Aggregation of platelet-rich plasma was triggered with ADP, after which full disaggregation was provoked by blocking of P2 $\mathrm{Y}_{12}$ receptors with ARC69931MX (ARC). Subsequent addition of collagen can cause a second aggregation response. Changes in light transmission are shown.

ADP acts as primary or secondary agonist. For instance, in patients with delta-storage pool deficiency, where stored ADP is limiting or absent, platelet aggregate formation is a partly or completely transient reaction. ${ }^{16}$ Furthermore, once ADP-induced aggregates consisting of normal platelets are formed, post-treatment with cAMP-elevating agents leads to complete disaggregation, accompanied by reversibility in fibrinogen binding. ${ }^{16}$ In platelets from man as well as mouse, the $\mathrm{P}_{2} \mathrm{Y}_{12}$ receptors (rather than $\mathrm{P}_{2} \mathrm{Y}_{1}$ receptors) are particularly implicated in the regulation of disaggregation. ${ }^{17,18}$ Recent work, where this was investigated in detail, has shown that application of the P2Y $\mathrm{Y}_{12}$ antagonist ARC69931MX to preactivated platelets effectively causes full disaggregation, again being accompanied by abolition of fibrinogen- and PAC-1 binding to $\alpha$ llb $\beta 3 .{ }^{19,20}$ Interestingly, such disaggregated platelets can still undergo a second aggregation reaction, for example when activated by collagen (see Fig. 1). Note that reversible platelet aggregation is often but not always accompanied by integrin inactivation. For instance, in platelets where the allb subunit was cleaved by the protease elastase, disaggregation occurred, whereas PAC-1 binding remained unchanged. ${ }^{21}$

However, parallel studies of ADP-induced platelet aggregation and $\alpha \mathrm{llb} \beta 3$ activation have indicated that persistent $\mathrm{P} 2 \mathrm{Y}_{12}$ signaling is needed to keep the integrin in its activated state. Several groups have investigated the signaling pathways implicated in the perpetuation of $\alpha \mathrm{llb} \beta 3$ activation. Next to Gi protein-mediated lowering of cAMP, activation of phosphoinositide 3-kinase (PI3K) was found to be important. This is illustrated by the fact that disaggregation and $\alpha$ llb $\beta 3$ inactivation can be instantaneously provoked upon treatment of aggregates with $\mathrm{PI} 3 \mathrm{~K}$ inhibitors like wortmannin and LY294002. ${ }^{16,18,19,22}$ Two different PI3K isoforms, $\beta$ and $\gamma$, appear to be involved in persistent integrin activation downstream of $\mathrm{P}_{2} \mathrm{Y}_{12 .}{ }^{19,23}$ Of particular interest is $\mathrm{PI} K \mathrm{~K} \beta$, as this is an upstream activator of Akt kinase (PKB) and the small G-protein Rap $1 \mathrm{~b} .^{24,25}$ It is feasible that Rap1b acts as a time-dependent switch to control the integrin (in)activation. Evidence for this idea comes, for example, from the finding that deficiency in Rap $1 \mathrm{~b}$ diminishes platelet aggregation as well as $\alpha$ llb $\beta 3$ activation. ${ }^{26}$ Furthermore, activated Rap1b can return to its inactive GDP-bound form after blocking of the $\mathrm{P} 2 \mathrm{Y}_{12}$ receptors. ${ }^{20}$ 




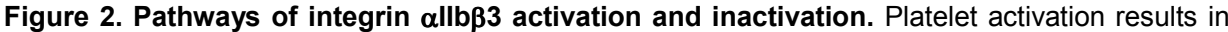
an activating, conformational change of integrin $\alpha$ llb $\beta 3$ by inside-out signaling. In the case of ADP stimulation, this activated state (required for binding fibrinogen and PAC-1) is a transient state and fully reversible. Outside-in signaling of the integrin and contact-dependent signaling can consolidate an activated $\alpha$ llb $\beta 3$ conformation. Under conditions of prolonged high $\mathrm{Ca}^{2+}$ levels, such as in annexin A5-binding platelets exposing phosphatidylserine, $\alpha$ llb $\beta 3$ becomes secondarily inactivated and no longer binds fibrinogen and PAC-1. The structure of this inactivated state is still unknown.

Also, a link of Rap1b via its effector RIAM (Rap 1 interacting adaptor molecule) to talin-allbß3 interaction has been proposed. ${ }^{27}$

Together, this leads to the concept that, in response to ADP and, hence, also other agonists that release ADP, the activating conformational change of allb $\beta 3$ (binding fibrinogen and PAC-1), is an intrinsically reversible rather than a unidirectional event (Fig. 2). In such a model, the integrin requires continuous input through signaling via $\mathrm{P} 2 \mathrm{Y}_{12}$ receptors to $\mathrm{PI3K}$ isoforms and Rap1b in order to retain its activated conformation and to keep the platelet aggregate together. What the role is of the $\beta 3$-associated cytoskeletal proteins in this model of dynamic integrin activation needs further investigation.

\section{Thrombus stabilization and persistent $\alpha$ llb $\beta 3$ activation}

A key question is how the intrinsic reversibility of $\alpha \mathrm{llb} \beta 3$ activation affects the process of thrombus formation in flowing blood. A first answer may come from the observation that murine thrombi, formed in vivo, are markedly unstable in mice lacking $\mathrm{P}_{2} \mathrm{Y}_{12}$ receptors. ${ }^{18}$ Similarly, ex vivo flow studies with (reconstituted) blood show that thrombi on collagen easily disintegrate if $\mathrm{P} 2 \mathrm{Y}_{12}$ receptors are absent or blocked, particularly at physiologic, millimolar concentrations of $\mathrm{Mg}^{2+}$ and $\mathrm{Ca}^{2+} \cdot{ }^{19,28,29}$ Importantly, late application of $\mathrm{P}_{2} \mathrm{Y}_{12}$ blockers also leads to immediate disintegration of the thrombi. The same holds for inhibition of signaling pathways downstream of $\mathrm{P}_{2} \mathrm{Y}_{12}$. Thrombi formed in vivo and ex vivo are markedly unstable, when using mice lacking the $\mathrm{PI} 3 \mathrm{~K} \gamma$ isoform, ${ }^{30,31}$ or when PI3K $\beta$ is blocked with TGX-221. ${ }^{19,24}$

There is some evidence that also the other ADP receptor, $P 2 Y_{1}$, contributes to thrombus stabilization, for example by evoking oscillatory $\mathrm{Ca}^{2+}$ responses which link to activation of $\alpha \mathrm{llb} \beta 3 .{ }^{29}$ However, in thrombus formation on collagen at high shear rate, it appears that blockade of $\mathrm{P}_{2} \mathrm{Y}_{1}$ receptors is much less effective in causing platelet disaggregation than $\mathrm{P}_{2} \mathrm{Y}_{12}$ blockade. ${ }^{19}$ Furthermore, the small effect of $\mathrm{P} 2 \mathrm{Y}_{1}$ blockade is 
surpassed by co-inhibition of $\mathrm{PI} 3 \mathrm{~K} \beta$ or $\mathrm{PI} 3 \mathrm{~K} \gamma$, and does not increase the effect of $\mathrm{P}_{2} \mathrm{Y}_{12}$ inhibitors. Another study has shown that signaling via $\mathrm{P}_{2} \mathrm{Y}_{12}$ (probably next to $\mathrm{P} 2 \mathrm{Y}_{1}$ ), together with integrin $\alpha$ llb $\beta 3$ engagement, contributes to the onset of oscillatory $\mathrm{Ca}^{2+}$ fluxes. ${ }^{32}$ Together, these findings suggest that $\mathrm{P}_{2} \mathrm{Y}_{1}$ contributes to thrombus stabilization by enforcing feed-forward loops involving $\mathrm{P}_{2} \mathrm{Y}_{12}$. In this setting, the oscillatory $\mathrm{Ca}^{2+}$ fluxes may function to promote secretion of ADP.

Activated $\alpha$ llb $\beta 3$ itself also contributes to thrombus stability by another feed-forward loop, that is by outside-in activation following ligand binding. Fibrinogen binding to $\alpha$ llb $\beta 3$ results in tyrosine phosphorylation of the cytoplasmic part of the $\beta 3$ chain, which triggers the complex formation of a plethora of integrin-binding proteins, including signaling and cytoskeletal proteins. ${ }^{1,33,34}$ Evidence that outside-in signaling pathways are important for thrombus stabilization comes from studies with mutant diYF mice, where the $\beta 3$ tyrosines $\mathrm{Y} 747$ and $\mathrm{Y} 759$ were substituted by phenylalanines. Platelets from these mice show impaired integrin outside-in signaling, which is accompanied by defective platelet aggregate formation and increased disaggregation. ${ }^{35}$ Interestingly, threoninephosphorylation of the $\beta 3$ chain may also contribute to outside-in activation. ${ }^{36}$ Outside-in signaling leads, for instance, to activation of PI3K. However, no studies have addressed the issue of which part of PI3K activation is directly downstream of $\alpha$ llb $\beta 3$ or downstream of $\mathrm{P}_{2} \mathrm{Y}_{12}$ receptor function. The reported effects of PI3K inhibitors on $\alpha$ llb $\beta 3$ activationdependent platelet responses, including persistent aggregation, ${ }^{24,37,38}$ thus may or may not involve signaling events via $\mathrm{P}_{2} \mathrm{Y}_{12}$ receptors. In summary, it appears that thrombus formation under flow is a dynamic process, which relies on persistent ADP release and continuous $\mathrm{P}_{2} \mathrm{Y}_{12}$-mediated inside-out signaling to $\mathrm{PI} 3 \mathrm{~K}$ isoforms $\beta$ and $\gamma$ and integrin activation. Positive feed-forward loops of integrin outside-in signaling may provide an additional way to keep the formed thrombi together. In other words, stabilization of ADPthrombi requires a continuous signaling input.

\section{Secondary inactivation of $\alpha$ llb $\beta 3$ in procoagulant platelets}

Platelets that are subjected to strongly activating conditions, such as evoked by glycoprotein (GP) VI interaction with collagen, ${ }^{39}$ or by the combination of thrombin and ADP ${ }^{40}$, can undergo a marked loss in adhesiveness. They often lose their pseudopods and lamellipods, disintegrate, form membrane blebs and microparticles, decrease contact with the underlying surface, and finally adopt a balloon-like shape. ${ }^{41,42}$ These platelets characteristically show prolonged, high intracellular $\mathrm{Ca}^{2+}$ rises, and can be identified by their ability to bind annexin A5, which is a probe for surface-exposed phosphatidylserine. ${ }^{43}$ As these platelets bind coagulation factors and greatly enhance thrombin formation at their surface, they have been termed procoagulant platelets. Alternatively, platelets which form blebs and microparticles are also described as having a sustained $\mathrm{Ca}^{2+}$ induced platelet (SCIP) morphology. ${ }^{41}$ Experiments designed to characterise the relationship between the SCIP, bleb-forming and phosphatidylserineexposing platelets have revealed them to be markers of the same platelet population 
(J.W.M. Heemskerk and S.P. Jackson, unpublished). Other groups have referred to these cells as 'coated' platelets. ${ }^{44,45}$

The changed morphology and the gradual decrease in adhesiveness of phosphatidylserine-exposing platelets suggests a loss of function of the integrins in these activated cells, for instance by inactivation or cleavage. It has indeed been reported that platelet aggregate formation greatly diminishes under conditions favoring phosphatidylserine exposure. ${ }^{46}$ Several groups have shown that phosphatidylserineexposing platelets lose their ability to bind to fibrinogen and PAC-1, while retaining expression of $\alpha \mathrm{llb} \beta 3$ at their surface. ${ }^{41,45}$ This suggests that integrins are not cleaved from the platelet surface. One proposal is that under conditions of static adhesion to collagen, the $\alpha$ llb $\beta 3$ integrins on such platelets are inactivated by a mechanism involving calpain and extracellular transglutaminase (platelet-derived factor XIII). ${ }^{41}$ On the other hand, there is evidence for a critical function of prolonged high $\mathrm{Ca}^{2+}$ in association with tyrosine phosphorylation without contribution of factor XIII. ${ }^{45}$ In phosphatidylserineexposing platelets, effects of calpain ( $\mathrm{a} \mathrm{Ca}^{2+}$-dependent protease) were also reported in relation to microparticle formation. ${ }^{39,47}$ If calpain is involved in the inactivation of $\alpha$ llb $\beta 3$, this suggests regulation by intracellular proteolytic cleavage, for example of the $\beta 3$ chain itself or of associated cytoskeletal proteins.

Typically, in thrombus formation, only a sub-population of the platelets develops into this phenotype with phosphatidylserine exposure and $\alpha$ llb $\beta 3$ inactivation. Probably because of the loss of adhesion, these cells are nearly completely separated from the fibrin(ogen)-binding platelets in aggregates. This is compatible with their likely function, that is, assembly and activation of coagulation factors, ${ }^{48}$ as this requires optimal accessibility to the plasma factors. Together, these findings provide substantial evidence for a second mechanism of $\alpha$ llb $\beta 3$ inactivation which occurs in procoagulant platelets with high $\mathrm{Ca}^{2+}$ levels, following stimulation with potent agonists (Fig. 2). The molecular conformation of this inactivated form is still unknown.

\section{Integrin $\alpha$ llb $\beta 3$-independent interactions in thrombus formation}

Especially in the early phases of thrombus formation, when paracrine ADP plays an important role, platelet $\alpha$ llb $\beta 3$ seems to undergo an equilibrium shift to the activated conformation that keeps the thrombus together (see above). However, it is important to realise that a number of other factors and processes also influence the (ir)reversibility of aggregate formation. One of these, relevant for in vitro conditions, is the extracellular concentration of $\mathrm{Ca}^{2+}$ and $\mathrm{Mg}^{2+}$. Lowering of the concentration of these divalent cations, as in citrated plasma, leads to aggregate stabilization (J. Cosemans, unpublished data; see also ${ }^{49}$ ). This is probably due to conformational effects on the divalent cation-binding regions of $\alpha$ llb and $\beta 3$ ( $\beta$-propeller and $\beta$ A-domains, respectively). ${ }^{50}$

More relevant for the in vivo situation is the fact that stronger agonists than ADP, such as collagen and (low) thrombin, form platelet aggregates that are less prone to fall apart. ${ }^{19,51}$ As $\mathrm{P}_{2} \mathrm{Y}_{12}$ receptors can desensitize in activated platelets, ${ }^{52}$ a possible explanation for more stable aggregates, after stimulation with strong agonists, is 
diminished $\mathrm{P}_{2} \mathrm{Y}_{12}$ desensitization. On the other hand, as summarized by various authors, there is ample evidence that so-called contact-dependent signaling contributes to the formation of stable thrombi, especially in later phases in the thrombus-forming process. ${ }^{15,28,53,54}$ Platelets contain various receptors for contact-dependent signaling, including Gas6 receptors, Eph kinases, P-selectin, and other cell adhesion molecules. It is not our aim to discuss these pathways extensively here. We only remark that these stabilising processes may occur secondarily to $\alpha$ llb $\beta 3$ outside-in signaling, and hence function to make integrin-mediated platelet-platelet interactions irreversibly. Another recent finding is that platelets aggregated at a collagen surface have the capability to contract to each other within the short time span of one minute, even in the absence of thrombin and fibrin. ${ }^{55}$ This contraction is the consequence of Rho kinase and myosin activity. The receptor requirements were not investigated, but they likely involve postintegrin contact-dependent receptor pathways. This raises the intriguing hypothesis that perhaps only non-contracted platelets show reversible integrin activation and are prone to disaggregation. Finally, local thrombin generation and fibrin network formation will obviously consolidate thrombi as well.

The findings described thus far lead to a model where the activated conformation of $\alpha$ llb $\beta 3$ is not always a fixed end state (Fig. 2). In particular, platelet exposure to ADP results in transient exposure of $\alpha \mathrm{llb} \beta 3$ activation epitopes and in reversible binding of fibrinogen and PAC-1. As soon as the ADP concentration drops, signaling through P2Y 12 receptors and $\mathrm{PI} 3 \mathrm{~K}$ isoforms stops, and $\alpha \mathrm{llb} \beta 3$ returns to its resting state. Platelets in a more advanced state of activation, probably involving outside-in and contact-dependent signaling events, may express $\alpha$ llb $\beta 3$ in a conformation that is no longer reversible. However, platelets that are exposed to potent agonists such as collagen and thrombin/ADP, and show a prolonged $\mathrm{Ca}^{2+}$ elevation, again inactivate their integrins. These platelets then no longer bind fibrinogen and PAC-1, but show exposure of phosphatidylserine and contribute to coagulation.

\section{Multiple activation states of integrin $\alpha 2 \beta 1$}

During platelet activation also integrin $\alpha 2 \beta 1$ converts to an active state with increased binding affinity to collagen. ${ }^{56}$ As illustrated in Fig. 3, platelet interaction with collagen via GPVI evokes simultaneous activation of both $\alpha$ llb $\beta 3$ and $\alpha 2 \beta 1$ integrins. $^{57}$ It is wellestablished that, in platelet binding to collagen, (activated) $\alpha 2 \beta 1$ reinforces the GPVIinduced signaling to phospholipase $\mathrm{C} \gamma 2$ activation, and $\mathrm{Ca}^{2+}$ release and secretion, in addition to integrin activation. ${ }^{58-60}$ In this way, $\alpha 2 \beta 1$ contributes to stable thrombus formation, as is underlined by the observation that deficiency of $\alpha 2 \beta 1$ can provoke destabilization of murine thrombi. ${ }^{51}$ The additive function of $\alpha 2 \beta 1$ is also apparent from ex vivo flow studies with human and mouse platelets on collagen. Here, some of the platelets appear to be activated by GPVI before binding to $\alpha 2 \beta 1$, whereas the remaining platelets first bind via $\alpha 2 \beta 1$ prior to stable adhesion. ${ }^{61}$ The implication of this dual behaviour is that some platelets probably need activation of $\alpha 2 \beta 1$ via GPVI for stable adhesion, whereas other platelets adhere to collagen via their resting $\alpha 2 \beta 1$ 


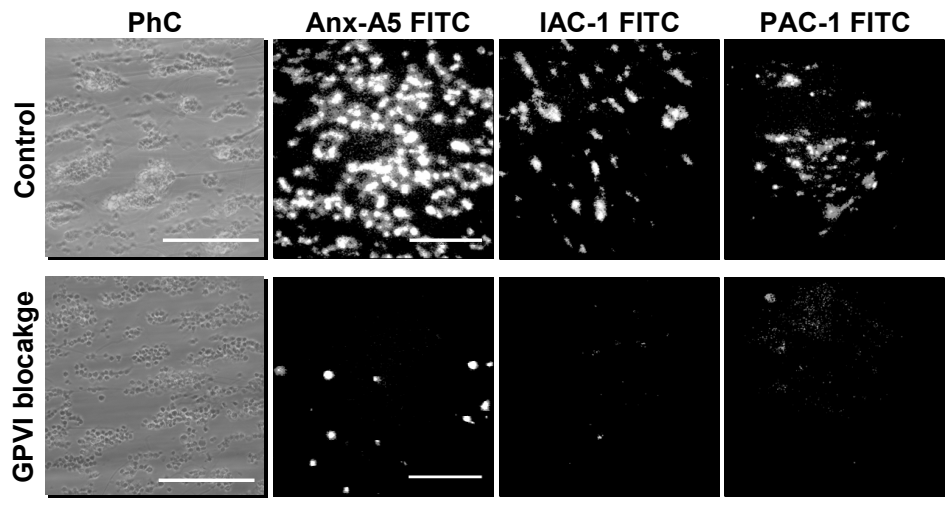

Figure 3. Simultaneous activation of platelet $\alpha 2 \beta 1$ and $\alpha$ llb $\beta 3$ integrins during collageninduced thrombus formation. Thrombi were formed by perfusion of human blood over collagen at wall shear rate of $1000 \mathrm{~s}^{-1}$. Phase contrast $(\mathrm{PhC})$ images show aggregated platelets (bars, $\left.50 \mu \mathrm{m}\right)$, which were stained for phosphatidylserine exposure (annexin A5 FITC), activated $\alpha 2 \beta 1$ (IAC-1 FITC) or activated $\alpha$ llb $\beta 3$ (PAC-1 FITC). Note that blockage of GPVI (anti-GPVI monoclonal antibody 9012) dramatically suppresses phosphatidylserine exposure as well as activation of $\alpha 2 \beta 1$ and $\alpha \mathrm{llb} \beta 3$ integrins. See also ${ }^{57}$.

conformation. ${ }^{57}$ However, platelets may also interact with different epitopes on the collagen fibers, as these contain both high-affinity and low-affinity GXX'GER recognition sequences for $\alpha 2 \beta 1$ binding. $^{7}$

Firm evidence that $\alpha 2 \beta 1$ can exist in multiple activation states comes from experiments using soluble collagen and IAC-1. ${ }^{56,62}$ Soluble collagen is considered to bind primarily to platelet $\alpha 2 \beta 1$, and IAC-1 is an antibody that only binds to the activated $\alpha 2 \beta 1$ conformation. Epitope mapping shows that IAC-1 recognizes a region in the activated $\alpha 2$ I-domain, distant from the MIDAS (Table 1). This site is only exposed after platelet activation, and is not much affected upon ligand binding. ${ }^{62}$ Similarly, two other anti- $\alpha 2$ Idomain antibodies, 6F1 and 12F1, have higher affinities for $\alpha 2 \beta 1$ on activated than on resting platelets. $^{63,64}$

The mechanism of $\alpha 2 \beta 1$ activation (inside-out signaling) is believed to be similar to that of other integrins. ${ }^{65}$.Thus, binding of talin to the $\beta 1$ cytoplasmic tail is considered to cause unclasping of the $\alpha 2 \beta 1$ transmembrane domains, after which conformational changes expose the extracellular $\alpha 2$ I-domain and $\beta 1 \mathrm{~A}$-domain. Direct evidence for this model comes from experiments with a cell-permeable peptide, containing the $\alpha 2$ cytoplasmic tail sequence, KLGFFKR. This sequence interacts with the intracellular $\beta 1$ tail and regulates integrin activity. ${ }^{66}$ Addition of this peptide to Chinese hamster ovary cells expressing human $\alpha 2 \beta 1$ was found to provoke inside-out activation of the integrin, as was apparent from an increased binding of both soluble collagen and IAC-1. ${ }^{67}$ Recent findings indicate that, similarly to $\alpha \operatorname{llb} \beta 3$, both talin and kindlin-3 are required for activation of (murine) $\alpha 2 \beta 1$. $^{11-13}$

Activation of $\alpha 2 \beta 1$ can also be induced by outside manipulation of the integrin using either: (i) the divalent cation $\mathrm{Mn}^{2+}$, (ii) reducing agents which break disulfide bonds within the $\beta$ chain, or (iii) the activating anti- $\beta 1$ antibody $T S 2 / 16 .{ }^{68,69}$ Surprisingly, outside manipulation results in binding of soluble collagen but not of IAC-1, showing that the 




Figure 4. Pathways of $\alpha 2 \beta 1$ activation. From the resting state, integrin $\alpha 2 \beta 1$ can be activated by outside manipulation to achieve a partly active conformation to which soluble collagen but not IAC-1 monoclonal antibody binds. Platelet activation via inside-out signaling leads to a fully active state of $\alpha 2 \beta 1$, exposing binding sites of both collagen and IAC-1. The partly active state may advance to the fully activated state. The conformation changes of $\alpha 2 \beta 1$ are probably reversible, but at present there is no evidence supporting this.

neo-epitope of IAC-1 is not exposed under such conditions. ${ }^{67}$ The 'partial' activation state of $\alpha 2 \beta 1$ induced by outside manipulation is influenced by extracellular $\mathrm{Mg}^{2+}$ and $\mathrm{Ca}^{2+}$. This artificial outside manipulation may not be accompanied by a change in the intracellular structure (clasping) of the integrin chains, which fits with the idea that cytoskeletal changes (talin) are required for IAC-1 binding. There is limited evidence that ligand-occupied $\alpha 2 \beta 1$ evokes outside-in signaling events. Platelet $\alpha 2 \beta 1$ binding to GFOGER peptide provokes activation of Src and Syk kinases as well as of phospholipase $\mathrm{C} \gamma 2 .{ }^{70}$ This pathway is surprisingly similar to the outside-in signaling events induced by activated $\alpha$ llb $\beta 3$, suggesting a common or perhaps even converging signaling mechanism.

Summarizing, it appears that $\alpha 2 \beta 1$ can assume three different activation states: (i) a resting state with neither collagen nor IAC-1 binding; (ii) a partially activated state, induced by outside manipulation, with only binding to soluble collagen ligand; and (iii) a fully activated state, induced by inside-out signaling, where both soluble collagen and IAC-1 bind (Fig. 4). At present, we speculate that in the partly activated state of $\alpha 2 \beta 1$ only the collagen-binding site is opened, whereas the IAC-1 binding pocket remains inaccessible. Whether, by outside manipulation, the other integrin, allb $\beta 3$, can also assume a different activation state is unknown, although $\mathrm{Mn}^{2+}$ treatment has been shown to induce binding of fibrinogen and PAC-1 to $\alpha$ llb $\beta 3$. Furthermore, whether $\alpha 2 \beta 1$ can return to its resting state from the (fully) activated state of, such as described above for $\alpha \mathrm{llb} \beta 3$, is also unknown but likely. Thus, whereas the literature shows marked similarities between the activating changes of both integrins, it is too early to conclude that their (in)activation mechanisms are identical.

\section{Cross-talk of $\alpha$ llb $\beta 3$ and $\alpha 2 \beta 1$ activation}

Recent work reveals an unexpected interaction between signaling pathways leading to $\alpha \operatorname{llb} \beta 3$ and $\alpha 2 \beta 1$ activation. It was found that activation of $\alpha 2 \beta 1$ can occur as a direct consequence of ligand binding to allb $\beta 3$. In other words, platelets appear to bind IAC-1 
as well as soluble collagen in a manner that is directly dependent on $\alpha$ llb $\beta 3$ activation. ${ }^{71}$ Support for this conclusion comes from the finding that inhibition of $\alpha$ llb $\beta 3$ with tirofiban or absence of $\alpha$ llb $\beta 3$ as in Glanzmann's platelets, effectively prevents all $\alpha 2 \beta 1$ activation, detectable as the absence of IAC-1 and soluble collagen binding. The expression of $\alpha 2 \beta 1$, however, remains unchanged. Conversely, treatment of platelets with the low-affinity $\alpha$ llb $\beta 3$ ligand, RGDS, results in both IAC-1 and collagen binding. This contrasts with data from others, who suggested a trans-dominant negative effect and claimed that fibrinogen binding to $\alpha$ llb $\beta 3$ led to inactivation of $\alpha 2 \beta 1$. In addition, blockage of $\alpha$ llb $\beta 3$ with the antagonist lamifiban restored $\alpha 2 \beta 1$-dependent events (i.e. static adhesion of platelets to collagen). ${ }^{72}$ Another study reported that GPVI-deficient platelets showed fibrinogen binding upon $\alpha 2 \beta 1$-dependent adhesion to collagen, thus hinting at positive cross-talk from $\alpha 2 \beta 1$ to $\alpha \operatorname{llb} \beta 3 .{ }^{73}$ However, in these last two studies it was not excluded that feed-forward loops mediated by ADP release and P2 $\mathrm{Y}_{12}$ stimulation could have contributed to the activity/activation state of $\alpha$ llb $\beta 3$. Given the facts that $\alpha$ llb $\beta 3$ is expressed on platelets at a much higher copy number than $\alpha 2 \beta 1$ and that ligand-occupied $\alpha$ llb $\beta 3$ has a non-negligible signaling capacity, it is very plausible that $\alpha$ llb $\beta 3$ outside-in signaling extends to $\alpha 2 \beta 1$ activation.

\section{Conclusions}

This review discusses a number of novel aspects of integrin activation that regulate the adhesiveness of platelets. The activating changes of $\alpha$ llb $\beta 3$ appear to be surprisingly reversible in ADP-stimulated, as well as in high activated, procoagulant platelets. Quite probably, the reversible $\alpha$ llb $\beta 3$ activation is an important mechanism to restrict the growth of a thrombus at sites of vascular damage. On the other hand, the low adhesiveness of procoagulant, phosphatidylserine-exposing platelets will make them optimally accessible to coagulation factors and, hence, help to localize the sites of thrombin generation. Synchrony in the activation of $\alpha 2 \beta 1$ and $\alpha \operatorname{llb} \beta 3$ guarantees efficient control of overall adhesiveness of platelets. From a clinical point of view, current $\alpha$ llb $\beta 3$ inhibitors are relatively difficult to handle in antithrombotic therapies because of their side effects, including a risk of severe bleeding. It is feasible that drugs, which function to shift the activated integrin towards its resting state, are more favorable in clinical use. Inhibitors of $\mathrm{PI} 3 \mathrm{~K} \beta$ and $\gamma$ isoforms might function in this way.

\section{Acknowledgements}

This work was supported by the Netherlands Organization for Scientific Research (NWO, 11-400-076 and 902-16-276) and the Belgian Fund for Scientific Research (FWO, G.0613.07).

\section{References}

1. Ma YQ, Qin J, Plow EF. Platelet integrin $\alpha$ llbß3: activation mechanisms. J Thromb Haemost. 2007;5:1345-1352. 
2. Depraetere H, Wille C, Gansemans $Y$, Stanssens P, Lauwereys M, Baruch D, De Reys S, Deckmyn $\mathrm{H}$. The integrin $\alpha 2 \beta 1$ (GPla/lla) I-domain inhibits platelet-collagen interaction. Thromb Haemost. 1997;77:981-985.

3. Xiong JP, Stehle T, Goodman SL, Arnaout MA. Integrins, cations and ligands: making the connection. J Thromb Haemost. 2003;1:1642-1654.

4. Knight CG, Morton LF, Peachey AR, Tuckwell DS, Farndale RW, Barnes MJ. The collagenbinding A-domains of integrins $\alpha 1 \beta 1$ and $\alpha 2 \beta 1$ recognize the same specific amino acid sequence, GFOGER, in native (triple-helical) collagens. J Biol Chem. 2000;275:35-40.

5. Emsley J, Knight CG, Farndale RW, Barnes MJ, Liddington RC. Structural basis of collagen recognition by integrin $\alpha 2 \beta 1$. Cell. 2000;101:47-56.

6. Raynal N, Hamaia SW, Siljander PR, Maddox B, Peachey AR, Fernandez R, Foley LJ, Slatter DA, Jarvis GE, Farndale RW. Use of synthetic peptides to locate novel integrin $\alpha 2 \beta 1$-binding motifs in human collagen III. J Biol Chem. 2006;281:3821-3831.

7. Siljander PR, Hamaia S, Peachey AR, Slatter DA, Smethurst PA, Ouwehand WH, Knight CG Farndale RW. Integrin activation state determines selectivity for novel recognition sites in fibrillar collagens. J Biol Chem. 2004;279:47763-47772.

8. Shattil SJ, Kashiwagi H, Pampori N. Integrin signaling, the platelet paradigm. Blood 1998;91:2645-2657.

9. Frelinger AL, Du X, Plow EF, Ginsberg MH. Monoclonal antibodies to ligand-occupied conformers of integrin $\alpha \mathrm{llb} \beta 3$ (glycoprotein $\mathrm{Ilb} / \mathrm{llla}$ ) alter receptor affinity, specificity, and function. J Biol Chem. 1991;266:17106-17111.

10. Luo BH, Carman CV, Springer TA. Structural basis of integrin regulation and signaling. Ann Rev Immunol. 2007;25:619-647.

11. Nieswandt B, Moser M, Pleines I, Varga-Szabo D, Monkley S, Critchley D, Fassler R. Loss of talin1 in platelets abrogates integrin activation, platelet aggregation, and thrombus formation in vitro and in vivo. J Exp Med. 2007;204:3113-3118

12. Petrich BG, Marchese P, Ruggeri ZM, Spiess S, Weichert RA, Ye F, Tiedt R, Skoda RC Monkley SJ, Critchley DR, Ginsberg $\mathrm{MH}$. Talin is required for integrin-mediated platelet function in hemostasis and thrombosis. J Exp Med. 2007;204:3103-3111.

13. Moser M, Nieswandt B, Ussar S, Pozgajova M, Fassler R. Kindlin-3 is essential for integrin activation and platelet aggregation. Nat Med. 2008;14:325-330.

14. Calderwood DA. Integrin activation. J Cell Sci. 2004;117:657-666.

15. Jackson SP. The growing complexity of platelet aggregation. Blood. 2007;109:5087-5095.

16. Cattaneo M, Canciani MT, Lecchi A, Kinlough-Rathbone RL, Packham MA, Mannucci PM, Mustard JF. Released adenosine diphosphate stabilizes thrombin-induced human platelet aggregates. Blood. 1990;75:1081-1086

17. Fabre JE, Nguyen M, Latour A, Keifer JA, Audoly LP, Coffman TM, Koller BH. Decreased platelet aggregation, increased bleeding time and resistance to thromboembolism in $\mathrm{P}_{2} \mathrm{Y}_{1-}$ deficient mice. Nat Med. 1999;5:1199-1202.

18. André $P$, Delaney SM, LaRocca T, Vincent D, DeGuzman F, Jurek M, Koller B, Phillips DR Conley $\mathrm{PB}$. $\mathrm{P}_{2} \mathrm{Y}_{12}$ regulates platelet adhesion/activation, thrombus growth, and thrombus stability in injured arteries. J Clin Invest. 2003;112:398-406.

19. Cosemans JM, Munnix IC, Wetzker R, Heller R, Jackson SP, Heemskerk JW. Continuous signaling via PI3K isoforms $\beta$ and $\gamma$ is required for platelet ADP receptor function in dynamic thrombus stabilization. Blood. 2006;108:3045-3052.

20. Kamae T, Shiraga M, Kashiwagi H, Kato H, Tadokoro S, Kurata Y, Tomiyama Y, Kanakura $Y$ Critical role of ADP interaction with $\mathrm{P}_{2} \mathrm{Y}_{12}$ receptor in the maintenance of $\alpha$ llb $\beta 3$ activation: association with Rap1B activation. J Thromb Haemost. 2006;4:1379-1387.

21. Trumel C, Si-Tahar M, Balloy V, Chignard M, Chap H, Payrastre B, Plantavid M, Pidard D. Phosphoinositide 3-kinase inhibition reverses platelet aggregation triggered by the combination of the neutrophil proteinases elastase and cathepsin $\mathrm{G}$ without impairing $\alpha$ llb $\beta 3$ integrin activation. FEBS Lett. 2000;484:184-188. 
22. Trumel C, Payrastre B, Plantavid M, Hechler B, Viala C, Presek P, Martinson EA, Cazenave JP, Chap H, Gachet C. A key role of adenosine diphosphate in the irreversible platelet aggregation induced by the PAR1-activating peptide through the late activation of phosphoinositide 3-kinase. Blood. 1999;94:4156-4165.

23. Schoenwaelder SM, Ono A, Sturgeon S, Chan M, Mangin $P$, Maxwell MJ, Turnbull $S$, Mulchandani M, Anderson K, Kauffenstein G, Rewcastle GW, Kendall J, Gachet C, Salem $\mathrm{HH}$, Jackson SP. Identification of a unique co-operative PI 3-kinase signaling mechanism regulating integrin $\alpha$ llb $\beta 3$ adhesive function in platelets. J Biol Chem. 2007;282:28648-28658.

24. Jackson SP, Schoenwaelder SM, Goncalves I, Nesbitt WS, Yap CL, Wright CE, Kenche V Anderson KE, Dopheide SM, Yuan Y, Sturgeon SA, Prabaharan H, Thompson PE, Smith GD, Shepherd PR, Daniele N, Kulkarni S, Abbott B, Saylik D, Jones C, Lu L, Giuliano S, Hughan SC, Angus JA, Robertson AD, Salem HH. PI 3-kinase p110ß: a new target for antithrombotic therapy. Nat Med. 2005;11:507-514.

25. Offermanns $\mathrm{S}$. Activation of platelet function through $\mathrm{G}$ protein-coupled receptors. Circ Res. 2006;99:1293-1304.

26. Chrzanowska-Wodnicka M, Smyth SS, Schoenwaelder SM, Fischer TH, White GC. Rap1b is required for normal platelet function and hemostasis in mice. J Clin Invest. 2005;115:680-687.

27. Han J, Lim CJ, Watanabe N, Soriani A, Ratnikov B, Calderwood DA, Puzon-McLaughlin W, Lafuente EM, Boussiotis VA, Shattil SJ, Ginsberg MH. Reconstructing and deconstructing agonist-induced activation of integrin $\alpha$ llb $\beta 3$. Curr Biol. 2006;16:1796-1806.

28. Ruggeri ZM. Platelets in atherothrombosis. Nat Med. 2002;8:1227-1234.

29. Goto S, Tamura N, Ishida H, Ruggeri ZM. Dependence of platelet thrombus stability on sustained glycoprotein IIb/llla activation through adenosine 5'-diphosphate receptor stimulation and cyclic calcium signaling. J Am Coll Cardiol. 2006;47:155-162.

30. Hirsch E, Bosco O, Tropel P, Laffargue M, Calvez R, Altruda F, Wymann M, Montrucchio G. Resistance to thromboembolism in PI3K $\gamma$-deficient mice. FASEB J. 2001;15:2019-2021.

31. Lian L, Wang Y, Draznin J, Eslin D, Bennett JS, Poncz M, Wu D, Abrams CS. The relative role of PLC $\beta$ and PI3K $\gamma$ in platelet activation. Blood. 2005;106:110-117.

32. Nesbitt WS, Giuliano S, Kulkarni S, Dopheide SM, Harper IS, Jackson SP. Intercellular calcium communication regulates platelet aggregation and thrombus growth. J Cell Biol. 2003;160:1151-1161.

33. Phillips DR, Nannizzi-Alaimo L, Prasad KS. $\beta 3$ tyrosine phosphorylation in $\alpha$ llb $\beta 3$ (platelet membrane GP Ilb/llla) outside-in integrin signaling. Thromb Haemost. 2001;86:246-258.

34. Watson SP, Auger JM, McCarty OJ, Pearce AC. GPVI and integrin $\alpha$ llb $\beta 3$ signaling in platelets. J Thromb Haemost. 2005;3:1752-1762.

35. Law DA, DeGuzman FR, Heiser P, Ministri-Madrid K, Killeen N, Phillips DR. Integrin cytoplasmic tyrosine motif is required for outside-in $\alpha$ llb $\beta 3$ signalling and platelet function. Nature. 1999;401:808-811.

36. Lerea KM, Cordero KP, Sakariassen KS, Kirk RI, Fried VA. Phosphorylation sites in the integrin $\beta 3$ cytoplasmic domain in intact platelets. J Biol Chem. 1999;274:1914-1919.

37. Banfic H, Tang X, Batty IH, Downes CP, Chen C, Rittenhouse SE. A novel integrin-activated pathway forms PKB/Akt-stimulatory phosphatidylinositol 3,4-bisphosphate via phosphatidylinositol 3-phosphate in platelets. J Biol Chem. 1998;273:13-16.

38. Kovacsovics TJ, Bachelot C, Toker A, Vlahos CJ, Duckworth B, Cantley LC, Hartwig JH. Phosphoinositide 3-kinase inhibition spares actin assembly in activating platelets but reverses platelet aggregation. J Biol Chem. 1995;270:11358-11366.

39. Siljander P, Farndale RW, Feijge MA, Comfurius P, Kos S, Bevers EM, Heemskerk JW Platelet adhesion enhances the glycoprotein VI-dependent procoagulant response: Involvement of p38 MAP kinase and calpain. Arterioscler Thromb Vasc Biol. 2001;21:618627. 
40. van der Meijden PE, Feijge MA, Giesen PL, Huijberts M, van Raak LP, Heemskerk JW Platelet $\mathrm{P}_{2} \mathrm{Y}_{12}$ receptors enhance signalling towards procoagulant activity and thrombin generation. A study with healthy subjects and patients at thrombotic risk. Thromb Haemost. 2005;93:1128-1136.

41. Kulkarni S, Jackson SP. Platelet factor XIII and calpain negatively regulate integrin $\alpha$ llb $\beta 3$ adhesive function and thrombus growth. J Biol Chem. 2004;279:30697-30706.

42. Heemskerk JW, Kuijpers MJ, Munnix IC, Siljander PR. Platelet collagen receptors and coagulation. A characteristic platelet response as possible target for antithrombotic treatment. Trends Cardiovasc Med. 2005;15:86-92.

43. Heemskerk JW, Vuist WM, Feijge MA, Reutelingsperger CP, Lindhout T. Collagen but not fibrinogen surfaces induce bleb formation, exposure of phosphatidylserine and procoagulant activity of adherent platelets. Evidence for regulation by protein tyrosine kinase-dependent $\mathrm{Ca}^{2+}$ responses. Blood. 1997;90:2615-2625

44. Dale GL. Coated-platelets: an emerging component of the procoagulant response. J Thromb Haemost. 2005;3:2185-2192.

45. Munnix IC, Kuijpers MJ, Auger J, Thomassen CM, Panizzi P, van Zandvoort MA, Rosing J, Bock PE, Watson SP, Heemskerk JW. Segregation of platelet aggregatory and procoagulant microdomains in thrombus formation. Regulation by transient integrin activation. Arterioscler Thromb Vasc Biol. 2007;27:2484-2490.

46. Bachelot-Loza C, Badol P, Brohard-Bohn B, Fraiz N, Cano E, Rendu F. Differential regulation of platelet aggregation and aminophospholipid exposure by calpain. $\mathrm{Br} \mathrm{J}$ Haematol. 2006;133:419-426.

47. Pasquet JM, Dachary-Prigent J, Nurden AT. Calcium influx is a determining factor of calpain activation and microparticle formation in platelets. Eur J Biochem. 1996;239:647-654.

48. Zwaal RF, Schroit AJ. Pathophysiological implications of membrane phospholipid asymmetry in blood cells. Blood. 1997;89:1121-1132.

49. Mustard JF, Perry DW, Kinlough-Rathbone RL, Packham MA. Factors responsible for ADPinduced release reaction of human platelets. Am J Physiol. 1975;228:1757-1765.

50. Phillips DR, Teng W, Arfsten A, Nannizzi-Alaimo L, White MM, Longhurst C, Shattil SJ, Randolph A, Jakubowski JA, Jennings LK, Scarborough RM. Effect of $\mathrm{Ca}^{2+}$ on GP IIb/IIla interactions with integrilin: enhanced GP IIb/IIla binding and inhibition of platelet aggregation by reductions in the concentration of ionized calcium in plasma anticoagulated with citrate. Circulation. 1997;96:1488-1494

51. Kuijpers MJ, Pozgajova M, Cosemans JM, Munnix IC, Eckes B, Nieswandt B, Heemskerk JW. Role of murine integrin $\alpha 2 \beta 1$ in thrombus stabilization and embolization: contribution of thromboxane $A_{2}$. Thromb Haemost. 2007;98:1072-1080.

52. Hardy AR, Conley PB, Luo J, Benovic JL, Poole AW, Mundell SJ. P2Y 1 and P2Y 12 receptors for ADP desensitize by distinct kinase-dependent mechanisms. Blood. 2005;105:3552-3560.

53. Brass LF, Stalker TJ, Zhu L, Lu B, Woulfe DS, Prevost N. Boundary events: contactdependent and contact-facilitated signaling between platelets. Sem Thromb Hemost. 2004;30:399-410

54. Angelillo-Scherrer A, Burnier L, Flores N, Savi P, DeMol M, Schaeffer P, Herbert JM, Lemke G, Goff SP, Matsushima GK, Earp HS, Vesin C, Hoylaerts MF, Plaisance S, Collen D, Conway EM, Wehrle-Haller B, Carmeliet P. Role of Gas6 receptors in platelet signaling during thrombus stabilization and implications for antithrombotic therapy. J Clin Invest. 2005;115:237-246

55. Ono A, Westein E, Hsiao S, Nesbitt WS, Hamilton JR, Schoenwaelder SM, Jackson SP Identification of a fibrin-independent platelet contractile mechanism regulating primary hemostasis and thrombus growth. Blood. 2008;112:90-99.

56. Jung SM, Moroi M. Activation of the platelet collagen receptor integrin $\alpha 2 \beta 1$. Its mechanism and participation in the physiological functions of platelets. Trends Cardiovasc Med. 2000;10:285-292 
57. Lecut C, Schoolmeester A, Kuijpers MJ, Broers JL, van Zandvoort MA, Vanhoorelbeke K, Deckmyn H, Jandrot-Perrus M, Heemskerk JW. Principal role of glycoprotein VI in $\alpha 2 \beta 1$ and $\alpha$ llb $\beta 3$ activation during collagen-induced thrombus formation. Arterioscler Thromb Vasc Biol. 2004;24:1727-1733.

58. Kuijpers MJ, Schulte V, Bergmeier W, Lindhout T, Brakebusch C, Offermanns S, Fässler R, Heemskerk JW, Nieswandt B. Complementary roles of glycoprotein VI and $\alpha 2 \beta 1$ integrin in collagen-induced thrombus formation in flowing whole blood ex vivo. FASEB J. 2003;17:685687.

59. Chen $\mathrm{H}$, Kahn ML. Reciprocal signaling by integrin and nonintegrin receptors during collagen activation of platelets. Mol Cell Biol. 2003;23:4764-4777.

60. Suzuki-Inoue K, Inoue O, Frampton J, Watson SP. Murine GPVI stimulates weak integrin activation in PLC $\gamma 2-/-$ platelets: involvement of PLC $\gamma 1$ and PI3-kinase. Blood. 2003;102:13671373.

61. Auger JM, Kuijpers MJ, Senis YA, Watson SP, Heemskerk JW. Adhesion of human and mouse platelets to collagen under shear: a unifying model. FASEB J. 2005;19:825-827.

62. Schoolmeester A, Vanhoorelbeke K, Katsutani S, Depraetere H, Feys HB, Heemskerk JW, Hoylaerts MF, Deckmyn H. Monoclonal antibody IAC-1 is specific for activated $\alpha 2 \beta 1$ and binds to amino acids 199 to 201 of the integrin $\alpha 2$ I-domain. Blood. 2004;104:390-396.

63. Estavillo D, Ritchie A, Diacovo TG, Cruz MA. Functional analysis of a recombinant glycoprotein la/lla (integrin $\alpha 2 \beta 1$ ) I-domain that inhibits platelet adhesion to collagen and endothelial matrix under flow conditions. J Biol Chem. 1999;274:35921-35926.

64. Cruz MA, Chen J, Whitelock JL, Morales LD, Lopez JA. The platelet glycoprotein Ib-von Willebrand factor interaction activates the collagen receptor $\alpha 2 \beta 1$ to bind collagen: activationdependent conformational change of the $\alpha 2-I$ domain. Blood. 2005;105:1986-1991.

65. Moes M, Rodius S, Coleman SJ, Monkley SJ, Goormaghtigh E, Tremuth L, Kox C, van der Holst PP, Critchley DR, Kieffer N. The integrin binding site 2 (IBS2) in the talin rod domain is essential for linking integrin $\beta$-subunits to the cytoskeleton. J Biol Chem. 2007;282:1728017288.

66. Wang Z, Leisner TM, Parise LV. Platelet $\alpha 2 \beta 1$ integrin activation: contribution of ligand internalization and the $\alpha 2$-cytoplasmic domain. Blood. 2003;102:1307-1315.

67. Van de Walle GR, Vanhoorelbeke K, Majer Z, Illyes E, Baert J, Pareyn I, Deckmyn H. Two functional active conformations of the integrin $\alpha 2 \beta 1$, depending on activation condition and cell type. J Biol Chem. 2005;280:36873-36882.

68. Kamata T, Takada Y. Direct binding of collagen to the I domain of integrin $\alpha 2 \beta 1$ in a divalent cation-independent manner. J Biol Chem. 1994;269:26006-26010.

69. Mekrache M, Kieffer N, Baruch D. Activation of recombinant $\alpha$ llb $\beta 3$ expressed in Chinese hamster ovary cells exposes different binding sites for fibrinogen or von Willebrand factor: evidence using monoclonal antibodies to $\alpha \mathrm{llb} \beta 3$. Br J Haematol. 2002;116:636-644.

70. Inoue O, Suzuki-Inoue K, Dean WL, Frampton J, Watson SP. Integrin $\alpha 2 \beta 1$ mediates outsidein regulation of platelet spreading on collagen through activation of Src kinases and PLC $\gamma 2 . J$ Cell Biol. 2003;160:769-780.

71. Van de Walle GR, Schoolmeester A, Iserbyt BF, Cosemans JM, Heemskerk JW, Hoylaerts MF, Nurden A, Vanhoorelbeke K, Deckmyn H. Activation of $\alpha$ llb $\beta 3$ is a sufficient but also an imperative prerequisite for activation of $\alpha 2 \beta 1$ on platelets. Blood. 2007;109:595-602.

72. Riederer MA, Ginsberg MH, Steiner B. Blockade of platelet GPIIb/llla (integrin $\alpha$ llb $\beta 3$ ) in flowing human blood leads to passivation of prothrombotic surfaces. Thromb Haemost. 2002;88:858-864.

73. Kehrel B, Wierwille S, Clemetson KJ, Anders O, Steiner M, Knight CG, Farndale RW, Okuma $M$, Barnes MJ. Glycoprotein $\mathrm{VI}$ is a major collagen receptor for platelet activation: it recognizes the platelet-activating quaternary structure of collagen, whereas CD36, glycoprotein Ilb/llla, and von Willebrand factor do not. Blood. 1998;91:491-499. 




General discussion 


\section{The thrombogenic role of plaque-derived collagens}

Fibrillar type I and III collagens provide stability and strength not only to healthy blood vessels, but also to atherosclerotic plaques inside an artery. Once exposed to the circulating blood, the same collagens can act as potent platelet agonists by interacting with glycoprotein $\mathrm{VI}(\mathrm{GPVI})$ and integrin $\alpha 2 \beta 1$ receptors at the platelet surface. Using a newly developed monoclonal anti-human GPVI antibody, 9012, ${ }^{1}$ we were able to examine the contribution of purified and plaque-derived collagens to the platelet activating events in thrombus formation (chapter 2). In these experiments, purified type I collagen appeared to be more potent than purified type III collagen in causing thrombus formation under high shear flow conditions. However, blocking of GPVI abolished the aggregation of platelets and the procoagulant response of platelets, regardless of the type of collagen that was used. Interestingly, the 9012 antibody also abolished the activation events of platelets that were flowed over human plaque material. In comparison, blockage of the platelet adenosine diphosphate (ADP) receptors, $\mathrm{P}_{2} \mathrm{Y}_{1}$ and $P 2 Y_{12}$, was less effective. These results are in good agreement with other reports, describing a key role of GPVI in the platelet-activating effect of homogenized advanced plaques, ${ }^{2}$ and an assistant role of the ADP receptors. ${ }^{3}$

Another thrombogenic component present in atherosclerotic plaques is tissue factor, which triggers the extrinsic coagulation cascade towards thrombin generation. Plaques are known to contain sufficient amounts of tissue factor to effectively stimulate the coagulation process. ${ }^{4,5}$ This is also described in chapter 2 , in which it is furthermore shown that those plaques with the highest amount of tissue factor are most potent in stimulating thrombin generation. Intriguingly, with platelets present, collagen in plaques can have an additional stimulatory effect on thrombin generation via GPVI-induced platelet activation. This was apparent from the finding that GPVI blockage suppressed a substantial part of the thrombin-generating effect of some but not all plaques. Supporting evidence comes from findings in chapter 3, showing that purified type I collagen strongly enhanced tissue factor-triggered thrombin generation in platelet-rich plasma. Purified type III collagen was clearly less potent in this case. By using the same antibody, 9012, we demonstrated that the enhancing effect of type I collagen completely relied on GPVI stimulation. Detailed investigations further indicated that integrin $\alpha 2 \beta 1$ and signaling via autocrine produced ADP and thromboxane $\mathrm{A}_{2}\left(\mathrm{TxA}_{2}\right)$ facilitated and amplified the GPVIdependent thrombin generation. We therefore conclude that exposed collagen plays a central role in the platelet-activating effect of plaque material, even in the presence of (tissue factor and) coagulation.

Fibrillar collagens, including the collagens in an atherosclerotic plaque, are considered to be processed continuously by matrix metalloproteinases (MMPs). ${ }^{6}$ Given the fact that plasma and platelets contain several MMP isoforms, it was of interest to see whether these MMPs are able to process collagen that becomes exposed after vessel wall damage or plaque rupture. Indeed, this appeared to be the case, since both plasmaand platelet-derived MMPs caused degradation of immobilized collagen fibers within a time period of several hours (chapter 4). Strikingly, the degraded collagen was no longer able to support platelet adhesion and activation (via GPVI) in flow-dependent thrombus 
formation. Similar collagen-degrading and antithrombotic effects were obtained by treatment of the collagen fibers with purified MMP preparations. Here, the collagenase MMP-1 was more active than the gelatinases MMP-2 and MMP-9. A surprising observation was that human plasma was more active than mouse plasma in degrading collagen (chapter 4). The physiological significance of this difference is not clear.

Collectively, these new data illustrate that plasma- and platelet-derived MMPs are capable to down-regulate the thrombogenic role of exposed collagen fibers in a longer term. The processing of collagens by MMPs may explain why in another published study the total collagen content of a human plaque only poorly correlated with the plateletactivating potency of the plaque material. ${ }^{2}$ During the writing of chapter 4 , another research group also provided preliminary data that show that the platelet-activating effect of collagen is affected by proteolysis through MMPs. ${ }^{7}$

\section{Thrombus formation as a multidirectional and dynamic process}

Generally, platelet plug formation at a site of vascular injury is considered to be a straightforward and unidirectional series of events. A classical scheme distinguishes three consecutive phases in thrombus formation: initiation, extension and perpetuation (Fig. 1). ${ }^{8,9}$ The initiation phase involves transient platelet adhesion to collagen-bound von Willebrand factor (VWF) via glycoprotein Ib-IX-V (GPIb-IX-V). Subsequent platelet interaction with collagen via GPVI and integrin $\alpha 2 \beta 1$ leads to stable adhesion and platelet activation. ${ }^{10,11}$ In the extension phase, the activated platelets secrete autocoid mediators such as ADP and $\mathrm{TxA}_{2}$, which recruit other platelets to build a platelet aggregate. In the perpetuation phase, platelets can become procoagulant and generate thrombin, after which the formed fibrin network is supposed to accomplish stabilization of the thrombus. However, in contrast to this classical model, observations of the thrombotic process in vivo have shown that thrombin and fibrin can already be formed at a quite early stage, i.e. after several seconds of vascular injury. ${ }^{12}$ Other work indicates that platelets are capable to evoke a multitude of responses even after their incorporation into an aggregate. ${ }^{13,14}$ These and other new findings dispute the classical, unidirectional model.

A number of observations in this thesis support the idea that thrombus formation is not a simple sequence of events, but instead a dynamic and multidirectional process. In this dynamic view of thrombus formation, initial platelet adhesion and aggregation are followed by events that positively or negatively regulate the overall rate and progression of thrombus build-up (Fig. 2). These events include: the maintenance of high affinity adhesion bonds between $\alpha$ llb $\beta 3$ and fibrinogen for thrombus stabilization; the continuous secretion of a multitude of autocrine platelet agonists and antagonists; the contraction of platelets, which facilitates contact-dependent signaling between adjacent platelets; and the ectodomain shedding of receptors from the platelet surface. In this novel concept, these positive and negative events can take place simultaneously in different parts of the developing thrombus. Nevertheless, from the perspective of individual platelets, the events can be arranged according to a global time plan. As schematized in Table 1, a 


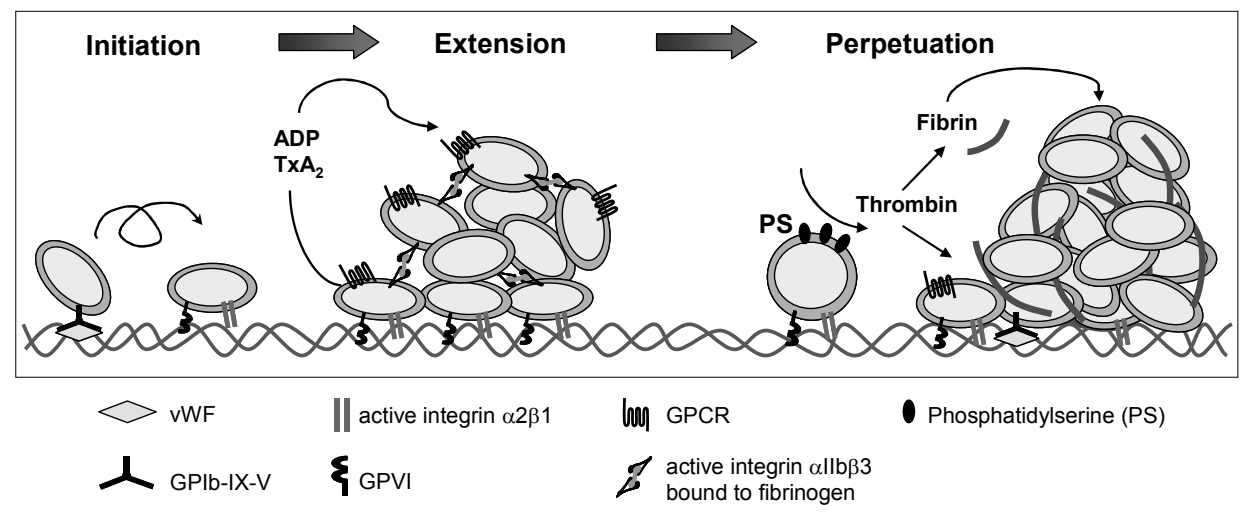

Figure 1. Classical, unidirectional model of thrombus formation consisting of three subsequent phases. The initiation phase involves transient platelet adhesion to collagen-bound vWF via GPIb-IX-V. Subsequent platelet interaction with collagen via GPVI and integrin $\alpha 2 \beta 1$ leads to stably adhered platelets that become activated. In the extension phase, secreted autocoid mediators, such as ADP and $\mathrm{TxA}_{2}$, recruit other platelets to build a platelet aggregate. In the perpetuation phase, fibrin formation stabilizes the thrombus. Adapted from Refs. ${ }^{8,9}$

useful way of ordering can be from early and more reversible events to late and irreversible events. Findings in the present thesis supporting this concept are discussed below.

\section{Early-reversible and late-irreversible events in dynamic thrombus formation}

The initial events of platelet adhesion to collagen/vWF and subsequent thrombus formation are extensively discussed elsewhere. ${ }^{15,16}$ Briefly, platelet interaction with (plaque-derived) collagen via GPVI results in secretion of autocrine mediators and induces activation of the integrins $\alpha \mathrm{llb} \beta 3$ and $\alpha 2 \beta 1$. Activated $\alpha 2 \beta 1$ reinforces GPVIinduced signaling to $\mathrm{Ca}^{2+}$ release and $\alpha \mathrm{llb} \beta 3$ activation. ${ }^{17,18}$ By binding fibrinogen, activated $\alpha$ llb $\beta 3$ mediates platelet aggregation. Various chapters in this thesis pay attention to (the reversibility of) these initial adhesion and aggregation events (Table 1).

The aim of chapter 5 was to find the signaling events that keep a thrombus together and thus prevent disaggregation and embolization of the platelets in a thrombus. Central to the stabilization of thrombi appeared to be maintenance of the high affinity integrin $\alpha$ llb $\beta 3$ adhesion bonds. Persistent integrin $\alpha$ llb $\beta 3$ activation was critically dependent on signals operating downstream of $\mathrm{P}_{2} \mathrm{Y}_{12}$ receptors. By using isoform-specific inhibitors of phosphoinositide 3-kinase (PI3K) $\beta$ and $\gamma$ and by using mice deficient in PI3K $\gamma$, it became clear that both $\mathrm{PI} 3 \mathrm{~K}$ isoforms are required for persistent $\mathrm{P} 2 \mathrm{Y}_{12}$-dependent $\alpha$ llb $\beta 3$ activation. However, each isoenzyme seems to have a different role herein. Activation of $\mathrm{PI} 3 \mathrm{~K} \beta$ mediated individual platelet-platelet contacts, whereas $\mathrm{PI} 3 \mathrm{~K} \gamma$ was essential for maintaining the integrity of the entire aggregate. As discussed in chapter 7 , other groups have shown that the signaling pathway from $P I 3 K \beta$ to $\alpha$ llb $\beta 3$ activation involves the protein kinase Akt and the molecular switch protein Rap1b. ${ }^{19,20}$ How PI3K $\gamma$ mediates integrin activation is less clear, but this may involve both catalytic and non-catalytic 


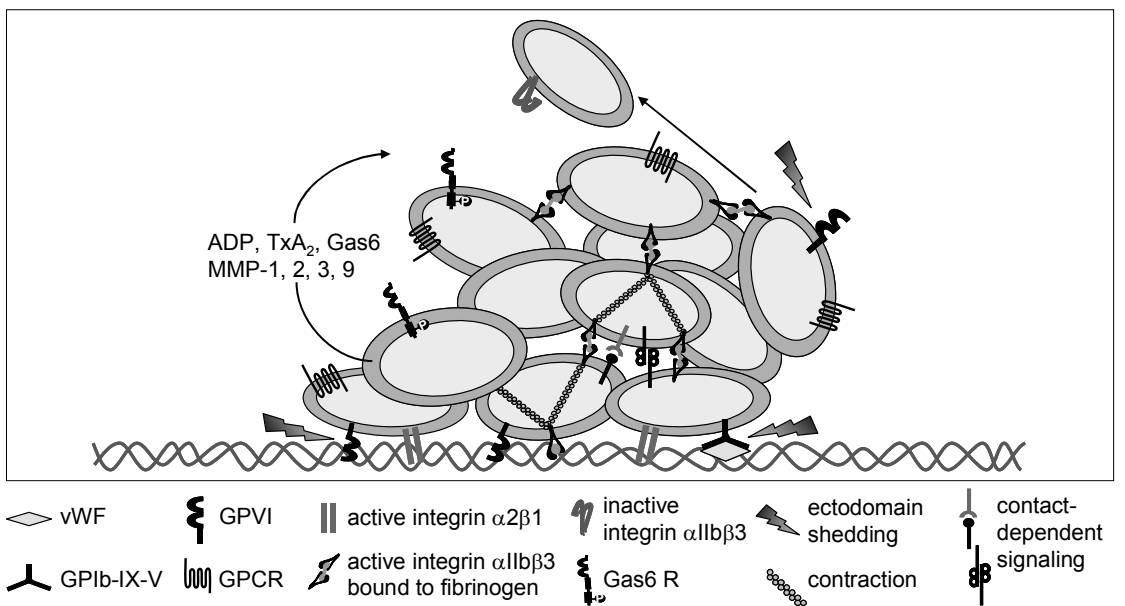

Figure 2. Thrombus formation as a multidirectional and dynamic process. Schematic representation of the events taking place after initial thrombus formation in different parts of the developing thrombus. Maintenance of fibrinogen-integrin $\alpha$ llb $\beta 3$ binding is essential for stable platelet-platelet interaction, especially at the growing thrombus surface. Continuous secretion of ADP, $\mathrm{TxA}_{2}$, Gas 6 and MMPs from activated platelets regulates platelet activation. In the thrombus core, contraction reduces the gap size between adjacent platelets and enables contact-dependent signaling events. The shedding of GPVI and GPIb may to restrict thrombus growth.

signaling mechanisms. ${ }^{21}$ Although continuous $\mathrm{P} 2 \mathrm{Y}_{12}$-dependent signaling appeared to be the major pathway for persistent $\alpha$ llb $\beta 3$ activation and prevention of embolization, we also found that interaction of Gas 6 with Gas6 receptors can have a contributing role (chapter 6).

In chapter 4, the contribution of MMPs to platelet activation and thrombus formation under flow conditions was examined by using blood from mice deficient in MMP-2, MMP3 or MMP-9. Whereas MMP-2 deficiency resulted in reduced platelet deposition and activation, MMP-9 deficiency had opposite effects (Table 1). Deficiency in MMP-3 did not alter thrombus formation. These results extend the data from other groups that investigated the effects of pharmacological MMP inhibitors and recombinant MMP proteins on platelet function. It was shown that platelet-derived MMP-1 and MMP-2 had a stimulating effect on platelet activation, ${ }^{22-25}$ whereas MMP-9 acted inhibitory. ${ }^{23,26}$ Currently, the mechanism underlying these opposite actions of MMP isoforms is unclear. There is strong evidence that released pro-MMP-2 is cleaved and activated by plateletbound MT-MMP1, ${ }^{27}$ but it is unknown whether the activated MMPs affect platelet function by proteolytic activity. A few years ago, a role for MMPs in ectodomain shedding of GPVI has been postulated, ${ }^{28}$ but recently it was shown that the metalloproteinase disintegrin10 (ADAM-10) is in fact responsible for this shedding. ${ }^{29}$ On the other hand, it is still possible that MMP isoforms can modify the activity of GPVI or other receptors at the platelet surface. Alternatively or in addition, the MMPs may bind to collagen and, thereby interfere with receptor-collagen interactions. Whether MMP isoforms regulate platelet activation in a reversible or irreversible way also needs to be established.

During the progress of this work, two studies have appeared that identified an additional way of platelet-platelet interaction, namely by thrombin- and fibrin-independent 
Table 1. Early-reversible and late-irreversible events in dynamic thrombus formation.

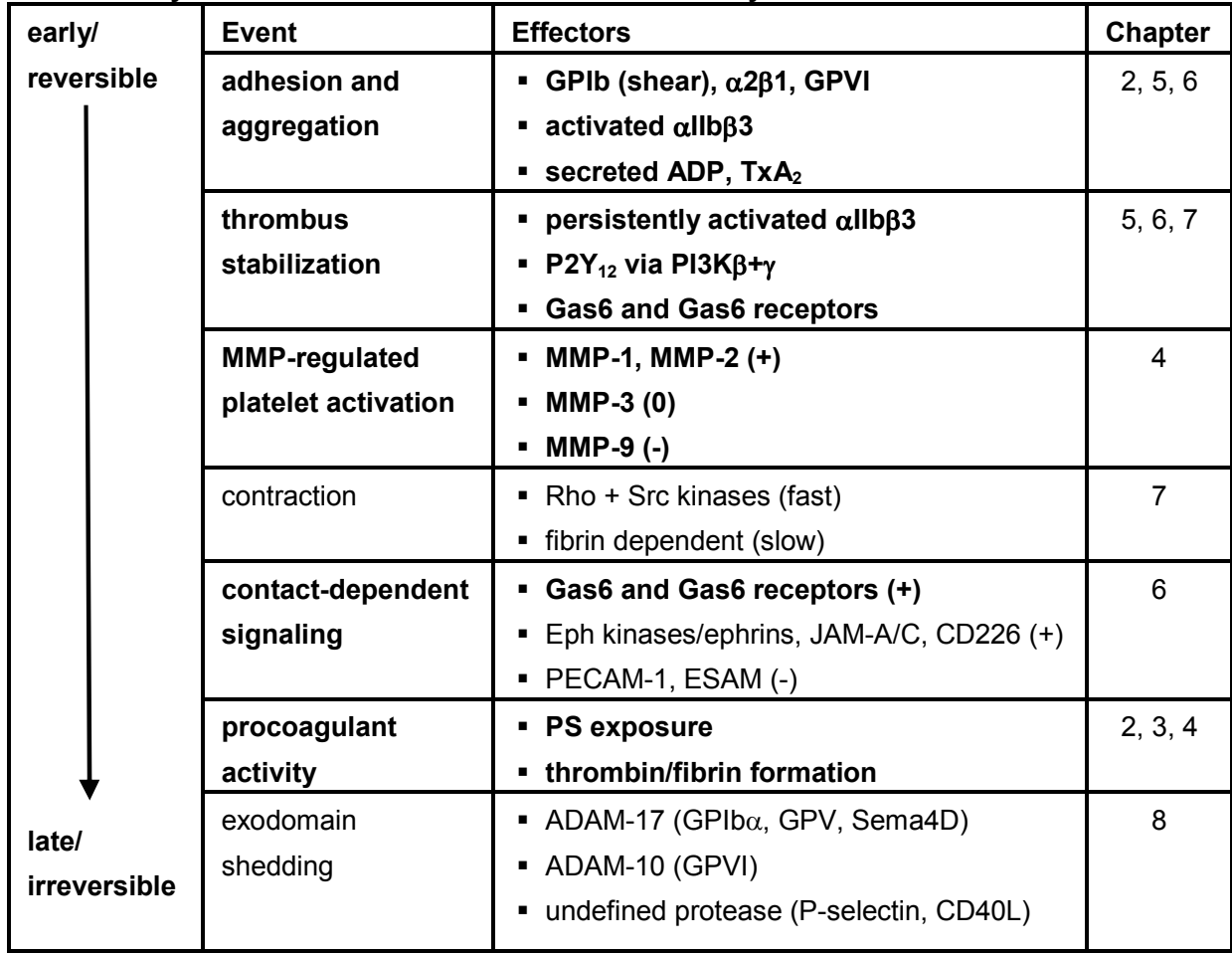

Schematic overview of early and late events that take place in thrombus formation. Effector molecules and/or responses are indicated, as well as the chapter(s) where these events are discussed. Parts in bold are most extensively studied in this thesis.

thrombus contraction. Collagen-induced tightening of platelet-platelet contacts via the actin and myosin cytoskeleton was detected as a relatively fast response, occurring within one minute through signaling pathways involving Rho and Src kinases. ${ }^{30,31}$ This contraction is supposed to reduce the gap size between adjacent platelets, and hence may limit the escape of autocrine agonists from this gap. As discussed in chapter 7 , fibrin-independent platelet contraction is likely one of the mechanisms that contributes to irreversible thrombus stabilization. Platelet contraction also occurs at a slower time scale under coagulant conditions, once fibrin is formed. This event results in plateletdependent clot retraction. ${ }^{32}$

Platelets also interact with each other via other surface proteins, which are collectively termed as contact-dependent signaling molecules. The contact-dependent signaling events likely have an important role in thrombus stabilization. Receptors involved in this way of thrombus stabilization are Eph tyrosine kinases, members of the immunoglobulin superfamily (JAM-A, JAM-C and CD226), and members of the Gas6 receptor family (Axl, Sky and Mer). ${ }^{33,34}$ Other immunoglobulin-like receptors, ESAM and PECAM-1, appear to play a negative role in platelet activation (Fig. $2+$ Table 1). In this thesis we have only focussed on the roles of Gas6 and Gas6 receptors. 
Earlier evidence indicated that mice lacking Gas6 or Gas6 receptors are protected against venous and arterial thrombosis, without showing prolonged bleeding. The mechanism involved was considered to be impaired PI3K and Akt signaling in platelets, due to the absence of Gas6-Gas6 receptor interaction. ${ }^{35,36}$ Since the contribution of Gas 6 in platelet activation was controversial for the human system, ${ }^{37,38}$ we examined this in more detail in chapter 6 . We found that Gas6 is abundantly present in human plasma, but is only limitedly expressed in human platelets. The plasma-derived Gas6 did support human platelet aggregation under static and high-shear flow conditions. Interestingly, depletion of Gas6 from human plasma caused platelet disaggregation, which was most prominent after several minutes of perfusion. This is in line with the key role for ADP/P2Y 12 -mediated signaling in the initial stabilization of a thrombus (described in chapter 5), and it suggests that Gas6-Gas6 receptor interaction becomes progressively more important at later stages, i.e., when the ADP pathway reduces or desensitizes.

In chapter 6 is further described that Gas6-Gas6 receptor interaction co-signals with $A D P / P 2 Y_{12}$ at the level of PI3K, likely via the PI3K $\beta$ isoform and its effector, protein kinase $B$ (Akt). At least part of Gas6 receptor signaling takes place downstream of $\mathrm{P}_{2} \mathrm{Y}_{12}$ signaling, which suggests that the $\beta$ isoform of $\mathrm{PI} 3 \mathrm{~K}$ can directly interact with the $\mathrm{P}_{2} \mathrm{Y}_{12}$ receptor. From a structural point of view, this was unexpected, since neither the $\alpha$-nor the $\beta \gamma$-subunits of $\mathrm{G}_{\mathrm{i}}$ (coupling to the $\mathrm{P} 2 \mathrm{Y}_{12}$ receptor) have recognition sites for binding to the $\mathrm{SH} 2 / 3$ domains of the $\mathrm{p} 85$ regulatory subunit of $\mathrm{PI} 3 \mathrm{~K} \beta .{ }^{39}$ On the other hand, a recent study reports that also in other cell types (macrophages and fibroblasts), PI3K $\beta$ functions directly downstream of G-protein coupled receptors. ${ }^{40}$

Our research group has extensively studied the development of procoagulant activity of platelets that interact with collagen under flow conditions or are subjected to conditions of coagulation. The surface exposure of the negatively charged phospholipid, phosphatidylserine (PS), plays an essential role in the platelet procoagulant response. $^{41,42}$ In chapter 2 is described that also plaque-derived collagens are capable to induce this response. Furthermore, chapter 3 indicates that purified fibrillar collagens evoke $\mathrm{Ca}^{2+}$ mobilization and subsequent PS exposure via GPVI-induced signaling. This appeared to be an important pathway to trigger platelet-dependent thrombin generation. Modification of platelet activation via MMP-2 and MMP-9 may affect the exposure of PS (chapter 4), but Gas6-Gas6 receptor signaling has likely no effect on this response (chapter 6). It is known is that the exposure of PS is a rather slow platelet response, which is accompanied by cytoskeleton degradation and irreversible changes in platelet morphology, including formation of membrane blebs and microparticles. ${ }^{41,43,44}$

By definition irreversible is the relatively slow ectodomain shedding of key platelet surface receptor proteins, including GPlba, ${ }^{45} \mathrm{GPV},{ }^{46}$ Sema4D, ${ }^{47} \mathrm{GPVI},{ }^{29} \mathrm{P}_{\text {-selectin, }}{ }^{48}$ and CD40L. ${ }^{49}$ In contrast to the cleavage of GPIb $\alpha$ and GPVI, which is known to impair platelet function, cleavage of Sema4D and CD40L produces bioactive fragments that can stimulate platelets and other nearby cells. The disintegrin metalloproteinases, ADAM-17 and ADAM-10, are responsible for the shedding of several of these platelet receptors. ${ }^{50}$ The contribution of this type of receptor cleavage to thrombus formation and stabilization is still unclear. 


\section{Implications for antithrombotic therapy}

Marked progress made in recent years in elucidating the roles of platelet ligands and receptors has resulted in the identification of many target molecules for new drugs that inhibit thrombus formation. To be successful, anti-platelet drugs preferentially fulfill two criteria: they are directed against 'platelet-specific' molecules and they do not provoke bleeding. Within the context of the proposed concept of dynamic and multidirectional thrombus formation, schematized in Table 1, it is interesting to speculate at which stages anti-platelet drugs are most effective. The possible therapeutic use of anti-GPIb and antiGPVI directed drugs will not be discussed here, as this has been reviewed elsewhere. $^{51,52}$

Antithrombotic drugs that are used in current clinical practice mostly function to target early and/or reversible events in thrombus formation. This concerns therapy directed against the $\mathrm{P} 2 \mathrm{Y}_{12}$ and integrin $\alpha$ llb $\beta 3$ receptors, and against formation of $\mathrm{TxA}_{2}$. The cyclooxygenase inhibitor aspirin is widely used in cardiovascular disease prevention with little side effects. However, aspirin also show incomplete efficacy, likely because thromboxane formation contributes only little to thrombus stability. The P2Y 12 receptor appears to be an effective target for antithrombotic drugs, probably because this ADP receptor not only controls persistent $\alpha$ llb $\beta 3$ activation (this thesis), but also contributes to the late response of platelet procoagulant activity. ${ }^{42,53}$ Furthermore, P2Y 12 blockage dissolves preformed aggregates, with little effect on the thrombus core. The anti-P2 $\mathrm{Y}_{12}$ prodrug clopidogrel is reasonably effective in the clinical settings of acute coronary syndrome and percutaneous coronary intervention. However, limitations for the use of clopidogrel are the relatively slow onset of action (i.e., metabolism of the prodrug is required) and the large response variability or resistance. In the last couple of years, several new $\mathrm{P}_{2} \mathrm{Y}_{12}$ antagonist have been tested, including the irreversible thienopyridine prasugrel, and the reversible ATP analogues, cangrelor and AZD6140. ${ }^{54,55}$ In phase 2 studies, these novel $\mathrm{P}_{2} \mathrm{Y}_{12}$ antagonists appear to show a more rapid onset of action and a greater degree of platelet inhibition than clopidogrel, without increase in major bleeding events. ${ }^{56-58}$ Phase 3 studies with these drugs are being completed. ${ }^{59}$

Direct integrin $\alpha$ llb $\beta 3$ inhibitors are relatively difficult to handle in antithrombotic therapy, because of their relatively high risk of bleeding. ${ }^{52}$ Early attempts to develop integrin blockers for oral use were even contra-productive, as these led to increased mortality. ${ }^{60,61}$ Given these drawbacks, it is feasible that signaling molecules that help to sustain integrin $\alpha$ llb $\beta 3$ activation are better targets than $\alpha$ llb $\beta 3$ blockers. As argued in this thesis, inhibitors of $\mathrm{PI} 3 \mathrm{~K} \beta$ and $\mathrm{PI} 3 \mathrm{~K} \gamma$ isoforms might act in this way. In vivo support comes from the observation that mice deficient in $\mathrm{PI} 3 \mathrm{~K} \gamma$ or injected with the PI3K $\beta$ inhibitor TGX221 have a marked reduction in arterial thrombus formation, without showing prolongation of the bleeding time. ${ }^{19,62,63}$ While deficiency of $\mathrm{PI} 3 \mathrm{~K} \gamma$ in mice is very well tolerated, deficiency in PI3K $\beta$ causes embryonic lethality. ${ }^{62,64}$ Therefore, the tolerance and suitability of $\mathrm{PI} 3 \mathrm{KK} \beta$ inhibitors in humans is still uncertain.

Concerning the late and irreversible events in thrombus formation, prevention of contact-dependent signaling is an interesting possibility of antagonism. However, most of the contact-dependent signaling molecules at the platelet surface have a wider 
expression profile, which limits their suitability as a target for anti-platelet medication. Mouse thrombosis models point to a role of Gas 6 and platelet Gas 6 receptors in venous and arterial thrombus formation, importantly without affecting bleeding. ${ }^{35,36}$ The present findings show that plasma-derived Gas 6 also stabilizes human thrombus formation in vitro, which may allow extrapolation of the mouse data to the human system. Gas6 inhibition only partly inhibits the formation of platelet aggregates, which makes Gas 6 and its receptors attractive targets for antithrombotic medication.

Targeting the MMP and ADAM families of proteases is also conceivable for antithrombotic therapy. Selective MMP-1 and MMP-2 inhibitors, once developed, might be useful to inhibit platelet function, even while the targets of these proteases in the platelet membrane are still unknown. However, the fact that the MMPs also play an important role in degrading matrix components can be disadvantageous. Stimulation of the shedding of platelet receptors, e.g. of GPIb $\alpha$ (by ADAM-17) or GPVI (by ADAM-10), ${ }^{50}$ is another interesting possibility for controlling thrombus growth and stability. In this case, a complication is that these proteases, especially ADAM-17, have a broader range of action than only platelets. Taken together, the new mechanistic insight in early and late events in thrombus formation has greatly widened the perspectives and possibilities for antithrombotic medication. Whilst newly discovered molecules, such as PI3K isoforms and Gas6 (receptors), are currently of primary interest to the academic community, they might rapidly turn into clinically relevant targets as well.

\section{References}

1. Lecut C, Feeney LA, Kingsbury G, Hopkins J, Lanza F, Gachet C, Villeval JL, Jandrot-Perrus $\mathrm{M}$. Human platelet glycoprotein $\mathrm{VI}$ function is antagonized by monoclonal antibody-derived Fab fragments. J Thromb Haemost. 2003;1:2653-2662.

2. Penz S, Reininger AJ, Brandl R, Goyal P, Rabie T, Bernlochner I, Rother E, Goetz C, Engelmann B, Smethurst PA, Ouwehand WH, Farndale R, Nieswandt B, Siess W. Human atheromatous plaques stimulate thrombus formation by activating platelet glycoprotein $\mathrm{VI}$. FASEB J. 2005;19:898-909.

3. Penz SM, Reininger AJ, Toth O, Deckmyn H, Brandl R, Siess W. Glycoprotein Ib $\alpha$ inhibition and ADP receptor antagonists, but not aspirin, reduce platelet thrombus formation in flowing blood exposed to atherosclerotic plaques. Thromb Haemost. 2007;97:435-443.

4. Ardissino D, Merlini PA, Bauer KA, Bramucci E, Ferrario M, Coppola R, Fetiveau R, Lucreziotti S, Rosenberg RD, Mannucci PM. Thrombogenic potential of human coronary atherosclerotic plaques. Blood. 2001;98:2726-2729.

5. Niemetz J, Fallon JT, Harrington E, Hathcock J. Rapid generation of thrombin by atheroma and platelets. J Thromb Haemost. 2004;2:321-326.

6. Heeneman S, Cleutjens JP, Faber BC, Creemers EE, van Suylen RJ, Lutgens E, Cleutjens $\mathrm{KB}$, Daemen MJ. The dynamic extracellular matrix: intervention strategies during heart failure and atherosclerosis. J Pathol. 2003;200:516-525.

7. Howes JM, Pugh N, Farndale R. Modified platelet deposition on MMP-cleaved collagen. Proceedings of the $10^{\text {th }}$ UK Platelet Meeting, Bradford, UK 2008.

8. Ruggeri ZM. Platelets in atherothrombosis. Nat Med. 2002;8:1227-1234.

9. Prevost N, Woulfe D, Tognolini M, Brass LF. Contact-dependent signaling during the late events of platelet activation. J Thromb Haemost. 2003;1:1613-1627.

10. Nieswandt B, Watson SP. Platelet-collagen interaction: is GPVI the central receptor? Blood. 2003;102:449-461. 
11. Auger JM, Kuijpers MJ, Senis YA, Watson SP, Heemskerk JW. Adhesion of human and mouse platelets to collagen under shear: a unifying model. FASEB J. 2005;19:825-827.

12. Furie B, Furie BC. Thrombus formation in vivo. J Clin Invest. 2005;115:3355-3362.

13. Brass LF, Zhu L, Stalker TJ. Minding the gaps to promote thrombus growth and stability. J Clin Invest. 2005;115:3385-3392.

14. Jackson SP. The growing complexity of platelet aggregation. Blood. 2007;109:5087-5095.

15. Kuijpers MJ. Platelet receptors and procoagulant activity in thrombus formation. PhD Thesis, Maastricht University, Maastricht, The Netherlands. ISBN-10: 90-5278-517-1. 2006.

16. Munnix IC. Platelet signaling to procoagulant activity and heterogeneity in thrombus formation. An in vivo and ex vivo approach. PhD Thesis, Maastricht University, Maastricht, The Netherlands. ISBN 978-90-5278-630-8. 2007.

17. Chen $\mathrm{H}, \mathrm{Kahn} \mathrm{ML}$. Reciprocal signaling by integrin and nonintegrin receptors during collagen activation of platelets. Mol Cell Biol. 2003;23:4764-4777.

18. Kuijpers MJ, Schulte V, Bergmeier W, Lindhout T, Brakebusch C, Offermanns S, Fassler R, Heemskerk JW, Nieswandt B. Complementary roles of glycoprotein VI and $\alpha 2 \beta 1$ integrin in collagen-induced thrombus formation in flowing whole blood ex vivo. FASEB J. 2003;17:685687.

19. Jackson SP, Schoenwaelder SM, Goncalves I, Nesbitt WS, Yap CL, Wright CE, Kenche V, Anderson KE, Dopheide SM, Yuan Y, Sturgeon SA, Prabaharan H, Thompson PE, Smith GD, Shepherd PR, Daniele N, Kulkarni S, Abbott B, Saylik D, Jones C, Lu L, Giuliano S, Hughan SC, Angus JA, Robertson AD, Salem HH. PI 3-kinase p110ß: a new target for antithrombotic therapy. Nat Med. 2005;11:507-514.

20. Lova P, Paganini S, Hirsch E, Barberis L, Wymann M, Sinigaglia F, Balduini C, Torti M. A selective role for phosphatidylinositol 3,4,5-trisphosphate in the $\mathrm{G}_{\mathrm{i}}$-dependent activation of platelet Rap1B. J Biol Chem. 2003;278:131-138.

21. Schoenwaelder SM, Ono A, Sturgeon S, Chan M, Mangin P, Maxwell MJ, Turnbull S, Mulchandani M, Anderson K, Kauffenstein G, Rewcastle GW, Kendall J, Gachet C, Salem $\mathrm{HH}$, Jackson SP. Identification of a unique co-operative PI 3-kinase signaling mechanism regulating integrin $\alpha$ llb $\beta 3$ adhesive function in platelets. J Biol Chem. 2007;282:28648-28658.

22. Radomski A, Stewart MW, Jurasz P, Radomski MW. Pharmacological characteristics of solidphase von Willebrand factor in human platelets. Br J Pharmacol. 2001;134:1013-1020.

23. Galt SW, Lindemann S, Allen L, Medd DJ, Falk JM, McIntyre TM, Prescott SM, Kraiss LW Zimmerman GA, Weyrich AS. Outside-in signals delivered by matrix metalloproteinase-1 regulate platelet function. Circ Res. 2002;90:1093-1099.

24. Falcinelli E, Guglielmini G, Torti M, Gresele P. Intraplatelet signaling mechanisms of the priming effect of matrix metalloproteinase-2 on platelet aggregation. J Thromb Haemost. 2005;3:2526-2535.

25. Choi WS, Jeon $\mathrm{OH}$, Kim HH, Kim DS. MMP-2 regulates human platelet activation by interacting with integrin $\alpha$ llb33. J Thromb Haemost. 2008;6:517-523.

26. Sheu JR, Fong TH, Liu CM, Shen MY, Chen TL, Chang Y, Lu MS, Hsiao G. Expression of matrix metalloproteinase- 9 in human platelets: regulation of platelet activation in in vitro and in vivo studies. $\mathrm{Br} \mathrm{J}$ Pharmacol. 2004;143:193-201.

27. Kazes I, Elalamy I, Sraer JD, Hatmi M, Nguyen G. Platelet release of trimolecular complex components MT1-MMP/TIMP2/MMP2: involvement in MMP2 activation and platelet aggregation. Blood. 2000;96:3064-3069.

28. Stephens G, Yan Y, Jandrot-Perrus M, Villeval JL, Clemetson KJ, Phillips DR. Platelet activation induces metalloproteinase-dependent GPVI cleavage to down-regulate platelet reactivity to collagen. Blood. 2005;105:186-191.

29. Gardiner EE, Karunakaran D, Shen Y, Arthur JF, Andrews RK, Berndt MC. Controlled shedding of platelet glycoprotein (GP)VI and GPIb-IX-V by ADAM family metalloproteinases. J Thromb Haemost. 2007;5:1530-1537. 
30. Ono A, Westein E, Hsiao S, Nesbitt WS, Hamilton JR, Schoenwaelder SM, Jackson SP Identification of a fibrin-independent platelet contractile mechanism regulating primary hemostasis and thrombus growth. Blood. 2008;112:90-99.

31. Auger JM, Watson SP. Dynamic tyrosine kinase-regulated signaling and actin polymerisation mediate aggregate stability under shear. Arterioscler Thromb Vasc Biol. 2008;28:1499-1504.

32. Shattil SJ, Kashiwagi H, Pampori N. Integrin signaling: the platelet paradigm. Blood. 1998;91:2645-2657.

33. Prevost N, Woulfe DS, Jiang H, Stalker TJ, Marchese P, Ruggeri ZM, Brass LF. Eph kinases and ephrins support thrombus growth and stability by regulating integrin outside-in signaling in platelets. Proc Natl Acad Sci USA. 2005;102:9820-9825.

34. Brass LF, Zhu L, Stalker TJ. Novel therapeutic targets at the platelet vascular interface. Arterioscler Thromb Vasc Biol. 2008;28:s43-50.

35. Angelillo-Scherrer A, de Frutos P, Aparicio C, Melis E, Savi P, Lupu F, Arnout J, Dewerchin M, Hoylaerts M, Herbert J, Collen D, Dahlbäck B, Carmeliet P. Deficiency or inhibition of Gas6 causes platelet dysfunction and protects mice against thrombosis. Nat Med. 2001;7:215-221.

36. Angelillo-Scherrer A, Burnier L, Flores N, Savi P, DeMol M, Schaeffer P, Herbert JM, Lemke G, Goff SP, Matsushima GK, Earp HS, Vesin C, Hoylaerts MF, Plaisance S, Collen D, Conway EM, Wehrle-Haller B, Carmeliet P. Role of Gas6 receptors in platelet signaling during thrombus stabilization and implications for antithrombotic therapy. $J$ Clin Invest. 2005;115:237-246.

37. Balogh I, Hafizi S, Stenhoff J, Hansson K, Dahlbäck B. Analysis of Gas6 in human platelets and plasma. Arterioscler Thromb Vasc Biol. 2005;24:1280-1206.

38. Clauser S, Bachelot-Lozat C, Fontana P, Gaussem P, Remones V, Aiach M, Borgel D. Physiological plasma Gas6 levels do not influence platelet aggregation. Arterioscler Thromb Vasc Biol. 2006;26:e22.

39. Engelman JA, Luo J, Cantley LC. The evolution of phosphatidylinositol 3-kinases as regulators of growth and metabolism. Nat Rev Genet. 2006;7:606-619.

40. Guillermet-Guibert J, Bjorklof K, Salpekar A, Gonella C, Ramadani F, Bilancio A, Meek S, Smith AJH, Okkenhaug K, Vanhaesebroeck B. The $p 110 \beta$ isoform of phosphoinositide 3kinase signals downstream of $\mathrm{G}$ protein-coupled receptors and is functionally redundant with p110 $\gamma$. Proc Natl Acad Sci USA. 2008;105:8292-8297.

41. Heemskerk JW, Kuijpers MJ, Munnix IC, Siljander PR. Platelet collagen receptors and coagulation. A characteristic platelet response as possible target for antithrombotic treatment. Trends Cardiovasc Med. 2005;15:86-92.

42. Van der Meijden PE, Feijge MA, Giesen PL, Huijberts M, van Raak LP, Heemskerk JW Platelet $P 2 Y_{12}$ receptors enhance signalling towards procoagulant activity and thrombin generation. A study with healthy subjects and patients at thrombotic risk. Thromb Haemost. 2005;93:1128-1136.

43. Bevers EM, Comfurius P, van Rijn JL, Hemker HC, Zwaal RF. Generation of prothrombinconverting activity and the exposure of phosphatidylserine at the outer surface of platelets. Eur J Biochem. 1982;122:429-436.

44. Fox JE, Austin CD, Boyles JK, Steffen PK. Role of the membrane skeleton in preventing the shedding of procoagulant-rich microvesicles from the platelet plasma membrane. J Cell Biol. 1990;111:483-493.

45. Bergmeier W, Piffath CL, Cheng G, Dole VS, Zhang Y, von Andrian UH, Wagner DD. Tumor necrosis factor- $\alpha$-converting enzyme (ADAM17) mediates GPIb $\alpha$ shedding from platelets in vitro and in vivo. Circ Res. 2004;95:677-683.

46. Rabie T, Strehl A, Ludwig A, Nieswandt B. Evidence for a role of ADAM17 (TACE) in the regulation of platelet glycoprotein V. J Biol Chem. 2005;280:14462-14468.

47. Zhu L, Bergmeier W, Wu J, Jiang H, Stalker TJ, Cieslak M, Fan R, Boumsell L, Kumanogoh A, Kikutani H, Tamagnone L, Wagner DD, Milla ME, Brass LF. Regulated surface expression and shedding support a dual role for semaphorin 4D in platelet responses to vascular injury. Proc Natl Acad Sci USA. 2007;104:1621-1626. 
48. Berger G, Hartwell DW, Wagner DD. P-selectin and platelet clearance. Blood. 1998;92:44464452.

49. Henn V, Steinbach S, Buchner K, Presek P, Kroczek RA. The inflammatory action of CD40 ligand (CD154) expressed on activated human platelets is temporally limited by coexpressed CD40. Blood. 2001;98:1047-1054.

50. Andrews RK, Karunakaran D, Gardiner EE, Berndt MC. Platelet receptor proteolysis: a mechanism for downregulating platelet reactivity. Arterioscler Thromb Vasc Biol. 2007;27:1511-1520.

51. Clemetson KJ, Clemetson JM. Collagen receptors as potential targets for novel anti-platelet agents. Curr Pharm Des. 2007;13:2673-2683.

52. Barrett NE, Holbrook L, Jones S, Kaiser WJ, Moraes LA, Rana R, Sage T, Stanley RG, Tucker KL, Wright B, Gibbins JM. Future innovations in anti-platelet therapies. Br J Pharmacol. 2008;154:918-939.

53. Gachet C. P2 receptors, platelet function and pharmacological implications. Thromb Haemost. 2008;99:466-472.

54. Van Giezen JJ, Humphries RG. Preclinical and clinical studies with selective reversible direct P2Y 12 antagonists. Semin Thromb Hemost. 2005;31:195-204.

55. Michelson AD. P2Y ${ }_{12}$ antagonism: promises and challenges. Arterioscler Thromb Vasc Biol. 2008;28:s33-38.

56. Wiviott SD, Antman EM, Winters KJ, Weerakkody G, Murphy SA, Behounek BD, Carney RJ Lazzam C, McKay RG, McCabe CH, Braunwald E. Randomized comparison of prasugrel (CS-747, LY640315), a novel thienopyridine P2Y 12 antagonist, with clopidogrel in percutaneous coronary intervention: results of the Joint Utilization of Medications to Block Platelets Optimally (JUMBO)-TIMI 26 trial. Circulation. 2005;111:3366-3373.

57. Greenbaum AB, Grines CL, Bittl JA, Becker RC, Kereiakes DJ, Gilchrist IC, Clegg J, Stankowski JE, Grogan DR, Harrington RA, Emanuelsson H, Weaver WD. Initial experience with an intravenous $\mathrm{P}_{2} \mathrm{Y}_{12}$ platelet receptor antagonist in patients undergoing percutaneous coronary intervention: results from a 2-part, phase II, multicenter, randomized, placebo- and active-controlled trial. Am Heart J. 2006;151:689.e1-689.e10.

58. Cannon CP, Husted S, Harrington RA, Scirica BM, Emanuelsson H, Peters G, Storey RF. Safety, tolerability, and initial efficacy of AZD6140, the first reversible oral adenosine diphosphate receptor antagonist, compared with clopidogrel, in patients with non-ST-segment elevation acute coronary syndrome: primary results of the DISPERSE-2 trial. J Am Coll Cardiol. 2007;50:1844-1851.

59. Wiviott SD, Braunwald E, McCabe CH, Montalescot G, Ruzyllo W, Gottlieb S, Neumann FJ, Ardissino D, De Servi S, Murphy SA, Riesmeyer J, Weerakkody G, Gibson CM, Antman EM. Prasugrel versus clopidogrel in patients with acute coronary syndromes. $\mathrm{N}$ Engl $\mathrm{J}$ Med. 2007;357:2001-2015.

60. Quinn MJ, Plow EF, Topol EJ. Platelet glycoprotein Ilb-Illa inhibitors: recognition of a twoedged sword. Circulation. 2002;106:379-385.

61. Bassler N, Loeffler C, Mangin P, Yuan Y, Schwarz M, Hagemeyer CE, Eisenhardt SU, Ahrens I, Bode C, Jackson SP, Peter K. A mechanistic model for paradoxical platelet activation by

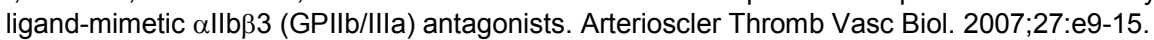

62. Hirsch E, Bosco O, Tropel P, Laffargue M, Calvez R, Altruda F, Wymann M, Montrucchio G. Resistance to thromboembolism in PI3K $\gamma$-deficient mice. FASEB J. 2001;15:2019-2021.

63. Lian L, Wang Y, Draznin J, Eslin D, Bennett JS, Poncz M, Wu D, Abrams CS. The relative role of PLC $\beta$ and PI3K $\gamma$ in platelet activation. Blood. 2005;106:110-117.

64. Bi L, Okabe I, Bernard DJ, Nussbaum RL. Early embryonic lethality in mice deficient in the p110 $\beta$ catalytic subunit of PI 3-kinase. Mamm Genome. 2002;13:169-172. 
Summary 


\section{Dynamic regulation of thrombus stability}

Atherothrombosis results from rupture of an atherosclerotic plaque, by which plaquederived constituents are exposed to the blood stream. Platelets adhere to sites of plaque rupture, become activated, and secrete secondary mediators that recruit other circulating platelets to form a multiplatelet aggregate or a thrombus. A growing thrombus can lead to occlusion at the site where the thrombus is formed, or in downstream vessels by emboli. When occlusion occurs in the heart or in the brain, this causes a myocardial infarction or stroke, respectively. Although traditional antiplatelet drugs have been shown to be effective in reducing arterial thrombosis, drawbacks are an increased risk of bleeding and/or a limited protective effect. In the past few years, research has focused both on finding ways to improve existing antiplatelet therapy, and on identifying new target platelet proteins for antithrombotic treatment. For this purpose more precise knowledge of the process of thrombus formation is required. The research described in this thesis has two main goals. The studies in the first part (chapters 2-4) are performed to gain a better insight into the signaling pathways that underlie the thrombogenic role of (modified) collagen that is present in or is derived from advanced atherosclerotic plaques. In the second part of this thesis (chapters 5-7) the goal was to find platelet receptors and signaling molecules that play a role in the stabilization of a thrombus.

In the first part of chapter 1 the function of the two main thrombogenic components in plaques, e.g. collagen and tissue factor, is discussed. Collagen type I and III fibers provide tissue stability to both the healthy vessel wall and plaques within the vessel. However, after vessel wall damage or plaque rupture, the collagen fibers become exposed to the circulating blood and act as potent platelet agonists. Collagens in general, and plaque collagens in particular, are continuously processed by matrix metalloproteinases (MMPs). By degrading collagen, MMPs are known to influence plaque stability. Furthermore, the MMP isoforms, MMP-1, MMP-2, and MMP-9, have a direct effect on platelet activation. The literature does not explain how these apparently different functions of MMPs jointly contribute to thrombus formation under flow conditions.

In the second part of chapter 1 an overview is given of those platelet receptors and downstream signaling pathways that are relevant for this thesis. Collagen activates platelets by interacting with the glycoprotein (GP)VI receptor. Signaling via this receptor activates amongst others the effector enzyme phospholipase $\mathrm{C} \gamma 2$, which results in a rise of intracellular free $\mathrm{Ca}^{2+}$ levels, and subsequent exposure of phosphatidyl serine (PS) at the platelet surface. Second, a rise in intracellular $\mathrm{Ca}^{2+}$, together with activation of protein kinase $C$, leads to the secretion of the autocrine mediators, adenosine diphosphate (ADP), Gas6 and thromboxane $A_{2}\left(T_{x} A_{2}\right)$. Phosphoinositide 3-kinase (PI3K) is a key enzyme in platelet activation, as it becomes active following signaling via GPVI, the thrombin receptors, PAR1 and PAR4, the ADP receptor, $\mathrm{P}_{2} \mathrm{Y}_{12}$, and the Gas6 receptors, Axl, Sky and Mer. One of the outcomes of PI3K signaling is activation of integrin $\alpha$ llb $\beta 3$, which is a key event for fibrinogen binding and platelet aggregation. While a clearer understanding about the initial events in thrombus formation is emerging, 
it is poorly understood which platelet receptors and signaling molecules play a role in the later stages of this process.

In chapter 2 the thrombogenic properties of collagen in advanced atherosclerotic plaques are compared to those of purified collagens, types I and III. Studies were performed to measure thrombus formation and procoagulant activity during high-shear perfusion of human whole blood over the collagen-containing plaque material or one of the isolated collagens. Plaque material and type I collagen (but not type III collagen) strongly stimulated platelet adhesion and thrombus formation. Blockage of GPVI with the newly developed anti-human GPVI antibody, 9012, abolished thrombus formation and procoagulant activity, both on plaque material and isolated collagen. In comparison, blockage of the ADP receptors, $\mathrm{P}_{2} \mathrm{Y}_{1}$ and $\mathrm{P}_{2} \mathrm{Y}_{12}$, was less effective. It was concluded that GPVI interaction with collagen plays a key role in the platelet-activation effect of advanced plaques, while ADP receptor signaling only has a supporting role.

Another thrombogenic component present in atherosclerotic plaques is tissue factor, which triggers the extrinsic coagulation cascade towards thrombin generation and subsequent fibrin formation. In chapters 2 and 3 , the effect of plaque material and purified collagens on thrombin generation in platelet-containing plasma is measured by use of the thrombogram method. The amount of formed thrombin correlated well with the tissue factor concentration in the different atherosclerotic plaques. In some plaques, GPVI blockage suppressed a substantial part of the thrombin-generating effect, which indicated that the collagen within these plaques contributed to platelet activation and thrombin generation. Detailed investigations in chapter 3 with isolated type I collagen showed that GPVI signaling to PS exposure is responsible for the stimulating effect of collagen on thrombin generation. Platelet adhesion through integrin $\alpha 2 \beta 1$ or signaling via autocrine produced $\mathrm{ADP}$ and $\mathrm{TxA}_{2}$ facilitated and amplified the GPVI-dependent thrombin generation.

From the literature it was known that the total collagen content of a human plaque only poorly correlates with the platelet-activating potency of that plaque. An explanation for this discrepancy may be the processing of the collagens within the plaque by MMPs. Since plasma and platelets contain significant amounts of MMPs, in chapter 4 it was investigated whether MMPs from these two sources can degrade collagen that is exposed after vessel wall damage or plaque rupture. By immunohistochemical staining, it was shown that the MMPs present in plasma as well as in platelets destroyed the normal triple helical structure of fibrillar collagen type I within a time period of several hours. Strikingly, the degraded collagen was no longer able to support platelet adhesion and activation in flow-dependent thrombus formation. Furthermore, in this chapter the effect of MMPs on platelet activation was studied. By using mice lacking one of the MMP isoforms present in platelets, MMP-2, MMP-3 or MMP-9, it was demonstrated that MMP-2 has a stimulating effect on platelet deposition and activation under high-shear flow conditions, while MMP-9 acts inhibitory. Deficiency in MMP-3 did not alter thrombus formation. Together, these results demonstrate that plasma- and platelet-derived MMP isoforms have a dual function in collagen-dependent thrombus formation. They appear to have a balancing effect on platelet adhesion to collagen and thrombus formation under 
flow, and, on a longer term, they downregulate the thrombogenic property of collagen fibers by proteolytic cleavage.

To prevent occlusion of a vessel, thrombus growth needs to be confined to the site of vascular damage. In chapter $\mathbf{5}$ it is investigated which platelet receptors and downstream signaling pathways are involved in the growth and stabilization of a thrombus. By measurements of the active conformation of integrin $\alpha$ llb $\beta 3$ under both high-shear flow and static conditions, it was concluded that continuous activation of $\alpha$ llb $\beta 3$ is needed to keep the thrombus together. Blockage of the $\mathrm{P}_{2} \mathrm{Y}_{12}$ receptor for ADP or inhibition of PI3K led to secondary inactivation of previously active $\alpha \operatorname{llb} \beta 3$ and to disintegration of formed thrombi. Inhibition of $\mathrm{TXA}_{2}$ formation or the second ADPreceptor, $\mathrm{P}_{2} \mathrm{Y}_{1}$, was much less effective. By using newly developed inhibitors of $\mathrm{PI} 3 \mathrm{~K} \beta$ and $\mathrm{PI} 3 \mathrm{~K} \gamma$ isoforms and by using mice lacking $\mathrm{PI} 3 \mathrm{~K} \gamma$, it was further demonstrated that both these $\mathrm{PI} 3 \mathrm{~K}$ isoforms are involved in the $\mathrm{P} 2 \mathrm{Y}_{12}$-dependent integrin $\alpha \mathrm{llb} \beta 3$ activation. Here, activation of $\mathrm{PI} 3 \mathrm{~K} \beta$ seemed to be more important for establishing individual platelet-platelet contacts, whereas $\mathrm{PI} 3 \mathrm{~K} \gamma$ was essential for maintaining the integrity of the entire aggregate. From these and other results, it was concluded that continuous signaling via the $\mathrm{P}_{2} \mathrm{Y}_{12}$ receptors through $\mathrm{PI} 3 \mathrm{~K} \beta$ as well as $\mathrm{PI} 3 \mathrm{~K} \gamma$ is necessary for persistent $\alpha$ llb $\beta 3$ activation and, hence, for stable thrombus formation.

The results described in chapter 6 indicate that also Gas6 receptor signaling contributes to $\alpha \mathrm{llb} \beta 3$ activation. Interestingly, the contribution of Gas 6 was most prominent in later phases of thrombus formation, i.e. when the availability of ADP is diminishing. From perfusion experiments with blood from mice lacking one of the Gas6 receptors, Axl, Sky, or Mer, it was concluded that all three receptors are needed for Gas6 function. In contrast to suggestions in the literature that Gas 6 may not contribute to the activation of human platelets, experiments in this chapter showed that the removal of Gas6 from human plasma resulted in thrombi that were unstable (under flow conditions) and platelet aggregates that were smaller (under static conditions). Other data in this thesis and in the literature indicated that PI3K is a key component of signaling via Gas6 receptors (chapter $\mathbf{6}$ ) and the $\mathrm{P} 2 \mathrm{Y}_{12}$ receptor (chapter 5). It was found that blockage of $\mathrm{PI} 3 \mathrm{~K} \beta$ suppressed integrin $\alpha \mathrm{llb} \beta 3$ activation regardless of the presence or absence of Gas6. This implies that the Gas6 receptor signaling pathway is downstream of $P 2 Y_{12}$ and that this receptor likely is a direct activator of PI3K $\beta$.

In chapter 7 the evidence for different and transient activation stages of integrin $\alpha \operatorname{llb} \beta 3$ and $\alpha 2 \beta 1$ is discussed in depth. Platelet activation results in an activating, conformational change of $\alpha$ llb $\beta 3$ by inside-out signaling. In case of ADP stimulation, this activated state is a transient state and fully reversible. Active $\alpha$ llb $\beta 3$ binds fibrinogen, which results in outside-in activation and consolidation of the active conformation of $\alpha$ llb $\beta 3$. Under conditions of prolonged high $\mathrm{Ca}^{2+}$ levels, such as in PS-exposing platelets, $\alpha$ llb $\beta 3$ becomes secondarily inactivated and no longer binds fibrinogen. Integrin $\alpha 2 \beta 1$ appears to be activated by a mechanism that is directly linked to $\alpha$ llb $\beta 3$ activation and it can also adopt different activation states, depending on the type of platelet agonist.

In chapter $\mathbf{8}$ the main findings presented in this thesis are discussed, as well as their possible clinical significance. It is argued that thrombus formation is not a unidirectional 
sequence of events but, instead, a highly dynamic and multidirectional process. Based on this concept, a summary is given of the events that can positively or negatively regulate the overall rate and progression of thrombus build-up. Taken together, the studies in this thesis add to the current knowledge of the multiple processes in thrombus formation, which will hopefully lead to improved treatments of arterial thrombosis. 

Samenvatting 


\section{Dynamische regulatie van trombusstabiliteit}

Atherotrombose wordt gekarakteriseerd door het scheuren van een atherosclerotische plaque in de arteriële vaatwand, als gevolg waarvan activerende componenten van die plaque, zoals collageen en weefselfactor, aan de bloedstroom worden blootgesteld. Bloedplaatjes hechten aan een gescheurde plaque en raken daardoor geactiveerd. Geactiveerde plaatjes scheiden diverse stoffen uit, waardoor plaatjes in de circulatie worden aangetrokken en zo een plaatjesaggregaat oftewel trombus vormen. Een groeiende trombus kan leiden tot afsluiting van een bloedvat, zowel op de plaats van de ruptuur als stroomafwaarts door losgeraakte stukken van de trombus. Gebeurt dit in de hartstreek, dan leidt dit tot een hartinfarct en als het in de hersenen plaatsvindt, tot een beroerte. De huidige behandeling van arteriële trombose richt zich vooral op het remmen van de plaatjesactivering. Hoewel antiplaatjesmedicatie effectief is gebleken in het reduceren van arteriële trombose, zijn belangrijke nadelen van de huidige medicijnen aan de ene kant het niet volledige effectief zijn en aan de andere kant een verhoogd risico op bloedingen. De laatste jaren heeft het onderzoek zich gericht op het verbeteren van de medicatie tegen bekende doeleiwitten, maar ook op het identificeren van nieuwe doeleiwitten voor antiplaatjesmedicatie. Duidelijk is daarbij geworden dat er meer kennis over het ontstaan, de groei en stabilisatie van een trombus vereist is. Het onderzoek beschreven in dit proefschrift heeft een tweeledig doel. Het eerste deel (hoofdstukken 2-4) beoogt een beter inzicht te geven in de signaleringspaden in plaatjes, die optreden na interactie met (gemodificeerd) collageen in plaques. In het tweede deel van dit proefschrift (hoofdstukken 5-7) is onderzocht welke plaatjesreceptoren en signaleringsmoleculen een rol spelen bij het in stand houden oftewel de stabilisatie van een groeiende trombus.

In het inleidende hoofdstuk $\mathbf{1}$ is allereerst ingegaan op de precieze functie van de twee belangrijkste trombogene componenten van een plaque, namelijk collageen en weefselfactor. Collageen van type I en III zorgt voor stevigheid van zowel de gezonde vaatwand als van plaques in de vaatwand. Echter bij beschadiging komen deze collagenen in contact met het stromend bloed, en worden daarmee een sterke plaatjesactivator. De collagenen in plaques zijn onderhevig aan continue afbraak door matrix metalloproteinases (MMPs). Door deze afbraak verminderen de MMPs de stabiliteit van een plaque. Daarnaast hebben specifieke MMP isovormen (namelijk MMP1, MMP-2 en MMP-9) ook een effect op de plaatjesactivering. Echter in de literatuur wordt niet ingegaan op de bijdrage van deze ogenschijnlijk verschillende functies van MMPs aan de trombusvorming onder stromingscondities.

Ten tweede is in hoofdstuk 1 een overzicht gegeven van bekende plaatjesreceptoren en signaleringsroutes, voor zover die relevant zijn voor dit proefschrift. Collageen activeert plaatjes door interactie met de glycoproteïne (GP)VI receptor. Signalering via deze collageenreceptor activeert onder andere het enzym fosfolipase Cy2, dat ervoor zorgt dat het intracellulaire calciumniveau stijgt. Een langdurig verhoogd calciumniveau resulteert in het verschijnen van stollingsactief fosfatidylserine (PS) op het plaatjesoppervlak. Daarnaast zorgt een verhoogd calciumniveau samen met proteïne kinase C ook voor de secretie van 
adenosinedifosfaat (ADP), Gas6, en tromboxaan $A_{2}\left(T_{x} A_{2}\right)$, die op hun beurt weer andere plaatjes kunnen activeren. Aangegeven is dat fosfoinositide 3-kinase (PI3K) een sleutelenzym is in de plaatjesactivering, aangezien het betrokken is bij de signalering door GPVI, door de trombinereceptoren, PAR1 en PAR4, de ADP-receptor, P2Y 12 , en de Gas6-receptoren, Axl, Sky en Mer. Het PI3K zorgt onder meer via activering van de eiwitten Akt en Rap 1b voor het actief maken van integrine allb $\beta 3$. Via interactie van actief $\alpha$ llb $\beta 3$ met fibrinogeen kunnen plaatjes aan elkaar hechten, hetgeen bekend staat als plaatjesaggregatie. Hoewel er steeds meer bekend wordt over deze initiële gebeurtenissen in trombusvorming, is het onduidelijk welke plaatjesreceptoren en signaleringsmoleculen een rol spelen in de latere fasen van trombusvorming en stabilisatie.

In hoofdstuk 2 zijn de trombogene eigenschappen van gevorderde atherosclerotische plaques vergeleken met die van gezuiverd collageen type I of III. Het trombusvormende proces is gemeten met behulp van een stromingskamer tijdens de perfusie van humaan bloed over plaquemateriaal of een oppervlak van gezuiverd collageen onder een hoge afschuifsnelheid. Gebleken is dat zowel plaquemateriaal als type I collageen (maar niet type III collageen) sterk de plaatjesadhesie en trombusvorming stimuleerde. Blokkering van de GPVI-receptor met behulp van een nieuw ontwikkeld anti-humaan GPVI antilichaam, 9012, remde de trombusvorming op plaquemateriaal of geïsoleerd collageen volledig. Blokkering van beide ADP-receptoren $P 2 Y_{1}$ en $P 2 Y_{12}$ was daarentegen minder effectief. Samengevat is aangetoond dat de interactie van collageen met GPVI noodzakelijk is voor de vorming van een trombus op plaquemateriaal, terwijl signalering via de ADP-receptoren een ondersteunde rol heeft.

De tweede belangrijke trombogene component in plaques is weefselfactor. Deze brengt de bloedstolling op gang, waardoor trombine en fibrine gevormd worden. In hoofdstukken 2 en $\mathbf{3}$ is met behulp van de trombogrammethode de vorming van trombine gemeten in de aanwezigheid van plaquemateriaal of geïsoleerd collageen. De weefselfactorconcentratie in de diverse atherosclerotische plaques bleek goed te correleren met de hoeveelheid gevormd trombine. Blokkering van GPVI onderdrukte een substantieel deel van de trombinegeneratie, wat aangeeft dat het collageen uit plaques een meetbare bijdrage levert aan de trombinegeneratie. Gedetailleerd onderzoek in hoofdstuk 3, waarbij gebruik gemaakt is van geïsoleerd type I collageen, wees uit dat signalering via GPVI resulterend in PS expositie verantwoordelijk is voor het stimulerend effect van collageen op de trombinegeneratie. Plaatjesadhesie aan integrine $\alpha 2 \beta 1$ en signalering via ADP- en $\mathrm{TxA}_{2}$-receptoren versterkten het GPVI effect.

Uit de literatuur was al bekend dat de hoeveelheid collageen in een plaque niet altijd overeenkomt met het plaatjesactiverend effect van dit collageen. Een aannemelijke verklaring hiervoor was modificatie of afbraak van het collageen in bepaalde plaques door MMPs. Aangezien ook plasma en plaatjes MMP activiteit bevatten, is in hoofdstuk 4 onderzocht of deze MMPs in staat zijn om collageen af te breken, dat blootgelegd wordt na vaatwandschade of plaqueruptuur. Immunohistochemische kleuring toonde aan dat de MMPs aanwezig in plasma en plaatjes de normale helicale structuur van collageen type I binnen enkele uren volledig konden afbreken. Uit perfusieproeven bleek 
vervolgens dat het gedegradeerde collageen niet langer in staat was plaatjes te laten hechten. Naast de collageenafbrekende eigenschappen van MMPs is in dit hoofdstuk ook het effect van MMPs op de activering van plaatjes onderzocht. Door gebruik te maken van muizen die deficiënt waren in één van de in plaatjes aanwezige MMP isovormen MMP-2, MMP-3 of MMP-9, kon aangetoond worden dat MMP-2 een stimulerend effect heeft op de plaatjesadhesie en de trombusvorming onder stromingscondities, terwijl MMP-9 juist remmend werkt. Afwezigheid van MMP-3 had geen effect op de trombusvorming. Samengevat tonen deze resultaten aan dat de MMPs uit plasma en plaatjes een tweeledige functie hebben in de trombusvorming op collageen. Initieel hebben ze een subtiel regulerend effect op de plaatjesactivering en op de lange termijn onderdrukken ze de trombogene functie van het collageen door afbraak.

Om afsluiting van een bloedvat te voorkomen, dient een trombus beperkt te blijven tot de plaats van vaatwandbeschadiging. In hoofdstuk $\mathbf{5}$ is onderzocht welke plaatjesreceptoren en onderliggende signaleringspaden betrokken zijn bij de aangroei en de stabilisatie van een trombus. Door het bepalen van de activeringsstatus van integrine $\alpha$ llb $\beta 3$ onder stromings en statische condities, bleek dat voortdurende activering van $\alpha$ llb $\beta 3$ noodzakelijk was voor het in stand houden van een trombus. Remming van de $\mathrm{P}_{2} \mathrm{Y}_{12}$ ADP-receptor of van diens signalering naar PI3K zorgde ervoor dat actief $\alpha$ llb $\beta 3$ weer in de inactieve toestand kwam en dat gevormde trombi uit elkaar vielen. Remmen van de $\mathrm{TxA}_{2}$-vorming of van de werking van de tweede $A D P$-receptor $P 2 Y_{1}$ was veel minder effectief. Door gebruik te maken van nieuw ontwikkelde remmers tegen de isovormen $\mathrm{PI} 3 \mathrm{~K} \beta$ en $\mathrm{PI} 3 \mathrm{~K} \gamma$ en middels muizen die deficiënt waren in $\mathrm{PI} 3 \mathrm{~K} \gamma$ kon aangetoond worden dat beide PI3K typen betrokken zijn bij de $\mathrm{P} 2 \mathrm{Y}_{12}$-gemedieerde $\alpha$ llb $\beta 3$-activering. Hierin leek PI3K $\beta$ vooral het contact tussen afzonderlijke plaatjes te beïnvloeden terwijl $\mathrm{PI} 3 \mathrm{~K} \gamma$ belangrijker was voor de integriteit van het gehele aggregaat. Uit deze resultaten is geconcludeerd dat continue signalering via de $\mathrm{P}_{2} \mathrm{Y}_{12}$-receptoren en vervolgens via $\mathrm{PI} 3 \mathrm{~K} \beta$ en $\mathrm{PI} 3 \mathrm{~K} \gamma$ noodzakelijk is voor aanhoudende $\alpha$ llb $\beta 3$-activering en daarmee voor stabiele trombusvorming.

Uit de resultaten van hoofdstuk $\mathbf{6}$ is gebleken dat ook Gas6 receptorsignalering een bijdrage levert aan het activeren van $\alpha$ llb $\beta 3$ op plaatjes, echter vooral in een later stadium van de trombusvorming, wanneer de beschikbaarheid van ADP afneemt. Uit perfusieproeven met bloed van muizen die deficiënt waren in één van de Gas6receptoren Axl, Sky of Mer, kwam naar voren dat alle drie de receptoren nodig waren voor deze functie van Gas6. In tegenstelling tot suggesties in de literatuur dat Gas6 geen rol speelt bij de activering van humane plaatjes, lieten experimenten in dit hoofdstuk zien dat het verwijderen van Gas6 uit humaan plasma ervoor zorgde dat trombi eerder uit elkaar vielen (onder stromingscondities) en dat de plaatjesaggregatie verminderde (onder statische condities). Verdere resultaten in dit proefschrift en in de literatuur tonen aan dat PI3K een centrale component is in de signalering via zowel Gas6-receptoren (hoofdstuk 6) als $\mathrm{P}_{2} \mathrm{Y}_{12}$ (hoofdstuk 5). Remming van de isovorm PI3K $\beta$ onderdrukte de activering van integrine $\alpha$ llb $\beta 3$ onafhankelijk van de aanwezigheid of afwezigheid van Gas6. Dit impliceert dat het Gas6-receptor signaleringspad een afgeleide is van de $\mathrm{P} 2 \mathrm{Y}_{12}$-receptor signalering en dat $\mathrm{P}_{2} \mathrm{Y}_{12}$ vermoedelijk rechtstreeks $\mathrm{PI} 3 \mathrm{~K} \beta$ activeert. 
In hoofdstuk 7 is dieper ingegaan op de verschillende activeringsstadia van de integrines $\alpha$ llb $\beta 3$ en $\alpha 2 \beta 1$. Plaatjesactivering leidt door middel van 'inside-out' signalering tot een conformatieverandering en daarmee tot het actief worden van $\alpha \mathrm{llb} \beta 3$. In het geval van ADP-stimulatie blijkt deze activeringsstap omkeerbaar. Actief $\alpha$ llb $\beta 3$ bindt fibrinogeen, wat leidt tot 'outside-in' activering en daarmee tot consolidatie van de actieve conformatie van het integrine. In geval van een langdurig verhoogd calciumniveau binnen het plaatje, bijvoorbeeld na stimulatie met collageen en trombine, wordt $\alpha$ llb $\beta 3$ opnieuw inactief. Dit gebeurt met name in plaatjes die PS exposeren. Integrine $\alpha 2 \beta 1$ wordt op soortgelijke wijze geactiveerd als $\alpha$ llb $\beta 3$, maar kan echter verschillende activeringsconformaties aannemen, al naargelang de activator.

In hoofdstuk 8 zijn de bevindingen van dit proefschrift bediscussieerd in de context van de literatuur en is ingegaan op de mogelijke klinische relevantie. Het is beargumenteerd dat de trombusvorming geen eenvoudige opeenvolging van gebeurtenissen is, maar een dynamisch en multidirectioneel proces. Op grond van dit concept is er een overzicht gegeven van de gebeurtenissen die op positieve of negatieve wijze de opbouw en stabiliteit van een trombus beïnvloeden. De studies in dit proefschrift beogen bij te dragen tot een beter inzicht in de vroege en late processen die plaatsvinden tijdens de trombusvorming, wat moet leiden tot verbeterde medicatie voor de behandeling van atherotrombose. 

Dankwoord 
Zoals trombusvorming een dynamisch proces is, geldt dit zeker ook voor promoveren. Tijdens de afgelopen 5 jaar zijn vele factoren van belang geweest bij de totstandkoming van dit proefschrift. Middels dit dankwoord wil ik iedereen hartelijk bedanken die me op wetenschappelijk gebied of daarbuiten gesteund heeft.

Allereerst wil ik graag mijn promotieteam bestaande uit mijn promotor Jan Rosing en copromotor Johan Heemskerk bedanken. Jan, de afgelopen jaren was jij voornamelijk langs de zijlijn aanwezig, maar wist wel altijd waar ik mee bezig was. Bedankt voor de nuttige tips ter verbetering van mijn proefschrift. Johan, je hebt me de kans gegeven om in de plaatjesgroep promotieonderzoek te doen. De vastberadenheid om elk onderzoek tot een goed einde te brengen is kenmerkend voor jou. Bedankt voor de kritische beoordeling van mijn resultaten en manuscripten.

Een speciaal woord van dank voor mijn directe collega's van de afgelopen jaren. Imke, jij hebt de plaatjesgroep inmiddels verlaten. Ik heb het altijd fijn gevonden om met jou samen te werken en de twee "aussi adventures" zal ik nooit vergeten. Super dat je mijn paranimf wilt zijn. Paola, aan het begin van de opleiding Gezondheidswetenschappen zijn we vriendinnen geworden en uiteindelijk naast elkaar op de kamer terecht gekomen als collega aio's. Gedurende de afgelopen jaren hebben we heel wat promotieleed samen gedeeld. Ik kijk met veel plezier terug op alle ervaringen die we op hebben gedaan tijdens de vele cursussen en congressen. Erg fijn dat je mijn paranimf wilt zijn. Marion en Marijke, jullie zijn twee stabiliserende factoren binnen de groep. Bedankt dat ik altijd op jullie terug kon vallen. Mijn andere huidige kamergenootjes Karen en Roger, bedankt voor de gezellige sfeer op de kamer. Karen, je bent altijd behulpzaam en een fijne collega. Ik wens je veel succes met de rest van je promotieonderzoek en met de bouw van jullie huis. Roger, voor jou is het promotieavontuur pas begonnen, maar tot nu toe weet je je goed staande te houden tussen al die vrouwen binnen onze groep. Saskia, voor jou komt het einde van je promotieonderzoek al langzaam in zicht. Succes met de laatste loodjes. Jeffrey, Mieke, Kristof en Sandra, bedankt voor leuke tijd binnen en buiten het lab tijdens de eerste jaren van mijn aio-schap. Reyhan en Remco, ook jullie wens ik het allerbeste voor de toekomst.

During the past 5 years several $\mathrm{PhD}$ students from abroad stayed in our lab for a few months up till one year. A special thank you to Jocelyn, Amrei and Michelle. I enjoyed having you around and wish you good luck in your future careers.

I would like to thank Prof. Dr. Regine Heller, Prof. Dr. Marc Hoylaerts, Prof. Dr. Alastair Poole, Prof. Dr. Shaun Jackson, and their labmembers for welcolming me into their labs and helping me with experiments. Both on a scientific and on a personal level these visits have been a great learning experience for me. 
Alle medewerkers van de vakgroep Biochemie bedankt voor de fijne sfeer op de afdeling en daarbuiten, zoals tijdens het jaarlijkse dagje uit en de diverse aio-cursussen. Een aantal van jullie wil ik specifiek noemen. Simone, eigenlijk behoor jij thuis in het rijtje van de directe collega's. Jij hebt me regelmatig met raad en daad bijgestaan en je oprechtheid heb ik altijd erg gewaardeerd. Theo en Edouard, jullie zijn altijd geïnteresseerd en betrokken bij het plaatjesonderzoek. Bedankt voor de nuttige opmerkingen, waardoor ik vaak net een stapje verder ging denken. Marjolein en Leon, bedankt voor het maken van het Gas6 gedepleteerd plasma en hulp bij de westernblots. Leon, een extra bedankje voor de aangename gesprekken tijdens de treinreizen van en naar Randwyck. Trees, ongemerkt vervul jij een belangrijke rol binnen de vakgroep. Bedankt voor de secretariële ondersteuning en de gezellige gesprekken.

Alle vrijwilligers die de afgelopen jaren bloed hebben gegeven voor mijn onderzoek, dank jullie wel.

Voorts een vermelding van enkele coauteurs die nog niet eerder in dit dankwoord genoemd zijn. Prof. Dr. Hans Deckmyn, Brecht Iserbyt, Prof. Dr. Peter Carmeliet, Prof. Dr. Anne Angelillo-Scherrer, Dr. Jason Johnson, Dr. Christelle Lecut, and Dr. Martine Jandrot-Perrus thank you for your contributions to the different chapters of this thesis. Sylvia Heeneman en Jack Cleutjens van de afdeling Pathologie bedankt voor het delen van jullie expertise op het gebied van atherosclerose en histologische analyses.

Hylke, Ilona en Kyra, we zijn al jaren goede vriendinnen. Ondanks of juist vanwege onze uiteenlopende karakters klikt het tussen ons. De vakanties en vele uitstapjes zorgden ervoor dat ik steeds weer met nieuwe energie aan de slag kon. Hoewel we allemaal steeds meer een eigen leven opbouwen, hoop ik dat onze vriendschappen nog lang blijven voortduren.

Alle andere vrienden, familieleden en kennissen, erg bedankt voor jullie steun en interesse. Hopelijk wordt jullie vraag "Wat doe je nu eigenlijk?" bij het doorbladeren van dit proefschrift en bij mijn verdediging nu beter beantwoord.

Mijn grootste dank ben ik verschuldigd aan mijn ouders. Mam en pap, jullie hebben mij altijd onvoorwaardelijk gesteund en hielpen me te relativeren tijdens de stressvolle momenten. Enorm bedankt voor alles. Mijn broer(tje) Mathijs, jij hebt me altijd getriggerd om mijn uiterste best te doen en bent vanuit Boston een grote hulp geweest bij de laatste loodjes van dit proefschrift. Ik kan me geen betere broer wensen en hoop over een tijd in de zaal te zitten bij jouw promotie. 

Curriculum Vitae 


\section{Curriculum vitae}

Judith Cosemans was born on November $27^{\text {th }} 1980$ in Born, The Netherlands. In 1993 she started secondary school at the Serviam College in Sittard. In 1999 she received her Gymnasium beta certificate, after which she studied Biological Health Sciences at the Maastricht University. She followed her graduate internship at the Department of Biochemistry of this university, after which she received her Master's Degree with distinction on August $31^{\text {th }}$ 2003. Subsequently, she obtained a position as a PhD student at the Cardiovascular Research Institute Maastricht (CARIM) at the Department of Human Biology and later the Department of Biochemistry. Here she performed research, described in this thesis, which was supervised by Dr. J.W.M. Heemskerk. After taking several courses in the field of cardiovascular research, she received the CARIM PhDTraining Certificate in 2006. During her PhD period, she visited congresses in Erfurt and Würzburg (Germany), Sydney (Australia), Rome (Italy), Reading and London (United Kingdom) and Geneva (Switzerland) to present research data. These visits were honoured twice with a travel award. Part of her research was performed in the laboratories of Prof. Dr. R. Heller (Jena, Germany), Prof. Dr. M. Hoylaerts (Leuven, Belgium), Prof. Dr. A.W. Poole (Bristol, United Kingdom) and Prof. Dr. S.P. Jackson (Melbourne, Australia). Since October $1^{\text {st }} 2007$ she is working as a postdoctoral fellow at the Department of Biochemistry of Maastricht University. 


\section{Curriculum vitae}

Judith Cosemans werd geboren op 27 november 1980 te Born. Zij begon in 1993 haar middelbare schoolopleiding aan het Serviam College te Sittard, waar zij het Gymnasium bèta diploma behaalde. In 1999 startte ze vervolgens met de opleiding Gezondheidswetenschappen aan de Universiteit Maastricht (UM). Na het behalen van haar propedeuse in 2000 vervolgde zij deze studie in de richting Biologische Gezondheidskunde. Haar afstudeerstage liep ze bij de vakgroep Biochemie (UM), waarna zij op 31 augustus 2003 het doctoraaldiploma Gezondheidswetenschappen met als judicium "met genoegen" in ontvangst nam. Op 1 oktober 2003 begon zij als assistent in opleiding (aio) binnen het Cardiovascular Research Institute Maastricht (CARIM) bij de vakgroep Humane Biologie en later de vakgroep Biochemie. Het onderzoek dat zij daar verrichtte en wat beschreven staat in dit proefschrift, vond plaats onder directe begeleiding van dr. J.W.M. Heemskerk. Na het volgen van verscheidene cursussen op het gebied van hart- en vaatziekten kreeg zij in 2006 het CARIM PhD-Training Certificaat. Tijdens haar aio-periode presenteerde zij onderzoeksresultaten op congressen in Erfurt en Würzburg (Duitsland), Sydney (Australië), Rome (Italië), Reading en Londen (Verenigd Koninkrijk) en Genève (Zwitserland), en kreeg hiervoor tweemaal een internationale reisbeurs. Zij verrichtte een deel van haar onderzoek in de laboratoria van prof. dr. R. Heller (Jena, Duitsland), prof. dr. M. Hoylaerts (Leuven, België), prof. dr. A.W. Poole (Bristol, Verenigd Koninkrijk) en prof. dr. S.P. Jackson (Melbourne, Australië). Sinds 1 oktober 2007 is zij werkzaam als postdoctoraal onderzoeker bij de vakgroep Biochemie (UM). 

Publications 


\section{List of publications}

Papers

- Cosemans JMEM, Kuijpers MJE, Lecut C, Heeneman S, Jandrot-Perrus M, Heemskerk JWM. Contribution of platelet glycoprotein VI to the thrombogenic effect of collagens in fibrous atherosclerotic lesions. Atherosclerosis. 2005; 181: 19-27.

- Lecut C, Feijge MAH* $^{*}$ Cosemans JMEM*, Jandrot-Perrus M, Heemskerk JWM. Fibrillar type I collagens enhance platelet-dependent thrombin generation via glycoprotein VI with direct support of $\alpha 2 \beta 1$ but not $\alpha$ llb $\beta 3$ integrin. Thromb Haemost. 2005; 94: 107-14. *Authors contributed equally to this work

- Cosemans JMEM, Munnix ICA, Wetzker R, Heller R, Jackson SP, Heemskerk JWM. Continuous signaling via PI3K isoforms $\beta$ and $\gamma$ is required for platelet ADP receptor function in dynamic thrombus stabilization. Blood. 2006; 108: 3045-52.

- Van de Walle GRAJ, Schoolmeester A, Iserbyt B, Cosemans JMEM, Heemskerk JWM, Kieffer N, Hoylaerts MF, Nurden A, Vanhoorelbeke K, Deckmyn H. Activation of $\alpha$ llb $\beta 3$ is a sufficient but also an imperative prerequisite for activation of $\alpha 2 \beta 1$ on platelets. Blood. 2007; 109: 595-602.

- Strehl A, Munnix ICA, Kuijpers MJE, van der Meijden PEJ, Cosemans JMEM, Feijge MAH, Nieswandt B, Heemskerk JWM. Dual role of platelet protein kinase $C$ in thrombus formation: stimulation of proaggregatory and suppression of procoagulant activity in platelets. J Biol Chem. 2007; 282: 7046-55.

- Kuijpers MJE, Pozgajova M, Cosemans JMEM, Munnix ICA, Eckes B, Nieswandt B, Heemskerk JWM. Unidentified role of murine integrin $\alpha 2 \beta 1$ in thrombus stabilization and embolization. Tromb Haemost. 2007; 98: 1072-80.

- Van der Meijden PEJ, Schoenwaelder SM, Feijge MAH, Cosemans JMEM, Wetzker $\mathrm{R}$, Heller R, Jackson SP, Heemskerk JWM. Dual $\mathrm{P} 2 \mathrm{Y}_{12}$ receptor signaling in thrombin stimulated platelets - involvement of phosphoinositide 3-kinase $\beta$ but not $\gamma$ isoform in $\mathrm{Ca}^{2+}$ mobilization and procoagulant activity. FEBS J. 2008; 275: 371-85.

- Kuijpers MJE, Munnix ICA, Cosemans JMEM, van Vlijmen BJM, Reutelingsperger PM, oude Egbrink MGA, Heemskerk JWM. Key role of platelet procoagulant activity in tissue factor- and collagen-dependent thrombus formation in arterioles and venules in vivo. Differential sensitivity to thrombin inhibition. Microcirculation. 2008; 15: 26984.

- Cosemans JMEM, Iserbyt BF, Deckmyn H, Heemskerk JWM. Multiple ways to switch platelet integrins on and off. J Thromb Haemost. 2008; 6: 1253-61.

- Hall KJ, Harper MR, Gilio K, Cosemans JMEM, Heemskerk JWM, Poole AW. Genetic analysis of the role of protein kinase $\mathrm{C} \theta$ in platelet function and thrombus formation. PLoS ONE. 2008; 3 (9): e3277. 
- Cosemans JMEM. Dynamische regulatie van trombusstabiliteit. Nieuwsbrief Vasculaire Geneeskunde. 2008; 6.

- Cosemans JMEM, Munnix ICA, Schurgers LJ, Schols SEM, Angelillo-Scherrer A, Hoylaerts M, Carmeliet P, Heemskerk JWM. Roles of human and mouse Gas6 and Gas6 receptors in the formation and stabilization of thrombi. Submitted, 2008.

- Cosemans JMEM, van der Meijden PEJ, Feijge MAH, Munnix ICA, Cleutjens JPM, Poole AW, Johnson JL, Heemskerk JWM. Effects of plasma- and platelet-derived matrix metalloproteinases on collagen-dependent thrombus formation. Submitted, 2008.

- Konopatskaya O, Gilio K, Harper MT, Cosemans JMEM, Karim ZA, Whiteheart SW, Molkentin JD, Verkade P, Heemskerk JWM, Poole AW. PKC $\alpha$ is a critical regulator of platelet function and thrombus formation. Submitted, 2008.

- Van der Meijden PEJ, Munnix ICA, Auger JM, Cosemans JMEM, Kuijpers MJE, Spronk HM, Watson SP, Renné T, Heemskerk JWM. Dual role of collagen in factor $\mathrm{XII/XI-dependent} \mathrm{thrombus} \mathrm{formation} \mathrm{and} \mathrm{clot} \mathrm{formation.} \mathrm{Blood.} \mathrm{Major} \mathrm{revision,} 2008$.

- Munnix ICA, Cosemans JMEM, van Montfoort APA, Feijge MAH, Farndale RW, Jackson SP, Sage SO, Heemskerk JWM. Role of PI3K isoforms in GPVI-dependent calcium signaling in human platelets. Submitted, 2008. 


\section{Abstracts}

- Cosemans JMEM, Kuijpers MJE, Lecut C, Heeneman S, Jandrot-Perrus M, Heemskerk JWM. Thrombogenic effects of human collagens. Platelets. 2004; 15 (8): 487.

- Cosemans JMEM, Kuijpers MJE, Lecut C, Heeneman S, Jandrot-Perrus M, Heemskerk JWM. Thrombogenic effects of human collagens. Platelets. 2005; 16 (3): 232.

- Cosemans JMEM, Munnix ICA, Angelillo-Scherrer A, Carmeliet P, Heemskerk JWM. Role of platelet ADP and Gas6 receptors in thrombus stability. J Thromb Haemost. 2005; 3: supplement 1.

- Cosemans JMEM, Munnix ICA, Wetzker R, Heller R, Jackson SP, Heemskerk JWM. Platelet ADP receptors and phosphoinositide 3-kinases are essential in preventing thromboembolism on collagen and fibrous atherosclerotic lesions. Atherosclerosis Supplements 2006; 7 (3): 325.

- Cosemans JMEM, Munnix ICA, van der Meijden PEJ, Kuijpers M, Auger J, Watson $S$, Heeneman S, oude Egbrink $M$, Jandrot-Perrus $M$, Heemskerk JWM. Complementary roles of collagen and tissue factor in atherosclerotic lesions on shear-induced thrombus formation via platelet GPVI signaling. Atherosclerosis Supplements 2006; 7 (3): 390.

- Cosemans JMEM, van der Meijden PEJ, Kuijpers MJE, Wetzker R, Heller R, Jackson SP, Munnix ICA, Heemskerk JWM. Differential contribution of phosphoinositide 3-kinases to platelet responses. Proceedings of the $\mathrm{XXI}^{\text {st }}$ European Platelet Meeting, Wittenberg, Germany 2006.

- Cosemans JMEM, van der Meijden PEJ, Wetzker R, Heller R, Jackson SP, Munnix ICA, Heemskerk JWM. Role of PI3K isoforms in platelet thrombus formation and procoagulant activity. Proceedings of the $3^{\text {rd }}$ Focused Meeting on PI3K signaling and disease, Bath, UK 2006.

- Cosemans JMEM, van der Meijden PEJ, Wetzker R, Heller R, Jackson SP, Heemskerk JWM, Munnix ICA. Role of PI3K isoforms in platelet aggregate formation and platelet procoagulant activity. Platelets 2007; 18 (4): 294.

- Cosemans JMEM, van der Meijden PEJ, Cleutjens JPM, Heeneman S, Heemskerk JWM. Dual effect of platelet-derived matrix metalloproteinases on occlusive thrombus growth. J Thromb Haemost. 2007; 5: supplement 2.

- Kuijpers MJE, Cosemans JMEM, Feijge MAH, Heemskerk JWM. Inhibition of P2Y 12 by AZD6140 reduces thrombus formation and procoagulant activity on collagen and atherosclerotic plaques. J Thromb Haemost. 2007; 5: supplement 2. 
- Munnix ICA, Cosemans JMEM, van der Meijden PEJ, van Montfoort APA, Feijge MAH, Koyasu S, Heller R, Sage SO, Jackson SP, Heemskerk JWM. Specific roles of phosphoinositide 3-kinase (PI3K) isoforms $\alpha$ and $\beta$ in glycoprotein VI (GPVI)-induced platelet signaling to procoagulant activity. J Thromb Haemost. 2007; 5: supplement 2.

- Cosemans JMEM, van der Meijden PEJ, Cleutjens JPM, Heeneman S, Heemskerk JWM. Platelet-derived matrix metalloproteinases have a dual role in occlusive thrombus growth under flow. Proceedings of the $9^{\text {th }}$ UK $-1^{\text {st }}$ Netherlands Platelet Meeting, London, UK 2007.

- Gilio K, Harper MT, Cosemans JMEM, Hall KJ, Konopatskaya O, Molkentin JD, Munnix ICA, Littman DR, Poole AW, Heemskerk JWM. Opposite role of platelet PKC isoforms $\alpha, \delta$ and $\theta$ in flow-induced thrombus formation. Proceedings of the $9^{\text {th }}$ UK $1^{\text {st }}$ Netherlands Platelet Meeting, London, UK 2007.

- Hall KJ, Harper MT, Gilio K, Cosemans JMEM, Heemskerk JWM, Poole AW. Genetic analysis of the role of protein kinase $\mathrm{C} \theta$ in platelet function and thrombus formation. Proceeding of the $10^{\text {th }}$ UK Platelet Meeting, Bradford, UK 2008. 


\section{Awards}

- Travel award from the Netherlands Foundation for Thrombosis and Haemostasis to visit the XX Congress of The International Society on Thrombosis and Haemostasis (ISTH), Sydney, Australia (April 2005).

- Travel award from the Koninklijke Nederlandse Akademie van Wetenschappen (KNAW) / Van Walree Fonds (VWF) to visit the XXI Congress of The International Society on Thrombosis and Haemostasis (ISTH), Geneva, Switzerland (February 2007).

- PhD student of December 2008 of newsletter Vascular Medicine. 
